Reflectance of botanical, production and geographical origin on the unique compositional traits of purple grape juices 


\section{Thesis Committee}

\section{Promotors}

Prof. Dr Saskia M. van Ruth

Professor of Food Authenticity and Integrity

Wageningen University

Prof. Dr Vincenzo Fogliano

Professor of Food Quality and Design

Wageningen University

\section{Other Members}

Prof. Dr Harry Gruppen, Wageningen University

Dr Carsten Fauhl-Hassek, Federal Institute for Risk Assessment, Berlin, Germany

Dr Frans J. M. Harren, Radboud University Nijmegen

Prof. Dr Jacques H. Trienekens, Wageningen University

This research was conducted under the auspices of the Graduate School VLAG (Advanced studies in Food Technology, Agrobiotechnology, Nutrition and Health Sciences). 


\section{REFLECTANCE OF BOTANICAL, PRODUCTION AND GEOGRAPHICAL ORIGIN ON THE UNIQUE COMPOSITIONAL TRAITS OF PURPLE GRAPE JUICES}

\section{Daniel GRANATO}

\section{Thesis}

submitted in fulfilment of the requirements for the degree of doctor

at Wageningen University

by the authority of the Rector Magnificus

Prof. Dr A.P.J. Mol,

in the presence of the

Thesis Committee appointed by the Academic Board to be defended in public

on Monday November $7^{\text {th }}, 2016$

at 1:30 p.m. in the Aula. 


\section{Daniel Granato}

Reflectance of botanical, production and geographical origin on the unique compositional traits of purple grape juices, 151 pages.

PhD thesis, Wageningen University, Wageningen, NL (2016)

With references, with summary in English

ISBN: 978-94-6257-907-1

DOI: http://dx.doi.org/10.18174/388693 


\section{TABLE OF CONTENTS}

Chapter 1

Chapter 2

Chapter 3

Chapter 4

Chapter 5

Chapter 6

Abstract

Acknowledgements

Curriculum vitae

List of publications
General Introduction

7

Characterization and comparison of phenolic composition, antioxidant capacity and instrumental taste profile of juices from different botanical origins

Characterization of conventional, biodynamic, and organic purple grape juices by chemical markers, antioxidant capacity and instrumental taste profile

Authentication of geographical origin and production management system of purple grape juices by phenolic compounds and antioxidant activity using chemometrics

Geographical provenancing of purple grape juices from different production management systems by proton transfer reaction mass spectrometry

General Discussion 


\section{LIST OF ABBREVIATIONS}

ABTS - 2,2'-azino-bis(3-ethylbenzothiazoline-6-sulphonic acid)

AH - Antioxidant

ANOVA - Analysis of variances

$\mathrm{BIO}$ - Biodynamic

CAE - Chlorogenic acid equivalent

CONV - Conventional

CTE - (+)-Catechin equivalent

CUPRAC - Cupric reducing antioxidant capacity

DPPH - 2,2-Diphenyl-1-picrylhydrazyl

EIT - Estimated intensity of taste

ET - Electron transfer

EU - European Union

FAAS - Flame atomic absorbtion spectroscopy

FRAP - Ferric reducing antioxidante power

GAE - Gallic acid equivalent

GC - Gas chromatography

HAT - Hydrogen atom transfer

HPLC - High-performance liquid chromatography

ICP-MS - Inductively coupled plasma mass spectrometry

$\mathrm{KNN}$ - K-nearest neighbours

LOD - Limit of detection

LOQ - Limit of quantification

MMSB - Mean mass spectrum of the blanks

ORAC-FL - Oxygen radical absorbance capacity based on fluorescein assay

ORG - Organic

PEF - Pulsed electric fields

PGJ - Purple grape juice

PLSDA - Partial least-squares discriminant analysis

ppbv - Parts per billion in volume

PTR-MS - Proton transfer reaction mass spectrometry

SD - Standard deviation

SIMCA - Soft independent modeling of class analogy

TA - Titratable acidity

TE - Trolox equivalent

TSS - Total soluble solids

VOC - Volatile organic compounds 


\section{OHAPTER I:}

\section{GENERAL INTRODUCTION}

This chapter is partialy published as: GRANATO, D.; CARRAPEIRO, M. M.; FOGLIANO, V.; van RUTH, S. M. Effects of geographical origin, varietal and farming system on the chemical composition and functional properties of purple grape juices: a review. Trends in Food Science and Technology, 52, 31-48, 2016. 


\subsection{Introduction}

Grapes represent one of the most consumed fruits and this fact may be related to intrinsic sensory factors (taste, freshness, aroma) as well as commercial availability, reasonable price, and more recently due to their functional properties demonstrated by a vast number of in vitro, in vivo, clinical, and epidemiologic studies (Vinson et al., 2000; Vinson et al., 2001; Singletary et al., 2003; Jung, Wallig, \& Singletary, 2006; Dani et al., 2007; Macedo et al., 2013; Dillenburg et al., 2013; Lima et al., 2014; Toaldo et al., 2015; Alaei, Siahmard, \& Reisi, 2015). In this sense, grapes and their technological by-products, such as jams, candies, wines, and juices are widely available worldwide as the production yield is relatively high. Besides wine, which is the most consumed grape-based product, grape juice has gained much attention as it does not contain ethyl alcohol and presents a relatively large amount of bioactive compounds, mainly phenolics, that display a considerable in vivo antioxidant, cardioprotective, and anti-inflammatory properties when moderately consumed as part of the regular diet (O’Byrne et al., 2002; Fragopoulou et al., 2003; Albers et al., 2004).

Grape juice is widely produced in China, United States, Italy, France, Spain, Turkey, and Chile. Furthermore, Argentina, Iran, Australia, and Brazil have emerged as potential producers (FAO, 2011). Herein, more products have been launched in the market place and the alleged positive health benefits of grape juice consumption have spread, the sales have been considerably increased over the past 10 years. In this scenario, the production of grapes without the use of pesticides, minimal use of off-farm inputs and agronomical management practices that restore, maintain, and enhance ecological harmony of the farm environment, the so-called organic and biodynamic production systems has also increased because of the consumer's demand (Kuepper, \& Gegner 2004). According to Lernoud and Willer (2015), global sales of organic food and drink reached US\$ 75 billion in 2013, in which revenues increased almost 500\% since 1999. The U.S.A. market of organic products reached US\$ 35 billion in 2013, thus being the largest consumer of such products (4\% of total food sales). In Europe, Germany, the Netherlands, France and Finland are the largest consumers, while in Latin America, Brazil has the largest organic products market. Colombia, Argentina, Peru, Chile are also important producers and exporters (Paull \& Hennig, 2011).

Besides the agronomical system in which grapes are cultivated, research has also demonstrated that the producing region affects the chemical compounds and quality traits of grapes and by-products, mainly wines and juices. However, experimental results are inconclusive: while some works clearly report that the chemical composition of grape juices is influenced by the region the grape is produced (Lima et al., 2014), some other authors state the chemical composition, and therefore the bioactivity of grape-based beverages, cannot be suitable markers to authenticate the geographical origin of the grape (Tassoni, Tango, \& Ferri, 2013). In this aspect, the chemistry of grapes and juices depend on many factors, such as soil quality and composition, degree of ripeness of berries, water stress, bunch sunlight exposure, pathogenesis, type of production management system, agronomical procedures, pre-processing of berries, pressing method, among others (Lachman, Sulc, \& Schilla, 2007; Leblanc, Johnson, \& Wilson, 2008; Cadahia et al., 2009; Iyer, Sacks, \& Padilla-Zakour, 2010; Natividade et al., 2013; Hopfer et al., 2015; Song et al., 2015; Genova, Tosetti, \& Tonutti, 2016). With all these factors, differences on chemical markers seem to be obvious for grapes, juices, and wines, but still there is no consensus on this matter as research continuously shows not convergent results. 


\subsection{Production, processing and regulation of grape juices}

\subsubsection{Global grape and juice production}

Grape (Vitis sp, Vitaceae) is a non-climacteric berry grown in different locations, in all continents, and its cultivation dates from 6,000 to 8,000 years in the South Caucasus between the Caspian and Black Seas (Lacombe \& Thomash, 2006). They usually grow in clusters containing 15-200 grapes and can be black, blue, yellow, green, orange, violet, crimson, and pink color (Mondavi \& McGovern, 2007). The difference in color is related to the production of natural pigments, namely anthocyanins, which vary in content and chemical structures according to genetic, environmental, and agronomical factors (Brouillard, Chassaing, \& Fougerousse, 2003). Obviously, these factors define the species and sub-species (varietal) that are better adapted to be commercially grown in different sites of the globe. In this sense, grapevines can be differentiated by their species and locations where they are cultivated: while Vitis vinifera L. varieties, such as Airen, Tempranillo, Chardonnay, Garnacha Tinta, Merlot, Cabernet Sauvignon, Syrah, Pinot Noir, Sauvignon Blanc. Trebbiano, and many others are basically grown for fine wine production in European countries, some African and American countries, Vitis labrusca L. varieties, such as Concord, Niagara, and Bordeaux, are grown in Eastern United States of America and Canada and Brazil (about 80\% of total production) to be destined for derived products manufacture (jams, juices, preserves, syrups, raisins, sauces, etc) (Robinson, 2003; Hugh \& Robinson, 2013). Herein, Vitis rotundifolia Michx. varieties, such as Muscadine, Supreme, Black Fry, Granny Val, Carlos, Noble, Black Beauty, and Thomas, are mainly grown in the south of the USA, Mexico, and some regions in Brazil for table consumption, juice and port wine production (Andersen, Crocker, \& Breman, 2003), and Vitis amurensis Rupr. species is vastly cultivated in Asian countries (Japan, China, North Korea) and have been crossed with other $V$. vinifera species because of their phytochemical profile (Huang \& Lin, 1999).

Overall, in South, North and Central America, purple grapes cultivated using organic, biodynamic, and conventional systems from Vitis bourquina and Vitis riparia (USA) (lesser extent) and principally from Vitis labrusca varieties, such as Bordeaux, Concord, Isabel (hybrid), Niágara and Niágara Rosada, are used to produce juices and nectars (internal market) and concentrate (export). In Brazil, the production of grape juices is mainly based on $V$. labrusca grapes ( $80 \%$ of total grape production), while in Chile, Argentina and Uruguay, noble grapes ( $V$. vinifera destined for wine production) are also used to produce grape juices, such as Cabernet Sauvignon, Merlot, Cabernet Franc, Malbec, Tannat, Red Globe, Autumn Royal, Ribier, and Crimson Seedless (Lutz et al., 2011; Silva et al., 2016). In South America, especially Chile, Uruguay, Brazil (South and Southeast regions), and Argentina, where the production of grapes is more intense, grape juices are widely consumed in the regular diet. For example, the Brazilian consumption of grape juices (mainly the purple type) was 10 million L in 2007, 50 million in 2012, and 78 million L in 2013, with a per capita consumption of about 3 $\mathrm{L} /$ person every year, corresponding to four times more than table wines made from Vitis vinifera varieties (20 million L) and sparkling wines (15.8 million L). In addition, the marketing of grape juices in Brazil has increased annually and as compared to 2003, an increase of about 2,000 was registered (Ibravin, 2014). Due to the quality traits of grape juices produced in South America, exports are significant and the main consumers are Japan, USA, Mexico, Dominican Republic, Thailand, South Korea, and New Zealand (Ibravin, 2014). 
The annual per capita consumption of fruit juice is about $21 \mathrm{~L}$ in the EU compared to $27 \mathrm{~L}$ in North America, $5 \mathrm{~L}$ in South America and only $2 \mathrm{~L}$ in Asia Pacific. The total production of juices in European countries in 2012 was 10,387 million L, and as the consumption of grape juice is not a tradition and does not represent a habit for most Europeans, its production is relatively negligible as compared to American countries, representing only about $3 \%$ of total production of fruit juice (100\% juice content) and nectars (AIJN, 2012, 2013). However, it is important to stress that a significant amount of grape juice (both white and purple) is used for blending with other fruit juices. Imports of grape juice from neighborly countries (especially from Spain, Germany, and Italy) are common practice and the commercial products are often a mixture of two or three grape varieties. Concerning grape juices, Muscadine ( . rotundifolia), Cabernet Sauvignon, Tempranillo, Cabernet Franc, Riesling, Tebbiano, Malbec (Argentina), Tannat (Uruguay), and Merlot grapes ( $V$. vinifera) are the main varieties used for the juice production. The main producers are Spain, France, Italy, Portugal, and Germany, while Germany, Finland, Austria, the Netherlands and Sweden are the largest per capita consumers of fruit juices in Europe (AIJN, 2012).

\subsubsection{Grape juice processing}

The logistic process to produce grape juice starts in the farm, where grapes are usually harvested mechanically (conventional grapes) or manually (organic and biodynamic grapes) at the stage of technical maturity (14-25 ${ }^{\circ}$ Brix) (OIV, 1990). Materials other than grape (bark, canes, petioles, leaves, and staples) should be separated from the grape cluster using appropriate machines or manually. Then, grapes must be processed within $48 \mathrm{~h}$ after harvesting to avoid contamination with deteriorating bacteria and fungi and production of ethyl alcohol by fermentative process. Prior to the juice preparation, grapes need to be cleaned and sanitized by using immersion water bath and sanitization with sodium hypochlorite solution (50 - 200 $\mathrm{mg} / \mathrm{L}$ ) for 10-20 min to lower the bacterial counts and further rinsed with water (Silva et al., 2016).

There are various methods for commercial processing of grape juices, such as cold pressing and hot pressing, and they have undergone continuous changes (improvements) to increase the quality and yield. However, the continuous hot-pressing method is the most used technique adopted worldwide as the cold press method renders a very low juice yield ( 18\%) (Monrad et al., 2014; Lima et al., 2015). According to Morris (1998) and Rizzon and Meneguzzo (2007), firstly, grapes are crushed in a stainless steel tank with the aid of routable propellers to increase the contact area and to extract the initial must containing the easily extractable pigments and soluble solids and to homogenize the content. Then, in the hot pressing method, grapes are heated (up to $85{ }^{\circ} \mathrm{C}$ ) for about 30 to $60 \mathrm{~min}$ to extract the anthocyanins and other compounds in the skin and to inactivate oxidative enzymes (i.e., polyphenol oxidases). In this stage, acidic pectinolytic enzymes (rotopectinases, polygalacturonases, lyases and pectin esterases) at a concentration between 2 to $4 \mathrm{~g} / 100 \mathrm{~L}$ of must are added at $55-60^{\circ} \mathrm{C}$ to the must to facilitate the maceration of membranes in the grape skin (accelerating the release anthocyanins and other chemical compounds into the juice) and also to lower the colloids content (pectines), facilitating thus the filtration process to obtain the clarified grape juice (Jayani, Saxena, \& Gupta, 2005). As enzymes and temperaturesabove $60^{\circ} \mathrm{C}$ are used, grape juice obtained by hot pressing contains higher total solids (including non-sugar solids) and higher phenolic content (including anthocyanins) as compared to 
the other methods. Obviously, juice quality is significantly affected by time and temperature of extraction as well as by the concentration and type of enzyme employed in the process (Rathburn \& Morris, 1990; Morris, 1998). After crushing, a dejuicer removes about $35 \%$ of the free-run juice using a 40 -mesh screen and the remaining pulp empties into a continuous screw press. The free-run and press juice are combined and filtrated under vacuum to eliminate insoluble suspended solids, yielding $\sim 74 \%$ of juice and $\sim 26 \%$ of grape cake (pomace containing skins and seeds). Finally, juice is passed through a heat exchanger $\left(\sim 75^{\circ} \mathrm{C}\right)$ and sterilized bottles are filled and then pasteurized $\left(85^{\circ} \mathrm{C} / 10 \mathrm{~s}\right.$ or $\left.95^{\circ} \mathrm{C} / 2 \mathrm{~s}\right)$ in stainless steel tubular heat exchangers, cooled to $\sim 20^{\circ} \mathrm{C}$, labeled and stored until distribution (Morris \& Striegler, 1996; Rizzon \& Meneguzzo, 2007). For storage purposes, even after pasteurization grape juice should be kept at storage temperatures below $10^{\circ} \mathrm{C}$ as the chemical stability of the color (i.e., anthocyanins) was found to be affected by a number of factors including the type of anthocyanin, the origin of the juice, and especially the storage temperature (Hellström, Mattila, \& Karjalainen, 2013). A flowchart containing the steps to produce grape juice is shown in Figure 1.1.

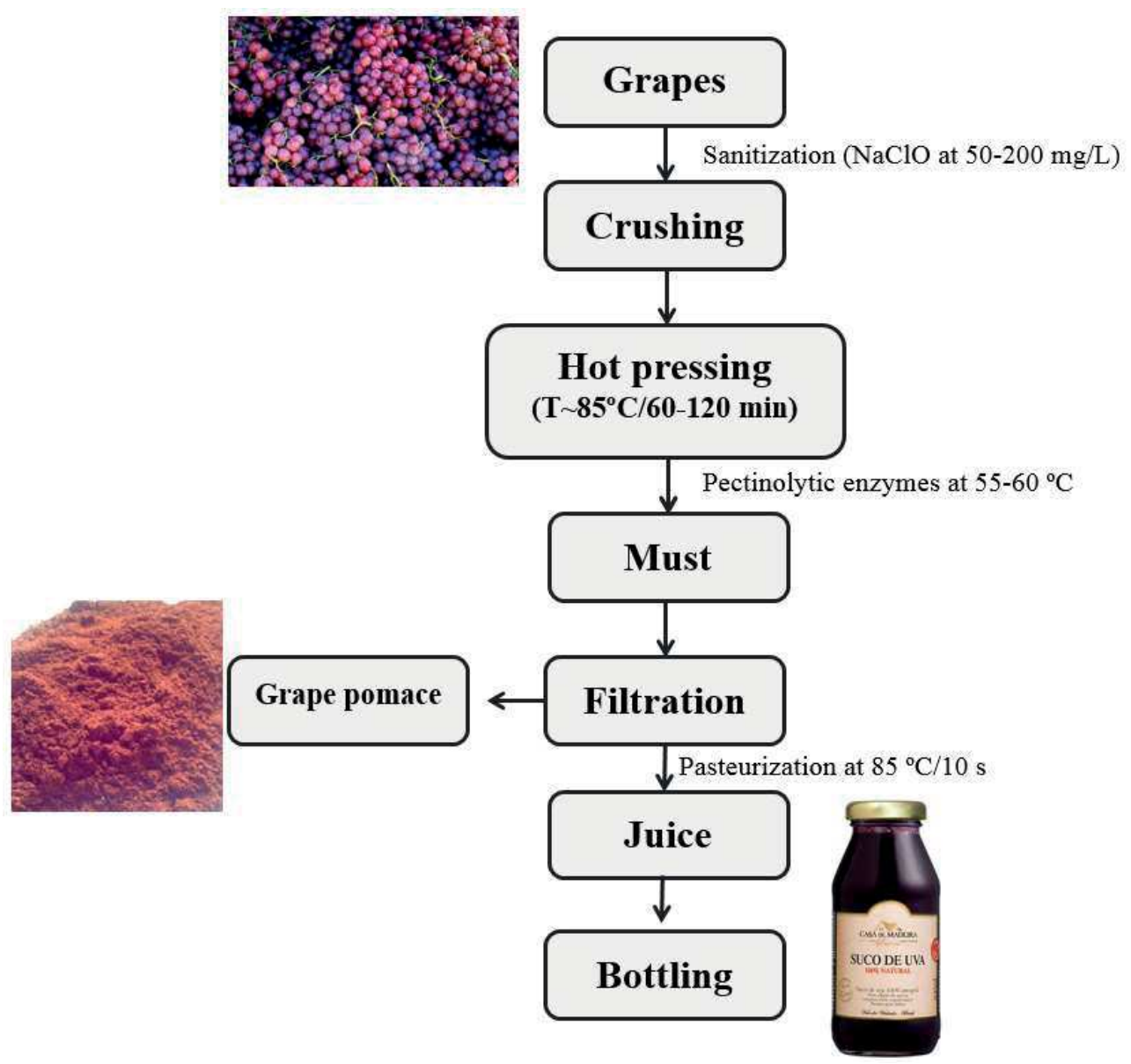

Figure 1.1: Steps and unit operations to produce grape juice by the hot-pressing method. 
As shown in Figure 1.1, the unit operations to manufacture grape juices by the hot-pressing method are quite simple. Therefore, some attention has been given to improve the process and increase the quality of the final product. Herein, recent technological trends have been tested to improve the quality of purple grape juice production: a study conducted by Yamamoto et al. (2015) showed that when Isabel grapes are treated with abscisic acid during maturation of berries, the content of monomeric anthocyanins is increased considerably and authors incentivize the use of abscisic acid for grape juice's color stabilization/enhancement. Leong, Buritt, and Oey (2016) used pulsed electric fields (PEF; constant pulse width of $20 \mu$ s, pulse frequency of $50 \mathrm{~Hz}$, electric field strength of $1.5 \mathrm{kV} / \mathrm{cm}$, pulse numbers of 243) as a pre-treatment of Pinot Noir grapes (Vitis vinifera $\mathrm{L}$.) obtained at different maceration times and verified that PEF increased $(\mathrm{p}<0.05)$ the content of malvidin-3-O-glucoside ( $+224 \%)$, content of total phenolics $(+61 \%)$ and ascorbic acid $(+19 \%)$, as well as an increase of $31 \%$ in the antioxidant activity measured by the DPPH assay. Hasan, Yun, Kwak, and Baek (2014) conducted a study aiming to increase the content of resveratrol in purple grape juice as this compound is decreased with the use of clarifying agents and during filtration. In this sense, the ultrasound technique was tested as a post-harvest cleaning of Campbell Early, Muscat Bailey A and Kyoho grapes (hybrid between Vitis labrusca and Vitis vinifera). Authors observed a significant increase of trans-resveratrol content in Campbell Early (153\%), Muscat Bailey A (115\%) and Kyoho grape juices (124\%) after ultrasonication treatment.

\subsubsection{Regulation of the authenticity of juices}

The general EU Food Law under Regulation (EC) number 178/2002 of the European Parliament and of the Council of 28 January 2002, food law aims at the protection of the interests of consumers and must provide a basis for consumers to make informed choices in the relation to the foods they consume, preventing fraudulent or deceptive practices, adulteration of foods and any other practices that may mislead the consumers.

According to Codex Alimentarius standard 247-2005 (CODEX, 2005), fruit juice must be obtained from the edible part of sound, appropriately mature and fresh fruit or fruit maintained in fresh condition by physical means and/or by treatments applied and the juice may be cloudy or clear and must have the essential characteristics typical of the juice of the fruit from which it comes from. For grape juice authenticity and standardization, a total soluble solids content of $13.5^{\circ} \mathrm{Brix}$ is the minimum concentration of solids grape juice must have to be labeled as 'pure juice' and no sucrose and water addition is allowed.

According to the European Union regulation under Council Directive 2001/112/EC (Eur-Lex, 2001), grape juices may be marketed in different technological forms, such as refreshments, nectars, pure juice, reconstituted or concentrated form, dehydrated/powdered juice. In accordance with the Brazilian legislation (Brasil, 2013), refreshments and nectars present a concentration of pure juice between 10 to 30\% and 50\%, respectively. Reconstituted juice can be added to the formulation, while pure juice cannot contain added water and/or sucrose, that is, only the grapes are used to manufacture the product. Concentrated grape juices are obtained by some technological operations such as cryoconcentration or evaporation, in which water is partially removed from the product (minimum of $65^{\circ} \mathrm{Brix}$ ) and, obviously, aromatic compounds are lost when grape juice is concentrated by evaporation. For the European Fruit Juice Association (AIJN, 2013), nectars are diluted fruit/vegetable juice and pulp, to which sweetening agents (i.e. sucrose, honey, syrups and/or 
sweeteners) need to be added for the purposes of production and the juice content is required to be equal to or in excess of $25 \% \mathrm{v} / \mathrm{v}$.

Food product's authenticity if of major concern not only in terms of food safety but also to guard against adulteration with other low-quality foodstuff (Vardin et al., 2008; Tres, O'Neill, \& van Ruth, 2011; Spink \& Moyer, 2016). Some authors have studied the adulteration of purple grape juice because it has been considered a functional food and, therefore, is a focus of adulteration (Tamborra \& Esti, 2010; Snyder et al., 2014). Adulteration of grape juice is usually performed by adding water and/or sucrose into pure juice and label it as ' $100 \%$ juice', or by adding a different variety of grape into the product labeled as 'Niagara grape juice', or by blending pure grape juice with other filler juice, such as apple and pear juices (Spinelli et al., 2016). More recently, chemical markers and methods of analysis have been proposed to detect the type of adulteration of fruit juices from different production systems and botanical origins, as well reviewed by Capuano, Boerringter-Eenling, van der Veer and van Ruth (2013), Borrás et al. (2015) and Danezis et al. (2016).

From the commercial standpoint, nectars are cheaper and present very attractive sensory appeal as flavoring and sucrose may have been added and, therefore, are widely marketed and consumed worldwide (Malacrida \& Motta, 2005).

\subsubsection{Regulation of the production of juices in organic and biodynamic farming systems}

Organic and biodynamic farming are a form of sustainable agriculture that started to gain space in the early 90 s due to consumers demand for healthy diet and food habits. In order to be certified in the USA and Member States of the European Union (EU), regulations on organic and biodynamic require limited (or even restriction) use of synthetic pesticides (including organochlorides), chemical fertilizers or sewage sludge, hormones, antibiotics, and genetic engineering techniques to promote the growth of plants (Capuano, Boerringter-Eenling, van der Veer, \& van Ruth, 2013). Farmers need to utilize hand weeding, mechanical control, mulches, cover crops, dense planting, crop rotation and use animal manure to provide nutrients to the plants and choose resistant varieties to protect the crops against microbial infection, weeds, pests, and diseases. Farmers pay attention to soil composition (nutrients and organic matter) in order to obtain yield comparable to that of conventional production management system, making the organic and biodynamic systems economically viable. From the agronomical standpoint, these farming systems promote and enhance biodiversity and the biological cycles of the soil, protecting the environment against pollution (air and water) and restore, maintain and enhance the ecological harmony of the farm (Brandt \& Mølgaard, 2001; Greene \& Kremen, 2003). For both farming systems, a higher independence of machinery (fossil fuels) is aimed by adopting artisanal operational strategies. However, it is also known that by adopting these practical strategies, there is a visible reduction in production compared to the conventional production management (Seufert, Ramankutty, \& Foley, 2012). From the organic processor standpoint, in order to ensure high standards, all organic ingredients must be separate from non-organic ones to avoid mixing and all activities and output references should be recorded (traceability) so consumers only get organic products. 
Organic production in the EU is based on the Regulation (EC) 834/2007 (European Comission, 2007, 2012) that introduced guidelines, principles and criteria for organic food processing. However, specific principles and related producing criteria (i.e., standardized protocols of cultivation and harvest) are missing to evaluate processing methods of different types of products, making the production of organic and biodynamic foods not operational, straightforward and, principally, standardized. The lack of standardized methods at international level in farms may be one of the many interlinked reasons for the observed differences in quality traits between organic products worldwide. As well defined by Kahl et al. (2012), the quality of organic foods is defined by some indicators (i.e., sensory, chemical, physical, physicochemical markers) that should be determined by means of specific methods. Therefore, the use of high-sensitivity and selective methods are required for a robust data acquisition aimed to compare products coming from the same cultivation system, geographical origin, and variety, etc.

According to Willer \& Meredith (2015), since 1990, the EU regulations has contributed to the development of a harmonized approach to consumer protection, preventing unfair competition and ensuring common standards for all production steps, such as labeling and marketing of organic products in European countries. A new and updated legislation has been proposed (European Commission, 2014a,b,c) to maintain consumer and producer confidence and to facilitate the switch to organic agriculture. Additionally, the European Commission proposes to reinforce controls by making them risk-based, to make it easier for small farmers to join organic farming by introducing the possibility for them to sign up to a group certification system, and to strengthen and harmonize rules for European countries and for imported products by removing some exceptions in terms of production and controls.

The number of countries with organic standards and legislation dedicated to the quality control (national inspection and certification activities) is 82 and 16 countries are in the process of drafting legislation on this matter. In European Union, 28 countries have all the standards and legislation considered as 'fully implemented', while in Americas and Caribbean, only Cuba, El Salvador, and Venezuela do not have a fully implemented legislation on organic farming system (Huber, Schmid, \& Mannigel, 2015).

In Brazil, for example, the organic production is based on the Law number 10831 from $23^{\text {rd }}$ December 2003 from the Ministry of Agriculture, Livestock and Food Supply (MAPA) and the general guidelines to be followed by producers and food companies are present in the Resolution 6323 from $27^{\text {th }}$ December 2007 from MAPA and states that the organic cultivation system that adopts specific techniques by optimizing the use of natural and socioeconomic available resources and respecting the cultural integrity of rural communities. The main aims are to obtain economic and ecological sustainability, maximization of social benefits, minimizing the use of non-renewable energy, using, where possible, cultural, biological and mechanical methods, as opposed to the use of synthetic materials, the elimination of the use of genetically modified organisms and ionizing radiation, at any stage of production process, processing, storage, distribution and marketing and protection of the environment. Additionally, the Brazilian legislation also emphasizes that the organic system must offer products without the use of intentional contaminants (pesticides), increment the biological activity of the soil, preserve the biological diversity of natural ecosystems, promote a balanced use of soil, water by reducing the use of machinery in the harvest, and all products should be certified to be labeled as 'organic'. 
The biodynamic system is very similar to the organic agriculture, but it relies on a more anthroposophic and holistic view of the relation between individuals, animals and the way to produce plants. In fact, to be certified as biodynamic, cultivation farms need to be previously certified as organic and go through a 3-year conversion period (Demeter International, 2012). Farmers that adopted the biodynamic agriculture need to use different types of preparations (herbs and other plants and/or animal tissues) to stimulate the soil nutrient cycle, enforce photosynthesis, thus improving the soil composition and increasing the plant production (yield) and decreasing the incidence of pests and infectious microbes (Koepf, Schaumann, \& Haccius, 2001). These preparations, which are a series of soil and plant amendments, were initially studied and developed by Rudolf Steiner (Steiner \& Gardner, 1993) and they are the basis of different commercial products marketed worldwide by different companies. In contrast to what is observed for organic farming, biodynamic agriculture has not been regulated officially so far. Therefore, producers must refer to protocols standardized by a private organization (Demeter International, 2012) to achieve the certification of 'biodynamic production management' (Parpinello, Rombolá, Simoni, \& Versari, 2015).

\subsubsection{Grape juice production in organic and biodynamic farming systems}

It is widely accepted that the sales of organic and biodynamic products (foods, cosmetics, feeds, among others) have increased steeply (28\% increase in the past two years) because of consumers' demand for special quality. The countries that present the largest areas dedicated to organic food production are Australia, Argentina, USA, China, Spain, Italy, France, Germany, Uruguay and Canada (Sahota, 2015 and according to the Organic Trade Association (OTA, 2015), North America is the highest consumer of organic foods (about $45 \%$ of total sales). The sales in the USA reached US\$ 31.5 billion in 2012 and the number increased to US\$ 35.1 billion in 2013 , in which $92 \%$ of this amount is related to food products, especially the fruit and vegetable category (43\%) followed by dairy goods (15\%) (Greene, 2013). The growth in sales is expected to be between $10-14 \%$ annually from 2013-2018 (Daniells, 2014).

The scenario in European countries was quite similar in 2011 (US\$21.7 billion) and 2012 (US\$ 23.6 billion), where Spain, Italy, Germany, France, Poland, United Kingdom, Austria, Turkey, Czech Republic, and Sweden are the ten countries with largest area destined for organic production (about 9.5 million hectares, which corresponds to nearly 240,000 farms and 5.4\% of total agricultural area) and Germany, France, United Kingdom, Italy, Switzerland, Austria, Spain, Sweden, Denmark, and the Netherlands present the highest sales. The main goods cultivated in these countries are: cereals, olives, protein crops, grapes and oil seeds (Willer \& Lernoud, 2014).

In Latin America, there are about 6.6 million ha of land producing organic food products, representing about $15 \%$ of the world's organic land, in which Brazil is the largest producer of organic products behind Argentina (3.2 million ha; share of $\sim 2 \%$ ), totaling more than 12,530 producers in over 0.80 million ha of total producing area, presenting a worldwide organic share of about $0.27 \%$. Falkand Islands/Malvinas (36.3\% share) and French Guiana (11.9\% share) present the highest share of organic land, while Dominican Republic and Uruguay present an organic share of $6 \%$. In these countries, cocoa, sugar meats, cereals, and tropical fruits are the specialties commodities in these countries (Flores, 2015). Brazil registered an internal consumption of 
organic products of US\$ 750 million in 2014 (25\% increase as compared to 2013) and exports reached US\$ 52 million in the first semester of 2014 (Organics Brasil, 2014).

As fruits and other vegetables lead the rank in the consumption, viticulture worldwide has experienced a gradual shift from conventional to other agronomical cultivation systems, namely organic and biodynamic farming (Villanueva-Rey, Vázquez-Rowe, Moreira, \& Feijoo, 2014). The countries with largest areas dedicated to the cultivation of organic grapes and by-products, such as wine and juice, are Spain (84,000 ha), Italy (68,000 ha), France (65,000 ha), China (19,000 ha), and USA (16,000 ha), but more than $90 \%$ of the world's organic grape area is within European countries (Lernoud \& Willer, 2015).

\subsection{Chemical composition of purple grape juices}

\subsubsection{Gross chemical composition of grape juices (macro components)}

Grape juice is a water-based sugar-rich medium containing different classes of metabolites with concentrations ranging from $\mathrm{mg} / \mathrm{L}$ (methionine, lysine, and trans-resveratrol) to $\mathrm{g} / \mathrm{L}$ (malic and tartaric acids). In this sense, pure freshly prepared purple grape juices usually presents 70 to $80 \mathrm{~g} / 100 \mathrm{~mL}$ of water, 15 to 25 $\mathrm{g} / 100 \mathrm{~mL}$ of carbohydrates (total soluble solids between 14 and $20^{\circ} \mathrm{Brix}$ ), in which glucose and fructose are usually present in equal amounts (1:1 mass ratio) (TACO, 2011; Yoon, Kim, \& Lee, 1997). Next to sugars, organic acids are the most abundant solids present in grape juice and the total titratable acidity between 0.40 to $7.0 \mathrm{~g} / \mathrm{L}$, in which citric, tartaric, lactic, acetic, and succinic acids are the main compounds, but malic and tartaric acids account for up to $90 \%$ of the total acids present in fresh grape juices (Garde-Cerdán et al., 2007; Nan et al., 2013). The acid and sugar composition of grapes is highly influenced by many factors such as variety, maturity index, climatic region, soil chemistry, cultural practices, and sunlight exposure (Morris, 1998). Additionally, grape juices contain nearly $0.20 \mathrm{~g} / 100 \mathrm{~mL}$ of dietary fibers and $0.20-0.6 \mathrm{~g} / 100 \mathrm{~mL}$ of ash content, while the lipid and nitrogen contents of grape juices are negligible and they have hardly nutritional interest in human diet (Garrido \& Borges, 2013). The $\mathrm{pH}$ of grape juices is below 4.0 and the density varies from 1.04 to $1.10 \mathrm{~g} / \mathrm{cm}^{3}$ (Yoon, Kim, \& Lee, 1997; Toaldo et al., 2015). Certain groups of minor components are present in grape juices and are detailed in the paragraphs below.

\subsubsection{Minor components in grape juices}

\subsubsection{Minerals, amino acids, vitamins, and carotenoids}

The gross composition of the ash in grape juice is: $16-70 \mathrm{mg} / \mathrm{L}$ of calcium, $110 \mathrm{mg} / \mathrm{L}$ of magnesium, 600-100 mg/L of potassium, $10 \mathrm{mg} / \mathrm{L}$ of sodium and phosphorus, $0.4-1.3 \mathrm{mg} / \mathrm{L}$ of iron, 0.4-0.7 mg of zinc, 2$6 \mu \mathrm{g} / \mathrm{L}$ of selenium, 1-5 $\mu \mathrm{g} / \mathrm{L}$ of cobalt, and $0.3-1.5 \mathrm{mg} / \mathrm{L}$ of copper (Toaldo, 2015). The contents of minerals vary considerably because of grape variety, climate, soil, fertilization, and other cultural practices. Grapes contain various nitrogenous compounds that are partially related to the umami taste and umami aftertaste (richness). These include ammonium cations some amino acids, peptides, and proteins. The total nitrogen concentration of the fruit increases during the maturation period and the main nitrogen compounds found in grape juices are arginine $(770 \mathrm{mg} / \mathrm{L})$ and proline $(120 \mathrm{mg} / \mathrm{L})$ as the main amino acids followed by alanine (82 $\mathrm{mg} / \mathrm{L})$, ammonium (47 mg/L), $\gamma$-amino butyric acid (38 mg/L), cystathionine (37 mg/L), glutamic acid (31 
$\mathrm{mg} / \mathrm{L})$, tryptophan $(30 \mathrm{mg} / \mathrm{L})$, methionine, serine, and leucine $(28 \mathrm{mg} / \mathrm{L})$, histidine and aspartic acids $(26$ $\mathrm{mg} / \mathrm{L}$ ). Isoleucine and leucine represent less than $1 \mathrm{mg} / \mathrm{L}$ and the total amino acid content in grape juice is comprehended between 700 to 1500 mg/L (Hernandz-Orte, Ibarz, Cacho, \& Ferreira, 2003; Garde-Cerdán, 2007).

In relation to the vitamin content, purple grape juice $(100 \mathrm{~mL})$ contains a mean level of $0.10-0.30 \mathrm{mg}$ of thiamine, $0.05 \mathrm{mg}$ of riboflavin, $0.05 \mathrm{mg}$ of pyridoxine, $0.43 \mu \mathrm{g}$ of $\alpha$-tocopherol, $4 \mathrm{mg}$ of choline, $3 \mu \mathrm{g}$ of folate, $0.20-0.40 \mathrm{mg}$ of niacin, and $\sim 10-30 \mathrm{mg}$ of ascorbic acid (TACO, 2011, DTU Food, 2009). According to Bunea et al. (2012), lutein and $\beta$-carotene (Figure 1.2) are the main carotenoids found in grapes at concentrations between 0.6 to $6 \mathrm{mg} / \mathrm{L}$, corresponding to $85 \%$ of total carotenoids. Other carotenoids found in low/trace levels are neochrome, neoxanthin, violaxanthin, luteoxanthin, flavoxanthin, and zeaxanthin. Lutein, $\beta$-carotene, neochrome and neoxanthin concentrations decrease during berry development, with rapid decrease of lutein and (9'z)-neoxanthin two weeks before harvesting, while neochrome $b$ and violaxanthin accumulates at early development and starts to decrease two weeks before harvesting (Yuan \& Qian, 2016). Carotenoids are directly involved in grapes aroma because they can suffer degradation reactions followed by apparition of norisoprenoid compounds (Wahlberg \& Eklund, 1998).

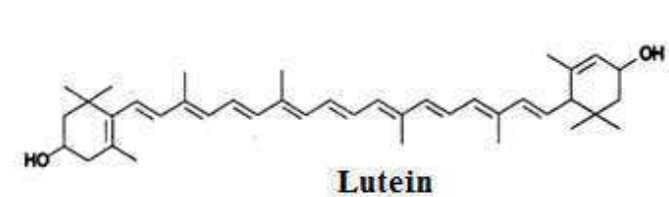

Lutein

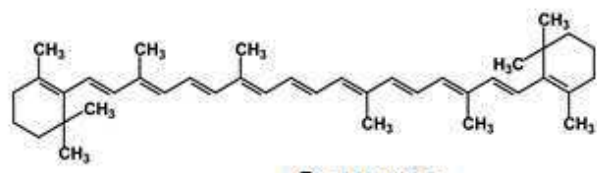

B-carotene

Figure 1.2: Chemical structure of the main carotenoids found in purple grape juice.

\subsubsection{Flavor compounds}

Sugars, organic acids and bitter compounds, especially phenolic compounds, are important contributors to the taste of grape juices and the overall flavor quality. Consumer acceptability of grape juices is a function of the presence and chemical interactions of the key character-impact compounds and the balance of volatile and non-volatile flavor components (Jella et al., 1998).

Aromatic compounds are one of the most important parameters in determining the quality of grapederived products and their concentration can reach up to $300 \mathrm{mg} / \mathrm{L}$ (Nan et al., 2013). This is true not only for wine, but also for unfermented grape juice and vinegar; moreover, aromatic compounds and precursors contained in the grape berry play a key role affecting the sensory quality of its products (Genova, 2012). The odorous compounds in grapes are largely present in the skin and the layers of cells immediately beneath it in free and bound forms. These compounds are quite complex and present in small amounts in the juice and the concentration of flavor compounds tends to increase during ripening and it is important that the grapes be harvested when the flavor production is at its peak (Alves, Barros, \& Rezende, 2014). During ripening and maturation process, a series of biochemical reactions occur and significantly contribute to the development of odor and taste-active compounds by means of the activation of enzymes responsible for the catalysis of such compounds from carbohydrates, acids, nitrogen and lipid constituents (Echeverria et al., 2004). Many factors 
affect the profile and concentration of aroma compounds in grapes, such as variety, time of harvesting, maturity index, climatic conditions, origin, type and amount of fertilization, among others (Sun, Sacks, Lerch, \& Vanden Heuvel, 2011; Vilanova et al., 2012; Slegers et al., 2015). Additionally, some aroma compounds are formed during crushing and maceration of grapes, for example, some aldehydes $\mathrm{C}_{6}$ aldehydes (grassy/herbaceous odor) are formed during crushing of grapes by enzymatic oxidation of grape lipids, whereas furfural and 5-(hydroxymethyl)-2-furaldehyde (chamomile-like odor) are synthetized from fructose if the grape must is heated at high temperatures $\left(>90^{\circ} \mathrm{C}\right)$ for a long period, for instance, $>15$ min (Jackson, 2008). Therefore, not only agronomical and environmental factors affect the flavor of grape juice but also the technology operations/conditions.

Various classes of aromatic compounds contribute to the flavor profile of grapes and grape-based products with alcohols, terpenes and esters providing the predominant contribution. Other classes include carbonyl compounds, few volatile phenols, and $\mathrm{C}_{13}$ norisoprenoids (derived from thermal degradation of caroteonoids caused by the pasteurization of juices and these compounds are responsible for the flowery aroma) (Arcanjo et al., 2015). Esters contribute to floral and fruity aroma attributes and represent the major class of aromatic compounds in fruit juices. Alcohols and aldehydes contribute to green and pungent aroma attributes and terpenoids are described by providing piney and floral characteristics (Echeverria et al., 2004). According to Baek, Cadwallader, Marroquin and Silva (1997), grape juices have a complex aromatic profile and more than 50 compounds were already identified. Alcohols and aldehyde were the most represented classes, followed by terpenoids benzoic derivatives and $\mathrm{C}_{13}$ norisoprenoids (i.e., vitispirane, damascenone, actinidol, $\alpha$ and $\beta$-ionone). For example, 2,5-dimethyl-4-hydroxy-3(2H)-furanone (furaneol) provides a burnt sugar-like aroma, while 2,3-butanedione, ethyl butanoate, ethyl 2-methylbutanoate, 2-phenylethanol, and $o$ aminoacetophenone are described as buttery/cream cheese, bubble gum/fruity, green apple/fruity, rosy, and foxy, respectively. For grape juices produced using $V$. labrusca and V. rotundifolia, the two main flavor compounds are acetovanillone, furaneol (2,5-dimethyl-4-hydroxy-2,3dihydro-3-furanone) and $o$ aminoacetophenone, while 2-phenylethanol usually is the main flavor component of $V$. vinifera juices. The chemical structures of some flavor components present in commercial grape juices are shown in Figure 1.3.

In general, aroma compounds may be markers of the origin (botanical and geographical) of grapes, and the varietal aroma originates from combinations of compounds and not from varietally-specific compounds. For example, the foxy aroma of some V. labrusca varieties comes from the content of ethyl 3mercaptopropianate or 2-aminoacetophenone, while the strawberry odor comes from furaneol or $\beta$ damascenone (Acree et al., 1990). 
<smiles>CC(=O)/C=C/C1=C(C)CCCC1(C)C</smiles>

B-Ionone<smiles>CC1=C(O)C(=O)OC1C</smiles>

Furaneol<smiles>C/C=C/C(=O)C1=C(C)C=CCC1(C)C</smiles>

B-Demascenone<smiles>OCCc1ccccc1</smiles>

\section{2-phenylethanol}

Figure 1.3: Chemical structure of some flavor components present in commercial grape juices.

\subsubsection{Phenolic compounds}

When it comes to grape juices, phenolic compounds are the main and most important class of bioactive compounds that is associated with physiological benefits in humans. Following sugars and acids, phenolic compounds are the most abundant constituents present in grapes, accounting between 400 to 3,000 mg/L of total phenolic content, depending on the maturity index, variety, geographical origin and soil type, sunlight exposure, and many other factors (Garrido \& Borges, 2013). Phenolic compounds are secondary metabolic products of plants derived from phenylalanine that possess one or more hydroxyl groups associated directly with the benzene ring structure (Shahidi \& Naczk, 2004). In the development of such compounds, phenylalanine is deaminated to cinnamic acid and tyrosine, which react with other compounds via phenylpropanoid and phenylpropanoid acetate pathways, wherein the key step in these metabolic pathways is the introduction of one or more hydroxyl groups on the phenyl ring, thus producing the phenolic compounds (Figure 1.4). As a result, the phenolic compounds are derivatives of a common structure: the phenylpropanol unit (Hollman, 2001). 


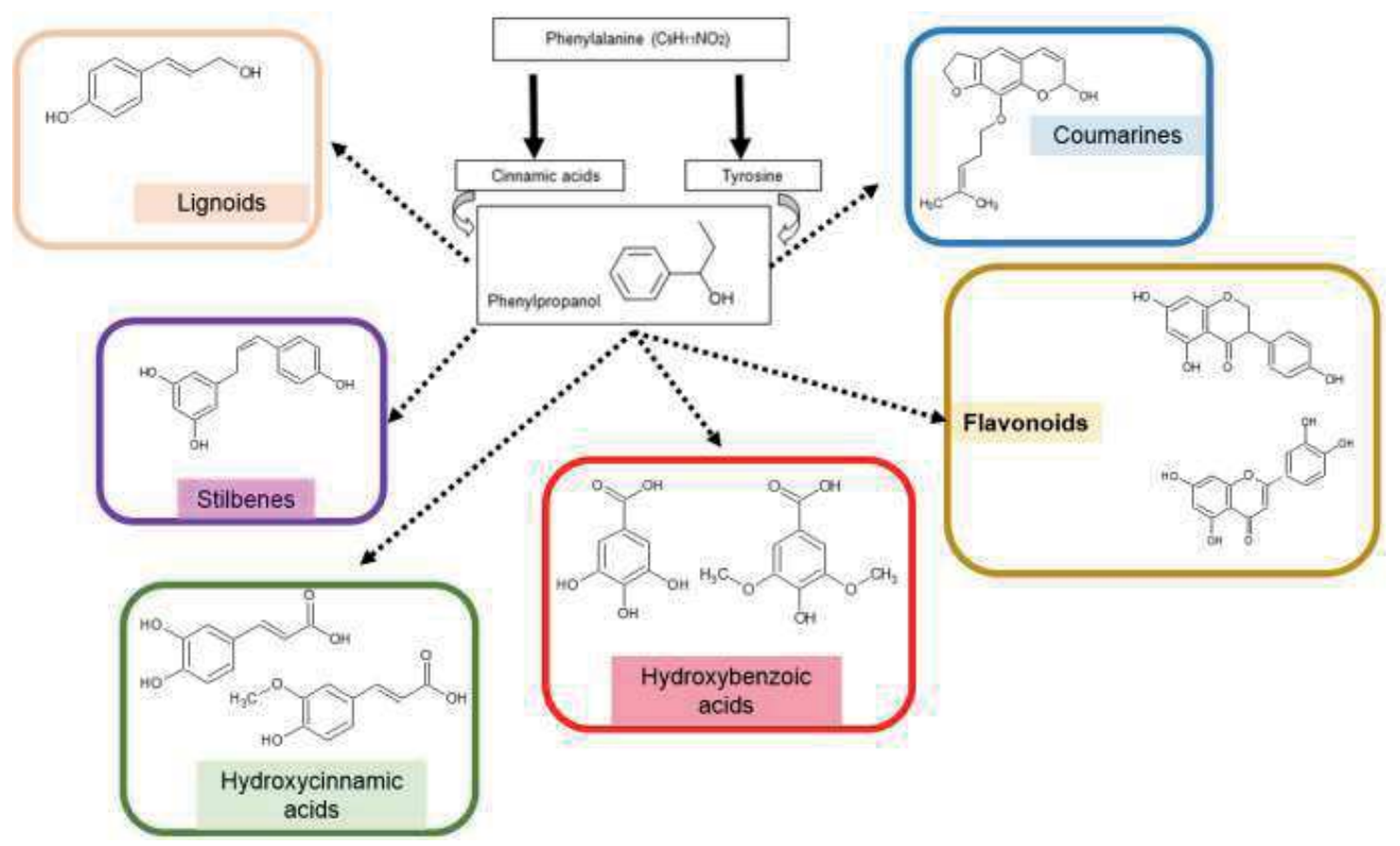

Figure 1.4: Biosynthesis of phenolic compounds in plants (adapted from Hollman, 2001 and Granato, Santos, Maciel, \& Nunes, 2016).

In general, phenolic compounds are divided into flavonoids $\left(\mathrm{C}_{6}-\mathrm{C}_{3}-\mathrm{C}_{6} \rightarrow\right.$ isoflavonoids, anthocyanins, flavanols, flavonols, proanthocyanidins) and nonflavonoids $\left(\mathrm{C}_{6}-\mathrm{C}_{3} \rightarrow\right.$ hydroxycinnamic and hydroxybenzoic acids, stilbenes, lignoids, coumarines) (Jackson, 2008). In grape berries, the phenolic compounds are concentrated mainly in the skins and seeds. In the peel, resveratrol isomers (cis and trans) together with anthocyanins (colorful pigments) are the most abundant phenolic compounds, while in seeds there is a predominance of flavanols, namely (+)-catechin and (-)-epicatechin, while the pulp is rich in phenolic acids. The amount of these compounds in both the grapes and the juices varies considerably according to some intrinsic and extrinsic factors, such as climate, amount of sunlight exposure and water stress, nutritional status and pathogenesis of vine nature and chemical composition of the soil, altitude, grape variety, and degree of grape maturation, and pH (Lachman, Sulc, \& Schilla, 2007; Song et al., 2015). Obviously, other factors related to the grape juice processing, especially the time and temperature of maceration and use of enzymes, affect quantitative and qualitatively the phenolic composition of grape juices (Pereira et al., 2008; Paranjpe, Ferruzzi, \& Morgan, 2012).

The phenolic composition of grapes and byproducts (i.e., grape pomace, wine, and juices) is based on flavonoids, such as anthocyanins, flavanols, and flavonols, stilbenes, such as cis and trans-resveratrol, and phenolic acids, such as gallic, vanillic, syringic, ellagic, protocatechuic, and caffeic acids. To date, in grape juice from $V$. labrusca species, usually there are more than 60 flavonoids, in which 25 are anthocyanins, indicating the complexity of chemical composition of such a food matrix (Stalmach et al., 2011). The levels 
of such compounds vary considerably within varietals and cultivation systems and this trend also occurs for the total phenol content (Dávalos et al., 2005; Dani et al., 2007; Natividade et al., 2013; Burin et al., 2014). Figure 1.5 contains the chemical structure of some phenolic compounds found in purple grape juices.<smiles>Oc1ccc(/C=C/c2cc(O)cc(O)c2)cc1</smiles>

trans-Resveratrol<smiles>O=C(O)c1cc(O)c(O)c(O)c1</smiles>

Gallic acid<smiles>O=c1c(O)c(-c2ccc(O)c(O)c2)oc2cc(O)cc(O)c12</smiles>

Quercetin<smiles>Oc1cc(O)c2c(c1)O[C@H](c1ccc(O)c(O)c1)C(O)C2</smiles>

(+)-Catechin<smiles></smiles>

Malvidin 3,5-diglucoside<smiles>O=C(O)c1ccc(O)c(O)c1</smiles>

Protocatechuic acid

Figure 1.5: Chemical structures of some phenolic compounds found in purple grape juices.

\subsection{Antioxidant activity of purple grape juices}

The antioxidant activity of grape juices has been widely studied using in vitro, ex vivo, and in vivo protocols, and a direct and positive correlation between antioxidant activity and the content of phenolic compounds is usually obtained (Lima et al., 2014). According to Halliwell and Gutteridge (2007), an antioxidant is a substance that, when present at a low concentration compared with that of an oxidizable substrate in the medium, inhibits oxidation of the substrate. Phenolic compounds, by nature, are able to protect cells from oxidizing agents and, therefore, can be considered antioxidants. These substances can be classified according to their function (free-radical scavengers, metal chelators, scavengers of non-radical oxidants compounds that induce the production of antioxidants, and compounds that inhibit the generation of oxidants), polarity (water-soluble or lipophilic agents), source (exogenous - diet, or endogenous), and mechanism of action (hydrogen atom transfer [HAT], electron transfer [ET], a combination of HAT and ET mechanisms) (Prior et al., 2005; Sies, 2007; Bouayed \& Bohn, 2010; Rizzo et al., 2010; López-Alarcón \& Denicol, 2013; Apak et al., 2013).

The ET-based assays are dependent on the medium $\mathrm{pH}$ and are simulated in vitro by means of a redoxpotential probe (i.e. oxidizing agent) instead of peroxyl radicals (HAT-based essays). Some HAT assays are: oxygen radical absorbance capacity (ORAC), inhibition of lipoperoxidation of brain/liver/egg homogenate, crocin bleaching assay using 2,2'-azobis(2-amidinopropane) hydrochloride as a probe, and $\beta$-carotene 
bleaching assay, while some ET-based methods include free-radical scavenging activity toward 2,2-diphenyl1-picrylhydrazyl (DPPH) and 2,2'-azino-bis(3-ethylbenzothiazoline-6-sulphonic acid (ABTS), cupric-ion reducing antioxidant capacity (CUPRAC), and Folin-Ciocalteu reducing capacity (Shahidi \& Zhong, 2015). It is noteworthy that DPPH and ABTS assays combine HAT and ET mechanisms.

As in any other aerobic living, humans are constantly exposed to oxidizing agents (endogenous and exogenous) that are capable to induce irreparable damages in tissues via oxidation reactions. These reactions also produce reactive species (both radical and non-radical substances) derived from oxygen (ROS), such as peroxide anion, hydrogen peroxide $\left(\mathrm{H}_{2} \mathrm{O}_{2}\right)$, alkoxyl (LO), peroxyl (LOO), hydroxyl radicals ( $\left.\mathrm{OH}\right)$, and reactive nitrogen species (RNS), such as nitric oxide $(\cdot \mathrm{NO})$, peroxynitrite anion $\left(\mathrm{ONOO}^{-}\right)$, and nitrogen dioxide $\left(\cdot \mathrm{NO}_{2}\right)$ that continuously react with either cells or substances that are able to block, neutralize, buffer, quench, or scavenge reactive species (Laguerre, Lecomte, \& Villeneuve, 2007). In terms of antioxidant compounds, grapes are considered a rich source of various bioactive compounds, such as stilbenes (cis and trans-resveratrol), phenolic acids (gallic acid, ellagic acid, caffeic acid), and flavonoids (anthocyanins, quercetin, rutin, myricetin) (Natividade et al., 2013). A detailed review on chemical in vitro and cellular-based assays to estimate the antioxidant activity of extracts is already described by Alam, Bristi, and Rafiquzzman (2013), López-Alarcón and Denicól (2013), and Shahidi and Zhong (2015). However, the most used protocols to assess the in vitro antioxidant capacity of natural products, including grape juices, are: DPPH, ABTS, FRAP, and ORAC (Halliwell, 2012; Schaich, Tian, \& Xie, 2015).

As well stressed by Forman et al. (2014), these in vitro methods differ among each other in relation to the principles of the chemical reaction, the target molecule, the way to express the results, the $\mathrm{pH}$ of the medium, reaction time, solvent, concentration of substrates, among others. Moreover, as many chemical mechanisms and multiple reactions are involved, no single method will ever accurately reflect the 'total' antioxidant capacity of complex matrices, such as grape juices (Alam, Bristi, \& Rafiquzzman, 2013; Apak et al., 2013). It is necessary, therefore, to assess the in vitro antioxidant capacity of grape juices by using multiple protocols that are based on distinct mechanisms, principles, and chemical reagents.

\subsection{Statistical methods applied in grape juice studies}

It is noteworthy that the use of mathematical and statistical methods in food science and technology has increased steeply in the last 20 years, and this trend is clearly followed by the development of different algorithms and computational software that facilitates the widespread use of those methods. This trend can be attributable to the low cost of computers and the increasing capacity of processing techniques to analyze complex and high volumes of experimental results aiming to facilitate the interpretation of experimental data. In food science and technology, applied statistics is widely used for numerous purposes: design of experiments, modeling of response variables using response surface methodology, and recently, the application of

multivariate statistical methods to unravel technological problems and to better understand complex experimental data (Farris \& Piergiovanni, 2009; Özdestan et al., 2013; Nunes et al., 2014; Ortea \& Gallardo et al., 2015). In this sense, undoubtedly, descriptive analysis (i.e., calculation of means, median, correlation, linear regression, standard deviation, among others) followed by inferential statistics (i.e., analysis of variances 
and multiple comparison of means) are the most frequently used methods (Kumar, Bansal, Sarma, \& Rawal, 2014). However, when many samples (usually $\mathrm{n}>10$ ) are analyzed for numerous characteristics, inferential statistical analysis is not sufficient to provide a deep and broad discussion of the experimental data. Thus, more sophisticated statistical methods, namely multivariate statistical techniques (or chemometrics), are often required (Brereton, 2015). Such methods can be divided into unsupervised multivariate methods, also known as multivariate exploratory methods, such as principal component analysis (PCA) and cluster analysis (CA), and supervised multivariate methods, such as partial least-squares discriminant analysis (PLSDA) and soft independent modeling of class analogy (SIMCA) (Richards \& Holmes, 2015).

As stated and explained by Nunes et al. (2015), chemometric techniques have been increasingly applied not only in food science and technology but also in correlated fields, such as experimental nutrition and analytical chemistry (Corrêa et al., 2014; Araújo et al., 2014; Kumar, Bansal, Sarma, \& Rawal, 2014; Hong, Wang \& Qi, 2015). Some important and innovative applications in food research are: the identification of bioactive substances from food and herbal sources (Chen, Luo, Zhang, \& Kong, 2016), classification of geographical origin of honeys according to VOC profile and physicochemical properties (Karabagias et al., 2014) as well as with the profile of phenolic acids (Zhao et al., 2016), the authentication of organic and conventional eggs according to the profile of carotenoids (van Ruth et al., 2011), classification of olive oils based on the profile of volatile organic compounds, VOC (Araghipour et al., 2008), verification of geographical origin of palm oil based on the chromatographic fingerprinting of triacylglycerols (Ruiz-Samblás et al., 2013) and butters according to the VOC profile (Maçatelli et al., 2009), differentiation of pasteurized conventional and organic milk and weidermelk (typical Dutch milk) based on fatty acid and triacylglycerols (Capuano et al., 2015), detection of adulterants added in food products and ingredients (Xu et al., 2015), verification of producing region of spirits (Peng et al., 2015), verification of impacts of production location, production system and variety on the volatile composition and sensory characteristics of tomatoes (Muilwijk et al., 2015), identification of geographical origin of lentils (Longobardi et al., 2015b) and honeys (Di Bella et al., 2015), classification the geographical origin of corn distillers dried grains with solubles (Zhou et al., 2015), among others.

The use of different chemometric methods in food science and technology is widespread because nowadays ready-to-use free-access and commercial toolboxes are available to develop models using various techniques, including pattern recognition (exploratory analysis), classification and multivariate calibration. Chemometrics enables a multivariate analysis of complex data and the extraction of relevant information, both qualitative and quantitative, is usually obtained (Ares, 2014; Longobardi et al., 2015a,b). However, in order to obtain significant and holistic comprehension of experimental data and statistical outputs, it is required not only meaningful data but also rational analysis and understanding of the purpose of the analysis.

In the viticulture area, chemometrics (classification methods, i.e., partial least-squares discriminant analysis, PLSDA) has been used together with Fourier-transform infrared spectroscopy to authenticate the concentration of grape juice in nectars (Snyder et al., 2014), while nuclear magnetic resonance fingerprinting allied with exploratory multivariate methods (principal component analysis, PCA) to differentiate the grape varietals (Ali et al., 2011) and to monitor the overall quality of grape juice during storage (Silva, Campos, 
Simonelli, \& Barison, 2009). Chemometrics has also been applied with different spectroscopic methods to identify different grape species, cultivars and processing conditions (Defernez, Kemsley, \& Wilson, 1995) or to assess the chemical, physicochemical composition (including phenolic compounds, $\mathrm{pH}$, acidity and total soluble solids, sugar composition, phenolic acids profile, and minerals) and antioxidant activity of grapes and derived products (Yoon, Kim, \& Lee, 1997; Ferreira et al., 2002; Gishen, Dambergs, \& Cozzolino, 2005; Yildirim, 2013; Cozzolino, 2015; Lima et al., 2015).

\subsection{Research aim and thesis outline}

The main objective of this study is to elucidate the reflectance of origin in the unique compositional traits of purple grape juices. Origin is sub-divided into botanical origin, production management system origin, and geographical origin (Figure 1.6). Juice characteristics involved are the composition of the volatile compounds, instrumental taste profiles, phenolics and in vitro antioxidant capacity (Figure 1.7, Table 1.1). Furthermore, the implications of these unique characteristics determined by these origin factors for the authentication of juices is explored. A schematic flow of the $\mathrm{PhD}$ study is represented in Figure 1.8.

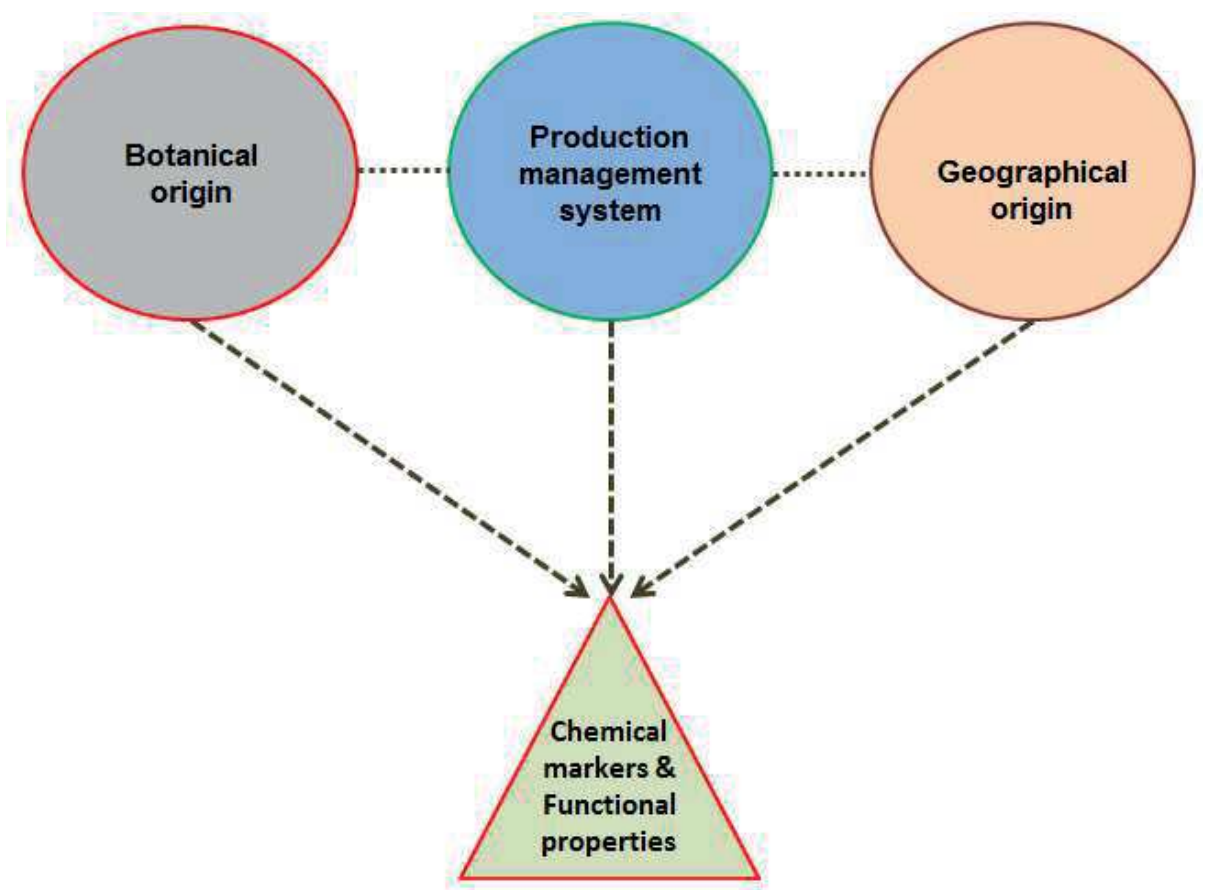

Figure 1.6: Schematic representation of the main components of the thesis. 


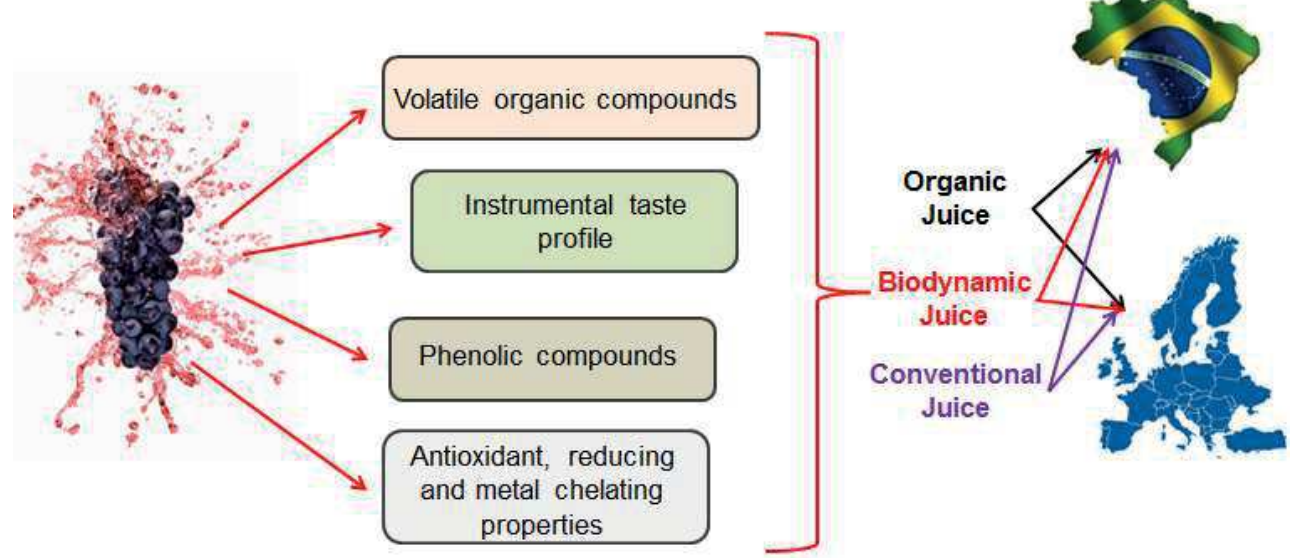

Figure 1.7: Representation of the elements included in the present $\mathrm{PhD}$ study to assess the quality parameters of grape juices.

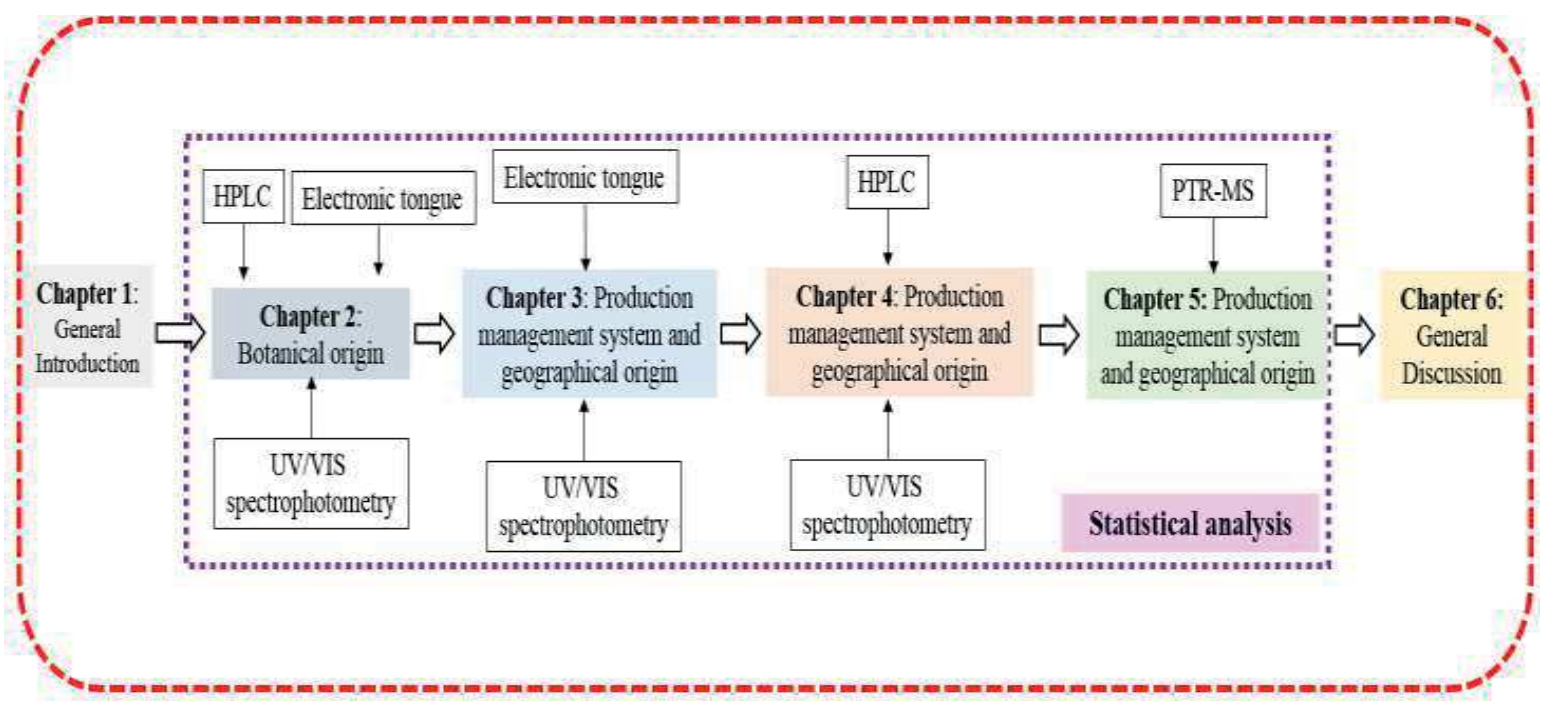

Figure 1.8: Representation of the schematic flow adopted to perform the study of the $\mathrm{PhD}$ project. 


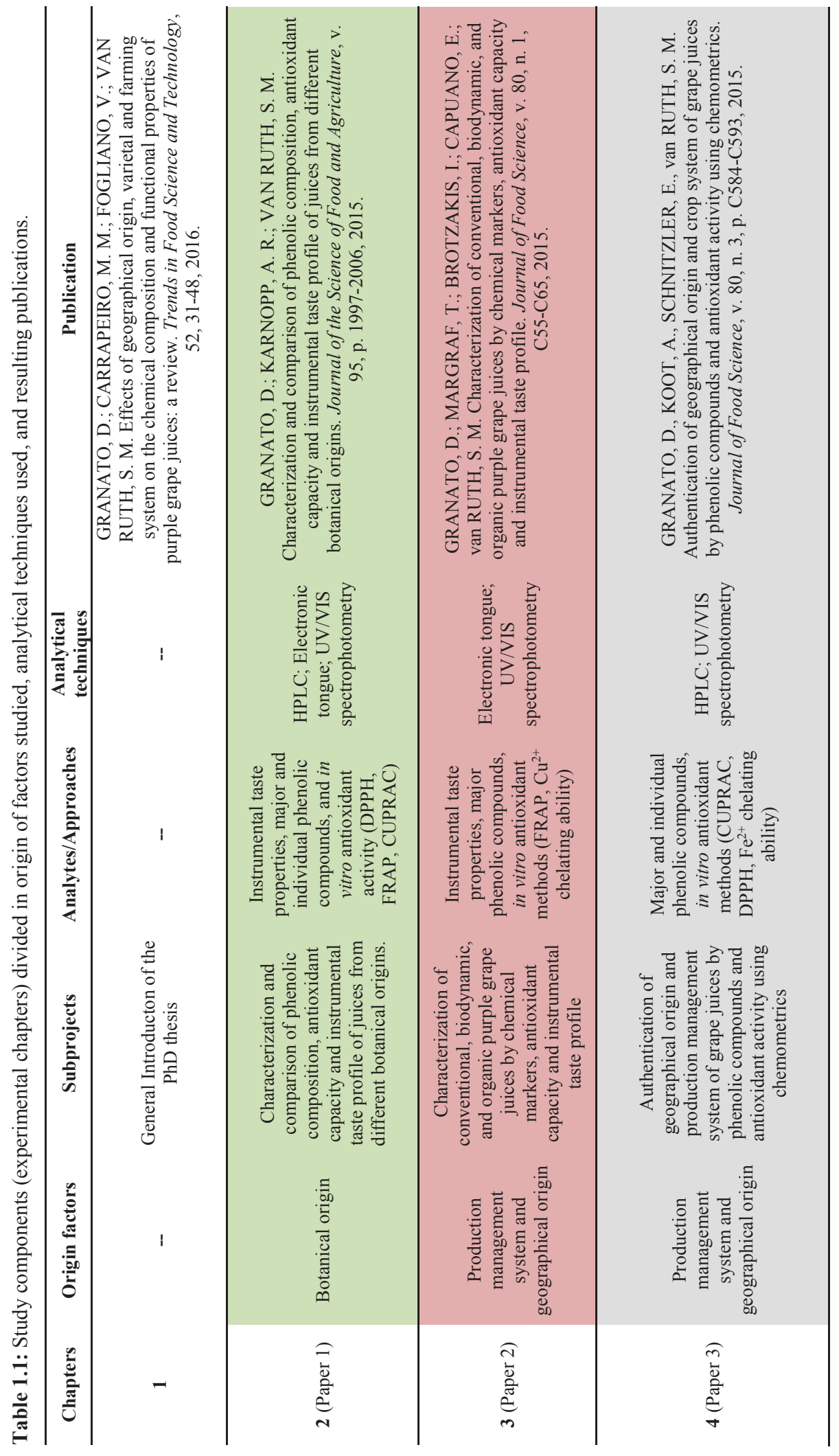

ข 


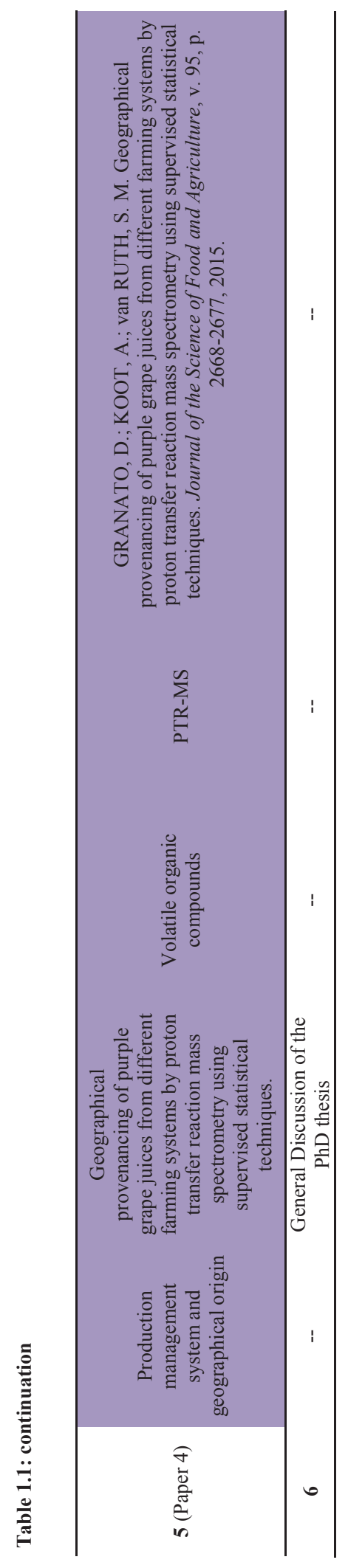


The thesis is outlined as follows (summary in Table 1.1. A General Introduction of the $\mathrm{PhD}$ thesis is presented in Chapter $\mathbf{1}$ and it contains theoretical information about the topics covered in this study. In

Chapter 2, the botanical origin of different juices marketed in the Dutch market was characterized by quality traits related to $\mathrm{pH}$ and total soluble solids, instrumental taste properties (electronic tongue parameters), phenolic composition (individual compounds and some major classes) as well as in vitro antioxidant capacity (FRAP, CUPRAC, DPPH assays). For this purpose, some analytical methods were tested to be further applied to study the grape juices. In Chapter 3, the production management system origin (organic, biodynamic and conventional) of European purple grape juices was studied by using physicochemical parameters ( $\mathrm{pH}$ and total soluble solids), instrumental taste profile, phenolic composition (spectrophotometric determinations of major classes), and antioxidant activity $\left(\mathrm{Cu}^{2+}\right.$ chelating ability and FRAP). In Chapter 4 , the characteristics resulting from the production management systems (organic, biodynamic and conventional) and geographical origins (Brazil and Europe) used to produce the grapes were assessed by quantifying the total and individual phenolic compounds and in vitro antioxidant activity (DPPH, CUPRAC, and $\mathrm{Fe}^{2+}$ chelating capacity) of grape juices. In Chapter 5, the influence of the production management origin and geographical origin of purple grape juices was evaluated by characterizing the volatile organic compounds (VOCs) measured by proton transfer reaction mass spectrometry (PTR-MS). Subsequently characteristics of organic, biodynamic, and conventional purple grape juices produced in Brazil and Europe were subjected to chemometrics to develop an approach to classify Brazilian and European grape juices based on the VOC profiles. As the VOC profile was very distinct between locations, intraregional methods were also developed to classify juices based on the production system origin. In Chapter 6, data from the Chapters 2 to 5 were compared and integrated to achieve the main objective of this thesis.

\subsection{References}

Acree, T. E., Lavin, E. H., Nishida, R., Watanabe, S. (1990). O-Aminoacetophenone, the foxy smelling component of Labruscana grapes. In: Flavour Science and Technology. YY. Bessiere and A. F. Thomas, eds.), p. 49-52. $6^{\text {th }}$ ed. Weurman Flavour Research Symposium, John Wiley, United Kingdom.

Alaei, H., Siahmard, Z., Reisi, P. (2015). Chapter 86 - Red Grape Juice and Alzheimer's Disease. In: Diet and Nutrition in Dementia and Cognitive Decline. Martin, C. R., Preedy, V. (Editors). Academic Press, $1^{\text {st }}$ edition, p. 935-942.

Alam, M. D., Bristi, N. J., Rafiquzzman, M. (2013). Review on in vivo and in vitro methods evaluation of antioxidant activity. Saudi Pharmaceutical Journal, 21, 143-152.

Albers, A. R., Varghese, S., Vitseva, O., Vita, J. A., Freedman, J. E. (2004). The antiinflammatory effects of purple grape juice consumption in subjects with stable coronary artery disease. Arteriosclerosis, Thrombosis, and Vascular Biology, 24, e179-e180.

Ali, K., Maltese, F., Fortes, A. M., Pais, M. S., Verpoorte, R., Choi, Y. H. (2011). Pre-analytical method for NMR-based grape metabolic fingerprinting and chemometrics. Analytica Chimica Acta, 703(2), 179186. 
Alves, A. A. R., Barros, E. B. P., Rezende, C. M. (2014). Method development and optimization of liquidliquid extraction for the quantitative analysis of volatile compounds from Brazilian grape juices. In: Flavor Science Proceedings, 417-421.

Andersen, P. C., Crocker, T. E., Breman, J. (2003). The Muscadine grape. Available at: http://edis.ifas.ufl.edu/pdffiles/HS/HS10000.pdf. Access 15 March 2015.

Apak, R., Gorinstein, S., Böhm, V., Schaich, K. M., Özyürek, M., Güçlü, K. (2013). Methods of measurement and evaluation of natural antioxidant capacity/activity (IUPAC Technical Report). Pure and Applied Chemistry, 85(5), 957-998.

Araghipour, N., Colineau, J., Koot, A., Akkermans, W., Rojas, J. M. M., Beauchamp, J., Wisthaler, A., Märk, T. D., Downey, G., Guillou, C., Mannina, L., van Ruth, S. (2008). Geographical origin classification of olive oils by PTR-MS. Food Chemistry, 108(1), 374-383.

Araújo, J., Teixeira, J., Gaio, A. R., Lopes, C., Ramos, E. (2014). Dietary patterns among 13 -y-old Portuguese adolescentes. Nutrition, 31(1), 148-154.

Arcanjo, N. M. O., Bezerra, T. K. A., Silva, F. L. H., Madruga, M. S. (2015). Optimization of the HS-SPMEGC/MS technique for determining volatile compounds in red wines made from Isabel grapes (Vitis labrusca). Food Science and Technology (Campinas), 35(4), 676-682.

Ares, G. (2014). Cluster analysis: application in food science and technology. In: Granato, D., Ares G. (Org.). Mathematical and Statistical Approaches in Food Science and Technology. $1^{\text {st }}$ ed. Oxford: Wiley Blackwell, 1, 103-119.

Baek, H. H., Cadwallader, K. R., Marroquin, E., Silva, J. L. (1997). Identification of predominant aroma compounds in Muscadine grape juice. Journal of Food Science, 62(2), 249-252.

Benzie, I. F. F., Strain, J. J. (1996). The ferric reducing ability of plasma (FRAP) as a measure of " antioxidant power": The FRAP assay. Analytical Biochemistry, 239, 70-76.

Berg, D., Youdim, M. B. (2006). Role of iron in neurodegenerative disorders. Topics in Magnetic Resonance Imaging, 17, 5-17.

Borrás, E., Ferré, J., Boqué, R., Mestres, M., Aceña, L., Busto, O. (2015). Data fusion methodologies for food and beverage authentication and quality assessment - A review. Analytica Chimica Acta, 891, 1-14.

Bouayed, J., Bohn, T. (2010). Exogenous antioxidants-Double-edged swords in cellular redox state. Oxidative Medicine and Cellular Longevity, 3(4), 228-237.

Brandt, K, Mølgaard, J. P. (2001). Organic agriculture: does it enhance or reduce the nutritional value of plant foods?. Journal of the Science of Food and Agriculture, 81(9), 924-931.

Brasil. Ministério da Agricultura, Pecuária e Abastecimento. Instrução Normativa no 19, de 19 de junho de 2013. Available at: http://www.sucodeuvadobrasil.com.br/legislacao/INSTRUCAO_NORMATIVA_No_19_DE_19_DE_ JUNHO_DE_2013_pic_bebidas_n_alcoolicas.pdf. Access on 10 February 2015.

Brasil. Ministério da Agricultura, Pecuária e Abastecimento. Lei n ${ }^{\circ} 10.831$ de 23 de dezembro de 2003. Dispões sobre agricultura orgânica. Available at: http://www.planalto.gov.br/ccivil_03/leis/2003/L10.831.htm. Access on 22 January 2015. 
Brereton, R. G. (2015). Pattern recognition in chemometrics. Chemometrics and Intelligent Laboratory Systems, 149(B), 90-96.

Brewer, M. S. (2011). Natural antioxidants: sources, compounds, mechanisms of action, and potential applications. Comprehensive Reviews in Food Science and Food Safety, 10, 221-247.

Brouillard, R., Chassaing, S., Fougerousse, A. (2003). Why are grape/fresh wine anthocyanins so simple and why is it that red wine color lasts so long?. Phytochemistry, 64(7), 1179-1186.

Bunea, C. I., Pop, N., Babes, A. C., Matea, C., Dulf, F. V., Bunea, A. (2012). Carotenoids, total polyphenols and antioxidant activity of grapes (Vitis vinifera) cultivated in organic and conventional systems. Chemistry Central Journal, 6, 1-9.

Burin, V. M., Falcão, L. D., Gonzaga, L. V., Fett, R., Rosier, J. P., Bordignon-Luiz, M. T. (2010). Colour, phenolic content and antioxidant activity of grape juice. Ciência e Tecnologia de Alimentos, 30(4), $1027-$ 1032.

Burin, V. M., Ferreira-Lima, N. E., Panceri, C. P., Bordignon-Luiz, M. T. (2014). Bioactive compounds and antioxidant activity of Vitis vinifera and Vitis labrusca grapes: Evaluation of different extraction methods. Microchemical Journal, 114, 155-163.

Cadahia, E., Simón, B. F., Sanz, M., Poveda, P., Colio, J. (2009). Chemical and chromatic characteristics of Tempranillo, Cabernet Sauvignon and Merlot wines from Navarra aged in Spanish and French oak barrels. Food Chemistry, 115, 639-649.

Capuano, E., Boerringter-Eenling, R., van der Veer, G., van Ruth, S. M. (2013). Analytical authentication of organic products: an overview of markers. Journal of the Science of Food and Agriculture, 93(1), 1228.

Capuano, E., Gravink, R., Boerrigter-Eenling, R., van Ruth, S. M. (2015). Fatty acid and triglycerides profiling of retail organic, conventional and pasture milk: Implications for health and authenticity. International Dairy Journal, 42, 58-63.

Chen, Y., Luo, J., Zhang, Q., Kong, L. (2016). Identification of active substances for dually modulating the renin-angiotensin system in Bidens pilosa by liquid chromatography-mass spectrometry-based chemometrics. Journal of Functional Foods, 21, 201-211.

Codex Alimentarius. CODEX general standard for fruit juices and nectars (CODEX STAN 247-2005). Available at: http://www.codexalimentarius.org/input/download/standards/10154/CXS_247e.pdf

Corrêa, S. C., Pinheiro, A. C. M., Siqueira, H. E., Carvalho, E. M., Nunes, C. A., Vilas Boas, E. V. B. (2014). Prediction of the sensory acceptance of fruits by physical and physical-chemical parameters using multivariate models. LWT - Food Science and Technology, 59(1), 666-672.

Cozzolino, D. (2015). The role of visible and infrared spectroscopy combined with chemometrics to measure phenolic compounds in grape and wine samples. Molecules, 20(1), 726-737.

Dani, C., Oliboni, L. S., Vanderlinde, R., Bonatto, D., Salvador, M., Henriques, J. A. P. (2007). Phenolic content and antioxidant activities of white and purple juices manufactured with organically or conventionally-produced grapes. Food Chemical Toxicology, 45, 2574-2580. 
Daniells, S. US organic food market to grow 14\% from 2013-18. Available at: http://www.foodnavigatorusa.com/Markets/US-organic-food-market-to-grow-14-from-2013-18. Access 14 March 2015.

Dávalos, A., Bartolomé, B., Gómez-Cordovés, C. (2005). Antioxidant properties of commercial grape juice and vinegars. Food Chemistry, 93, 325-330.

Defernez, M., Kemsley, E. K., Wilson, R. H. (1995). Use of infrared spectroscopy and chemometrics for the authentication of fruit purees. Journal of Agricultural and Food Chemistry, 43(1), 109-113.

Danezis, G. P., Tsagkaris, A. S., Camin, F., Brusic, V., Georgiou, C. A. (2016). Food authentication: techniques, trends \& emerging approaches. Trends in Analytical Chemistry. In Press. DOI: 10.1016/j.trac.2016.02.026

Di Bella, G., Lo Turco, V., Potortì, A. G., Bua, G. D., Fede, M. R., Dugo, G. (2015). Geographical discrimination of Italian honey by multi-element analysis with a chemometric approach. Journal of Food Composition and Analysis, 44, 25-35.

Dillenburg, D. R., Mostarda, C., Moraes-Silva, I. C., Ferreira, D., Bós, D. S. G., Duarte, A. A. M., Irigoyen, M. C., Rigatto, K. (2013). Resveratrol and grape juice differentially ameliorate cardiovascular autonomic modulation in L-NAME-treated rats. Autonomic Neuroscience, 179(1-2), 9-13.

Echeverria, G., Grall, J., López, M. L., Lara, I. (2004). Volatile production, quality, and aroma related enzyme activities during maturation of Fuji apples. Postharvest Biology and Technology, 31, 217-227.

El-Kassas, F. B., Ali, A. M., Mostafa, S. E. (2014). Phenolic compounds as antioxidants of some products manufactured from two cultivated Egyptian varieties of seedless grapes. Annals of Agricultural Sciences, 59(2), 195-199.

Eur-Lex. Fruit juices and similar products - Council Directive 2001/112/EC. Available at: http://eurlex.europa.eu/legal-content/EN/TXT/?uri=URISERV:121132

European Commission (2002): Regulation (EC) number 178/2002 of the European Parliament and of the Council of 28 January 2002. European Commission, Brussels.

European Comission. (2007). Council Regulation (EC) No 834/2007 of 28 June 2007 on organic production and labelling of organic products and repealing Regulation (EEC) No 2092/91. Official Journal of the European Union, L, 189, 1-23.

European Comission. (2012). Commission implementing regulation (EU) No 203/2012 of 8 March 2012 amending Regulation (EC) No 889/2008 laying down detailed rules for the implementation of Council Regulation (EC) No 834/2007, as regards detailed rules on organic wine. Official Journal of the European Union, L, 71, 42-47.

European Commission (2014a): Proposal for a regulation of the European Parliament and of the Council on organic production and labeling of organic products, amending Regulation (EU) No XXX/XXX of the European Parliament and of the Council (Official controls Regulation) and repealing Council regulation (EC) No 834/2007. European Commission, Brussels.

European Commission (2014b): Action Plan for the future of Organic Production in the European Union. European Commission, Brussels. 
European Commission (2014c): Organics: commission proposal for more and better. Press release of March 25, 2014. Website of the European Commission, Brussels.

European Fruit Juice Association (AIJN). Market Report 2013. Available at: http://www.aijn.org/pages/main/facts-figures.html. Access on 10 February 2015.

Farris, F., Piergiovanni, L. (2009) Optimization of manufacture of almond paste cookies using response surface methodology. Journal of Food Process Engineering, 32, 64-87.

Ferreira, E. C., Gomes, S. H. R. B., Castro, M. M. F., Araujo, J. N., Araujo, A. R. N. (2002). Análise exploratória dos teores de constituintes inorgânicos em sucos e refrigerantes de uva. Eclética Química, 27(special), 77-90.

Flora, S. J. S., Pachauri, V. (2010). Chelation in metal intoxication. International Journal of Environmental Research and Public Health, 7(7), 2745-2788.

Flores, P. (2015). Organic agriculture in Latin America and the Caribbean. In: IFOAM: The world of organic agriculture. Statistics \& emerging trends 2015. Available at: International Federation of Organic Agriculture Movements.

Food and Agriculture Organization (FAO). Production of grapes. Available at: http://faostat.fao.org/site/339/default.aspx. Access on 12 March 2014.

Forman, H. J., Davies, K. J. A., Ursini, F. (2014). How do nutritional antioxidants really work: Nucleophilic tone and para-hormesis versus free radical scavenging in vivo. Free Radical in Biology \& Medicine, 66, 24-35.

Fragopoulou, E., Antonopoulou, S., Nomikos, T., Demopoulos, C. A. (2003). Structure elucidation of phenolic compounds from red/white wine with antiatherogenic properties. Biochimica et Biophysica Acta, 1632, 90-99.

Garcia-Alonso, F. J., Guidarelli, A., Periago, M. J. (2007). Phenolic-rich juice prevents DNA single-strand breakage and cytotoxicity caused by tert-butylhydroperoxide in U937 cells: the role of iron chelation. The Journal of Nutritional Biochemistry, 18(7), 457-466.

Garde-Cerdán, T., Arias-Gil, M., Marsellés-Fontanet, R., Ancín-Azpilicueta, C., Martín-Belloso, O. (2007). Effects of thermal and non-thermal processing treatments on fatty acids and free amino acids of grape juice. Food Chemistry, 18, 473-479.

Garrido, J., Borges, F. (2013). Wine and grape polyphenols - A chemical perspective. Food Research International, 54(2), 1844-1858.

Genova, G. (2012). Qualitative evaluation of aroma-active compounds in grape and grape-derived products by means of headspace SPME-GC/MS analysis. Perkin-Elmer Application Note, 7p.. Available at: http://www.perkinelmer.com/PDFs/downloads/APP_QualitativeEvaluationAromaGrapes.pdf

Genova, G., Tosetti, R., Tonutti, P. (2016). Berry ripening, pre-processing and thermal treatments affect the phenolic composition and antioxidant capacity of grape (Vitis vinifera L.) juice. Journal of the Science of Food and Agriculture, 96(2), 664-671.

Gishen, M., Dambergs, R. G., Cozzolino, D. (2005). Grape and wine analysis - enhancing the power of spectroscopy with chemometrics. Australian Journal of Grape and Wine Research, 11(3), 296-305. 
Granato, D., Santos, J. S., Maciel, L. G., Nunes, D. S. (2016). Chemical perspective and criticism on selected analytical methods used to estimate the total content of phenolic compounds in food matrices. Trends in Analytical Chemistry, 80, 266-279.

Greene, C., Kremen, A. (2003). U.S. Organic Farming in 2000-2001: Adoption of Certified Systems. USDA Agriculture Informative Bulletin, 780, 1-50.

Halliwell, B. (2012). Free radicals and antioxidants: updating a personal view. Nutrition Review, 70(5), 257265.

Halliwell, B. and Gutteridge, J. M. C. (2007). Free Radicals in Biology and Medicine. $4^{\text {th }}$ edition. Oxford: Oxford University Press, 888p.

Hasan, M., Yun, H. K., Kwak, E. J., Baek, K. H. (2014). Preparation of resveratrol-enriched grape juice from ultrasonication treated grape fruits. Ultrasonics Sonochemistry, 21(2), 729-734.

Hellström, J., Mattila, P., Karjalainen, R. (2013). Stability of anthocyanins in berry juices stored at different temperatures. Journal of Food Composition and Analysis, 31(1), 12-19.

Hernandz-Orte, P., Ibarz, M. J., Cacho, J., Ferreira, V. (2003). Amino acid determination in grape juices and wines by hplc using a modification of the 6-aminoquinolyl-n-hydroxysuccinimidyl carbamate (AQC) method. Chromatographia, 58(1-2), 29-35.

Hollman, P. C. H. (2001). Evidence for health benefits of plant phenols: local or systemic effects? Journal of the Science of Food and Agriculture, 81(9), 842-852.

Hong, X., Wang, J., Qi, G. (2015). E-nose combined with chemometrics to trace tomato-juice quality. Journal of Food Engineering, 149, 38-43.

Huang, D., Ou, B. and Prior, R. L. (2005). The chemistry behind antioxidant capacity assay. Journal of Agricultural and Food Chemistry, 53, 1841-1856.

Huang, K. S., Lin, M. (1999). Oligostilbenes from the roots of Vitis amurensis. Journal of Asian Natural Products Research, 2(1), 21-28

Huber, B., Schmid, O., Mannigel, C. (2015). Standards and Regulations. In: IFOAM: The world of organic agriculture. Statistics \& emerging trends 2015. Available at: International Federation of Organic Agriculture Movements.

Hugh, J., Robinson, J. (2013). The world Atlas of wine. $7^{\text {th }}$ edition, England: Mitchell Beazley, 400p.

Ibravin. (2014). Instituto Brasileiro do Vinho. Estatísticas. Available at: http://www.ibravin.org.br/dadosestatisticos. Access on: 8 Feb. 2014.

Iyer, M. M., Sacks, G. L., Padilla-Zakour, O. I. (2010). Impact of harvesting and processing conditions on green leaf volatile development and phenolics in Concord grape juice. Journal of Food Science, 75(3), C297-C304.

Jackson, R. S. (2008). Wine Science: principles and applications. $3^{\text {rd }}$ Ed, Academic Press: Unites States of America, p. 270-331.

Jayani, R. S., Saxena, S., Gupta, R. (2005). Microbial pectinolytic enzymes: A review. Process Biochemistry, 40(9), 2931-2944. 
Jella, P., Rouseff, R., Goodner, K., Widmer, W. (1998). Determination of key flavor coponents in methylene chloride extracts from processed grapefruit juice. Journal of Agricultural and Food Chemistry, 46, 242247.

Jung, K. J., Wallig, M. A., Singletary, K. W. (2006). Purple grape juice inhibits 7,12dimethylbenz[a]anthracene (DMBA)-induced rat mammary tumorigenesis and in vivo DMBA-DNA adduct formation. Cancer Letters, 233, 279-288.

Kahl, J., Baars, T., Bügel, S., Busscher, N., Huber, M., Kusche, D., Rembiałkowska, E., Schmid, O., Seidel, K., Taupier-Letage, B., Velimirov, A., Załęcka, A. (2012). Organic food quality: a framework for concept, definition and evaluation from the European perspective. Journal of the Science of Food and Agriculture, 92(14), 2760-2765.

Karabagias, I. K., Badeka, A., Kontakos, S., Karabournioti, S., Kontominas, M. G. (2014). Characterisation and classification of Greek pine honeys according to their geographical origin based on volatiles, physicochemical parameters and chemometrics. Food Chemistry, 146, 548-557.

Koepf, H., Schaumann, W., Haccius, M. (2001). Agricoltura Biodinamica: Antroposofica Editrice.

Kuepper, G, Gegner, L. Organic crop production overview. Available at: https://attra.ncat.org/attrapub/summaries/summary.php?pub=66. Access on 9 October 2014.

Kumar, N., Bansal, A., Sarma, G. S., Rawal, R. K. (2014). Chemometrics tools used in analytical chemistry: An overview. Talanta, 123, 186-199.

Lachman, J., Sulc, M., Schilla, M. (2007). Comparison of the total antioxidant status of Bohemian wines during the wine-making process. Food Chemistry, 103, 802-807.

Lacombe, P., Thomash, M. R. (2006). Historical origins and genetic diversity of wine grapes. Trends in Genetics, 22(9), 511-519.

Laguerre, M., Lecomte, J., Villeneuve, P. (2007). Evaluation of the ability of antioxidants to counteract lipid oxidation: Existing methods, new trends and challenges. Progress in Lipid Research, 46(5), 244-282.

Leblanc, M. R., Johnson, C. E., Wilson, P. W. (2008). Influence of pressing method on juice stilbene content in Muscadine and Bunch grapes. Journal of Food Science, 73(4), H58-H62.

Leong, S. Y., Buritt, D. J., Oey, I. (2016). Evaluation of the anthocyanin release and health-promoting properties of Pinot Noir grape juices after pulsed electric fields. Food Chemistry, 196, 833-841.

Lernoud, J., Willer, H. (2015). Organic agriculture worldwide: current statistics. In: IFOAM: The world of organic agriculture. Statistics \& emerging trends 2015. Available at: International Federation of Organic Agriculture Movements.

Lima, M. S., Dutra, M. C. P., Toaldo, I. M., Corrêa, L. C., Pereira, G. E., Oliveira, D., Bordignon-Luiz. M. T., Ninow, J. L. (2015). Phenolic compounds, organic acids and antioxidant activity of grape juices produced in industrial scale by different processes of maceration. Food Chemistry, 188, 384-392.

Lima, M., Silani, I., Toaldo, I. M., Corrêa, L., Biasoto, A., Pereira, G., Bordignon-Luiz M. T., Ninow, J. L. (2014). Phenolic compounds, organic acids, and antioxidant activity of grape juices produced from new Brazilian varieties planted in the Northeast region of Brazil. Food Chemistry, 161, 94-103. 
Loizzo, M. R., Tundis, R., Bonesi, M., Menichini, F., Mastellone, V., Avallone, L., Menichini, F. (2012). Radical scavenging, antioxidant and metal chelating activities of Annona cherimola Mill. (cherimoya) peel and pulp in relation to their total phenolic and total flavonoid contents. Journal of Food Composition and Analysis, 25(2), 179-184.

Longobardi, F., Casiello, G., Ventrella, A., Mazzilli, V., Nardelli, A., Sacco, D., Catucci, L., Agostiano, A. (2015a). Electronic nose and isotope ratio mass spectrometry in combination with chemometrics for the characterization of the geographical origin of Italian sweet cherries. Food Chemistry, 170, 90-96, 2015.

Longobardi, F., Casiello, G., Perini, M., Camin, F., Catucci, L., Agostiano, A. (2015b). Discrimination of geographical origin of lentils (Lens culinaris Medik.) using isotope ratio mass spectrometry combined with chemometrics. Food Chemistry, 188, 343-349.

López-Alarcón, C., Denicol, A. (2013). Evaluating the antioxidant capacity of natural products. A review on chemical and cellular-based assays. Analytica Chimica Acta, 763, 1-10.

Maçatelli, M., Akkermans, W., Koot, A., Buchgraber, M., Paterson, A., van Ruth, S. (2009). Verification of the geographical origin of European butters using PTR-MS. Journal of Food Composition and Analysis, 22(2), 169-175.

Macedo, L. F. L., Rogero, M. M., Guimarães, J. P., Granato, D., Lobato, L. P., Castro, I. A. (2013). Effect of red wines with different in vitro antioxidant activity on oxidative stress of high-fat diet rats. Food Chemistry, 137, 122-129.

Malacrida, C. R., Motta, S. (2005). Compostos fenólicos totais e antocianinas em suco de uva. Ciência e Tecnologia de Alimentos, 25, 659-664.

Mendez-Alvarez, E., Soto-Otero, R., Hermida-Ameijeiras, A., Lopez-Martin, M. E., Labandeira-Garcia, J. L. (2001). Effect of iron and manganese on hydroxyl radical production by 6-hydroxydopamine: mediation of antioxidants. Free Radicical Biology \& Medicine, 31, 986-998.

Mondavi, R. G., McGovern, P. E. (2007). Ancient wine: the search for the origins of viniculture. Princeton: Princeton University Press, 392 p.

Monrad, J. K., Suárez, M., Motilva, M. J., King, J. W., Srinivas, K., Howard, L. R. (2014). Extraction of anthocyanins and flavan-3-ols from red grape pomace continuously by coupling hot water extraction with a modified expeller. Food Research International, 65, 77-87.

Moreno-Montoro, M., Olalla-Herrera, M., Gimenez-Martinez, R., Navarro-Alarcon, M., Rufián-Henares, J. A. (2015). Phenolic compounds and antioxidant activity of Spanish commercial grape juices. Journal of Food Composition and Analysis, 38, 19-26.

Morris, J. R. (1998). Factors influencing grape juice quality. HortTechnology, 8(4), 471-478.

Morris, J. R., Striegler, K. (1996). Grape juice: factors that influence quality, processing technology, and economics. In: Processing Fruits: Science and Technology, $2^{\text {nd }}$ Ed. D.M. Barrett, L. Somogyi, and H. Ramaswamy, eds. CRC Press, Boca Raton, FL. p. 585.

Muilwijk, M., Heenan, S., Koot, A., van Ruth, S. M. (2015). Impact of production location, production system, and variety on the volatile organic compounds fingerprints and sensory characteristics of tomatoes. Journal of Chemistry, 2015, 1-7. 
Munõz-Espada, A. C., Wood, K. V., Bordelon, B., Watkins, B. A. (2004). Anthocyanin quantification and radical scavenging capacity of concord, Norton, and Marechal Foch grapes and wines. Journal of Agriculture and Food Chemistry, 52, 6779-6786.

Nan, L., Liu, L., Zhao, X., Qiu, S., Wang, H., Li, H. (2013). Effect of alternative new pruning system and harvesting times on aroma compounds of young wines from Ecolly (Vitis vinifera) in a new grape growing region of the Weibei Plateau in China. Scientia Horticulturae, 162, 181-187.

Natividade, M. M. P., Corrêa, L. C., Souza, S. V. C., Pereira, G. E., Lima, L. C. O. (2013). Simultaneous analysis of 25 phenolic compounds in grape juice for HPLC: Method validation and characterization of São Francisco Valley samples. Microchemical Journal, 110, 665-674.

Nunes, C. A. (2014). Vibrational spectroscopy and chemometrics to assess authenticity, adulteration and intrinsic quality parameters of edible oils and fats. Food Research International, 60, 255-261.

Nunes, C. A., Alvarenga, V. O., Sant'ana, A. S., Santos, J. S., Granato, D. (2015). The use of statistical software in food science and technology: Advantages, limitations and misuses. Food Research International, 75, 270-280.

O’Byrne, D. J., Devaraj, S., Grundy, S. M., Jialal, I. (2002). Comparison of the antioxidant effects of Concord grape juice flavonoids alpha-tocopherol on markers of oxidative stress in healthy adults. American Journal of Clinical Nutrition, 76(6), 1367-1374.

OIV, Office International de la Vigne et du Vin. (1990). Recueil des Méthodes Internationales d'Analyse des Vins et des Moûts. Paris: Office International de la Vigne et du Vin.

Organic Trade Association. Market analysis. Available at: https:/ota.com/what-ota-does/market-analysis. Access 14 March 2015.

Organics

Brasil.

Available

at:

http://www.organicsbrasil.org/dnfile/rdvutgnenb3wbt9yiima/pdf/downloads/0/arquivordvutgnenb3wbt9yiima.pdf. Access 14 March 2015.

Ortea, I., Gallardo, J. M. (2015). Investigation of production method, geographical origin and species authentication in commercially relevant shrimps using stable isotope ratio and/or multi-element analyses combined with chemometrics: An exploratory analysis. Food Chemistry, 170, 145-153.

Özdestan, Ö., van Ruth, S. M., Alewijn, M., Koot, A., Romano, A., Cappellin, L., Biasioli, F. (2013). Differentiation of specialty coffees by proton transfer reaction-mass spectrometry. Food Research International, 53, 433-439.

Paranjpe, S. S., Ferruzzi, M., Morgan, M. T. (2012). Effect of a flash vacuum expansion process on grape juice yield and quality. LWT - Food Science and Technology, 48(2), 147-155.

Parpinello, G. P., Rombolá, A. D., Simoni, M., Versari, A. (2015). Chemical and sensory characterisation of Sangiovese red wines: Comparison between biodynamic and organic management. Food Chemistry, $167,145-152$.

Paull, J., Hennig, B. (2011). A world map of organic agriculture. European Journal of Social Sciences, 24(3), 360-369. 
Peng, Q., Tian, R., Chen, F., Li, B., Gao, H. (2015). Discrimination of producing area of Chinese Tongshan kaoliang spirit using electronic nose sensing characteristics combined with the chemometrics methods. Food Chemistry, 178, 301-305.

Pereira, G. E., Lima, L. C. O., Regina, M. A., Rosier, J. P., Ferraz, V., Mourão Jr., M. (2008). Potential evaluation of five American cultivars for grape juices in the South of Minas Gerais State. Ciência e Agrotecnologia, 32(5), 1531-1537.

Prior, R. L., Wu, X. and Schaich, K. (2005). Standard methods for the determination of antioxidant capacity and phenolics in foods and dietary supplements. Journal of Agricultural and Food Chemistry, 53, 4290 4302.

Rathburn, I. M., Morris, J. R. (1990). Evaluation of varietal grape juice - Influence of processing method, sugar and acid adjustment, and carbonation. Journal of Food Quality, 13(6), 395-409.

Richards, S. E., Holmes, E. (2015). Chemometrics methods for the analysis of genomics, transcriptomics, proteomics, metabolomics, and metagenomics datasets. Metabolomics as a Tool in Nutrition Research, $37-60$.

Rivera-Mancía, S., Pérez-Neri, I., Ríos, C., Tristán-López, L., Rivera-Espinosa, L., Montes, S. (2010). The transition metals copper and iron in neurodegenerative diseases. Chemico-Biological Interactions, 186, 184-199.

Rizzo, A. M., Berselli, P., Zava, S., Montorfano, G., Negroni, M., Corsetto, P., Berra, B. (2010). Endogenous antioxidants and radical scavengers. Advances in Experimental Medicine and Biology, 698, 52-67.

Rizzon, L. A., Meneguzzo, J. (2003). Suco de Uva. Embrapa Informação Tecnológica. Brasília, DF. 45 p., 2007. Robinson, J. Vines, Grapes and wines: the wine drinker's guide to grape varieties. England: Mitchell Beazley, 280p.

Rufino, M. S. M., Alves, R. E., Brito, E. S., Morais, S. M., Sampaio, C. G., Pérez-Jiménez, J. Saura-Calixto, F. D. (2006). Metodologia científica: determinação da atividade antioxidante total em frutas pelo método de redução do ferro. Fortaleza: Embrapa Agroindústria Tropical. Embrapa Agroindústria Tropical. Comunicado Técnico, 125, 1-4.

Rufino, M. S. M., Alves, R. E., Brito, E. S. Morais, S. M., Sampaio, C. G., Pérez-Jiménez, J. Saura-Calixto, F. D. (2007). Metodologia científica: determinação da atividade antioxidante total em frutas pela captura do radical livre DPPH. Fortaleza: Embrapa Agroindústria Tropical. Embrapa Agroindústria Tropical. Comunicado Técnico, 127, 1-4.

Ruiz-Samblás, C., Arrebola-Pascual, C., Tres, A., van Ruth, S., Cuadros-Rodríguez, L. (2013). Authentication of geographical origin of palm oil by chromatographic fingerprinting of triacylglycerols and partial least square-discriminant analysis. Talanta, 116, 788-793.

Sahota, A. (2015). The global market for organic food and drink. In: IFOAM: The world of organic agriculture. Statistics \& emerging trends 2015. Available at: International Federation of Organic Agriculture Movements.

Schaich, K. M., Tian, X., Xie, J. (2015). Hurdles and pitfalls in measuring antioxidant efficacy: A critical evaluation of ABTS, DPPH, and ORAC assays. Journal of Functional Foods, 14, 111-125. 
Seufert, V., Ramankutty, N., Foley, J. A. (2012). Comparing the yields of organic and conventional agriculture. Nature, 485, 229-234.

Shahidi, F., Naczk, M. Phenolics in food and nutraceticals. New York: CRC Press, 2004. 365p.

Shahidi, F., Zhong, Y. (2015). Measurement of antioxidant activity. Journal of Functional Foods, 18, 757781.

Sies, H. (2007). Total antioxidant capacity: appraisal of a concept. Journal of Nutrition, 137, 1493-1495

Silva, C. W. P., Campos, F. R., Simonelli, F., Barison, A. (2009). Grape juice quality control by means of 1H NMR spectroscopy and chemometric analysis. Annals of Magnetic Ressonance, 8(3), 14-26.

Silva, J. K., Cazarin, C. B. B., Correa, L. C., Batista, A. G., Furlan, C. P. B., Biasoto, A. C. T., Pereira, G. E., Camargo, A. C., Maróstica Junior, M. R. (2016). Bioactive compounds of juices from two Brazilian grape cultivars. Journal of the Science of Food and Agriculture, 96(6), 1990-1996.

Singletary, K. W., Stansbury, M. J., Giusti, M., Van Breemen, R. B., Wallig, M., Rimando A. (2003). Inhibition of mammary tumorigenesis by Concord grape juice constituents. Journal of Agriculture and Food Chemistry, 51, 7280-7286.

Slegers, A., Angers, P., Ouellet, E., Truchon, T., Pedneault, K. (2015). Volatile compounds from grape skin, juice and wine from five interspecific hybrid grape cultivars grown in Québec (Canada) for wine production. Molecules, 20, 10980-11016.

Snyder, A. B., Sweeney, C. F., Rodriguez-Saona, L. E., Giusti, M. M. (2014). Rapid authentication of concord juice concentration in a grape juice blend using Fourier-Transform infrared spectroscopy and chemometric analysis. Food Chemistry, 147, 295-301.

Snyder, A. B., Sweeney, C. F., Rodriguez-Saona, L. E., Giusti, M. M. (2014). Rapid authentication of concord juice concentration in a grape juice blend using Fourier-Transform infrared spectroscopy and chemometric analysis. Food Chemistry, 147, 295-301.

Song, J., Smart, R., Wang, H., Dambergs, B., Sparrow, A., Qian, M. C. (2015). Effect of grape bunch sunlight exposure and UV radiation on phenolics and volatile composition of Vitis vinifera L. cv. Pinot Noir wine. Food Chemistry, 173, 424-431.

Spinelli, F. R., Dutra, S. V., Carnieli, G., Leonardelli, S., Drehmer, A. P., Vanderlinde, R. Detection of addition of apple juice in purple grape juice. Food Control, in press. doi:10.1016/j.foodcont.2016.04.005

Spink, J., Moyer, D. C. (2016). Introducing the Food Fraud Initial Screening model (FFIS). Food Control, in press. doi:10.1016/j.foodcont.2016.03.016

Stalmach, A., Edwards, C. A., Wightman, J. D., Crozier, A. (2011). Identification of (poly)phenolic compounds in concord grape juice and their metabolites in human plasma and urine after juice consumption. Journal of Agricultural and Food Chemistry, 59(17), 9512-9522.

Steiner, R., Gardner, M. (1993). Spiritual foundations for the renewal of agriculture: a course of lectures held at Koberwitz, Silesia, June 7 to June 16, 1924. Bio-Dynamic Farming and Gardening Association, Kimberton, Pennsylvania. 
Su, L., Yin, J. J., Charles, D., Zhou, K., Moore, J., Yu, L. L. (2007). Total phenolic contents, chelating capacities, and radical-scavenging properties of black peppercorn, nutmeg, rosehip, cinnamon and oregano leaf. Food Chemistry, 100(3), 990-997.

Sun, Q., Sacks, G., Lerch, S., Vanden Heuvel, J. E. (2011). Impact of shoot thinning and harvest date on yield components, fruit composition, and wine quality of Marechal Foch. American Journal of Enology and Viticulture, 62, 32-41.

Tabela Brasileira de Composição de Alimentos (TACO). Brazilian Food Composition Table. (2009). Available at: http://www.unicamp.br/nepa/taco/contar/taco_4_edicao_ampliada_e_revisada. Access on 28 June 2015.

Tamborra, P., Esti, M. (2010). Authenticity markers in Aglianico, Uva di Troia, Negroamaro and Primitivo grapes. Analytica Chimica Acta, 660(1-2), 221-226.

Tassoni, A., Tango, N., Ferri, M. (2013). Comparison of biogenic amine and polyphenol profiles of grape berries and wines obtained following conventional, organic and biodynamic agricultural and oenological practices. Food Chemistry, 139, 405-413.

Technical University of Denmark (DTU Food). Danish Food Composition Table. (2011). Available at: http://www.foodcomp.dk/v7/fcdb_details.asp?FoodId=1087. Access on 28 June 2015.

Toaldo, I. M., Cruz, F. A., Alves, T. L., Gois, J. S., Borges, D. L. G., Cunha, H. P., Silva, E. L., BordignonLuiz, M. T. (2015). Bioactive potential of Vitis labrusca L. grape juices from the Southern Region of Brazil: Phenolic and elemental composition and effect on lipid peroxidation in healthy subjects. Food Chemistry, 173, 527-535.

Tres, A., O’Neill, R., van Ruth, S. M. (2011). Fingerprinting of fatty acid composition for the verification of the identity of organic eggs. Lipid Technology, 23(2), 40-42.

van Ruth, S., Alewijn, M., Rogers, K., Newton-Smith, E., Tena, N., Bollen, M., Koot, A. (2011). Authentication of organic and conventional eggs by carotenoid profiling. Food Chemistry, 126(3), 12991305.

Vardin, H., Tay, A., Ozen, B., Mauer, L. (2008). Authentication of pomegranate juice concentrate using FTIR spectroscopy and chemometrics. Food Chemistry, 108(2), 742-748.

Vilanova, M., Siebert, T. E., Varela, C., Pretorius, I. S., Henschke, P. A. (2012). Effect of ammonium nitrogen supplementation of grape juice on wine volatiles and non-volatiles composition of the aromatic grape variety Albariño. Food Chemistry, 133(1), 124-131.

Villanueva-Rey, P., Vázquez-Rowe, I., Moreira, M. T., Feijoo, G. (2014). Comparative life cycle assessment in the wine sector: biodynamic vs. conventional viticulture activities in NW Spain. Journal of Cleaner Production, 65, 330-341.

Vinson, J. A., Teufel, K., Wu, N. (2001). Red wine, dealcoholized red wine, and especially grape juice, inhibit atheroclerosis in a hamster model. Atherosclerosis, 156, 67-72.

Vinson, J.A., J. Yang, J. Proch, X. Liang. (2000). Grape juice, but not orange juice, has in vitro, ex vivo, and in vivo antioxidant properties. Journal of Medicinal Food, 3(4), 167-171. 
Wahlberg, I., Eklund, A. M. In: Carotenoids: Biosynthesis and Metabolism. Britton G, Liaaen-Jensen S, Pfander Basel Boston, editor. Berlin: Birkäuser Verlag; 1998. Degraded carotenoids; pp. 195-216.

Willer, H., Lernoud, J. The European market for organic food. Available at: http://www.biofach.fibl.org/fileadmin/documents/de/news/2014/willer-schaack-2014-biofach-europemarket.pdf. Access 14 March 2015.

Willer, H., Meredith, S. (2015). Organic farming in Europe. In: IFOAM: The world of organic agriculture. Statistics \& emerging trends 2015. Available at: International Federation of Organic Agriculture Movements.

Yamamoto, L. Y., Assis, A. M., Roberto, S. R., Bovolenta, Y. R., Nixdorf, S. L., García-Romero, E., Hermosín-Gutiérrez, I. (2015). Application of abscisic acid (S-ABA) to cv. Isabel grapes (Vitis vinifera $\times$ Vitis labrusca) for color improvement: Effects on color, phenolic composition and antioxidant capacity of their grape juice. Food Research International, 77, 572-583.

Yildirim, H. K. (2013). Assessing wines based on total phenols, phenolic acids and chemometrics by multivariate analyses. African Journal of Biotechnology, 12(22), 3563-3569.

Yoon, J. H., Kim, K., Lee, D. S. (1997). Chemometric aspects of sugar profiles in fruit juices using HPLC and GC. Bulletin of the Korean Chemistry Society, 18(7), 695-702.

Yuan, F., Qian, M. C. (2016). Development of C13-norisoprenoids, carotenoids and other volatile compounds in Vitis vinifera L. Cv. Pinot Noir grapes. Food Chemistry, 192, 633-641.

Zhao, J., Du, X., Cheng, N., Xue, X., Zhao, J., Wu, L., Cao, W. (2016). Identification of monofloral honeys using HPLC-ECD and chemometrics. Food Chemistry, 194, 167-174.

Zhou, X., Yang, Z., Haughey, S. A., Galvin-King, P., Han, L., Elliott, C. T. (2015). Classification the geographical origin of corn distillers dried grains with solubles by near infrared reflectance spectroscopy combined with chemometrics: A feasibility study. Food Chemistry, 189, 13-18. 


\section{OHAPTeR 2:}

\section{CHARACTERIZATION AND COMPARISON OF PHENOLIC COMPOSITION, ANTIOXIDANT CAPACITY AND INSTRUMENTAL TASTE PROFILE OF JUICES FROM DIFFERENT BOTANICAL ORIGINS}

This chapter is published as: GRANATO, D.; KARNOPP, A. R.; VAN RUTH, S. M. Characterization and comparison of phenolic composition, antioxidant capacity and instrumental taste profile of juices from different botanical origins. Journal of the Science of Food and Agriculture, 95, 1997-2006, 2015. 


\begin{abstract}
The European Union registered a consumption of about 10.7 million liters of juices in 2011 and great part of this amount is imported from other countries, which makes the monitoring of their quality essential. This work was aimed to map the quality of various juices from different botanical origins from instrumental taste, chemical markers and antioxidant capacity perspectives. We also characterized the individual phenolic composition of juices previously grouped according to their antioxidant activity and total phenolic level. Overall, by using correlation analysis and chemometrics (HCA and PCA), data showed that total phenolics, specifically gallic acid, $p$-coumaric acid, anthocyanins, flavanols, and flavonols are the main contributors to the antioxidant activity. Elderberry and pomegranate juices presented the highest phenolic content and antioxidant activity. On the other hand, orange, apple, and cranberry juices had the lowest levels of total phenolics and flavonoids, DPPH, and CUPRAC. As a conclusion, the use of chemometrics coupled to ANOVA seems to be a suitable approach to evaluate the quality of fruit juices from different botanical origins. Additionally, the instrumental taste profile correlated well to the chemical composition and antioxidant capacity, showing its potential application in assessing the functionality of juices.
\end{abstract}

Keywords: Electronic tongue, flavonoids, principal component analysis, cluster analysis, phenolic composition.

\title{
2.1 Introduction
}

Fruit juices are widely consumed by most people owing to their freshness, sensory properties, as well as their nutritional value. In this sense, the European Union (EU) registered a consumption of about 10.7 billion liters of juices (100\% juices as well as nectars, which present between $25-99 \%$ of juice) in 2011, with twothirds of this amount relating to $100 \%$ fruit juices. The highest-consuming European countries are Germany, France, United Kingdom, Spain, and Italy ${ }^{1}$, while the most consumed juices are: orange, mixtures of two or more fruits, apple, peach, and pineapple, while the other juices representing 21\% (AIJN, 2012). Elderberry, blueberry, pomegranate, and cranberry juices are now being consumed more intensively owing to their alleged health benefits. Since Europe is not a large producer of most juices, especially tropical fruit juices, importation from many different countries, such as Brazil (orange), Peru/Ecuador (passion fruit), Costa Rica/Kenya/Thailand (pineapple), Cuba/Mexico/USA/Israel (grapefruit), India/Pakistan (mango), and Turkey/China/Moldova (apple), is a common practice. Therefore, the monitoring of the quality of fruit juices consumed in Europe is necessary to verify nutritional claims and to attest their authenticity and typicality.

Assessing the quality of fruit juices has been performed basically by measuring their content of chemical constituents, such as carotenoids, phenolic compounds, mineral trace elements, vitamins, volatile organic compounds, and also by their sensory properties, such as degree of liking of certain attributes and overall acceptability (Gardner, White, McPhail, \& Duthie, 2000; Sánchez-Moreno, Plaza, Ancos, \& Cano, 2006). However, measurements based on the antioxidant capacity have already been shown to be effective in analyzing fruit juices (Omena et al., 2012). Hence, the determination of chemical materials, such as major phenolic compounds and the antioxidant activity measured by different methods, allied to the juice's sensory properties represents an interesting and multidimensional approach to analyze the quality traits of fruit-based 
products. Regarding this aspect, not only analytical measurements are necessary to evaluate the quality of fruitbased products, but also the handling of data is of paramount importance, since many responses and test samples are usually assessed. Therefore, the use of appropriate statistical techniques is usually required when quality control programmes are conducted in food companies. In this regard, chemometric tools, also known as multivariate statistical techniques, have been extensively applied in food science and technology, such as assessing the authenticity of commercial UHT milk (Souza et al., 2011), evaluating the quality of Brazilian sugarcane spirits (Granato et al., 2014), herbal teas (Huo et al., 2014), red wines (Martelo-Vidal \& Vázquez, 2014), dairy products (Cruz et al., 2013; Aquino et al., 2014), essential oils (Besten et al., 2013), and soy-based products (Alezandro, Granato, Lajolo, \& Genovese, 2011) among others.

Based on these considerations and taking into the account that fruit juices are highly marketed and consumed worldwide, the objective of this work was to map the quality of various commercial ready for consumption juices from different botanical origins from instrumental taste, chemical markers and antioxidant capacity perspectives. We also characterized the individual phenolic composition of juices previously classified according to their antioxidant activity and total phenolic content.

\subsection{Material and Methods}

\subsubsection{Juices}

A total of $\mathrm{n}=20$ samples were acquired in local shops in the Netherlands during January - March 2014, in which: $\mathrm{n}=3100 \%$ red beet juices (Beta vulgaris), $\mathrm{n}=2$ cranberry nectars (Vaccinium macrocarpon), $\mathrm{n}=2$ pomegranate nectars (Punica granatum), $\mathrm{n}=3100 \%$ blueberry juices (Vaccinium spp.), $\mathrm{n}=2100 \%$ elderberry juices (Sambucus nigra), $\mathrm{n}=2100 \%$ orange juices (Citrus sinensis), $\mathrm{n}=1$ apple (80\%) and elderberry (20\%), $\mathrm{n}=1$ apple (80\%; Pyrus malus) and cherry (20\%; Prunus avium), and $\mathrm{n}=4100 \%$ apple juices from different varieties. All juices were fresh-squeezed and then pasteurized and marketed in a glass container.

\subsubsection{Chemicals}

Folin-Ciocalteu reagent, $(+)$-catechin, $(-)$-epicatechin, rutin, quercetin, $p$-coumaric acid, chlorogenic acid (5-O-caffeoylquinic acid), myricetin, 2,4,6-tris(2-pyridyl)-s-triazine (TPTZ), 6-hydroxy-2,5,7,8tetramethylchroman-2-carboxylic acid (Trolox), sodium carbonate, gallic acid, sodium nitrite, sodium hydroxide, sodium acetate, potassium chloride, neocuproine (2,9-dimethyl-1,10-phenanthroline), and pyrocatechol violet (3,3',4-trihydroxyfuchsone-2"-sulfonic acid), and 2,2-diphenyl-1-picrylhydrazyl (DPPH) were purchased from Sigma-Aldrich (the Netherlands). Procyanidin primer A2, pelargonidin-3-glucoside chloride, cyanidin-3-glucoside-chloride, malvidin-3,5-glucoside-chloride, delphinidin-3-glucoside-chloride, and malvidin-3-glucoside chloride were obtained from Extrasynthese (France). Ammonium acetate, copper (II) chloride, copper sulphate pentahydrate, $n$-butanol, acetic acid, ethanol, aluminum chloride hexahydrate, potassium chloride, methanol, hydrochloric acid, and sodium carbonate were purchased from Merck (Germany). Ultra-pure water (Milli-Q water) was used in all experiments. 


\subsubsection{Instrumental taste profile of juices by electronic tongue}

The instrumental taste profile of each of the commercial juice samples $(n=20)$ was evaluated by means of an electronic tongue (model SA402B, Intelligent Sensor Technology Inc., Japan) using the same experimental protocol described previously (Kobayashi et al., 2010). For this purpose, juice samples were initially centrifuged for $10 \mathrm{~min}$ at $400 \mathrm{x} g$ to remove particles that might have damaged the sensors, and about $30 \mathrm{~mL}$ of each juice was placed, in duplicate, in $50 \mathrm{~mL}$ plastic glasses for analysis. Lipid-based membrane sensors, which detect the potential difference between the sample and the standard solution $(30 \mathrm{mmol} / \mathrm{L} \mathrm{KCl}$ $+0.30 \mathrm{mmol} / \mathrm{L}$ tartaric acid; conductivity between 4.0 and $4.2 \mathrm{mS} / \mathrm{cm}$ and $\mathrm{pH}$ in the range 3.5-3.6), provided instrumental ratings for sourness, bitterness, richness (aftertaste due to umami), umami, astringency, saltiness, aftertaste due to bitterness, and aftertaste due to astringency.

The measuring time was set to $30 \mathrm{~s}$ for each sample, and sensors were rinsed lightly for $6 \mathrm{~s}$ using a standard solution to measure the aftertaste. After that, sensors were rinsed in an alcoholic solution $(28.5 \mathrm{~mL} / \mathrm{L}$ ethanol) for $90 \mathrm{~s}$ to remove adsorbed compounds from the lipid membrane and sensors were again rinsed in the cleaning solution $(30 \mathrm{mmol} / \mathrm{L} \mathrm{KCl}+0.30 \mathrm{mmol} / \mathrm{L}$ tartaric acid) for another $240 \mathrm{~s}$ to remove the alcohol and re-establish the sensors. A total of four replicated measurements were run on each sample, while the first cycle was discarded to assure stability of sensors, and the remaining three responses were averaged. The sensor outputs of the samples (electric potential) were converted into taste intensity values on a scale where one unit is the sensor output difference corresponding to a $20 \%$ concentration difference in the standard substance solution (Habara \& Toko, 2006). In the current research, these sensor intensities are designated as estimated intensity of taste (EIT) values.

\subsubsection{Phenolic compounds}

The total phenolic content was evaluated using the Folin-Ciocalteu reagent (Singleton \& Rossi Jr, 1965). The total phenolic content in commercial juices was determined in triplicate by an analytical curve of gallic acid ( 0 to $150 \mathrm{mg} / \mathrm{L})$ and results were expressed as $\mathrm{mg}$ of gallic acid equivalent per liter of juice (mg GAE/L).

The aluminum chloride method was used for the determination of the total flavonoid content (Zhishen, Mengeheng, \& Jianming, 1999). The flavonoid content was determined in triplicate by an analytical curve of $(+)$-catechin ( 0 to $90 \mathrm{mg} / \mathrm{L})$ and the results were expressed as $\mathrm{mg}$ of $(+)$-catechin equivalent per liter of juice (mg CTE/L). Non-flavonoid phenolics content was estimated by subtracting the content of total phenolic compounds and flavonoids.

Proanthocyanidins (condensed tannins) of all commercial juices were analysed in triplicate according to the butanol/HCL method described by Porter (1989). The quantity of proanthocyanidins was determined from an analytical curve of procyanidin primer A2 $(0-125 \mathrm{mg} / \mathrm{L})$. The results were expressed as $\mathrm{mg}$ of procyanidin A2 equivalent per liter of juice (mg PCY/L).

A high-performance liquid chromatographer (HPLC) coupled with diode array (DAD) and fluorescence (FL) detectors from Agilent Technologies 1100 series equipment containing a quaternary pump and an automated injector was used to quantify rutin, quercetin, myricetin, gallic acid, $p$-coumaric acid, $(+)$ - 
catechin, (-)-epicatechin, pelargonidin-3-glucoside, cyanidin-3-glucoside, malvidin-3,5-diglucoside, delphinidin-3-glucoside, and malvidin-3-glucoside. For this objective, a Phenomenex Gemini C18 column and guard column at $40{ }^{\circ} \mathrm{C}$ with $150 \times 4.6 \mathrm{~mm}$ x $3 \mu \mathrm{m}$ was used. Firstly, an analytical curve of all chemical standards was plotted using five evenly spaced concentrations, and all regression analyses were statistically significant $(\mathrm{p}<0.001)$ and presented determination coefficients above 0.995 .

Briefly, juices were diluted twofold with a $8.5 \mathrm{~mL} / \mathrm{L}$ phosphoric acid solution and filtered through a $0.45 \mu \mathrm{m}$ polyvinylidenedifluoride membrane (Pall Corporation, The Netherlands). The mobile phase was consisted of solvent A ( $8.5 \mathrm{~mL} / \mathrm{L}$ phosphoric acid solution) and solvent B (acetonitrile) using a flow rate of $0.50 \mathrm{~mL} / \mathrm{min}$ and $10 \mu \mathrm{L}$ of sample were injected in the HPLC. The gradient elution conditions started with $100 \%$ of solvent A and adjusted for $7 \%$ of solvent B in $10 \mathrm{~min} ; 10 \%$ of solvent B in $20 \mathrm{~min} ; 12 \%$ of solvent B in $30 \mathrm{~min} ; 23 \%$ of solvent B in $40 \mathrm{~min} ; 35 \%$ of solvent B in $45 \mathrm{~min}$; and $100 \%$ of solvent B in $55 \mathrm{~min}$ (Natividade et al., 2013). The DAD was set at $\lambda=360 \mathrm{~nm}$ to flavonols, $\lambda=270 \mathrm{~nm}$ to gallic acid; $\lambda=320 \mathrm{~nm}$ was set to $p$-coumaric acid and $\lambda=520 \mathrm{~nm}$ for anthocyanins, and the fluorescence detector was set at $\lambda_{\text {emission }}=320$ $\mathrm{nm}$ and $\lambda_{\text {excitation }}=280 \mathrm{~nm}$ for identification and quantification of flavanols. Typical HPLC-DAD-FL chromatograms of juice samples are presented in Figure 2.1.

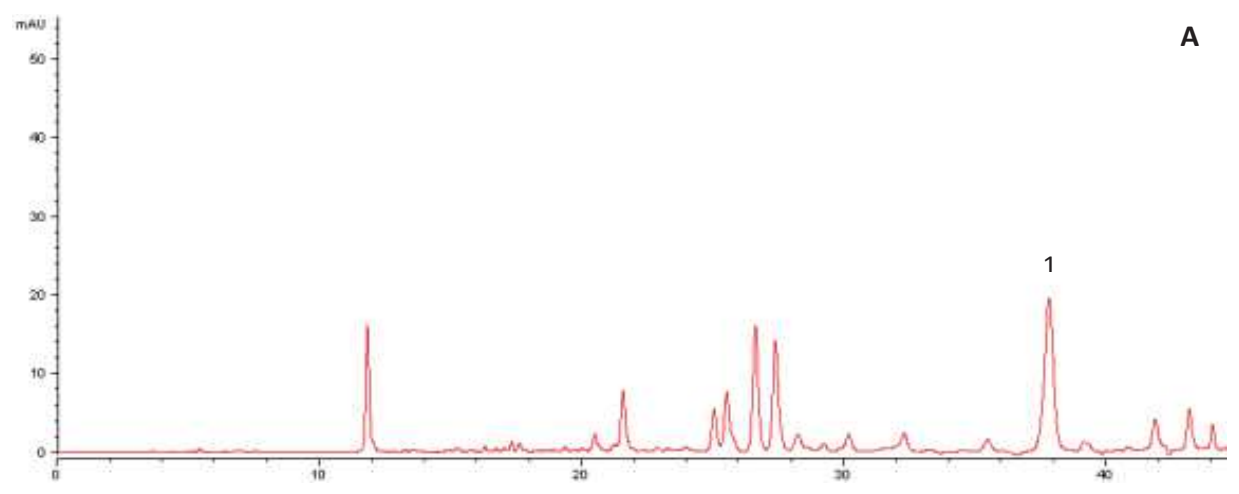


3
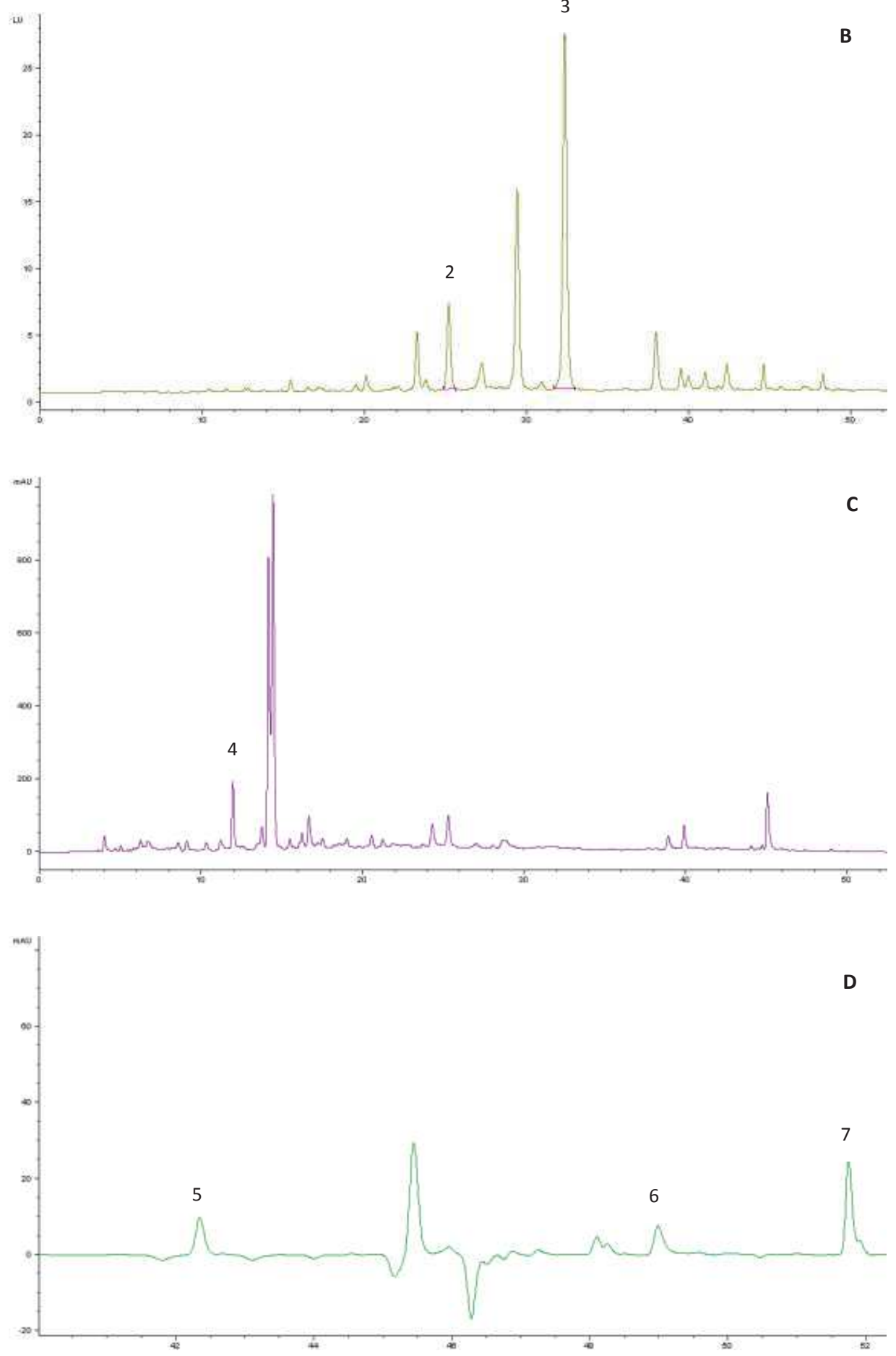

46 


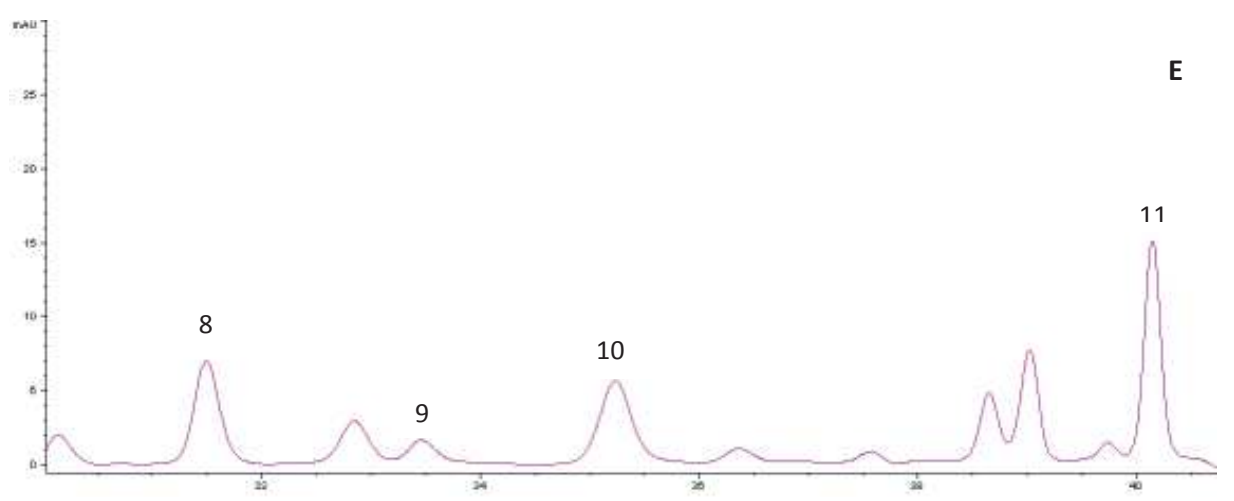

Figure 2.1: Chromatograms of the phenolic compounds evaluated in this study: A: (1) p-coumaric acid $(\mathrm{RT}=37.7 \mathrm{~min})$ in blueberry juice; $\mathbf{B}:(2)(+)$-catechin $(\mathrm{RT}=25.2 \mathrm{~min})$ and (3) (-)-epicatechin (RT=32.4 $\mathrm{min})$ in apple juice; $\mathbf{C}$ : (4) gallic acid ( $\mathrm{RT}=11.6 \mathrm{~min}$ ) in pomegranate juice; $\mathbf{D}:(5)$ rutin ( $\mathrm{RT}=42.7 \mathrm{~min}$ ) and (6) myricetin ( $\mathrm{RT}=48.8 \mathrm{~min})$ and $(7)$ quercetin $(\mathrm{RT}=51.6 \mathrm{~min})$ in cranberry juice; $\mathbf{E}:(8)$ cyanidin-3-glucoside ( $\mathrm{RT}=31.5 \mathrm{~min}$ ), (9) malvidin-3,5-diglucoside ( $\mathrm{RT}=33.2 \mathrm{~min}$ ), (10) pelargonidin-3-glucoside ( $\mathrm{RT}=35 \mathrm{~min}$ ), and (11) malvidin-3-glucoside (RT=40.2 $\mathrm{min}$ ) in blueberry juice.

\subsubsection{In vitro antioxidant power of juices}

The ferric-ion reducing antioxidant power (FRAP) of juices was measured as described by Benzie and Strain (1996) but with modifications to the microplates. Briefly, $20 \mu \mathrm{L}$ of each diluted sample were mixed with $280 \mu \mathrm{L}$ of freshly prepared FRAP reagent on 96-well plates. The FRAP reagent was prepared by mixing 10 volumes of $300 \mathrm{mmol} / \mathrm{L}$ acetate buffer (pH 3.6) with 1 volume of $10 \mathrm{mmol} / \mathrm{L}$ TPTZ (2,4,6-tripyridyl-s-triazine) prepared in $40 \mathrm{mmol} / \mathrm{L} \mathrm{HCl}$ and with 1 volume of $20 \mathrm{mmol} / \mathrm{L}$ ferric chloride hexahydrate. The mixture was incubated for $30 \mathrm{~min}$ and then the absorbance at a wavelength of $593 \mathrm{~nm}$ was recorded by a microplate spectrophotometer (Synergy-BIOTEK, Winooski, VT, USA). For quantification, an analytical curve of Trolox was prepared with dilutions from 0 to $500 \mu \mathrm{mol} / \mathrm{L}$. Each juice's antioxidant activity was measured three times and results were expressed as $\mu \mathrm{mol}$ of Trolox equivalent per liter of juice ( $\mu \mathrm{mol} \mathrm{TE} / \mathrm{L})$.

The cupric-ion reducing antioxidant activity (CUPRAC) of commercial juices was determined in triplicate by a colorimetric method that uses neocuproine as a chromogen and copper chloride in a system buffered at $\mathrm{pH}$ 7, following the procedures outlined by Apak, Guclu, Ozyurek, and Celik (2008). The CUPRAC of juices was quantified using an analytical curve employing Trolox $(90-3,000 \mu \mathrm{mol} / \mathrm{L})$ as a standard, and results were expressed as $\mu \mathrm{mol} \mathrm{TE} / \mathrm{L}$.

The radical-scavenging activity was determined using the DPPH assay as described by BrandWilliams, Cuvelier and Berset (1995), with slight modifications. Measurements were recorded at $\lambda=517 \mathrm{~nm}$, where methanol was used as blank solution and DPPH solution without test samples served as the control. The free radical-scavenging activity was calculated using an analytical curve of Trolox $(30-1,000 \mu \mathrm{mol} / \mathrm{L})$ and results were expressed as $\mu \mathrm{mol} \mathrm{TE} / \mathrm{L}$. 


\subsubsection{Data treatment}

Data were expressed as means and medians followed by the standard deviation of three measurements or by means followed by absolute amplitude between two mean values. Linear correlation analysis was performed to check for association between chemical composition, instrumental taste profile and antioxidant activity of juices. In order to test for similarities among fruit juices, principal component analysis was applied to the data set. Samples were inserted in rows and response variables (total phenolic compounds, flavonoids, non-flavonoid phenolics, proanthocyanidins, instrumental taste profile, and antioxidant data) were placed in columns. All response variables were auto-scaled prior to chemometrics application. Cluster analysis, based on the hierarchical approach (HCA), was also applied to check for groups of samples with similar characteristics as well as to associate response variables. Distances within juice samples were calculated as Euclidean distances and Ward's method was used to group samples. Another HCA analysis was applied aiming to group the juices based on the antioxidant activity measured by FRAP and CUPRAC assays and also on the total phenolic content. Aiming to compare the three suggested clusters, initial requirements to the application of one-way ANOVA were tested, that is, normality (Shapiro-Wilk test) and equivalence of variances (BrownForsythe test). The Welch-ANOVA was applied when data were not homoscedastic. Multiple comparisons of means were carried out using the Duncan's test. For all tests, $p<0.05$ was regarded as significant. Statistica 7 software (Statsoft, USA) and Chemoface (UFLA, Brazil) were used in the analysis.

\subsection{Results and Discussion}

As shown in Table 2.1, the total phenolic content ranged from 368 to 4,623 mg/L (median of all mean values $=1,038 \mathrm{mg} / \mathrm{L}$ ), which means that some juices presented a higher content than grape juices and red wines (Natividade et al., 2013; Hosu, Cristea, \& Cimpoiu, 2014). The total flavonoid content ranged from 61 to 1,191 $\mathrm{mg} / \mathrm{L}$ (median=287.44 $\mathrm{mg} / \mathrm{L}$ ), and these data are in accordance with results obtained for various fruit juices marketed in Europe (Zulueta, Esteve, Frasquet, \& Frígola, 2007). The content of proanthocyanidins ranged from 273 to $5,802 \mathrm{mg} / \mathrm{L}$ (median=867.14 $\mathrm{mg} / \mathrm{L}$ ), which means that a glass of $200 \mathrm{~mL}$ would provide between 54.68 to $1,160 \mathrm{mg}$ of these compounds. The intake of proanthocynidins of USA, Spanish, and Finnish citizens is estimated to be 137, 189, and $128 \mathrm{mg}$ /day, respectively (Gu et al., 2004; Saura-Calixto, Serrano, \& Goni, 2007). As well outlined by Kruger, Davies, Myburgh , Lecour (2014) when proanthocyanidins are consumed in food products, they present important physiological health benefits, especially in inhibiting the oxidation of low-density lipoprotein (LDL), thus decresing the risk of platelet aggregation and adhesion (atherosclerosis). One observation should be made here: although the level of proantocyanidins of redbeet is negligible, the Porter's method revelaed a mean value of $490.36 \mathrm{mg} / \mathrm{L}$. Red beet contains betalains (natural non-phenolic pigments) that absorve at $536 \mathrm{~nm}$. For betalain and anthocyanin-bearing extracts, the $p$ dimethylaminocinnamaldehyde assay should be used as the absorbance is read at $640 \mathrm{~nm}$, thus pigments $\left(\lambda_{\max }=535 \mathrm{~nm}\right)$ do not become interfering substances (overestimating the true value). 


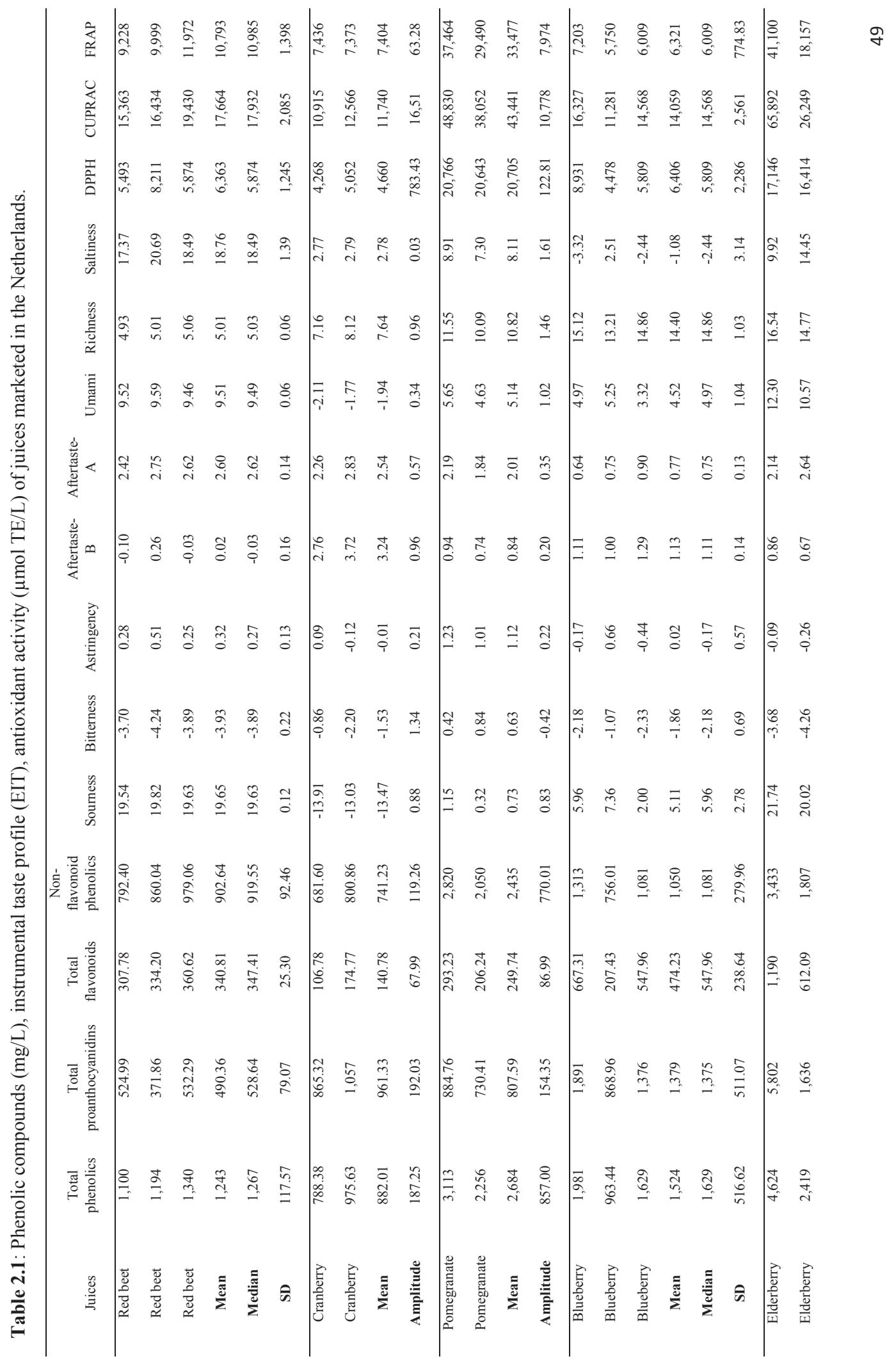




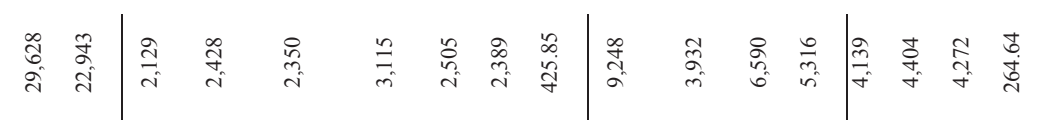

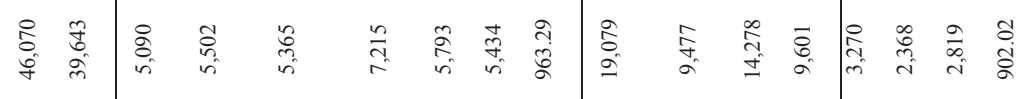

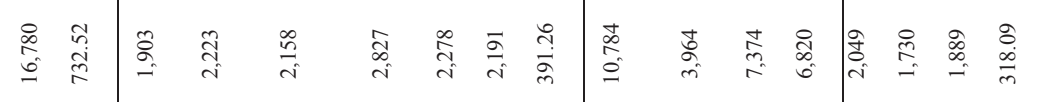

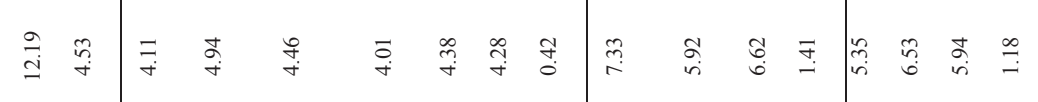

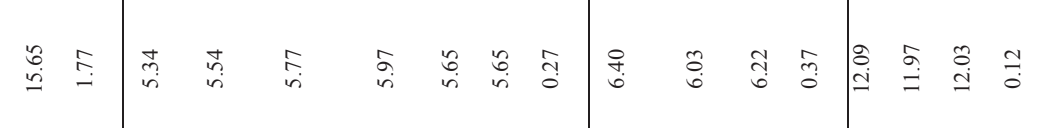

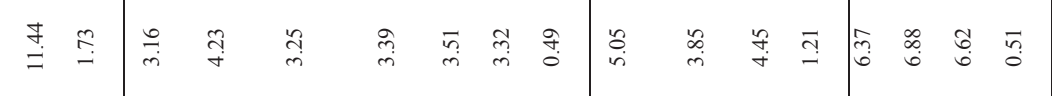

के

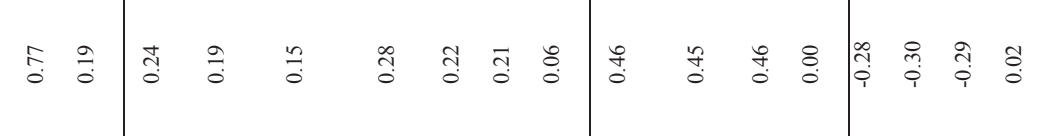

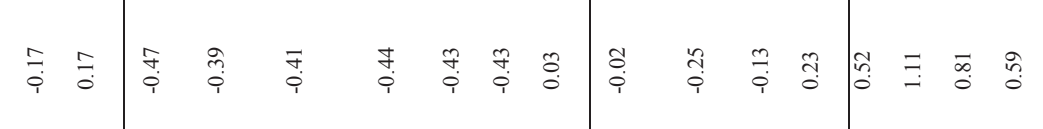

âj

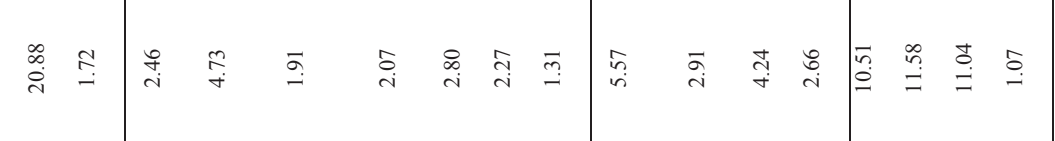

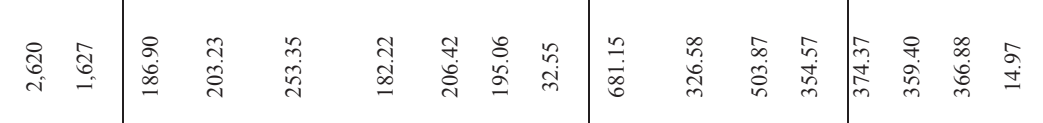

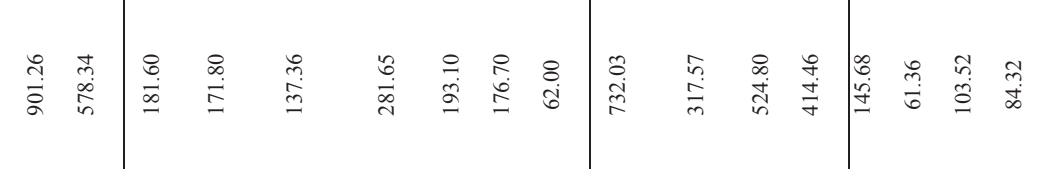

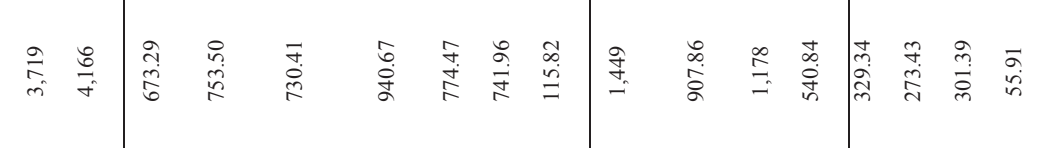

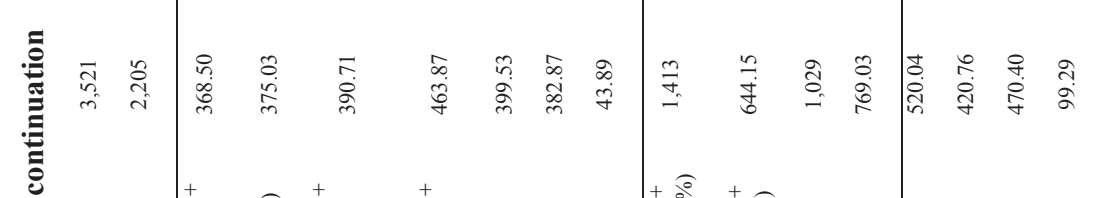

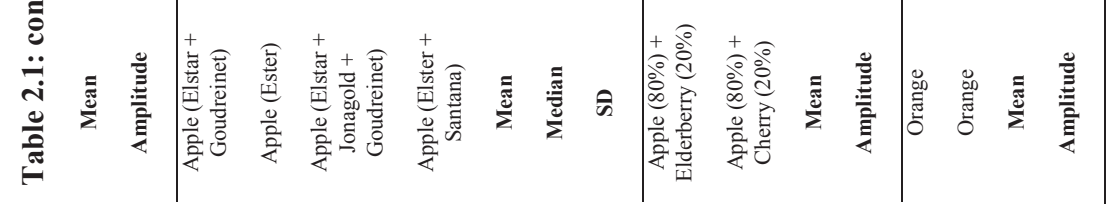


With regard to the antioxidant activity of samples, the DPPH ranged from 1,730 to $20,776 \mu \mathrm{mol} \mathrm{TE} / \mathrm{L}$, with pomegranate juices presenting the highest values on average, while CUPRAC values were between 2,368 to $65,892 \mu \mathrm{mol} \mathrm{TE} / \mathrm{L}$, with elderberry juices presenting the highest values on average. FRAP values varied in the range 2,128 - 41,100 $\mu \mathrm{mol} \mathrm{TE} / \mathrm{L}$, and pomegranate juices presented the highest mean values. Conversely, orange juices had the lowest CUPRAC values. The antioxidant activity measured by the DPPH assay, which involves an electron transfer mechanism between DPPH and antioxidants in juice, was significantly correlated $(\mathrm{p}<0.05)$ with the total phenolic content $(\mathrm{r}=0.870)$, proanthocyanidins $(\mathrm{r}=0.452)$, total flavonoids $(\mathrm{r}=0.520)$, and non-flavonoid phenolics $(\mathrm{r}=0.900)$, while CUPRAC and FRAP assays, which measure the reducing potential of juices, were also correlated not only to the of total phenolic content $(r=0.966, r=0.923)$, total flavonoids $(\mathrm{r}=0.667, \mathrm{r}=0.522)$, proanthocyanidins $(\mathrm{r}=0.719, \mathrm{r}=0.597)$, but also to the content of non-flavonoid phenolics ( $\mathrm{r}=0.974, \mathrm{r}=0.965)$, as observed in Table 2.2. One important result is that CUPRAC and DPPH were closely associated $(\mathrm{r}=0.891, \mathrm{p}<0.001)$, as well as DPPH and FRAP $(\mathrm{r}=0.913, \mathrm{p}<0.001)$ and CUPRAC and FRAP $(\mathrm{r}=0.978, \mathrm{p}<0.001)$. 
Aiming at a better comprehension of data structure and inferences about antioxidant activity of the juices selected in this study, principal component analysis and hierarchical cluster analysis were employed. Using a two-dimension (2D) projection of samples obtained by PCA (Figure 2.2A), it is possible to observe the clustering of juices from the same vegetable source based on instrumental taste profile, chemical composition, and antioxidant activity and this projection was able to explain up to $67 \%$ of data variability. Elderberry juice presented the highest of total phenolic content, proanthocyanidins, and antioxidant activity in comparison with all other juice samples. Red beet juices presented the highest instrumental saltiness, sourness, and umami, while orange juices presented similar chemical composition and antioxidant activity in comparison with apple juices. When a 3-dimensional (3D) scatter plot (samples and factor loadings) was generated (Figure 2.2B), a more comprehensive comparison among juices could be made: pomegranate juices seemed to be more astringent than other juices, while blueberry and cranberry juices presented the highest aftertaste due to astringency, while orange juice seemed to be more bitter. The 3D PCA explained up to $81 \%$ of the variability in data.

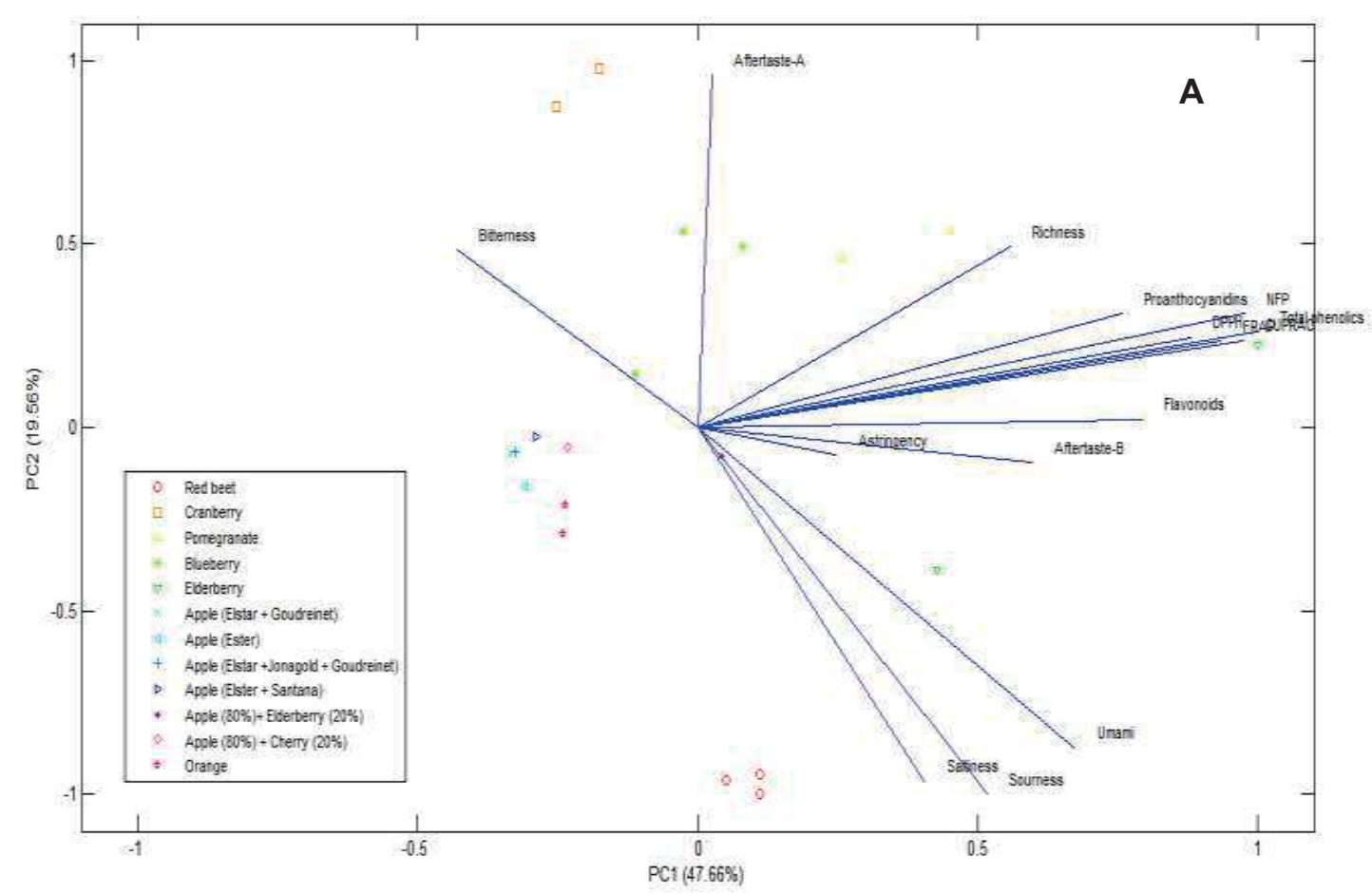




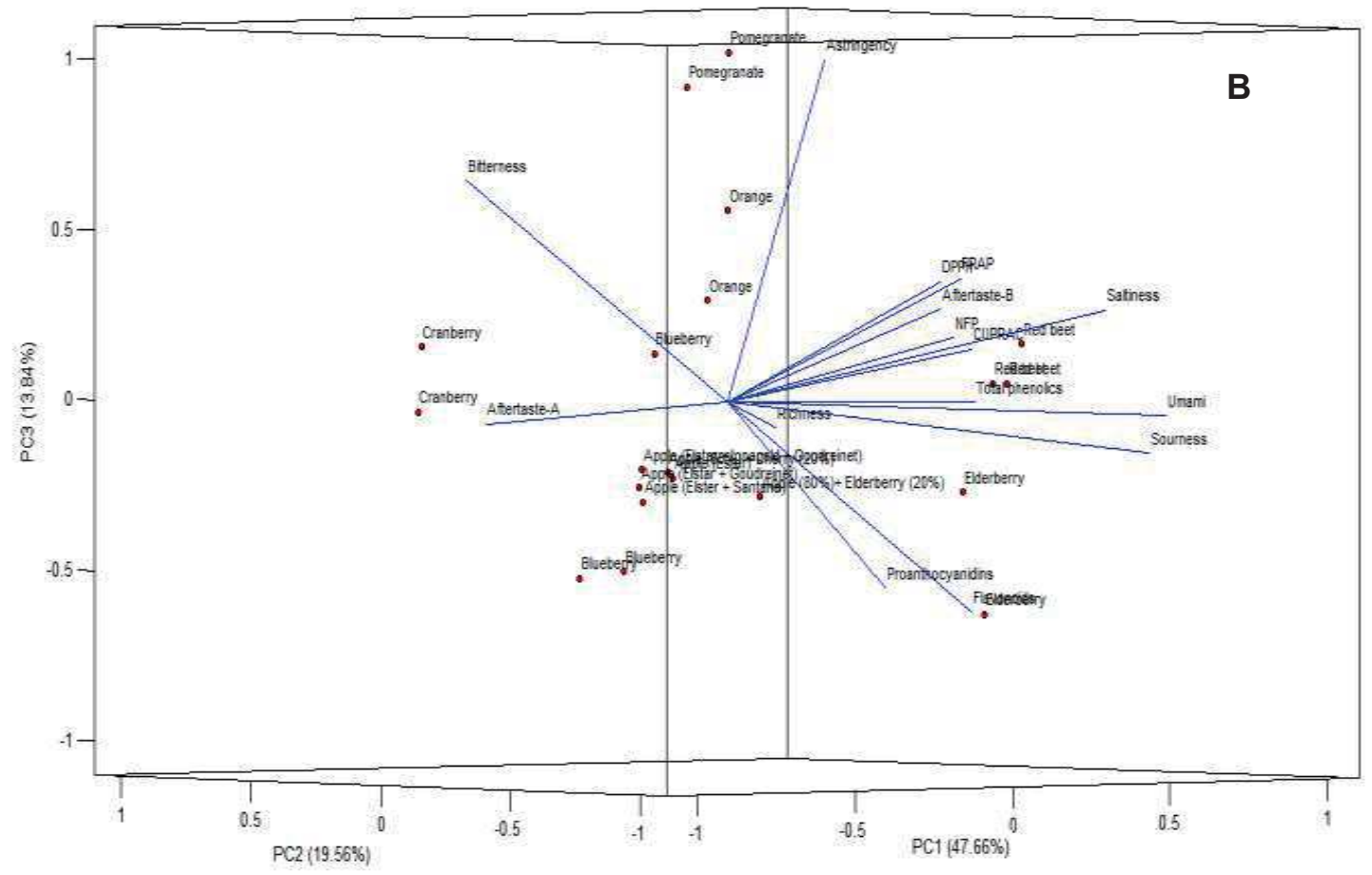

Figure 2.2: Principal component analysis applied to commercial juices from different origins using a 2D projection (A) and a 3D scatter plot of samples (B).

When HCA was applied to all data set and the Euclidean distance of 10.5 was considered, four different groups could be identified (Figure 2.3A): the first contained red beet juices and one elderberry juice, the second contained both pomegranate juices and one elderberry juice, the third cluster grouped two cranberry juices, and the fourth included orange, blueberry juices, and pure apple juices along with apple juices mixed with cherry or elderberry juices. When variables were used for HCA (Figure 2.3B), inferences about the association among all responses could be made: while the antioxidant activity seemed to be very associated with total phenolic content and non-flavonoid phenolics, the instrumental richness of juices (aftertaste evoked by umami substances) and instrumental aftertaste due to bitterness were linked to the content of total proanthocyanidins and flavonoids. Granato, Katayama and Castro (2010) evaluated the chemical composition and the antioxidant activity measured by the DPPH and the oxygen radical absorbance capacity (ORAC) assays of Brazilian red wines and verified that non-anthocyanin flavonoids was the main phenolic class exerting the antioxidant capacity. In addition to HCA applied to the variables, a quantitative measure of the degree of association between variables was performed using the Pearson's correlation coefficients, and the results are presented in Table 2.2. 


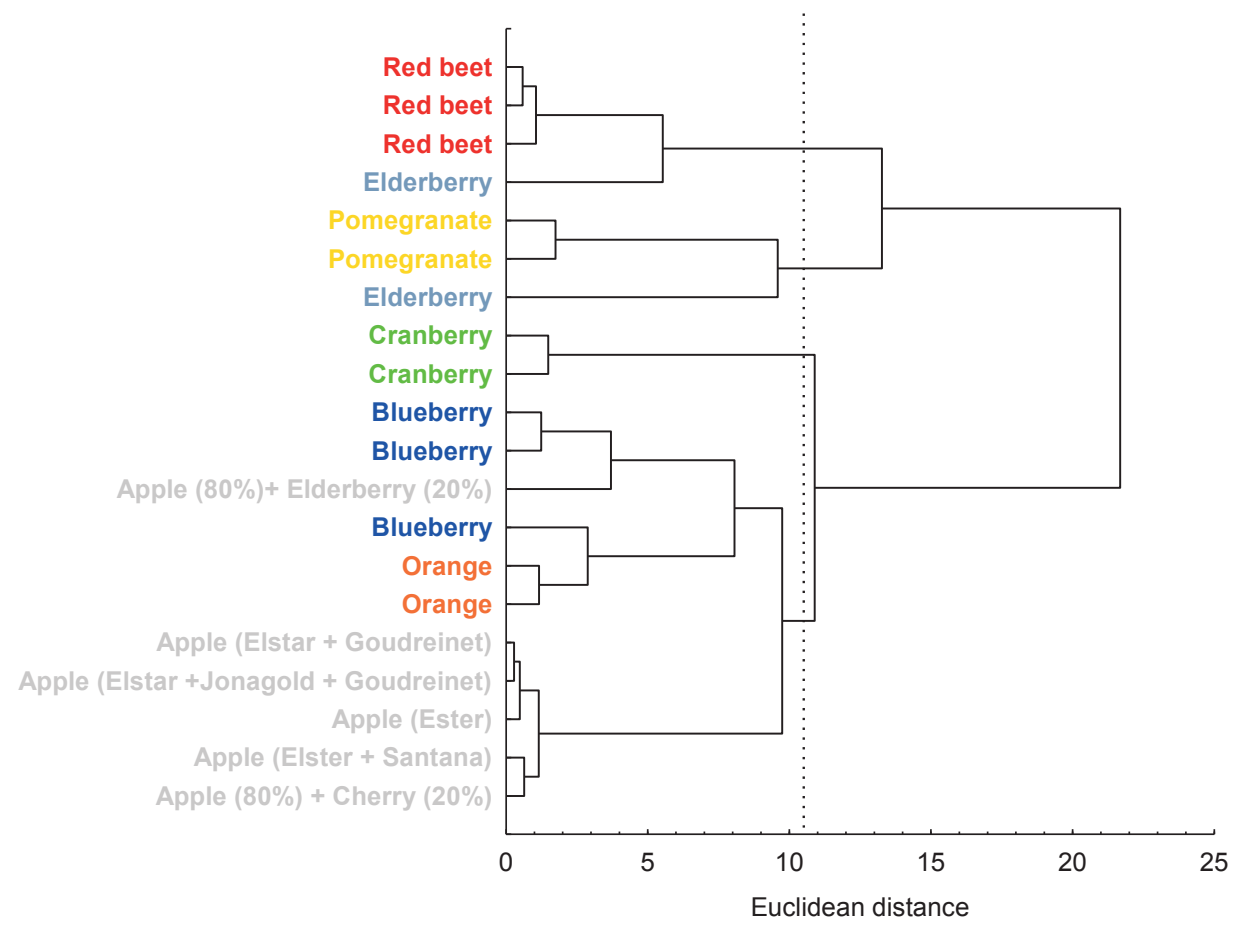

A

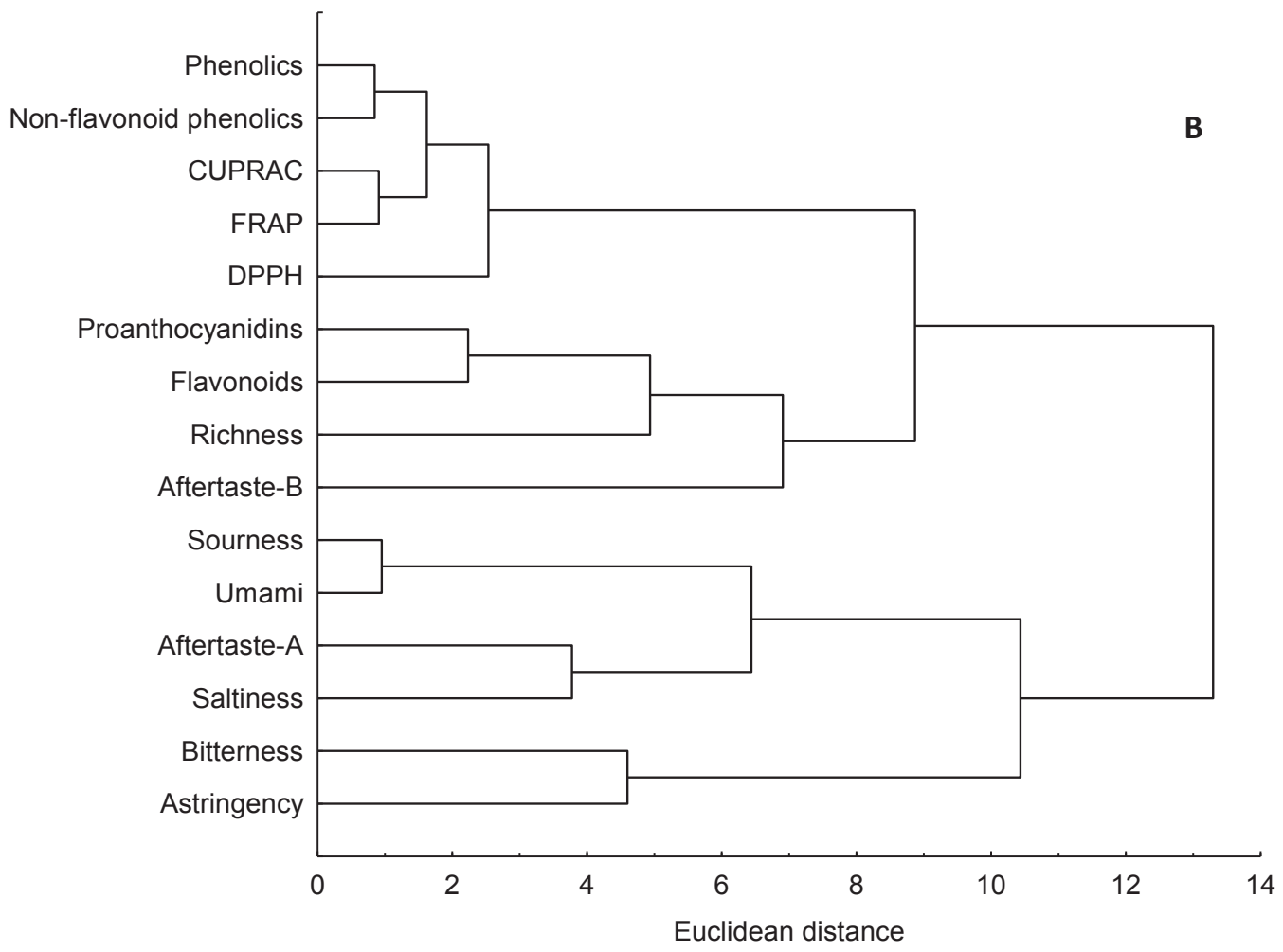




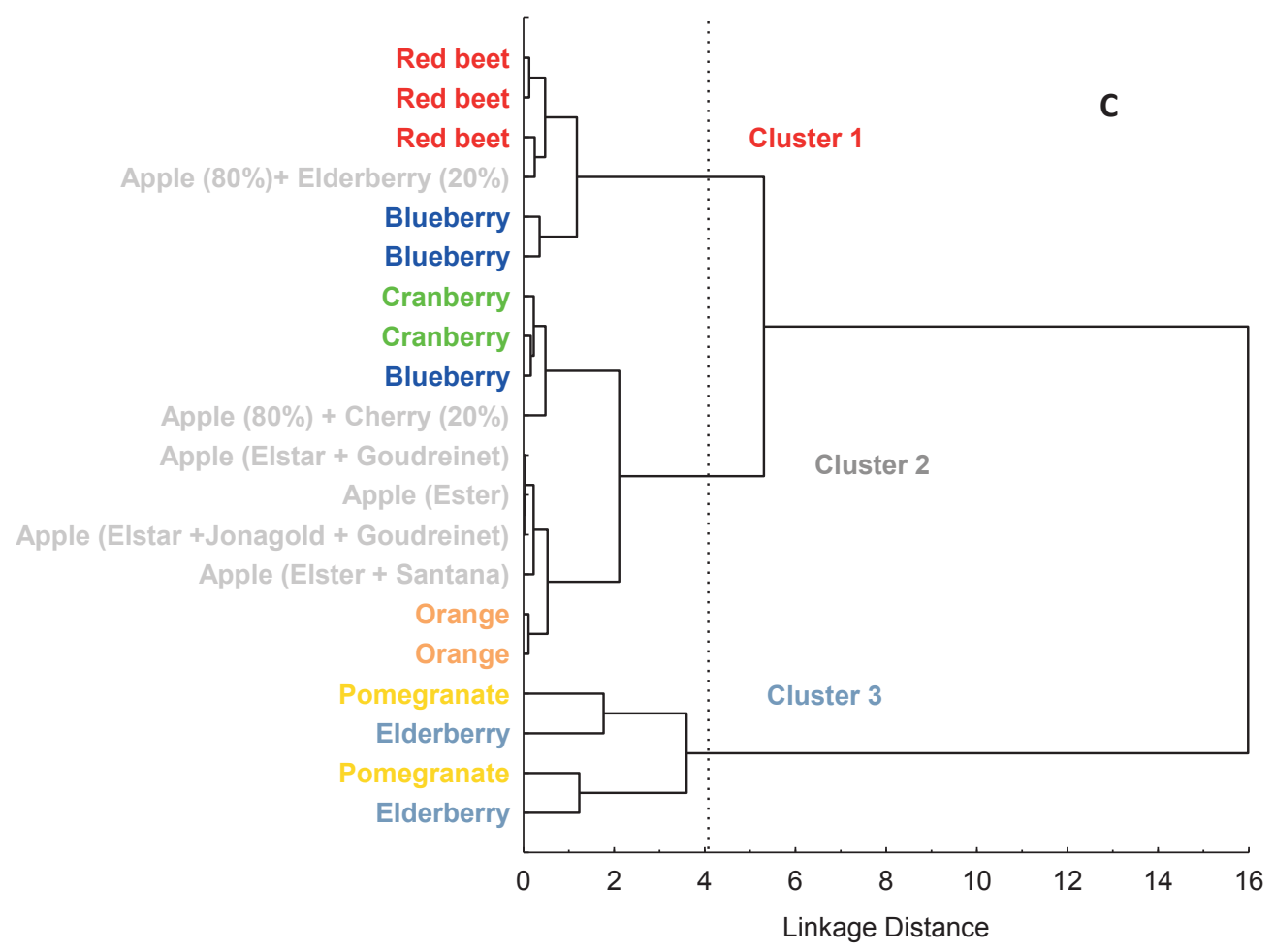

Figure 2.3: Hierarchical Cluster Analysis applied to the samples using all responses (A), HCA applied to the response variables (B) and classification of juices based on the content of total phenolic materials and antioxidant activity (CUPRAC + FRAP) (C).

Taking into account that the higher in vitro antioxidant activity is strongly associated with in vivo effectiveness of phenolic compounds (Macedo et al., 2013), the classification of commercial juices based on antioxidant capacity and total phenolic content seems to be reasonable. In this sense, when HCA was used to group the juice samples according to their total phenolic content and antioxidant activity (CUPRAC and FRAP), only three clusters can be observed using the Euclidean distance of 4 (Figure 2.3C). Cluster 1 ( $\mathrm{n}=6$ ) included three red beet, two blueberry, and an apple juice mixed with elderberry, while Cluster 2 ( $\mathrm{n}=10$ ) contained two cranberry, one blueberry, two orange, and all the other apple juices. Cluster $3(n=4)$ contained all pomegranate and elderberry juices.

A statistical comparison (Table 2.3) among these three groups was performed and results showed that Cluster 1 presented high content of flavonoids, intermediate level of total phenolic content and proanthocyanidins, as well as intermediate antioxidant activity, being thus denominated as 'intermediate functionality'. Cluster 2 presented the lowest antioxidant capacity and contents of flavonoids and total phenolic compounds and was denominated as 'low functionality'. Cluster 3 presented the highest $(\mathrm{p}<0.01)$ total phenolic content, gallic acid content, and antioxidant activity, and therefore was denominated 'high functionality' cluster. The antioxidant activity of Cluster 3 was attributable to $p$-coumaric acid $\left(\mathrm{r}_{\mathrm{DPPH}}=0.628\right.$; 
$\left.\mathrm{r}_{\mathrm{CUPRAC}}=0.727 ; \mathrm{r}_{\mathrm{FRAP}}=0.849\right)$, gallic acid $\left(\mathrm{r}_{\mathrm{DPPH}}=0.990\right),(+)$-catechin $\left(\mathrm{r}_{\mathrm{DPPH}}=0.998\right)$, cyanidin-3-glucoside $\left(\mathrm{r}_{\text {CUPRAC }}=0.819, \mathrm{r}_{\mathrm{FRAP}}=0.600\right)$, and quercetin $\left(\mathrm{r}_{\mathrm{CUPRAC}}=0.586\right)$.

Table 2.3: Statistical comparison [means (SD)] among juices from different botanical origins clustered according to their antioxidant capacity and total phenolic content.

\begin{tabular}{|c|c|c|c|c|}
\hline Response variables & $\begin{array}{l}\text { Cluster } 1(n=6)- \\
\text { Intermediate } \\
\text { functionality }\end{array}$ & $\begin{array}{l}\text { Cluster } 2(n=10)- \\
\text { Low functionality }\end{array}$ & $\begin{array}{l}\text { Cluster } 3(n=4)- \\
\text { High functionality }\end{array}$ & p-value ${ }^{1}$ \\
\hline \multicolumn{5}{|c|}{ Phenolic composition } \\
\hline Total phenolic content (mg GAE/L) & $1,443^{\mathrm{b}}(321)$ & $591.05^{\mathrm{c}}(239)$ & $3,103^{\mathrm{a}}(1,080)$ & $<0.01$ \\
\hline Total proanthocyanidins (mg PCY/L) & $1,024(628)$ & $740.01(256)$ & $2,263(2,392)$ & 0.08 \\
\hline Total flavonoids (mg CTE/L) & $491.65^{\mathrm{a}}(183.07)$ & $178.60^{\mathrm{b}}(76.39)$ & $575.50^{\mathrm{a}}(445.53)$ & 0.01 \\
\hline Non-flavonoid phenolics $(\mathrm{mg} / \mathrm{L})$ & $951.15^{\mathrm{b}}(225.93)$ & $412.45^{\mathrm{c}}(241.74)$ & $2,528^{\mathrm{a}}(742)$ & $<0.01$ \\
\hline $\operatorname{Rutin}(\mathrm{mg} / \mathrm{L})$ & $21.86(18.09)$ & $66.55(125.43)$ & $105.72(85.71)$ & 0.43 \\
\hline Myricetin $(\mathrm{mg} / \mathrm{L})$ & 0.00 & $12.65(28.44)$ & 0.00 & NA \\
\hline Quercetin $(\mathrm{mg} / \mathrm{L})$ & $1.68(4.12)$ & $28.71(57.01)$ & $8.45(11.51)$ & 0.43 \\
\hline Gallic acid (mg/L) & $12.69^{\mathrm{b}}(6.95)$ & $14.01^{\mathrm{b}}(19.23)$ & $130.34^{\mathrm{a}}(146.08)$ & 0.01 \\
\hline$p$-Coumaric acid $(\mathrm{mg} / \mathrm{L})$ & $10.91(8.35)$ & $18.12(32.87)$ & $13.97(2.97)$ & 0.85 \\
\hline$(-)$-Epicatechin (mg/L) & $2.15^{\mathrm{b}}(1.85)$ & $17.44^{\mathrm{b}}(15.14)$ & $2.19^{\mathrm{a}}(2.53)$ & 0.02 \\
\hline$(+)$-Catechin $(\mathrm{mg} / \mathrm{L})$ & $2.34(2.84)$ & $3.43(3.05)$ & $4.97(1.55)$ & 0.36 \\
\hline Cyanidin-3-glucoside (mg/L) & $9.64(20.08)$ & $0.05(0.17)$ & $223.54(424.40)$ & 0.12 \\
\hline Malvidin-3,5-diglucoside (mg/L) & $0.74(1.15)$ & $5.44(12.73)$ & $1.18(2.37)$ & 0.57 \\
\hline Malvidin-3-glucoside (mg/L) & $1.93(3.70)$ & $3.24(6.26)$ & $0.73(1.47)$ & 0.69 \\
\hline Pelargonidin-3-glucoside (mg/L) & $1.80(3.60)$ & $0.14(0.44)$ & $0.44(0.87)$ & 0.30 \\
\hline \multicolumn{5}{|c|}{ Instrumental taste profile } \\
\hline Sourness (EIT) & $12.08(8.41)$ & $1.66(8.69)$ & $10.81(11.65)$ & 0.08 \\
\hline Bitterness (EIT) & $-3.12^{\mathrm{b}}(0.92)$ & $-0.66^{a}(1.17)$ & $-1.67^{\mathrm{ab}}(2.67)$ & 0.02 \\
\hline Astringency (EIT) & $0.07(0.34)$ & $0.03(0.55)$ & $0.47(0.76)$ & 0.39 \\
\hline Aftertaste-B (EIT) & $0.50(0.58)$ & $0.82(1.34)$ & $0.80(0.12)$ & 0.82 \\
\hline Aftertaste-A (EIT) & $1.75^{\mathrm{ab}}(0.95)$ & $0.80^{\mathrm{b}}(095)$ & $2.20^{\mathrm{a}}(0.33)$ & 0.03 \\
\hline Umami (EIT) & $6.99^{\mathrm{ab}}(2.85)$ & $3.25^{\mathrm{b}}(3.02)$ & $8.29^{\mathrm{a}}(3.73)$ & 0.02 \\
\hline Richness (EIT) & $8.56(5.01)$ & $8.12(3.10)$ & $13.24(2.94)$ & 0.09 \\
\hline Saltiness (EIT) & $9.69(10.76)$ & $4.34(1.37)$ & $10.15(3.07)$ & 0.15 \\
\hline \multicolumn{5}{|c|}{ Antioxidant activity } \\
\hline DPPH $(\mu \mathrm{mol} \mathrm{TE} / \mathrm{L})$ & $7,517^{\mathrm{b}}(2,138)$ & $3,065^{\mathrm{c}}(1,245)$ & $18,742^{\mathrm{a}}(2,286)$ & $<0.01$ \\
\hline CUPRAC $(\mu \mathrm{mol}$ TE/L $)$ & $16,867^{\mathrm{b}}(1,974)$ & $7,305^{\mathrm{c}}(3,556)$ & $44,756^{\mathrm{a}}(16,840)$ & $<0.01$ \\
\hline FRAP $(\mu \mathrm{mol} \mathrm{TE} / \mathrm{L})$ & $8,943^{\mathrm{b}}(2,102)$ & $4,306^{\mathrm{b}}(1,971)$ & $31,553^{\mathrm{a}}(10,162)$ & $<0.01$ \\
\hline
\end{tabular}

Note: ${ }^{1}$ Probability values obtained by one-way ANOVA or Welch-ANOVA tests. Different letters in the same line represent statistically different results $(\mathrm{p}<0.05)$; NA $=$ not applicable.

Regarding the individual phenolic compounds evaluated by HPLC, it is possible to observe that only the contents of $(-)$-epicatechin $(\mathrm{p}=0.02)$ and gallic acid $(\mathrm{p}=0.01)$ were statistically different among Clusters. Delphinidin-3-glucoside was not detected (or values were below the LOD) in the juice samples. Cyanidin-3glucoside was remarkably present in juices grouped in Cluster 3 and showed a significant $(\mathrm{p}<0.01)$ correlation with CUPRAC $(\mathrm{r}=0.709)$ and FRAP $(\mathrm{r}=0.616)$. Correlation analysis showed a direct association between gallic acid and FRAP ( $r=0.647, \mathrm{p}=0.002)$, CUPRAC $(r=0.527, \mathrm{p}=0.017)$, and DPPH $(\mathrm{r}=0.695, \mathrm{p}=0.001)$.

The instrumental taste profile measured by the electronic tongue showed a high variability in taste profile within Clusters which may be due to the fact that each food company employs different unit operations 
and pulp/water ratios. Additionally, it is reasonable to consider that fruits are collected and/or produced in distinct locations, thus discrepancies in instrumental taste profile as well as chemical composition were expected. Cluster 3, which contained the juices presented intermediate intensity of bitterness, sourness, and aftertaste due to bitterness, and the highest intensity of astringency, aftertaste due to astringency, richness, and saltiness. This result is in-line with data reported by Benjamin and Gamrasni (2015).

The issue regarding the relation between potential health effects and sensory properties still remains very debatable, that is, it would be interesting if the most sensorialy acceptable juice presented the best profile of chemical compounds and higher antioxidant activity. In the current work, in terms of overall quality of the juices from different botanical origins, although Cluster 3 presented the highest antioxidant activity and higher content of phenolic compounds measured by both HPLC and UV-VIS spectrophotometry, higher values of instrumental astringency were obtained, which may hinder the sensory acceptance of the products (Lesschaeve \& Noble, 2005). Although individuals perceive astringency differently, research has shown consumers do not like too bitter and astringent food products (Dinnella, Recchia, Tuorila, \& Monteleone, 2011). As these juices are widely marketed in the Netherlands, our data corroborate the fact that possible beneficial health effects of the juices probably drive their consumption. In this sense, it is already known that if such a product presents a health claim on the label the perceived healthiness and nutritional value of both juices are considerably boosted (Sabbe et al., 2009).

\subsection{Conclusions}

Overall, by using correlation analysis and multivariate statistical techniques (HCA and PCA), we verified that total phenolic content, specifically gallic acid, $p$-coumaric acid, anthocyanins, flavanols, and flavonols are the main contributors to the in vitro antioxidant activity of the commercial juices analysed in the current work. Elderberry and pomegranate juices presented the highest total phenolic content and antioxidant activity measured by three different assays and also presented the highest intensity of astringency. On the other hand, orange, apple and cranberry juices had the lowest values of total phenolic and flavonoid compounds, DPPH, and CUPRAC. In this sense, the use of unsupervised statistical techniques coupled to ANOVA procedure was demonstrated to be a suitable approach to evaluate the quality of commercial fruit juices based on various analytical measurements.

\subsection{References}

Alezandro, M. R., Granato, D., Lajolo, F. M., Genovese, M. I. (2011). Nutritional aspects of second generation soy foods. Journal of Agricultural and Food Chemistry, 59(10), 5490-5497.

Apak, R., Guclu, K., Ozyurek, M., Celik, S. E. (2008). Mechanism of antioxidant capacity assays and the CUPRAC (cupric ion reducing antioxidant capacity) assay. Microchimica Acta, 160(4), 413-419.

Aquino, L. F. M. C., Silva, A. C. O., Freitas, M. Q., Cruz, A. G., Conte-Junior, C. A. (2014). Identifying cheese whey an adulterant in milk: Limited contribution of a sensometric approach. Food Research International, 62, 233-237. 
Benzie, I. F. F., Strain, J. J. (1996). The ferric reducing ability of plasma (FRAP) as a measure of "antioxidant power": the FRAP assay. Analytical Biochemistry, 239(1), 70-76.

Benjamin, O., Gamrasni, D. (2015). Electronic tongue as an objective evaluation method for taste profile of pomegranate juice in comparison with sensory panel and chemical analysis. Food Analytical Methods, in press. DOI: 10.1007/s12161-015-0350-0

Besten, M. A., Granato, D., Wisniewski, J. R. A., Nunes, D. S., Sens, S. L., Simionatto, E. L. (2013). Chemical composition of volatiles from male and female specimens of Baccharis trimera collected in two distant regions of southern Brazil: a comparative study using chemometrics. Quimica Nova, 36(8), 1096-1100.

Brand-Williams, W., Cuvelier, M. E., Berset, C. (1995). Use of free-radical method to evaluate antioxidant activity. LWT-Food Science and Technology, 28(1), 25-30.

Cruz, A. G., Cadena, R. S., Alvaro, M. B. V. B., Sant'Ana, A. S., Oliveira, C. A. F., Faria, J. A. F., Bolini, H. M. A., Ferreira, M. M. C. (2013). Assessing the use of different chemometric techniques to discriminate low-fat and full-fat yogurts. LWT - Food Science and Technology, 50, 210-214

Dinnella, C., Recchia, A., Tuorila, H., Monteleone, E. (2011). Individual astringency responsiveness affects the acceptance of phenol-rich foods. Appetite, 56(3), 633-642.

European Fruit Juice Association (AIJN), Liquid Fruit - Market report 2012. http://www.aijn.org/pages/main/file.handler?f=AIJNMarketReport2012.pdf. [29 April 2014].

Gardner, P. T., White, T. A. C., McPhail, D. B., Duthie, G. (2000). The relative contributions of vitamin C, carotenoids and phenolics to the antioxidant potential of fruit juices. Food Chemistry, 68(4), 471-474.

Granato, D., Katayama, F. C. U., Castro, I. A. (2010). Assessing the association between phenolic compounds and the antioxidant activity of Brazilian red wines using chemometrics. LWT - Food Science and Technology, 43(10), 1542-1549.

Granato, D., Katayama, F. C. U., Castro, I. A. (2011). Phenolic composition of South American red wines classified according to their antioxidant activity, retail price and sensory quality. Food Chemistry, 129(2), 366-373.

Granato, D., Oliveira, C. C., Caruso, M. S. F., Nagato, L. A. F., Alaburda, J. (2014). Feasibility of different chemometric techniques to differentiate commercial Brazilian sugarcane spirits based on chemical markers. Food Research International, 60, 212-217.

Gu, L., Kelm, M. A., Hammerstone, J. F., Beecher, G., Holden, J., Haytowitz, D., Gebhardt, S., Prior, R. L. (2004). Concentrations of proanthocyanidins in common foods and estimations of normal consumption. Journal of Nutrition, 134(3), 613-617.

Habara, M., Toko, K., Taste sensor. C. A. Grimes, E. C. Dickey, M. V. Pishko (Eds.). (2006). Encyclopedia of sensors. American Scientific Publishers, California, pp. 107-119.

Huo, D., Wu, Y., Yang, M., Fa, H., Luo, X., Hou, C. (2014). Discrimination of Chinese green tea according to varieties and grade levels using artificial nose and tongue based on colorimetric sensor arrays. Food Chemistry, 145, 639-645. 
Kobayashi, Y., Habara, M., Ikezazki, H., Chen, R., Naito, Y., Toko, K. (2010). Advanced taste sensors based on artificial lipids with global selectivity to basic taste qualities and high correlation to sensory scores. Sensors, 10(4), 3411-3443.

Kruger, M. J., Davies, N., Myburgh, K. H., Lecour, S. (2014). Proanthocyanidins, anthocyanins and cardiovascular diseases. Food Research International, 59, 41-52.

Lesschaeve, I., Noble, A. C. (2005). Polyphenols: factors influencing their sensory properties and their effects on food and beverage preferences. American Journal of Clinical Nutrition, 81(1), 330S-335S.

Macedo, L. F. L., Rogero, M. M., Guimarães, J. P., Granato, D., Lobato, L. P., Castro, I. A. (2013). Effect of red wines with different in vitro antioxidant activity on oxidative stress of high-fat diet rats. Food Chemistry, 137(1), 122-129.

Martelo-Vidal, M. J., Vázquez, M. (2014). Determination of polyphenolic compounds of red wines by UVVIS-NIR spectroscopy and chemometrics tools. Food Chemistry, 158, 1 28-34.

Natividade, M. M. P., Corrêa, L. C., Souza, S. V. C., Pereira, G. E., Lima, L. C. O. (2013). Simultaneous analysis of 25 phenolic compounds in grape juice for HPLC: Method validation and characterization of São Francisco Valley samples. Microchemical Journal, 110, 665-674.

Omena, C. M. B., Valentim, I. B., Guedes, G. S., Rabelo, L. A., Mano, C. M., Bechara, E. J. H., Sawaya, A. C. H. F., Trevisan, M. T. S., Costa, J. G., Ferreira, R. C. S., Sant'Ana, A. E. G., Goulart, M. O. F. (2012). Antioxidant, anti-acetylcholinesterase and cytotoxic activities of ethanol extracts of peel, pulp and seeds of exotic Brazilian fruits: Antioxidant, anti-acetylcholinesterase and cytotoxic activities in fruits. Food Research International, 49(1), 334-344.

Porter, L. J., Tannins. In: Methods in plant biochemistry. Plant Phenolics; Harborne, J. B., Academic Press, New York, pp. 389-419 (1989).

Sabbe, S., Verbeke, W., Deliza, R., Matta, V., van Damme. P. (2009). Effect of a health claim and personal characteristics on consumer acceptance of fruit juices with different concentrations of açaí (Euterpe oleracea Mart). Appetite, 53(1), 84-92.

Sánchez-Moreno, C., Plaza, L., Ancos, B., Cano, M. P. (2006). Nutritional characterisation of commercial traditional pasteurised tomato juices: carotenoids, vitamin $\mathrm{C}$ and radical-scavenging capacity. Food Chemistry, 98(4), 749-75.

Saura-Calixto, F., Serrano, J., Goni, I. (2007). Intake and bioaccessibility of total polyphenols in a whole diet. Food Chemistry, 101(2), 492-501.

Singleton, V. L., Rossi, J. R. J. A. (1965). Colorimetry of total phenolics with phosphomolybdicphosphotungstic acid reagent. American Journal of Enology and Viticulture, 16(3), 144-158.

Souza, S. S., Cruz, A. G., Walter, E. H. M., Faria, J. A. F., Celeghini, R. M. S., Ferreira, M. M. C., Granato, D., Sant'Ana, A.S. (2011). Monitoring the authenticity of Brazilian UHT milk: A chemometric approach. Food Chemistry, 124(2), 692-695.

Zhishen, J., Mengeheng, T., Jianming, W. (1999). The determination of flavonoid contents in mulberry and their scavenging effects on superoxide radicals. Food Chemistry, 64(4), 555-559. 
Zulueta, A., Esteve, M. J., Frasquet, I., Frígola, A. (2007). Vitamin C, vitamin A, phenolic compounds and total antioxidant capacity of new fruit juice and skim milk mixture beverages marketed in Spain. Food Chemistry, 103(4), 1365-1374. 


\section{OHAPTER 3:}

\section{CHARACTERIZATION OF CONVENTIONAL, BIODYNAMIC, AND ORGANIC PURPLE GRAPE JUICES BY CHEMICAL MARKERS, ANTIOXIDANT CAPACITY AND INSTRUMENTAL TASTE PROFILE}

This chapter is published as: GRANATO, D.; MARGRAF, T.; BROTZAKIS, I.; CAPUANO, E.; van RUTH, S. M. Characterization of conventional, biodynamic, and organic purple grape juices by chemical markers, antioxidant capacity and instrumental taste profile. Journal of Food Science, 80, C55-C65, 2015. 


\begin{abstract}
The objectives of this study were to characterize organic, biodynamic and conventional purple grape juices $(n=31)$ produced in Europe based on instrumental taste profile, antioxidant activity and some chemical markers and to propose a multivariate statistical model to analyze their quality and try to classify the samples from the three different crop systems. Results were subjected to ANOVA, correlation and regression analysis, principal component analysis (PCA), hierarchical cluster analysis (HCA), soft independent modelling of class analogy (SIMCA), and partial least squares discriminant analysis (PLSDA). No statistical significant differences ( $p>0.05$ ) were observed among juices from the three crop systems. Using PCA and HCA, no clear separation among crop systems was observed, corroborating the ANOVA data. However, PCA showed that the producing region highly affects the chemical composition, electronic tongue parameters and bioactivity of grape juices. In this sense, when organic and biodynamic were grouped as 'non-conventional' juices, SIMCA model was able to discriminate 12 out of 13 organic/biodynamic juices and 17 out of 18 conventional juices, while 11 out of 13 non-conventional and $100 \%$ conventional grape juices were correctly classified using PLSDA. The use of electronic tongue and the determination of antioxidant properties and major phenolic compounds have shown to be a quick and accurate analytical approach to assess the quality of grape juices.
\end{abstract}

Keywords: Electronic tongue, chemometrics, supervised statistical methods, functionality.

\title{
3.1 Introduction
}

The sales of fruit juices in the European Union, especially the ones labeled as $100 \%$ fruit juice, which means no addition of water or sucrose, have been raised considerably in the last five years and reached up about 11.8 billion liters in 2011. Germany, France, United Kingdom, and Spain represent the largest EU markets, while Germany, Finland, Austria, the Netherlands and Sweden are the largest per capita consumers of fruit juices in Europe (European Fruit Juice Association, 2012). Regarding the producing regions, grape fruit juice is widely produced in China, United States, Italy, France, Spain, Turkey, and Chile. However, some other countries have emerged as producers, such as Argentina, Iran, Australia, and Brazil (FAO, 2011). In this sense, consumers are more aware about the relation between eating habits and health conditions, and organic and biodynamic juices have been produced more intensively in those countries (Kuepper \& Gegner, 2004).

Organic production can be defined as an ecological production management system that promotes and enhances biodiversity, biological cycles, and soil biological activity, whereas biodynamic farming falls into the organic system definition, but it uses different preparations of herbs and other plants and/or animal tissues to aid the productivity and 'health' of the plant being considered an holistic and anthroposophyc. Both systems are based on minimal use of off-farm inputs and on management practices that restore, maintain, and enhance ecological harmony (Capuano et al., 2013). From the scientific standpoint, the only way to differentiate organic and biodynamic crop systems is to evaluate the effects of these herbal and tissue preparations on the chemical composition, production yield, sensory attributes, among other quality traits, but so far, much effort has been given to explain the mechanisms by which these preparations work, but they still are not fully known and/or understood (Heimler et al., 2012). An increasing number of farmers has adopted these production management systems in order to conserve non-renewable resources, capture high-value markets, and boost farm income 
(Greene \& Kremen, 2003). To be certificated, U.S. and EU regulations require that organic foods are grown without synthetic pesticides, growth hormones, antibiotics, modern genetic engineering techniques (including genetically modified crops), chemical fertilizers, or sewage sludge. Organic standards incorporate an ecological approach to farming: cultural, biological, and mechanical practices that foster cycling of resources, ecological balance, and protection of biodiversity (Greene \& Kremen, 2003). Considering the increasing importance and presence of organic/biodynamic products in the worldwide food market, their functional potential and chemical composition must be continuously evaluated and provided to consumers and to the scientific community.

Although organic production evolves a more sustainable and 'natural' approach, no standardization regarding all vegetable cultures is available and, therefore, from a scientific standpoint, inconclusive and inconsistent results comparing the nutritional value and the chemical/bioactivity of organically grown with biodynamic and/or conventional foods make this issue even more difficult to unravel. For example, in a study conducted by Vallverdú-Queralt et al. (2012), a total of 11 subgroups of tomato juices (5 organic and 6 conventional) were analyzed for total phenolic content and hydrophilic antioxidant capacity measured by the 2,2 azino-bis(3-ethylbenzothiazoline-6-sulphonic acid) method (ABTS) and DPPH assays and higher ( $<<0.05$ ) total phenolic content and antioxidant activity were observed for organically grown tomato. Similarly, Hallmann and Rembiałkowska (2012) assessed the bioactive compounds of organic and conventional sweet bell pepper (Capsicum annuum L.) grown in the same vicinity (similar soil and climatic conditions) and authors concluded that organically grown samples presented higher $(\mathrm{p}<0.05)$ contents of ascorbic acid, dry matter, total carotenoids, $\beta$-carotene, $\alpha$-carotene, $c i s-\beta$-carotene chlorogenic and gallic acids, quercetin $\mathrm{D}$-glucoside, quercetin and kaempferol, and total phenolic content. In addition, the production management system did not alter the concentration of luteolin. On the contrary, Luthria et al. (2010) evaluated the phenolic composition of different eggplant pulps (Solanum melongena L.) and verified that conventional samples presented higher total phenolic content and no statistical difference $(p>0.05)$ between organic and conventional eggplant pulps was observed in the content of 5-O-caffeoylquinic acid. In this sense, it is clear that more research needs to be conducted to broaden the evidences of differences and similarities of food products cultivated using different farming systems.

Not only because of financial reasons, the sensory characteristics, chemical composition, and authenticity of juices, here namely as typicality, could be assessed through analytical measurements. Some of the analytical techniques widely used to evaluate the quality of fruit juices include gas chromatography (volatile organic compounds), routine analysis of nutritional composition, instrumental color, and highperformance liquid chromatography of phenolic compounds, carotenoids, and some vitamins, among others (Obón et al., 2011). However, other techniques can also be employed to evaluate commercial fruit juices, such as sensory analysis using consumers and/or a trained taste panel or even by using an instrumental taste sensing system, the electronic tongue (Campos et al., 2013; Wang \& Qiu, 2014; Granato et al., 2014). As well stressed by Savage (2012), building, training, and maintaining a trained sensory panel is usually expensive for food companies and the analysis of taste by consumers generates subjective data. Then, profiling the instrumental taste as well by measuring the major phenolic compounds via UV-Vis spectrophotometry seems to be a quick 
and efficient approach in quality control programmes of juice companies. These analytical techniques allow a broader evaluation of fruit juices quality and typicality, as well as their authenticity when fraud is suspected (Capuano et al., 2013).

When it comes to quality of fruit juices, research has shown that the contents of individual phenolic compounds measured by HPLC (Natividade et al., 2013), carotenoids (Delpino-Rius et al., 2014), minerals (Toaldo et al., 2013), as well as the in vitro and in vivo (Pereira et al., 2014) antioxidant activity are usually assessed and discussed separately, that is, few reports evidence the multivariate and simultaneous correlation between chemical composition, sensory evaluation (trained panel or consumer-based studies) and potential functional properties of fruit juices. Although the univariate and bivariate approaches seem to be suitable and valid, limitations with regard to a multidimensional characterization of fruit juices composition and functional properties are evident. In addition, in quality control programmes performed by food companies the quantification of individual phenolic compounds or carotenoids as well the determination of selected minerals (i.e., zinc or manganese) requires a laborious preparation of the sample, use of high volumes of solvents, the use of expensive equipments and highly-trained staff to perform the analysis. To counteract this, the use of rapid and accurate fingerprinting techniques, such as spectrophotometric determination of some major phenolics, antioxidant activity assays, as well as the determination of electronic tongue parameters represent an interesting and less time-consuming approach for food companies to assess juice's quality traits (Sipos et al., 2012; Hong et al., 2014).

Based on the need of food companies and governmental agencies to monitor and assess the quality of fruit juices, and knowing the consumers have more interest in purchasing organic and biodynamic food products and pay a premium price, this work was performed aiming at characterizing organic, biodynamic and conventional purple grape juices produced in Europe based on instrumental taste profile, antioxidant activity and some chemical markers and to propose a multivariate statistical model to analyze their quality and try to classify the samples from the three different production management systems.

\subsection{Material and methods}

\subsubsection{Reagents}

Gallic acid, Folin-Ciocalteu reagent, chlorogenic acid (5-O-caffeoylquinic acid), 6-hydroxy-2,5,7,8tetramethylchroman-2-carboxylic acid (Trolox), sodium molybdate dihydrate, 2,4,6-tris(2-pyridyl)-s-triazine (TPTZ), and pyrocatechol violet (3,3',4-trihydroxyfuchsone-2"-sulfonic acid) were purchased from SigmaAldrich (The Netherlands), while ethanol, tartaric acid, and sodium carbonate were purchased from Merck (Germany). All other reagents were of analytical grade and Milli-Q water was used in the experiments.

\subsubsection{Grape juice samples}

A total of 31 authentic $100 \%$ purple grape juices (Vitis sp.) produced in Europe, in which 6 are biodynamic, 7 are organic, and 18 come from traditional crop system were acquired in the following countries: France, Italy, United Kingdom, Netherlands, Germany, Austria, and Spain. A total of two juices from Turkey were also evaluated as a comparative. It is important to note that all biodynamic juices were also certified by 
third parties for being organic. Samples (about $1 \mathrm{~L}$ ) were brought to the laboratory, and the floating particles were removed by centrifugation ( $400 \mathrm{x} g, 10 \mathrm{~min}$ ). In the sequence, the juices were analyzed immediately for the $\mathrm{pH}$ and total soluble solids content ( $\left.{ }^{\circ} \mathrm{Brix}\right)$ followed by the instrumental taste profile analysis. Juices were then aliquoted into Eppendorff tubes and stored at $-80^{\circ} \mathrm{C}$ until chemical analysis.

\subsection{3 pH, total soluble solids, and phenolic compounds}

$\mathrm{pH}$ values were measured in triplicate using a $\mathrm{pH}$ meter (model $827 \mathrm{pH}$ lab, Metrohm, Switzerland) previously calibrated, while the total soluble solids content was measured three times by a temperature compensating refractometer (Model Abbe, American Optical Corporation, USA) and results were expressed in ${ }^{\circ}$ Brix. The measurements were carried out at $25 \pm 1{ }^{\circ} \mathrm{C}$.

The total phenolic content of juices was measured three times using the Folin-Ciocalteu reagent (Singleton \& Rossi Jr, 1965), and measurements were performed using microplates. Briefly, an aliquot of 25 $\mu \mathrm{L}$ of diluted juices was placed in microplates and $25 \mu \mathrm{L}$ of 2-fold-diluted Folin-Ciocalteu phenol reagent were added together with $200 \mu \mathrm{L}$ of ultra-pure water. The solution remained 5 min to react and $25 \mu \mathrm{L}$ of a saturated sodium carbonate solution $(10 \mathrm{~g} / 100 \mathrm{~mL})$ were added. Then, plates were shaken for $15 \mathrm{~s}$ and the absorbance was measured at $\lambda=725 \mathrm{~nm}$ after $60 \mathrm{~min}$. An analytical curve of gallic acid ( 0 to $150 \mathrm{mg} / \mathrm{L}$ ) was plotted and results were expressed as mg of gallic acid equivalent per liter of grape juice (mg GAE/L).

The ortho-diphenols content was measured in triplicate using a colorimetric method based on the reaction between ortho-diphenols and sodium molybdate dihydrate in a solution of water:ethyl alcohol (1:1 $\mathrm{v} / \mathrm{v}$ ) according to the method proposed by Durán et al. (1991), with modifications. Briefly, an aliquot $60 \mu \mathrm{L}$ of juice (diluted at $1: 25 \mathrm{v} / \mathrm{v}$ ) was mixed with $200 \mu \mathrm{L}$ of a $5 \mathrm{~g} / 100 \mathrm{~mL}$ sodium molybdate dihydrate solution (ethanol in water at a proportion of 1:1 v/v) and let to react for $25 \mathrm{~min}$. The absorbance was recorded at $\lambda=370$ $\mathrm{nm}$ against a blank (EtOH:water 1:1 v/v) and the concentration of ortho-diphenols was estimated by means of an analytical curve of chlorogenic acid $(0-160 \mathrm{mg} / \mathrm{L})$ and results were expressed as $\mathrm{mg}$ of chlorogenic acid equivalent per liter of juice (mg CAE/L).

\subsubsection{Antioxidant activity}

The ferric-reducing antioxidant power (FRAP) of juices was measured as described by Benzie and Strain (1996), with modifications to microplates. Briefly, $20 \mu \mathrm{L}$ of diluted samples were mixed with $280 \mu \mathrm{L}$ of freshly prepared FRAP reagent on 96-well plates. The FRAP reagent was prepared by mixing 10 volumes of $300 \mathrm{mmol} / \mathrm{L}$ acetate buffer ( $\mathrm{pH} 3.6)$ with 1 volume of $10 \mathrm{mmol} / \mathrm{L}$ TPTZ (2,4,6-tripyridyl-s-triazine) in 40 $\mathrm{mmol} / \mathrm{L}$ hydrochloride acid and with 1 volume of $20 \mathrm{mmol} / \mathrm{L}$ ferric chloride hexahydrate. The mixture was incubated for $30 \mathrm{~min}$ and then absorbance at $\lambda=593 \mathrm{~nm}$ was recorded by a microplate spectrophotometer (Synergy-BIOTEK, Winooski, VT, USA). For quantification, an analytical curve composed of different concentrations of Trolox ( 0 to $500 \mu \mathrm{mol} / \mathrm{L}$ ) was prepared. Each juice's antioxidant activity was measured three times and results were expressed as mmol of Trolox equivalent per liter of juice (mmol TE/L).

Copper chelating activity was determined by the method employing pyrocatechol violet (Saiga et al., 2003). Briefly, $30 \mu \mathrm{L}$ of diluted juice or water (blank) were inserted in each well containing $200 \mu \mathrm{L}$ of sodium 
acetate buffer $(50 \mathrm{mmol} / \mathrm{L}, \mathrm{pH} 5.7)$. Then, $8.5 \mu \mathrm{L}$ of a $2 \mathrm{mmol} / \mathrm{L}$ pyrocatechol violet solution were added and let react for $3 \mathrm{~min}$, when $30 \mu \mathrm{L}$ of a $0.1 \mathrm{mg} / \mathrm{mL}(\mathrm{w} / \mathrm{v}) \mathrm{CuSo}_{4} .5 \mathrm{H}_{2} \mathrm{O}$ solution was added to each well and the mixture was allowed to react for $20 \mathrm{~min}$. In the sequence, the absorbance at $\lambda=632 \mathrm{~nm}$ was measured by a microplate spectrophotometer (Synergy-BIOTEK, Winooski, VT, USA). The inhibition of the pyrocatechol violet- $\mathrm{Cu}^{2+}$ complex formation was calculated as: $\% \mathrm{Cu}^{2+}$-chelating activity $=[1$ - $($ Absblank $\left.\mathrm{Abs}_{\text {sample }} / \mathrm{Abs}_{\text {blank }}\right] \mathrm{x} 100$.

\subsubsection{Instrumental taste profile (electronic tongue)}

The instrumental taste profile of each of the grape juice samples $(n=31)$ was evaluated by measuring the following attributes using a commercial electronic tongue (model SA402B, Intelligent Sensor Technology Inc., Japan): sourness (sensor CA0), bitterness (C00), umami (initial taste; sensor AAE) and richness (aftertaste due to umami substances - sensor AAE), astringency (sensor AE1), and saltiness (sensor CT0). The artificiallipid sensors were made of tetradodecylammonium bromide and trioctylmethylammonium chloride for the umami sensor, 1-hexadecanol and tetradodecylammonium bromide for the saltiness sensor, phosphoric acid di-n-decyl ester, oleic acid, and trioctylmetylammonium chloride for the sourness sensor, and tetradodecylammonium bromide for the bitterness and astringency sensors. Dioctyl phenylphosohonate, 2nitrophenyl octyl ether and dioctyl phenylphosphonate were used as the plasticizers. It is important to stress that these sensors have demonstrated to present high selectivity and thresholds agree well with the human gustatory sensation (Kobayashi et al., 2010).

A reference sensor probe consisted of a polymer membrane, an $\mathrm{Ag} / \mathrm{AgCl}$ reference electrode, and an internal probe filled with $3.3 \mathrm{~mol} / \mathrm{L} \mathrm{KCl}$ of a saturated aqueous solution made of $\mathrm{AgCl}$ were also used for the measurements. These electrodes were conditioned for 2 days in a solution of $30 \mathrm{mmol} / \mathrm{L} \mathrm{KCl}$ and $0.3 \mathrm{mmol} / \mathrm{L}$ tartaric acid before measurements.

Briefly, juice samples at $25^{\circ} \mathrm{C}$ were placed, in duplicate, in $50 \mathrm{~mL}$ plastic glasses for electronic tongue detection. The measuring time was set to $30 \mathrm{~s}$ for each sample, and sensors were rinsed lightly for $6 \mathrm{~s}$ using a reference solution $(30 \mathrm{mmol} / \mathrm{L} \mathrm{KCl}+0.30 \mathrm{mmol} / \mathrm{L}$ tartaric acid; conductivity between 4.0 and $4.2 \mathrm{mS} / \mathrm{cm}$ and $\mathrm{pH}$ in the range 3.5-3.6) to measure the aftertaste. This reference solution mimics the human saliva (no taste). After that, sensors were rinsed in an alcoholic solution $(28.5 \mathrm{~mL} / 100 \mathrm{~mL}$ ethanol) for $90 \mathrm{~s}$ to remove adsorbed compounds from the lipid membrane and sensors were again rinsed in the cleaning solution $(30 \mathrm{mmol} / \mathrm{L} \mathrm{KCl}$ $+0.30 \mathrm{mmol} / \mathrm{L}$ tartaric acid) for another $240 \mathrm{~s}$ to remove the alcohol and re-establish the stability of the sensors. The electrical potential corresponding to the intensity of the selected tastes was measured by the taste sensing system which detects the signs via membrane electrical potential measurements (Kobayashi et al., 2010).

A total of four replicated measurements were run on each sample, while the first cycle was discarded to ensure stability and the three responses were averaged. It is known that the taste intensity perceived by humans is proportional to the logarithm of concentration of taste substances and this trend follows the WeberFechner's law. In this sense, the sensor outputs for each sample (electric potential) were converted into taste intensity values on a scale where one unit is the sensor output difference corresponding to a $20 \%$ concentration 
difference in the reference solution (Habara \& Toko, 2006). The values of intensity for each taste are designated as estimated taste intensity (EIT).

\subsubsection{Statistical analysis}

Results are presented as medians and means followed by the standard deviation (SD). Correlation analysis was based on data distribution and expressed by Pearson's correlation coefficient, $r$. Comparison between the mean values of each sample for each juice class, that is, organic, biodynamic and conventional juices, was performed by one-factor ANOVA. When data were heteroscedastic $(p<0.05$ obtained by the Brown-Forsythe test), Welch-ANOVA test was applied. Significant differences were obtained when $\mathrm{p}<0.05$.

In order to pinpoint similarities among juices produced by different production management systems, principal component analysis (PCA) and hierarchical cluster analysis (HCA) were applied. For that purpose, the mean values for each sample, for each dependent variable, were autoscaled prior to chemometrics application in order to avoid misleading results in the interpretation of the generated plots and dendrograms. PCA was also performed to investigate the effect of country of origin on the selected parameters of juice quality. Factor loadings higher than 0.60 were used to project the samples on the factor plane. For HCA, the Euclidean distance was used as dissimilarity measure and Ward's method was used to suggest the clustering of grape juices.

Aiming at differentiating juices according to the production management system, soft independent modelling of class analogy (SIMCA) models were developed using the same standardized data set. SIMCA first develops principal component models for each training set classes. When the set of measurements of a new sample is projected into the space defined by the principal component set of each training class, the new sample is assigned to the class(es) it best fits. The efficiency (here denominated as accuracy) in discriminating juice samples, also known as the non-error rate, was calculated as the total percentage of correctly classified samples. To validate the initial classification of production management systems obtained by SIMCA, a discriminant classification model was built using partial least squares discriminant analysis (PLSDA). The generated model was cross-validated using the leave-one-out approach and the best model was externally validated, in which samples were subdivided into the calibration set ( $80 \%$ samples) and validation set $(20 \%$ samples) using the Kennard-Stone algorithm (Chemoface v.1.6, UFLA, Brazil). Statistica v. 7 (Statsoft, USA), Action v. 2.8 (Estatcamp, Brazil), and Pirouette v. 4.5 (Infometrix, USA) software were used for all statistical analyses.

\subsection{Results and Discussion}

\subsubsection{Univariate/Bivariate analysis of data}

The results (means, medians, and standard deviation) of the chemical analyses, antioxidant capacity, and instrumental taste profile of grape juices are presented in Table 3.1. The statistical comparison between organic, biodynamic, and conventional grape juices showed that although biodynamic presented higher mean values of total phenolic compounds, $o$-diphenols and antioxidant capacity in comparison with organic and conventional purple grape juices, no significant difference was observed for instrumental richness $(\mathrm{p}=0.75)$, 
umami $(p=0.13)$, saltiness $(p=0.06)$, sourness $(p=0.41)$, astringency $(p=0.45)$, bitterness $(p=0.25)$, total phenolic compounds $(\mathrm{p}=0.44)$, total soluble solids $(\mathrm{p}=0.40), \mathrm{pH}(\mathrm{p}=0.34)$, ortho-diphenols $(\mathrm{p}=0.33)$, copper chelating activity $(\mathrm{p}=0.10)$, and ferric reducing antioxidant power $(\mathrm{p}=0.61)$. Similarly, Heimler et al. (2009) assessed the antioxidant activity measured by the DPPH assay and the total polyphenol content of conventionally and biodynamically grown chicory (Cichorium intybus L.) and no difference was found between classes. Our findings are not in accordance with those reported by Dani et al. (2007), who verified that Brazilian organic purple grape juices presented higher $(\mathrm{p}<0.05)$ mean values of total phenolic content and trans-resveratrol in comparison with conventional grape juices. 


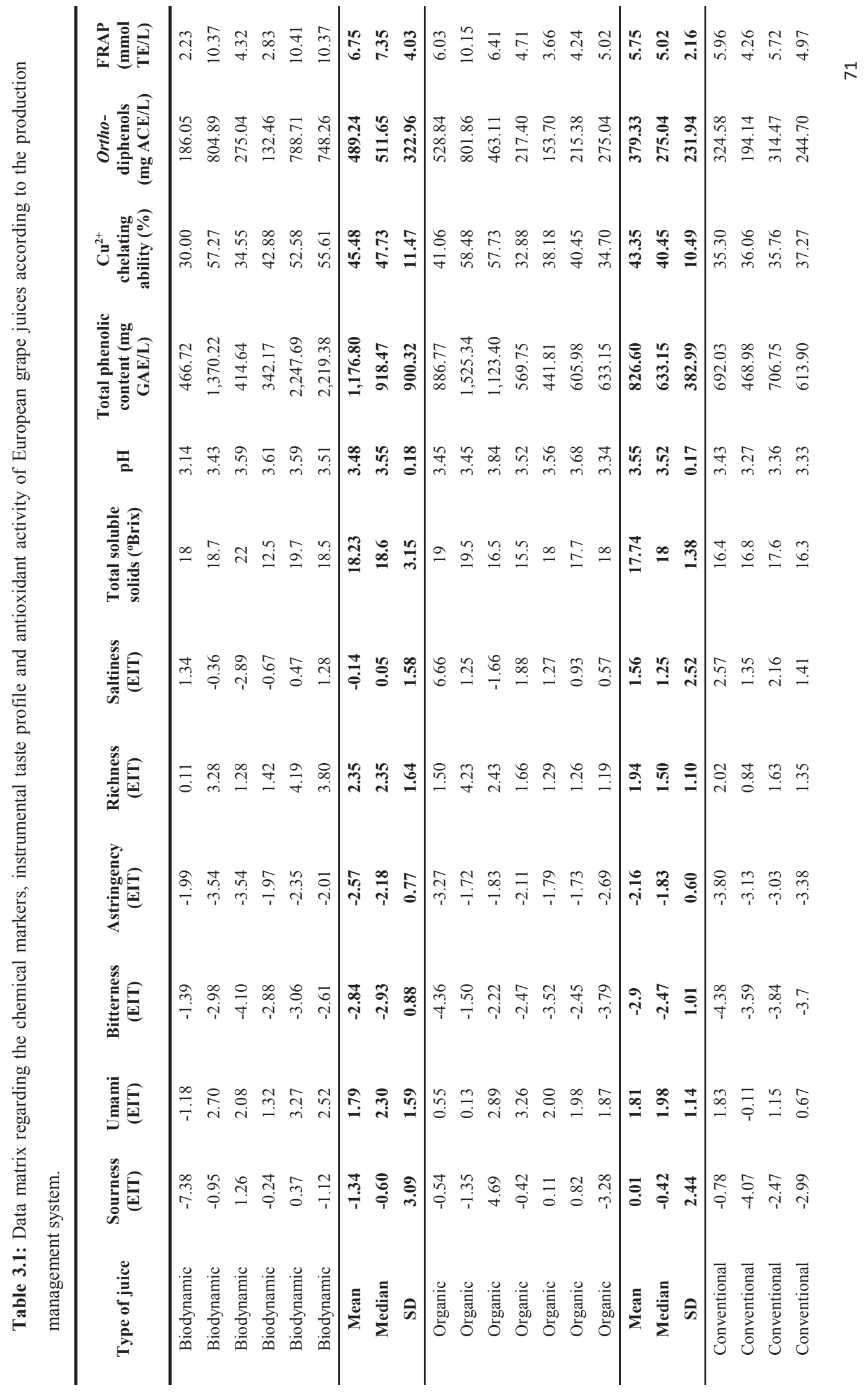




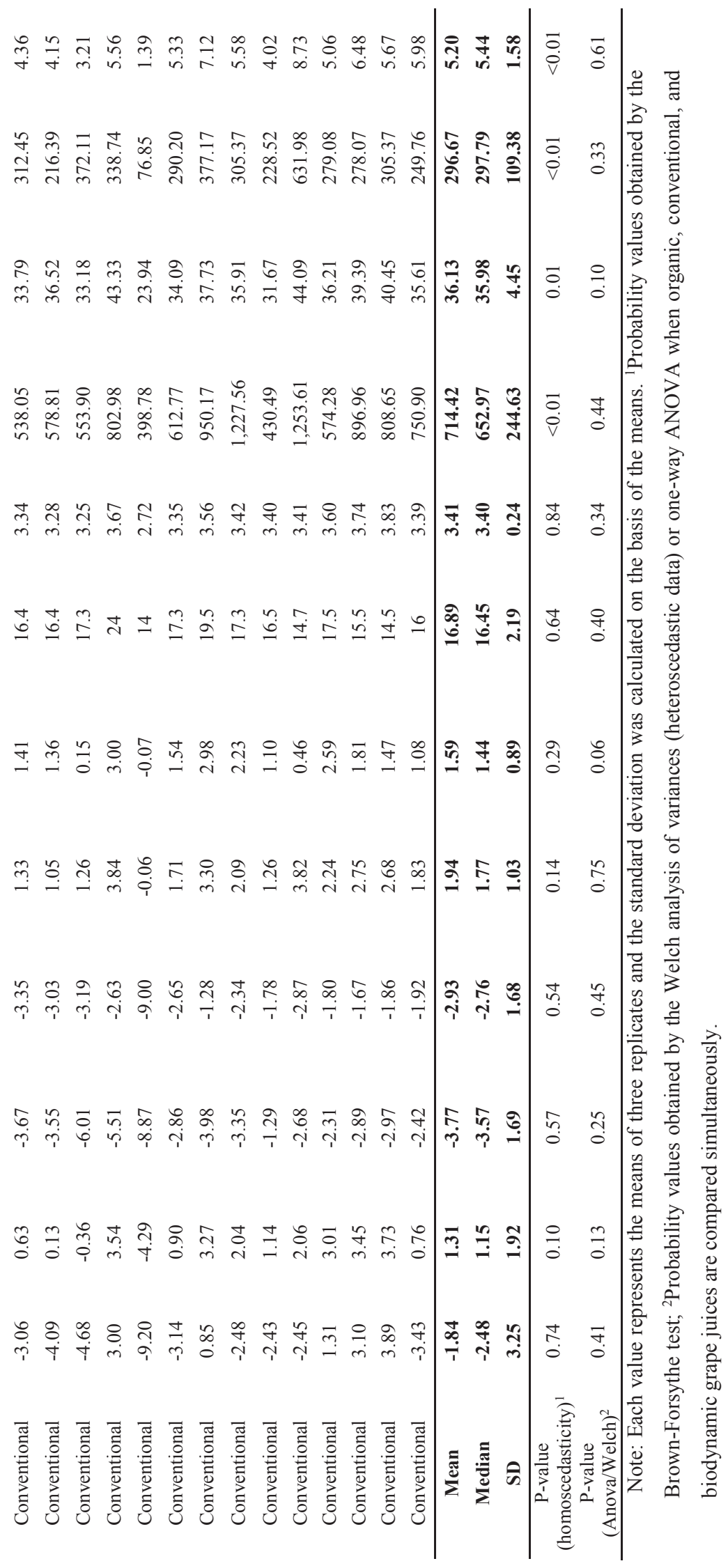


Research comparing organic, biodynamic, and conventional fruit-based products has shown contradictory and debatable results: while some authors concluded that there is no significant difference among production management systems with respect to phenolic composition and/or antioxidant capacity (Valavanidis et al., 2009; Tassoni et al., 2013), others have claimed that significant differences between organic and biodynamic products are conclusive (Asami et al., 2003; Reeve et al., 2005). Our results corroborate the findings that biodynamic, organic, and conventional grape juices present similar total phenolic and orthodiphenols contents as well as antioxidant activity (FRAP and copper chelating activity) and instrumental taste profile. As a comparative, organic and biodynamic juices were grouped in the same class, ORG/BIO, and results showed that bitterness of ORG/BIO juices was slightly higher $(\mathrm{p}=0.09)$ but only the copper chelating activity was statistically different $(\mathrm{p}=0.02)$ between groups $(\mathrm{ORG} / \mathrm{BIO}=44.33 \%$ inhibition; $\mathrm{CONV}=36.13 \%$ inhibition), probably because of a slightly higher total phenolic content (ORG/BIO=998.23 mg/L; $\mathrm{CONV}=714.42 \mathrm{mg} / \mathrm{L} ; \mathrm{p}=0.12)$ and $o$-diphenols content $(\mathrm{ORG} / \mathrm{BIO}=430.06 \mathrm{mg} / \mathrm{L} ; \mathrm{CONV}=296.66 \mathrm{mg} / \mathrm{L}$; $\mathrm{p}=0.06)$.

Besides no statistical significant differences were found for the response variables when all production management systems were compared, correlation analysis was performed in order to understand how the instrumental taste profile and some chemical markers were associated with the antioxidant activity of grape juices, and results are presented in Table 3.2. Data indicate higher sourness intensity ratings were associated with higher antioxidant activity of the grape juices, since phenolic acids, ascorbic acid, and flavonoids are recognized as antioxidants. 


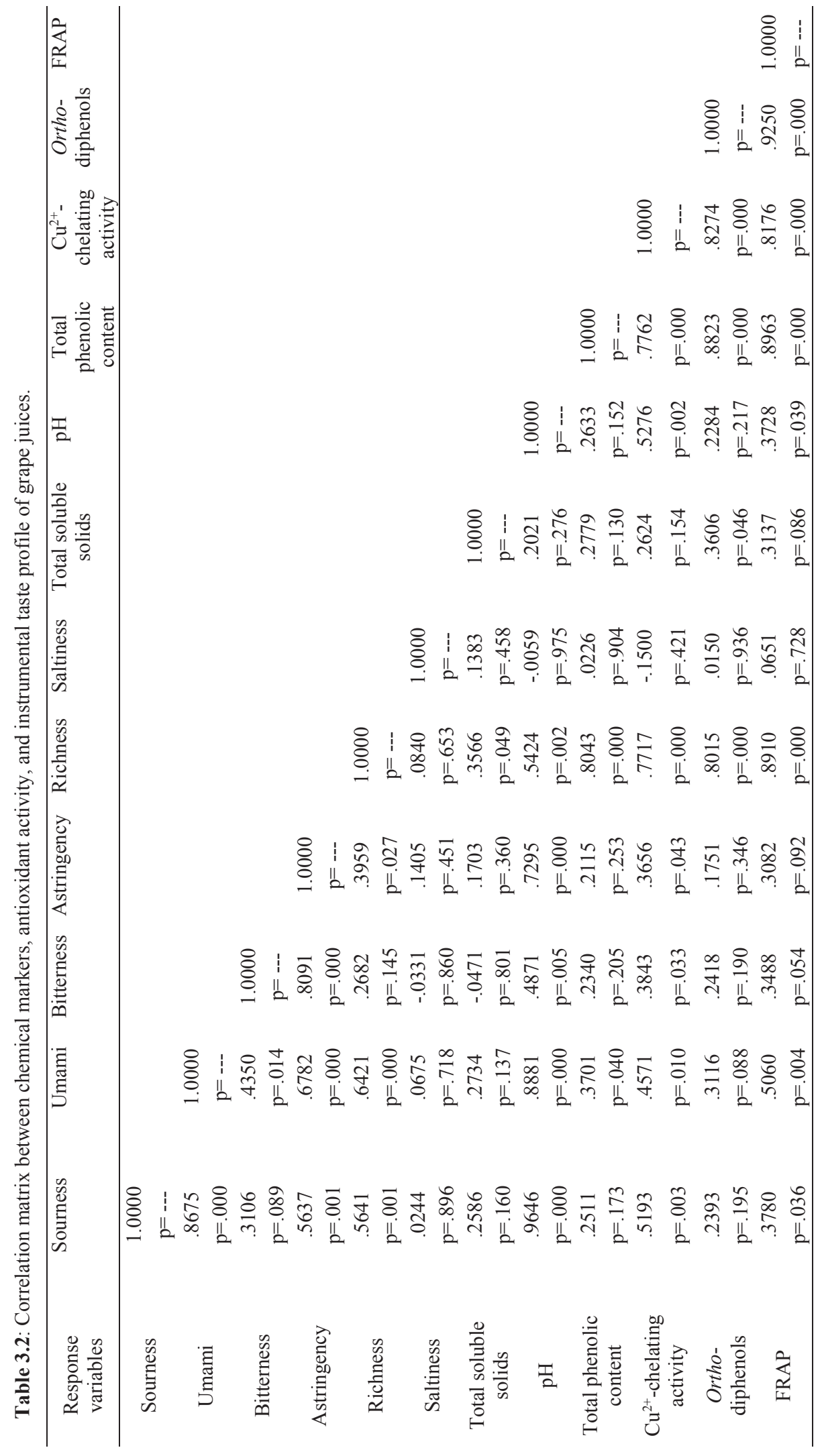


Astringency, which is a tactile sensation, is often perceived as drying, roughing and puckering of the epithelium of the oral cavity due to the content of phenolic compounds, and more accurately with the tannins content (Breslin et al., 1993). In the current work, a sparse and non-significant correlation was found between astringency and total phenolic compounds $(\mathrm{r}=0.211, \mathrm{p}=0.253)$. It is important to stress that not only physical and chemical parameters ( $\mathrm{pH}$, acidity level, viscosity) but also interactions between chemical compounds (tannins, sugars and some peptides) are effectively involved in the perception of astringency (Fontoin et al., 2008), so the correlation between instrumental astringency with a single class of compounds is not always straight-forward. In the same sense, instrumental richness of grape juice was strongly correlated to $\mathrm{pH}$ $(\mathrm{r}=0.542, \mathrm{p}=0.002)$ and total soluble solids $(\mathrm{r}=0.356, \mathrm{p}=0.049)$. The richness of grape juice, measured by the sensor array, was closely correlated to the ortho-diphenols content $(\mathrm{r}=0.801, \mathrm{p}<0.001), \mathrm{Cu}^{2+}$-chelating activity $(\mathrm{r}=0.772, \mathrm{p}<0.001)$, and also with the ferric reducing antioxidant power $(\mathrm{r}=0.891, \mathrm{p}<0.001)$. Therefore, instrumental richness, which is related to a higher content of peptides and amino acids in the matrix, is also associated with higher antioxidant activity of grape juices. In the same sense, umami was also correlated to other basic tastes (Table 3.2), $\mathrm{pH}(\mathrm{r}=0.888, \mathrm{p}<0.001), \mathrm{Cu}^{2+}$-chelating activity $(\mathrm{r}=0.457, \mathrm{p}=0.010)$, and FRAP $(\mathrm{r}=0.506, \mathrm{p}=0.004)$.

As expected, the content of total phenolic compounds and ortho-diphenols correlated well $(\mathrm{p}<0.05)$ to $\mathrm{Cu}^{2+}$-chelating activity $(\mathrm{r}=0.776 ; \mathrm{r}=0.827)$ and FRAP $(\mathrm{r}=0.896 ; \mathrm{r}=0.925)$. FRAP assay measures the ability of the pool of hydrophilic antioxidants present in grape juices to reduce ferric ion to ferrous ion at a low $\mathrm{pH}$, leading to the development of $\mathrm{Fe}^{2+}$-TPTZ (tripiridiltriazine-ferrous), which is a colored metal complex (LópezAlarcón \& Denicola, 2013). Phenolic compounds are able not only to donate electrons to free-radicals and stabilize these highly-reactive substances but also to chelate pro-oxidant transition metals in vitro and in vivo (Mira et al., 2002; Macedo et al., 2013). In the same way, $\mathrm{Cu}^{2+}$-chelating activity assays measures the ability of a sample to bind transition $\mathrm{Cu}^{2+}$ ions in a matrix and, therefore, is a measure of antioxidant capacity of the test material. The chelation of transition metal ions in human body, such as iron, zinc, and copper, can be very important in the prevention of free-radicals generation via Fenton or Haber-Weiss reactions, which damage biomolecules, such as DNA and cells, especially those from the neurological system (Christen, 2000). It has been shown that the use of phenolic compounds, particularly tannins extracted from natural sources, is effective in binding of metal ions and in stabilizing the pro-oxidative effects of metallic ions in tissues and cell membranes (Andrade et al., 2005).

\subsubsection{Multivariate exploratory tools: PCA and HCA}

Our first step in data analysis was to make inferences about grape juices produced using different production management systems, highlighting correlations between the instrumental taste profile, antioxidant capacity, and total phenolic content (including $o$-diphenols). However, when many quality traits and grape juices are analysed, univariate and bivariate statistical methods, such as linear correlations and ANOVA, are usually not enough to provide a holistic view of data structure and, therefore, understand the experimental results. Because of this limitation, chemometric methods, namely PCA and HCA, were used in the current study. 
By using principal component analysis, no clear separation among conventional, organic, and biodynamic grape juices was attained (Figure 3.1A, and 3.1B), corroborating the ANOVA data. The first three principal components accounted for $79 \%$ of data variability and it was possible to observe high variability in results (corroborating descriptive statistical analysis): some organic and biodynamic juices $(n=5)$ presented higher contents of phenolic compounds and antioxidant activity ( $2^{\text {nd }}$ and $3^{\text {rd }}$ quadrants) while some other organic and biodynamic samples $(n=6)$ presented a low antioxidant capacity and low total phenolic content ( $4^{\text {th }}$ quadrant). In a practical standpoint, this result was expected once biodynamic system does not follow a strict and standardized protocol, that is, farmers use preparations of herbs, minerals, treated or fermented animal tissues, water and/or soil in varying proportions and usage times during the plant growth to aid fertilization. This procedure enhances natural discrepancies in the chemical composition and bioactivity of grape berries cultivated in different farms (Heimler et al., 2009) and, therefore, variable results for the commercial grape juices analysed in the current study were clearly observed. 


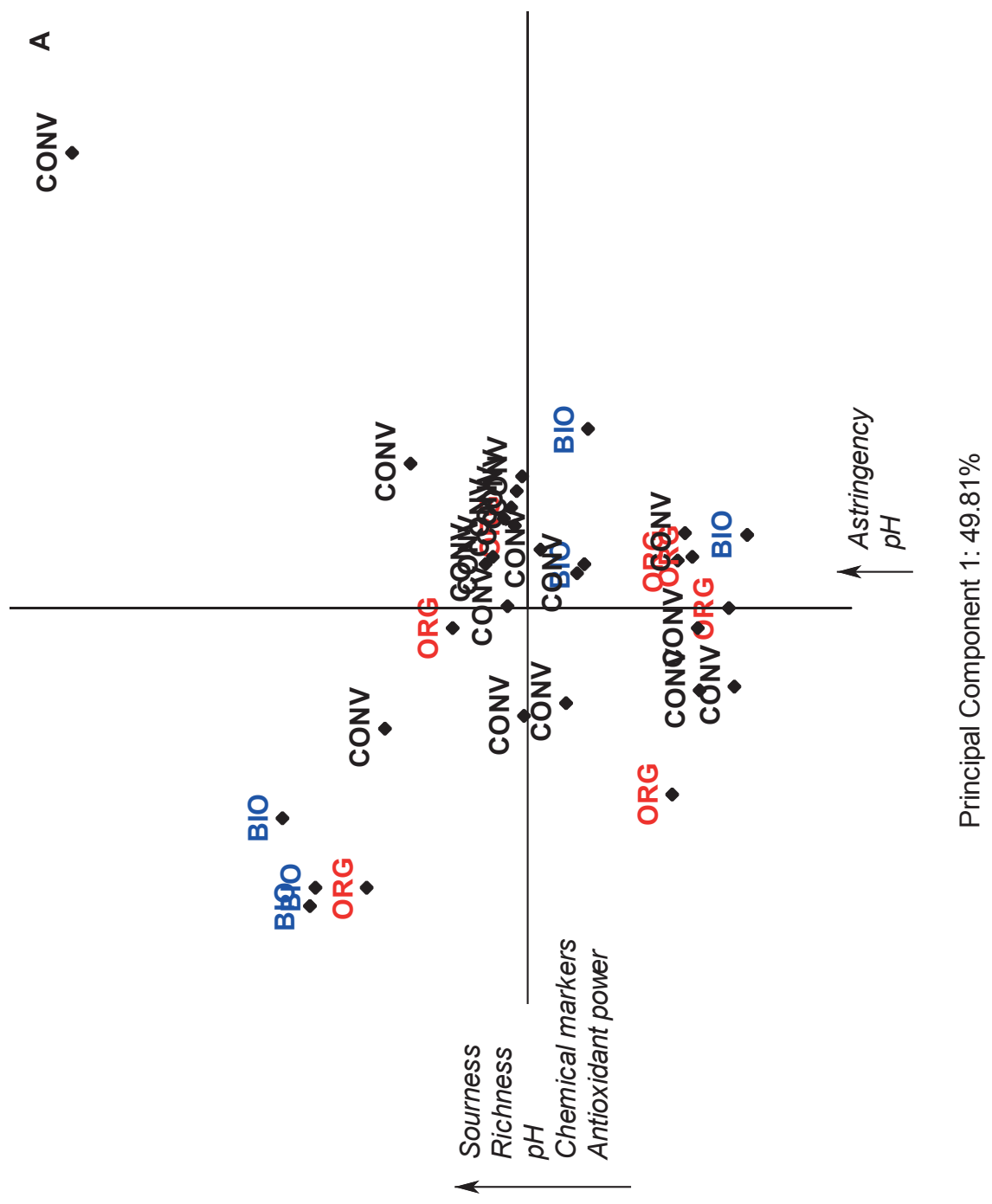

Principal Component 2: 18.9 
¿̀

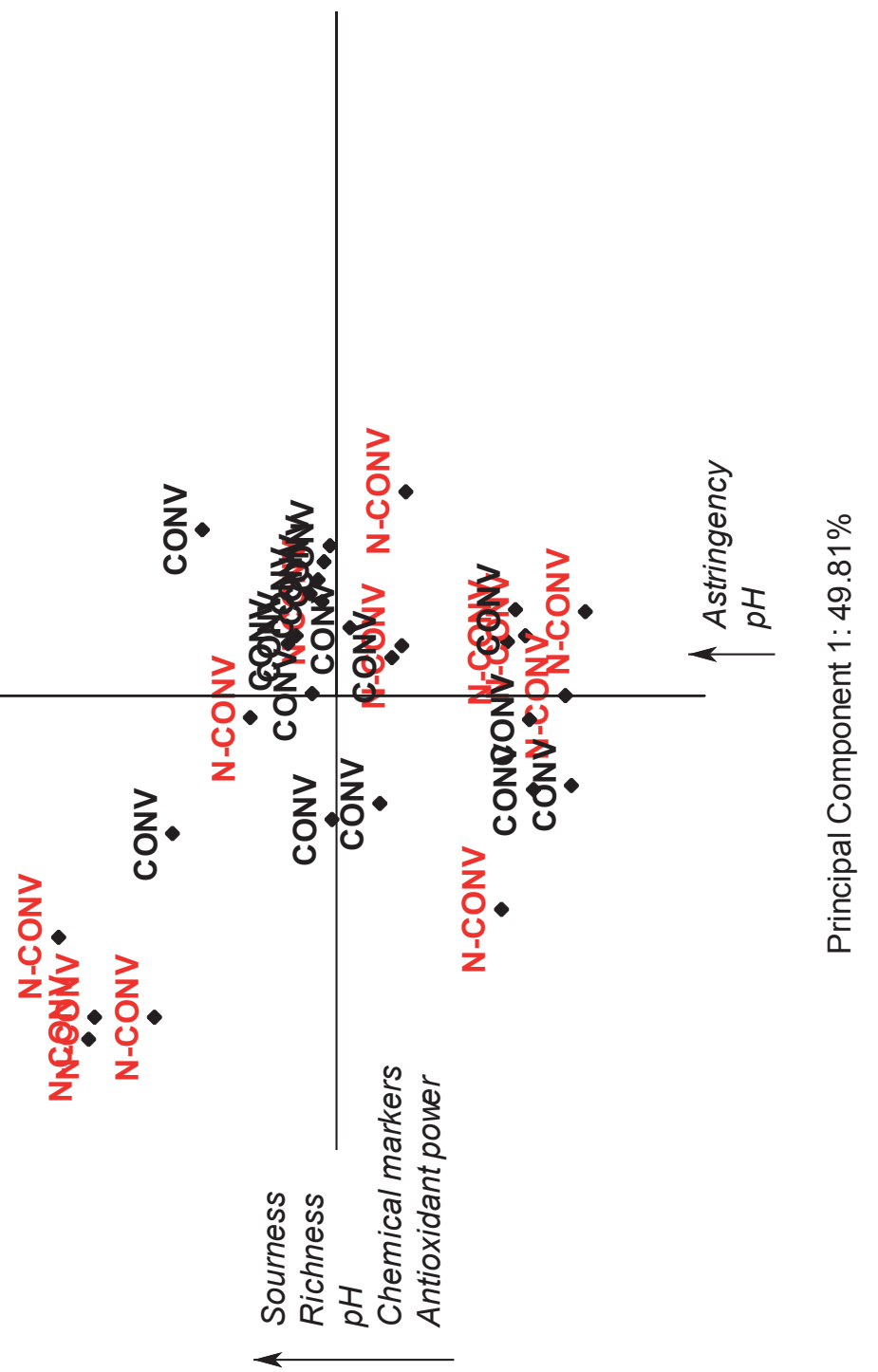

\%96.8L:乙 ұuəuodmoว jed!ou!ud 


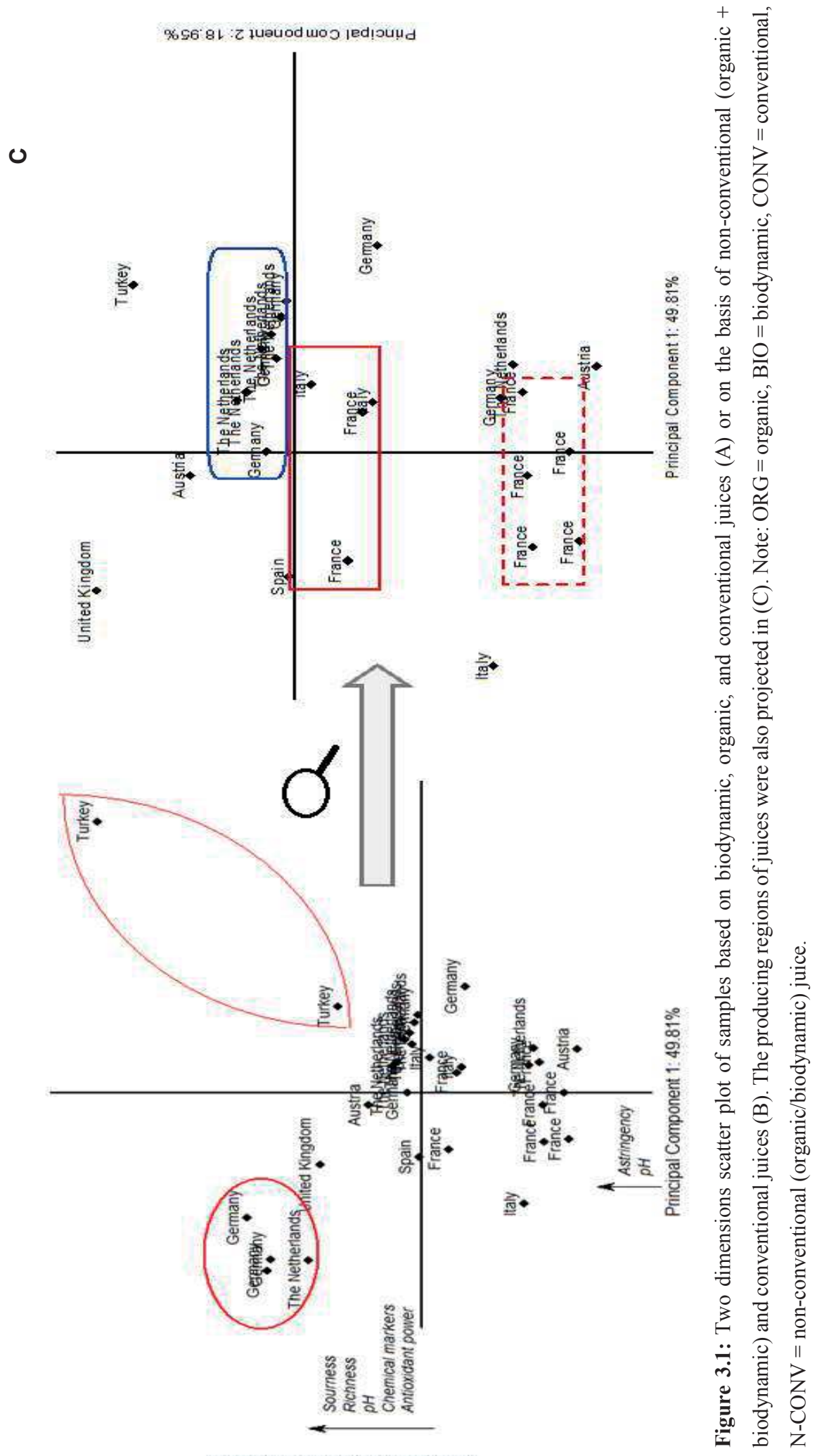

\%\$̣6' 8 z zuouodwo ledjoulyd 
In addition to the PCA analysis using the production management system as a factor, we also attempted to use the geographical origin of the grape juice as a factor, and results are shown in Figure 3.1C. Most samples from Germany and the Netherlands, which seemed to present the highest antioxidant capacity, instrumental richness, sourness, and total phenolic content were grouped, while most samples from France and Austria, which are characterized by high values of astringency and $\mathrm{pH}$, were also grouped at the bottom of the $3^{\text {rd }}$ quadrant. Two French and two Italian juices, which presented intermediate values of the variables, seemed to be very similar. Juices produced in Turkey seemed to be different from the other juices by presenting low levels of $\mathrm{pH}$, astringency, antioxidant activity and total phenolic content. Herein, a clear trend was observed using PCA: the producing region highly affects the instrumental taste profile, phenolic compounds, and antioxidant capacity of European purple grape juices. This result is in-line with other reports on fruit-based products cultivated in different regions (Pellerano et al., 2008; Longobardi et al., 2013). Additionally, in a recent study conducted by our group (Granato, Katayama, \& Castro, 2011), the effect of producing region and grape variety on the individual phenolic composition, antioxidant capacity, and sensory attributes of red wines were evaluated and we verified that the grape variety together with the geographical origin represent important discriminating factors of red wines (Vitis vinifera). Unlike of what we observed for purple grape juices, Vallverdú-Queralt et al. (2012) used PCA to analyze intrinsic differences in the chemical composition and antioxidant capacity of organic and conventional tomato juices produced in Spain and authors verified a suitable differentiation of samples using a 2-dimensional projection (PC1 x PC2). One important information about this study is that these results were obtained with samples grown in the same location, using the same method of preparation, which decrease the dissimilarity between samples from the same production management system.

The geographical origin was shown to be an important factor to differentiate purple grape juices based on the selected responses. It is known that the biosynthesis of chemical compounds, including aroma and phenolic compounds, is highly influenced by the gape genotype and terroir that fruits are cultivated, including quantity of rain, soil type and composition, degree of maturity, altitude, light intensity, among other factors. In this regard, Andjelkovic et al. (2008) evaluated the total and individual phenolic composition of monovarietal olive oil from France and Spain and verified that French oils presented lower total phenolic content and pinoresinol, concluding that the place of cultivation is a decisive factor in differentiating olive oils. This trend was also observed for bioactive compounds of pomegranate juice (Punica granatum L.) produced in different growing locations (altitude) in South Africa: PCA was applied and results revealed that the ggeographical origin influenced significantly the biosynthesis of flavonoids and thus the antioxidant activity measured by the DPPH and FRAP assays (Mphahlele et al., 2014).

Using HCA, which is an unsupervised method of 'classification', no significant/efficient differentiation of production management systems was observed (Figure 3.2). Group 1 was composed of seven juices, in which only one was biodynamic, while Group 2 contained five juices where two were either organic or biodynamic. Group 3 included a total of six samples, in which five were conventional juices, while Group $4(\mathrm{n}=5)$ contained three biodynamic, one organic, and one conventional grape juice. Group 5 clustered five organic/biodynamic and three conventional juices. Thus, HCA did not seem to be an accurate approach to 
differentiate commercial grape juices from distinct production management systems, corroborating the fact that grape juices from European countries cultivated under different production management systems present very similar composition, antioxidant capacity, and instrumental taste profile.

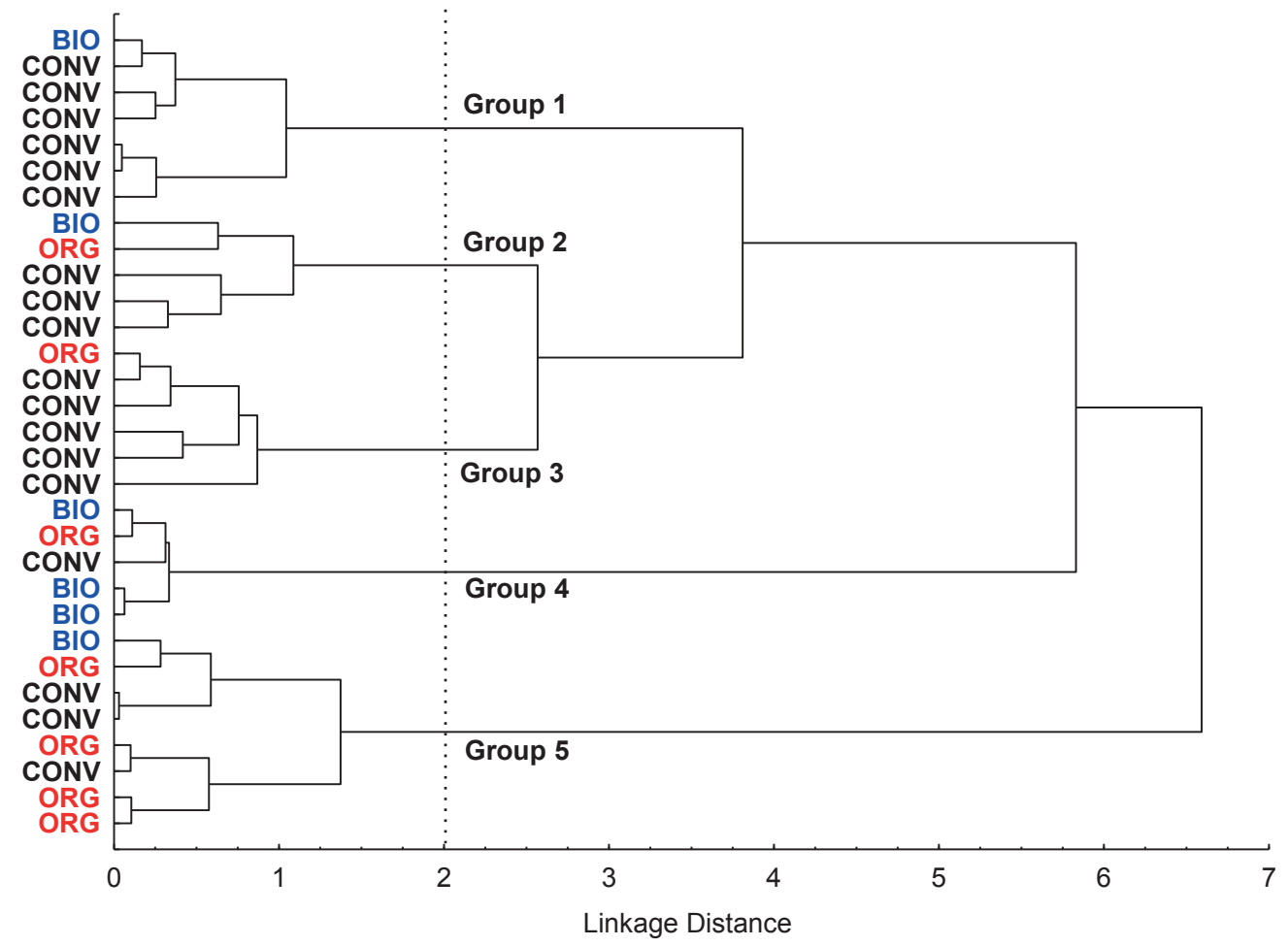

Figure 3.2: Dendrogram obtained by hierarchical cluster analysis based on all instrumental taste profile, chemical markers, and antioxidant activity. Note: $\mathrm{ORG}=$ organic, $\mathrm{BIO}=$ biodynamic, $\mathrm{CONV}=$ conventional juice.

\subsubsection{Class-modelling and Classification models}

Once PCA and HCA did not render satisfactory results in classifying European grape juices from three different production management systems, the instrumental taste profile as well as the total phenolic content, $\mathrm{pH}$, total soluble solids, and antioxidant activity data were altogether used to develop classification models which could predict the organic, biodynamic or conventional nature of the grape juice. SIMCA algorithm and PLSDA were used for that purpose. The first SIMCA model was developed using all response variables aiming to discriminate between conventional, organic and biodynamic juices. Four, two and two factors were selected for the conventional, organic and biodynamic classes, respectively, which explained $99.9 \%, 81 \%$ and $75 \%$ of the total variance for each class. The interclass distance (IC) values showed that the conventional and the biodynamic classes were relatively well separated $(\mathrm{IC}=2.2)$ whereas the $\mathrm{IC}$ values for the conventional vs organic pair ( $\mathrm{IC}=1.8$ ) and the organic vs biodynamic pair $(\mathrm{IC}=1.3)$ showed this SIMCA model was not efficient in discriminating the latter pair (implying a high similarity between organic and biodynamic juices). 
Notwithstanding, not even one juice was classified as 'no match', in which 17 out of 18 conventional juices, all biodynamic, and five out of seven organic juices were correctly classified ( $90.3 \%$ accuracy). The three most discriminative variables that contributed to the classification model were instrumental bitterness, saltiness, and astringency. When PLSDA was employed and cross-validated using the leave-one-out approach, results showed that using 4 factors, only one biodynamic and not a single organic grape juice was correctly classified, whereas all conventional grape juices were adroitly classified using 2 factors, rendering an unsatisfactory accuracy, 61\% (Table 3.3). SIMCA model was not cross-validated, so PLSDA results, which were validated by using the leave-one-out approach, should be considered more trustworthy.

Table 3.3: Discriminating models for biodynamic, organic, and conventional or non-conventional versus conventional grape juices using PLSDA.

\begin{tabular}{cllll}
\hline Type of juice & $\begin{array}{l}\text { Biodynamic } \\
\text { (4 factors })\end{array}$ & $\begin{array}{l}\text { Organic } \\
(4 \text { factors })\end{array}$ & $\begin{array}{l}\text { Conventional } \\
(2 \text { factors })\end{array}$ & No match \\
\hline Biodynamic & $\mathbf{1}$ & 4 & 0 & 1 \\
Organic & 3 & $\mathbf{0}$ & 4 & 0 \\
Conventional & 0 & 0 & $\mathbf{1 8}$ & 0 \\
\hline Type of juice & Non-conventional & Conventional & No match \\
\hline Non-conventional & $\mathbf{8}$ & $(2$ factors $)$ & 0 \\
Conventional & 0 & 5 & 0 & \\
\hline
\end{tabular}

Once an unsatisfactory classification was obtained by using the three production management systems, and taking into account that biodynamic and organic grape juices seemed to be very similar, a second SIMCA model was developed to try to discriminate between conventional (CONV) and non-conventional (N-CONV) juices. The organic and the biodynamic juices (ORG/BIO) were therefore combined in the 'non-conventional' class. Four factors were selected for both classes which explained 92 and $91 \%$ of the total variance. The IC between classes was 2.1, leading to a model with a suitable separation between conventional and organic/biodynamic grape juices (Figure 3.3). The variables that contributed to this classification (higher discriminating power) were instrumental richness, saltiness, and total soluble solids. Not even one juice was designated as 'no match' by this model and 12 out of 13 non-conventional samples and 17 out of 18 conventional juices were correctly classified. As compared to the first SIMCA model, the combination of organic and biodynamic grape juices in one class (ORG/BIO) seems to be a better strategy to differentiate juices. Using three latent variables (factors) in the PLSDA analysis, 93.5\% of grape juices were correctly classified, in which 11 out of $13 \mathrm{~N}-\mathrm{CONV}$ and $100 \%$ CONV purple grape juices were adroitly classified using the internal validation. When this model was externally validated, a total of $86 \%$ classification accuracy was obtained, indicating the PLSDA model is robust. This supervised statistical model was able to explain up to $73 \%$ of data variability and the most discriminating response variables were $\mathrm{Cu}^{2+}$ - chelating activity $>\mathrm{pH}>$ instrumental sourness. 


\section{Non-conventional juices}

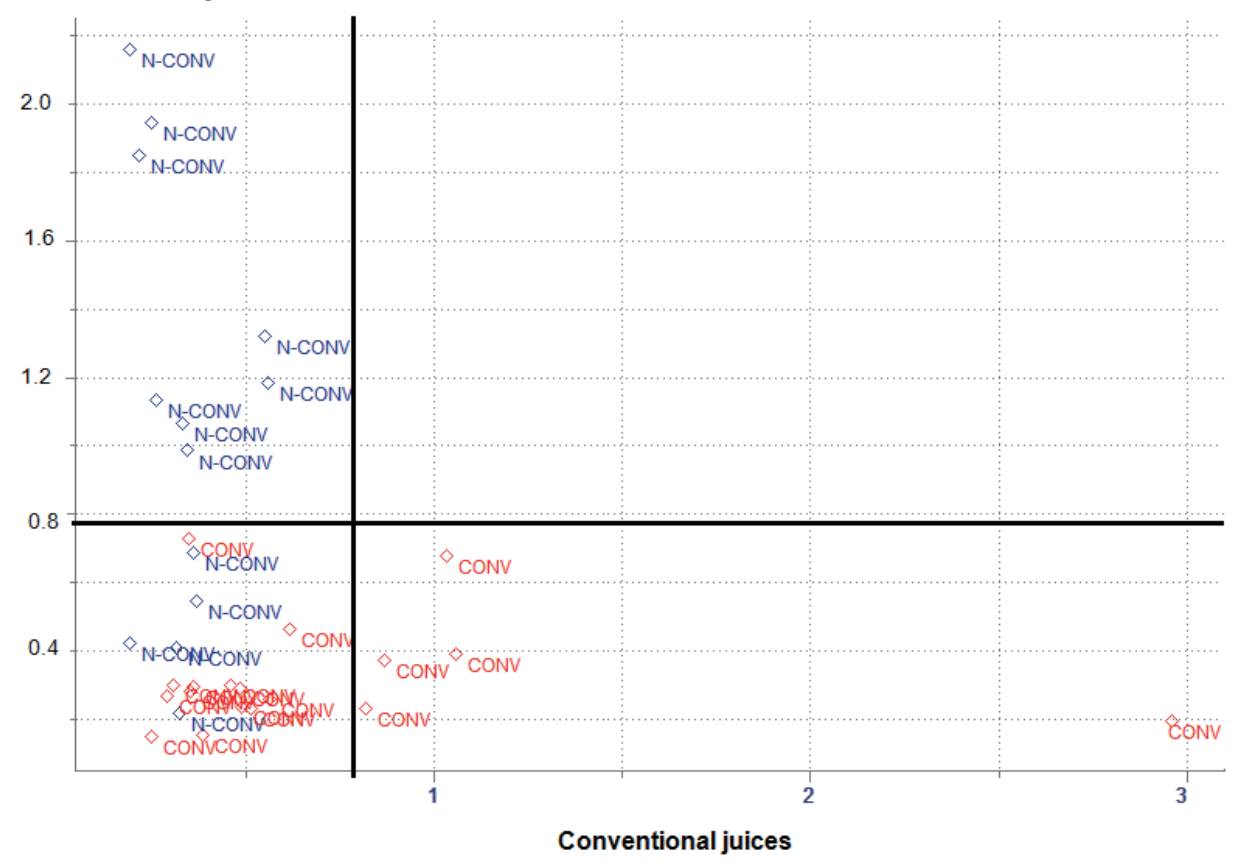

Figure 3.3: SIMCA plot (Coolman's plot) showing the separation between conventional and non-conventional (ORG/BIO) grape juices based on chemical markers, instrumental taste profile, and antioxidant activity.

The results obtained by ANOVA and by multivariate statistical techniques strike an important observation about grape juices produced in Europe: no statistical difference ( $p>0.05$ ) was observed among production management systems using inferential analysis and considering each of the three classes. SIMCA and PLSDA confirmed that the instrumental taste profile, physicochemical characteristics, antioxidant capacity and major phenolic composition of biodynamic and organic purple grape juices are indistinguishable once no statistical model was able to discriminate efficiently the three production management systems. Nonetheless, if the purpose is to discriminate conventional and non-conventional grape juice (regardless if the juice is biodynamic or organic) based on the analytical measurements performed in this study, either SIMCA or PLSDA could be used to predict the production management system nature of the purple grape juice.

\subsection{Conclusions}

Using ANOVA, our results corroborate the findings that biodynamic, organic, and conventional grape juices present no statistical difference $(\mathrm{p}>0.05)$ with respect to instrumental taste profile, physicochemical parameters, total phenolic and $o$-diphenols contents, and antioxidant activity as measured by FRAP and $\mathrm{Cu}^{2+}$ chelating activity. If organic and biodynamic purple grape juices are considered together and compared to the conventional juices, $\mathrm{Cu}^{2+}$-chelating activity is significantly higher in the ORG/BIO class. Once a good and significant correlation was observed between instrumental taste profile attributes and antioxidant activity, the 
use of electronic tongue was shown to be a quick and accurate analytical alternative to assess the quality traits of grape juices. SIMCA and PLSDA, which are supervised statistical techniques, were able to differentiate conventional and non-conventional (ORG/BIO) grape juices. However, a larger set of biodynamic and organic grape juices produced in Europe should be evaluated to confirm these preliminary results.

\subsection{References}

Andjelkovic, M., Camp, J. V., Pedra, M., Renders, K., Socaciu, C., Verhé, R. (2008). Correlations of the phenolic compounds and the phenolic content in some Spanish and French olive oils. Journal of Agricultural and Food Chemistry, 56(13), 5181-5187.

Andrade, R. G., Dalvi, L. T., Silva, J. M. C., Lopes, G. K. B., Alonso, A., Hermes-Lima, M. (2005). The antioxidant effect of tannic acid on the in vitro copper-mediated formation of free radicals. Archives Biochemistry Biophysics, 437(1), 1-9.

Asami, D. K., Hong, Y. J., Barrett, D. M., Mitchell, A. E. (2003). Comparison of the total phenolic and ascorbic acid content of freeze dried and air dried Marion berry, strawberry, and corn using conventional, organic and sustainable agriculture practices. Journal of Agricultural and Food Chemistry, 51(5), 1237-1241.

Benzie, I. F. F., \& Strain, J. J. (1996). The ferric reducing ability of plasma (FRAP) as a measure of "antioxidant power": the FRAP assay. Analytical Biochemistry, 239(1), 70-76.

Breslin, P. A., Gilmore, M. M., Beauchamp, G. K., Green B. G. (1993). Psychophysical evidence that oral astringency is a tactile sensation. Chemical Senses, 18(4), 405-417.

Campos, I., Bataller, R., Armero, R., Gandia, J. M., Soto, J., Martínez-Mañez, R., Gil-Sánchez, L. (2013). Monitoring grape ripeness using a voltammetric electronic tongue. Food Research International, 54(2), 1369-1375.

Capuano, E., Boerringter-Eenling, R., van der Veer, G., van Ruth, S. M. (2013). Analytical authentication of organic products: an overview of markers. Journal of the Science of Food and Agriculture, 93(1), 1228.

Christen, Y. (2000). Oxidative stress and Alzheimer disease. The American Journal of Clinical Nutrition, $71(2), 621 \mathrm{~S}-629 \mathrm{~S}$.

Dani, C., Oliboni, L. S., Vanderlinde, R., Bonatto, D., Salvador, M., Henriques, J. A. P. (2007). Phenolic content and antoxidant activites of white and purple juices manufactures with organically or conventionally-produced grapes. Food Chemical Toxicology, 45(12), 2574-2580.

Delpino-Rius, A., Eras, J., Marsol-Vall, A., Vilaró, F., Balcells, M., Canela-Garayoa, R. (2014). Ultra performance liquid chromatography analysis to study the changes in the carotenoid profile of commercial monovarietal fruit juices. Journal of Chromatography, 1331(8), 90-99.

Durán, R. M., Padilla, R. B., Martín, A. M., Ursinos, J. A. F., Mendoza, J. A. (1991). Biodegradación de los compuestos fenólicos presentes en el alpechín. Grasas y Aceites, 42(4), 271-276.

European Fruit Juice Association. Market Report (2012). Available at: http://www.aijn.org/pages/main/file.handler?f=AIJNMarketReport2012.pdf. Access 12 March 2014. 
Fontoin, H., Saucier, C., Teissedre, P. L., Glories, Y. (2008). Effect of pH, ethanol and acidity on astringency and bitterness of grape seed tannin oligomers in model wine solution. Food Quality and Preference, 19(3), 286-291.

Food and Agriculture Organization (FAO). Production of grape. (2014). Available at: http://faostat.fao.org/site/339/default.aspx. Access 12 March 2014.

Granato, D., Katayama, F. C. U., Castro, I. A. (2011). Phenolic composition of South American red wines classified according to their antioxidant activity, retail price and sensory quality. Food Chemistry, 129(2), 366-373.

Granato, D., Grevink, R., Zielinski, A. A. F., Nunes, D. S., van Ruth, S. M. (2014). Analytical strategy coupled with response surface methodology to maximize the extraction of antioxidants from green, yellow, and red teas (Camellia sinensis var sinensis). Journal of Agricultural and Food Chemistry, 62(42), 1028310296.

Greene C, Kremen A. (2003). U.S. Organic Farming in 2000-2001: Adoption of Certified Systems. USDA Agriculture Informative Bulletin, 780, 1-50.

Habara, M., Toko, K. Taste sensor. C. A. Grimes, E. C. Dickey, M. V. Pishko (Eds.), Encyclopedia of sensors, vol. 10 (pp. 107-119), American Scientific Publishers, California (2006).

Hallmann, E., Rembiałkowska, E. (2012). Characterisation of antioxidant compounds in sweet bell pepper (Capsicum annuum L.) under organic and conventional growing systems. Journal of the Science of Food and Agriculture, 92(12), 2409-2415.

Heimler, D., Isolani, L., Vignolini, P., Romani, A. (2009). Polyphenol content and antiradical activity of Cichorium intybus L. from biodynamic and conventional farming. Food Chemistry, 114(3), 765-770.

Heimler, D., Vignolini, P., Arfaioli, P., Isolani, L., Romani, A. (2012). Conventional, organic and biodynamic farming: differences in polyphenol content and antioxidant activity of Batavia lettuce. Journal of the Science of Food and Agriculture, 92(3), 551-556.

Hong, X., Wang, J., Qiu, S. (2014). Authenticating cherry tomato juices-Discussion of different data standardization and fusion approaches based on electronic nose and tongue. Food Research International, 60, 173-179.

Hosu, A., Cristea, V. M., Cimpoiu, C. (2014). Analysis of total phenolic, flavonoids, anthocyanins and tannins content in Romanian red wines: Prediction of antioxidant activities and classification of wines using artificial neural networks. Food Chemistry, 150, 113-118.

Kobayashi, Y., Habara, M., Ikezazki, H., Chen, R., Naito, Y., Toko, K. (2010). Advanced taste sensors based on artificial lipids with global selectivity to basic taste qualities and high correlation to sensory scores. Sensors, 10(4), 3411-3443.

Kuepper, G., Gegner, L. Organic crop production overview. (2004) Available at: https://attra.ncat.org/attrapub/summaries/summary.php?pub=66. Access 9 October 2014.

Longobardi, F., Ventrella, A., Bianco, A., Catucci, L., Cafagna, I., Gallo, V., Agostiano, A. (2013). Nontargeted $1 \mathrm{H}$ NMR fingerprinting and multivariate statistical analyses for the characterisation of the geographical origin of Italian sweet cherries. Food Chemistry, 141(3), 3028-3033. 
López-Alarcón, C., Denicola, A. (2013). Evaluating the antioxidant capacity of natural products: A review on chemical and cellular-based assays. Analytica Chimica Acta, 763, 1-10.

Luthria, D., Singh, A. P., Wilson, T., Vorsa, N., Banuelos, G. S., Vinyard, B. T. (2010). Influence of conventional and organic agricultural practices on the phenolic content in eggplant pulp: plant-to-plant variation. Food Chemistry, 121(2), 406-411.

Macedo, L. F. L., Rogero, M. M., Guimaraes, J. P., Granato, D., Lobato, L. P., Castro, I. A. (2013). Effect of red wines with different in vitro antioxidant activity on oxidative stress of high-fat diet rats. Food Chemistry, 137(1), 122-129.

Mira, L., Tereza Fernandez, M., Santos, M., Rocha, R., Helena Florêncio, M., Jennings, K. R. (2002). Interactions of flavonoids with iron and copper ions: a mechanism for their antioxidant activity. Free Radical Research, 36(11), 1199-1208.

Mphahlele, R. R., Stander, M. A., Fawole, O. A., Opara, U. L. (2014). Effect of fruit maturity and growing location on the postharvest contents of flavonoids, phenolic acids, vitamin $\mathrm{C}$ and antioxidant activity of pomegranate juice (cv. Wonderful). Scientia Horticulturae, 179, 36-45.

Pellerano, R. G., Mazza, S. S., Marigliano, R. A., Marchevsky, E. J. (2008). Multielement analysis of Argentinean lemon juices by instrumental neutronic activation analysis and their classification according to geographical origin. Journal of Agricultural and Food Chemistry, 56(13), 5222-5225.

Reeve, J. R., Carpenter-Boggs, L., Reganold, J. P., York, A. L., McGourty, G., McCloskey, L. P. (2005). Soil and winegrape quality in biodynamically and organically managed vineyards. American Journal of Enology and Viticulture, 56(4), 367-376.

Saiga, A. I., Tanabe, S., Nishimura, T. (2003). Antioxidant activity of peptides obtained from porcine myofibrillar proteins by protease treatment. Journal of Agricultural and Food chemistry, 51(12), 36613667.

Savage, N. (2012). Technology: The taste of things to come. Nature, 486, S-18-S19.

Singleton, V. L., Rossi, J. A. (1965). Colorimetry of total phenolics with phosphomolybdic-phosphotungstic acid reagents. American Journal of Enology and Viticulture, 16(3), 144-158.

Sipos, L., Kovács, Z., Sági-Kiss, V., Csiki, T., Kókai, Z., Fekete, A., Héberger, K. (2012). Discrimination of mineral waters by electronic tongue, sensory evaluation and chemical analysis. Food Chemistry, 135(4), 2947-2953.

Tassoni, A., Tango, N., Ferri, M. (2013). Comparison of biogenic amine and polyphenol profiles of grape berries and wines obtained following conventional, organic and biodynamic agricultural and oenological practices. Food Chemistry, 139(1), 405-413.

Toaldo, I. M., Fogolari, O., Pimentel, G. C., de Gois, J. S., Borges, D. L., Caliari, V., Bordignon-Luiz, M. (2013). Effect of grape seeds on the polyphenol bioactive content and elemental composition by ICPMS of grape juices from Vitis labrusca L. LWT-Food Science and Technology, 53(1), 1-8.

Valavanidis, A., Vlachogianni, T., Psomas, A., Zovoili, A., Siatis, V. (2009). Polyphenolic profile and antioxidant activity of five apple cultivars grown under organic and conventional agricultural practices. International Journal of Food Science \& Technology, 44(6), 1167-1175. 
Vallverdú-Queralt, A., Medina-Remón, A., Casals-Ribes, I., Lamuela-Raventos, R. M. (2012). Is there any difference between the phenolic content of organic and conventional tomato juices?.Food Chemistry, 130(1), 222-227. 


\section{OHAPTER 4:}

\section{AUTHENTICATION OF GEOGRAPHICAL ORIGIN AND PRODUCTION MANAGEMENT SYSTEM OF PURPLE GRAPE JUICES BY PHENOLIC COMPOUNDS AND ANTIOXIDANT ACTIVITY USING CHEMOMETRICS}




\begin{abstract}
The main goal of this work was to propose an authentication model based on the phenolic composition and antioxidant/metal chelating capacities of purple grape juices produced in Brazil and in Europe in order to assess their typicality. For this purpose, organic, conventional, and biodynamic grape juices produced in Brazil ( $\mathrm{n}=65$ ) and in Europe $(n=31)$ were analyzed and different multivariate class-modeling and classification statistical techniques were employed to differentiate juices based on the geographical origin and production management system. Overall, Brazilian juices, regardless of the production management system adopted, presented higher contents of total phenolic content and flavonoids, total monomeric anthocyanins, proanthocyanidins, flavonols, flavanols, cyanidin-3-glucoside, delphinidin-3-glucoside, and malvidin-3,5-diglucoside. No differences ( $p>0.05$ ) were observed for trans-resveratrol, malvidin-3-glucoside, and pelargonidin-3-glucoside between geographical origins and among production management systems. A total of $91 \%$ of Brazilian and $97 \%$ of European juices were adroitly classified using partial least squares discriminant analysis when the producing region was considered ( $92 \%$ overall correct classification), in which the free-radical scavenging activity towards DPPH, total phenolic content, gallic acid and malvidin-3-glucoside were the variables responsible for the classification. Intraregional models based on soft independent modelling of class analogy were able to differentiate organic from conventional Brazilian juices as well as conventional and organic/biodynamic European juices.
\end{abstract}

Keywords: Anthocyanin, chemometrics, PLSDA, organic foods, flavonoids, biodynamic foods.

\title{
4.1 Introduction
}

In Brazil, organic and conventional purple grape juices from Bordeaux, Concord, Isabel, and Niágara varieties, all from Vitis labrusca, are the main grape varieties used by the industry to produce juices and are widely consumed in the regular diet, especially in the South and Southeast regions. In 2010, the Brazilian consumption of grape juices was 550 million liters, with a per capita consumption of about 3 L every year. Additionally, as compared to 2003, the marketing of grape juices in Brazil increased 1,920\% (Ibravin, 2014). Therefore, the evaluation of the beneficial chemical compounds and potential functional properties of commercial grape juices is essential to consumer's knowledge in order to provide information about their possible health benefits.

Grape juice is consumed not only due to its unique flavor but also because consumers are more aware that it represents a good and cheap source of phenolic compounds that exert beneficial health effects when consumed in the regular diet. It is common sense that purple grape juices and red wines present numerous functional properties as repeatedly demonstrated by in vitro, in vivo and ex vivo protocols, such as antioxidant activity (Park et al., 2003; Rodrigo et al., 2005; Dani et al., 2007; Macedo et al., 2013), antiproliferative properties (Jung et al., 2006), lipid profile improvement (ZibaeeNezhad et al., 2012), antigenotoxic (Dani et al., 2009a), antiatherogenic (Vinson et al., 2001), and neuroprotective effects (Rodrigues et al., 2012), among others. Concerning the functional properties, some reports state that there is a significant association between in vitro and in vivo antioxidant activity of grape-based products (Rodrigo et al., 2005; Toaldo et al., 2015). 
When commercial samples are evaluated, attention needs to be paid once there are some different types of purple grape juices marketed worldwide: concentrated, ready-to-drink and reconstituted sugar-added juices (nectars), biodynamic, Kosher, and organic juices. With respect to that, some consumers also take into account the agricultural methods (conventional or organic, for example) when purchasing their juice (Dani et al., 2007). Interestingly, no information about antioxidant and metal chelating capacities or the antioxidant substances is present on the label of most Brazilian and European grape juices, which could be differential information for consumers to decide the purchase between brands.

Research has shown that commercial grape juices produced in Brazil are rich sources of functional chemical compounds, especially phenolic materials, such as trans-resveratrol, flavanols and anthocyanins (Ishimoto et al., 2006; Dani et al., 2007; Dani et al., 2009b; Burin et al., 2010; Natividade et al., 2013; Lima et al., 2014). However, it is important to mention that these studies employed a very limited number of samples (usually less than 20 juices) in addition to the determination of a limited number of chemical markers and functional properties, thus not allowing a detailed and holistic comprehension of what consumers actually drink. Taking into account these limitations regarding the sampling and analytical parameters and knowing that grape juices have been highly marketed in Brazil and a growing demand has been noted in European countries, the objective of this study was to assess the typicality of organic, biodynamic and conventional grape juices originating from Brazil and from some European countries based on various chemical markers and antioxidant/metal chelating activities and to propose authentication models based on chemometrics to differentiate juices from 3 production management systems and 2 geographical origins.

\subsection{Material and Methods}

\subsubsection{Grape juice samples}

Authentic samples of $100 \%$ purple grape juices from Brazil $(n=65$, in which 19 are certified organic and 46 are conventional juices) collected in July-September 2013 and in Europe ( $n=31$, in which 7 are certified organic, 6 are certified biodynamic, and 18 are conventional juices), collected in January-February 2014, were investigated. The Brazilian juices were acquired in following producing states: Santa Catarina, Paraná, Rio Grande do Sul, São Paulo, Minas Gerais, Sergipe, Ceará, and Paraíba, which correspond to more than 95\% of the grape producers in Brazil. The grape juices from Europe were acquired in the following producing countries: France, Italy, United Kingdom, Netherlands, Germany, Austria, and Spain. A total of 2 grape juices produced in Turkey were also included in this group. Grape juices were brought to the laboratory, and the floating particles were removed by centrifugation $(2,700 \mathrm{rpm}, 6 \mathrm{~min})$. Then the juices were aliquoted into Eppendorff tubes and stored at $-80^{\circ} \mathrm{C}$ until analysis.

\subsubsection{Chemicals}

(-)-Epicatechin, (+)-catechin, gallic acid, rutin hydrate, quercetin dihydrate, $p$-coumaric acid, chlorogenic acid (5-O-caffeoylquinic acid), myricetin, Folin-Ciocalteu reagent, 6-hydroxy-2,5,7,8tetramethylchroman-2-carboxylic acid (Trolox), 2,4,6-tripyridyl-s-triazine (TPTZ), ferrozine (3-(2-pyridyl)5,6-di(2-furyl)-1,2,4-triazine-5',5"-disulfonic acid disodium salt), 2,2-diphenyl-1-picrylhydrazyl (DPPH), and 
neocuproine (2,9-dimethyl-1,10-phenanthroline) were purchased from Sigma-Aldrich (The Netherlands). Pelargonidin-3-O-glucoside chloride (callistephin chloride), cyanidin-3-glucoside-chloride (kuromanin chloride), malvidin-3,5-di-O-glucoside-chloride (malvin chloride), delphinidin-3-glucoside-chloride (myrtillin chloride), malvidin-3-glucoside chloride (oenin chloride), trans-resveratrol, and procyanidin primer A2 standards were obtained from Extrasynthese (France). Acetonitrile, butanol, hydrochloric acid, methanol, phosphoric acid, ethanol, acetic acid, copper (II) chloride, aluminum chloride hexahydrate, ammonium acetate, iron II chloride tetrahydrate, iron II sulphate heptahydrate, and sodium carbonate were purchased from Merck (Germany). Milli-Q water was used in the experiments.

\subsubsection{Phenolic composition}

The total phenolic content in grape juices was evaluated in triplicate using the Folin-Ciocalteu reagent (Singleton \& Rossi, 1965), with modifications to 96-well microplates. The total phenolic content in grape juices was determined by an analytical curve of gallic acid ( 0 to $150 \mathrm{mg} / \mathrm{L}$ ) (total phenolic content=130.64 $\mathrm{x}$ absorbance $-0.2083 ; \mathrm{R}^{2}=0.994, \mathrm{p}<0.0001$ ), and results were expressed as $\mathrm{mg}$ of gallic acid equivalent per liter of grape juice (mg GAE/L).

The total flavonoid content of the grape juices was determined in triplicate using the colorimetric method that employs aluminum chloride as outlined by Zhishen et al. (1999), with slight modifications. The flavonoid content was determined by an analytical curve of (+)-catechin (0 to $90 \mathrm{mg} / \mathrm{L})$ (total flavonoids $=296.89 \times$ absorbance $\left.-0.5096 ; \mathrm{R}^{2}=0.999, \mathrm{p}<0.0001\right)$ and the results were expressed as $\mathrm{mg}$ of catechin equivalent per liter of grape juice (mg CTE/L).

Total monomeric anthocyanins content was determined using the $\mathrm{pH}$ differential method (Lee et al., 2005), adopting a buffer solution at $\mathrm{pH} 1.0(\mathrm{KCl}, 0.025 \mathrm{~mol} / \mathrm{L})$ and a buffer solution at $\mathrm{pH} 4.5\left(\mathrm{CH}_{3} \mathrm{CO}_{2} \mathrm{Na}\right.$, $0.40 \mathrm{~mol} / \mathrm{L}$ ). The absorbance of each tube was measured at a wavelength of 520 and $700 \mathrm{~nm}$ against a blank (ultrapure water) using a spectrophotometer (Varian, model Cary Bio 300, USA). Results were calculated by: Total monomeric anthocyanins $(\mathrm{mg} / \mathrm{L})=[(\mathrm{A} \times \mathrm{MW} \times \mathrm{D} \times 1000)] / e \times 1$, whereby: $\mathrm{A}=\left(\mathrm{A}_{510}-\mathrm{A}_{700}\right) \mathrm{pH}_{1}-\left(\mathrm{A}_{510}\right.$ $\left.-\mathrm{A}_{700}\right) \mathrm{pH}_{4.5}, e$ is malvidin-3-glucoside molar absorbance $(28,000)$, MW is the molecular weight for malvidin3-glucoside (493.2), D is a dilution factor (30) and 1 corresponds the path length (cuvette of $1 \mathrm{~cm}$ ). The results in every assay were obtained from three replicates and expressed as mg of malvidin-3-glucoside equivalent per liter (mg M3G/L).

The content of proanthocyanidins of grape juices was assessed in triplicate by the method proposed by Porter (1989), in which proanthocyanidins are degraded to anthocyanidins by heating under extreme acidic conditions, $\mathrm{pH} 1$, provided by a mixture of $n$-butanol and $\mathrm{HCl}$ at a proportion of $3: 2(\mathrm{v} / \mathrm{v})$. For quantification purposes, an analytical curve (Proanthocyanidins $=364.61 \mathrm{x}$ absorbance $+3.16 ; \mathrm{R}^{2}=0.998 ; \mathrm{p}<0.0001$ ) was constucted using procyanidin primer A2 $(0-125 \mathrm{mg} / \mathrm{L})$ as a standard. The results were expressed as $\mathrm{mg}$ of procyanidin primer A2 equivalent per liter of juice (mg PCY/L).

The quantification of individual anthocyanins, flavonols, phenolic acids, trans-resveratrol and flavanols was performed using a high-performance liquid chromatographer (HPLC) coupled with diode array and fluorescence detectors from Agilent Technologies 1100 series equipment containing a quaternary pump 
and an automated injector. The separation was conducted using a Phenomenex Gemini C18 column and guard column at $40{ }^{\circ} \mathrm{C}$ with $150 \times 4.6 \mathrm{~mm} \times 3 \mu \mathrm{m}$ according to a method validated for grape juices (Natividade et al., 2013). For this purpose, an aliquot of $450 \mu \mathrm{L}$ of the grape juice was diluted with $900 \mu \mathrm{L}$ with a $0.85 \%$ phosphoric acid solution and filtered through a $0.45 \mu \mathrm{m}$ polyvinylidene difluoride membrane (Pall Corporation, The Netherlands) prior to injection. The mobile phase was consisted of solvent A $(0.85 \%$ phosphoric acid solution) and solvent B (acetonitrile) and both were filtered using a $0.45 \mu \mathrm{m}$ pore size membrane filter (Millipore, Ireland) prior to the analysis. The gradient elution conditions started with $100 \%$ of solvent A and adjusted for $7 \%$ of solvent B in $10 \mathrm{~min} ; 10 \%$ of solvent B in $20 \mathrm{~min} ; 12 \%$ of solvent B in $30 \mathrm{~min} ; 23 \%$ of solvent B in $40 \mathrm{~min} ; 35 \%$ of solvent B in $45 \mathrm{~min}$; and 100\% of solvent B in $55 \mathrm{~min}$. The flow rate was 0.50 $\mathrm{mL} / \mathrm{min}$ and the injection volume was $10 \mu \mathrm{L}$. The quantification of the phenolic compounds was carried out by external calibration from the areas of the chromatographic peaks obtained by UV detection at the following wavelengths: $\lambda=360 \mathrm{~nm}$ was set to rutin, quercetin, and myricetin, $\lambda=270 \mathrm{~nm}$ for gallic acid; $\lambda=320 \mathrm{~nm}$ was set to $p$-coumaric acid, chlorogenic acid, and trans-resveratrol, and $\lambda=520 \mathrm{~nm}$ for anthocyanins. The fluorescence detector was set at $\lambda_{\text {emission }}=320 \mathrm{~nm}$ and $\lambda_{\text {excitation }}=280 \mathrm{~nm}$ for identification and quantification of $(+)$-catechin and (-)-epicatechin. Stock solutions of all standards were prepared using HPLC-grade methanol and the analytical curves were obtained from duplicate injections of five evenly spaced concentrations and linearity was assessed by the ordinary least squares regression method. For the HPLC analysis, phenolic compounds were identified by comparing their retention times and UV-VIS spectra with those of pure standards, which were used as control for each analysis. Three replicates from each sample were analyzed and all the samples and standards were injected three times to obtain the averages. The limit of detection (LOD) and limit of quantification (LOQ) were calculated as the concentration giving a signal equal to 3 and 10 times, respectively, the signal/noise ratio. The regression parameters, retention times, LOD, and LOQ of all phenolic compounds measured in the current study are presented in Table 4.1. As it can be observed, the method presented low LOD and LOQ and showed to be linear (high $\mathrm{R}^{2}$ ) and highly significant ( $\mathrm{p}$-value $<0.001$ ), and data are in agreement with the results obtained by Natividade et al., (2013) for Brazilian purple grape juices. 


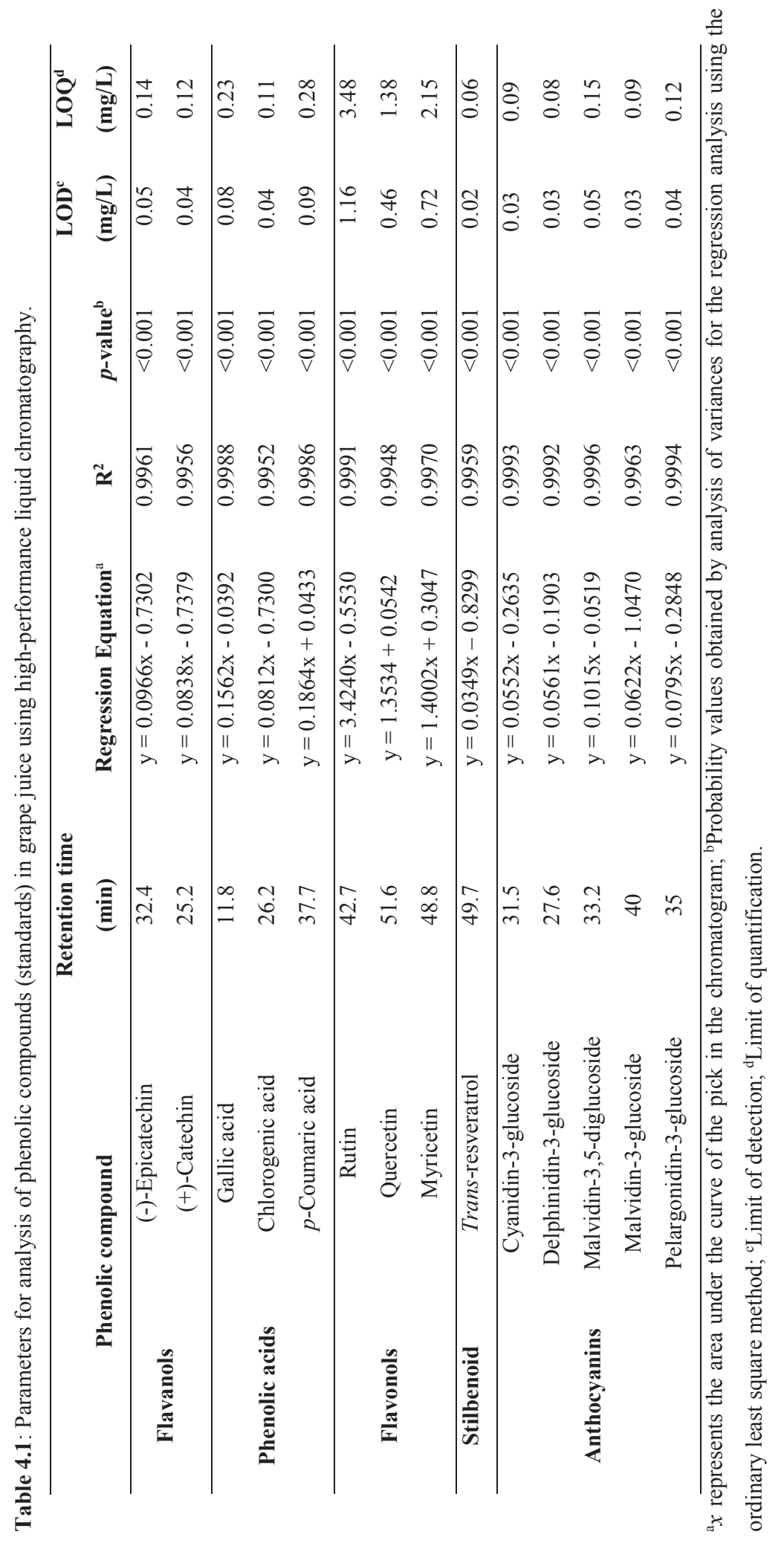




\subsubsection{Antioxidant and metal chelating capacities of grape juices}

\subsubsection{Cupric reducing antioxidant capacity (CUPRAC) assay}

The cupric reducing antioxidant activity of grape juices was assessed in triplicate by the method developed by Apak et al. (2008). Briefly, an aliquot of $100 \mu \mathrm{L}$ of diluted grape juice (1:10 v/v) was mixed with $1 \mathrm{~mL}$ each of the following reagents: $1.0 \times 10^{-2} \mathrm{~mol} / \mathrm{L} \mathrm{CuCl}_{2}$ solution, neocuproine alcoholic solution $(7.5 \times$ $10^{-3} \mathrm{~mol} / \mathrm{L}$ ) and $\mathrm{NH}_{4} \mathrm{Ac}$ buffer solution $(1 \mathrm{~mol} / \mathrm{L}, \mathrm{pH} 7.0)$ and $1 \mathrm{~mL}$ of water to make the final volume $4.1 \mathrm{~mL}$. After $30 \mathrm{~min}$, an aliquot of $250 \mu \mathrm{L}$ of each solution was placed in 96-well microplates and the absorbance was measured at a wavelength of $450 \mathrm{~nm}$ using a microplate spectrophotometer (Synergy-BIOTEK, Winooski, VT, USA). Trolox $(90-3,000 \mu \mathrm{mol} / \mathrm{L})$ was used as a standard and an analytical curve was plotted using thirteen evenly spaced concentrations (CUPRAC $=3,528.10 \mathrm{x}$ absorbance $-14.21 ; \mathrm{R}^{2}=0.997, \mathrm{p}<0.0001$ ) and results were expressed as mmol TE/L.

\subsubsection{Radical-scavenging activity toward 2,2-diphenyl-1-picrylhydrazyl (DPPH)}

The radical-scavenging activity of grape juices towards 2,2-diphenyl-1-picrylhydrazyl radical was measured in triplicate according to the method reported by Brand-Williams et al., (1995), with modifications. An aliquot of $40 \mu \mathrm{L}$ of diluted grape juice samples $(1: 45 \mathrm{v} / \mathrm{v})$ was placed in 96 -well microplates, and $260 \mu \mathrm{L}$ of a $0.10 \mathrm{mmol} / \mathrm{L}$ methanolic solution of DPPH was added. The mixture was allowed to react in the dark at $25^{\circ} \mathrm{C}$ for $30 \mathrm{~min}$ and the decrease of DPPH absorbance was measured at a wavelength of $517 \mathrm{~nm}$ by a microplate spectrophotometer (Synergy-BIOTEK, Winooski, VT, USA). Methanol was used as control and DPPH solution without test samples added with water served as the blank. The free-radical scavenging activity was calculated according to the following equation: $\% \mathrm{DPPH}$ inhibition $=\left[1-\left(\mathrm{A}_{517}\right.\right.$ sample/ $\mathrm{A}_{517}$ blank $\left.)\right] \mathrm{x}$ 100.

\subsubsection{Ferrous ion chelating capacity}

The metal chelating ability of juices was determined in triplicate by measuring the formation of the $\mathrm{Fe}^{2+}$-ferrozine complex according to the method proposed by Carter (1971), with modifications to microplates. For this purpose, to an aliquot of $50 \mu \mathrm{L}$ diluted grape juice (1:30 v/v) or water (blank), $160 \mu \mathrm{L}$ of ultrapure water and $15 \mu \mathrm{L}$ of a $0.30 \mathrm{mmol} / \mathrm{L} \mathrm{FeCl} \cdot 4 \mathrm{H}_{2} \mathrm{O}$ solution were added in a microtiter plate. After $5 \mathrm{~min}$ incubation, the reaction was initiated by adding $30 \mu \mathrm{L}$ of a $0.80 \mathrm{mmol} / \mathrm{L}$ ferrozine solution and the final mixture was incubated for $15 \mathrm{~min}$ at room temperature. Distilled water $(30 \mu \mathrm{L})$ instead of ferrozine solution was used as a blank, which is used to correct for unequal colour of the sample solutions. The absorbance was measured at $\lambda=562 \mathrm{~nm}$ and the ferrous ion chelating capacity was calculated as: Chelating rate $(\%)=\left[\left\{\left(\mathrm{A}_{\text {sample }}-\mathrm{A}_{\text {solution }}\right.\right.\right.$ without ferrozine $\left.\left.) / A_{\text {blank }}\right\}\right]$ x 100 .

\subsubsection{Statistical analysis}

Experimental data were presented as means $\pm \mathrm{SD}$. When appropriate, comparison of means among groups was carried out by one-factor analysis of variances (ANOVA) followed by post-hoc Duncan's multiple 
comparison test (all groups of juices). For this purpose, the normality and homoscedasticity of the whole data set were formally checked by the Shapiro-Wilk's and Brown-Forsythe's tests, respectively, using Statistica v.7 software (Statsoft, USA). Comparison between organic and conventional juices or Brazilian vs European juices for the same production management system was performed by Student- $t$ test or Mann-Whitney U test after checking for normality and variance consistency ( $F$-test). Box-Cox transformation was applied when data did follow a normal distribution. Correlation analysis based on the Pearson's correlation coefficient was calculated for the responses together with their statistical significance using Action v. 2.8 software (Estatcamp, Brazil). Any $p$-values below 5\% were considered statistically significant.

Because of the large quantity of data, principal component analysis (PCA), which is an exploratory multivariate statistical technique, was used to identify samples with similar chemical composition and antioxidant/metal chelating properties. For this purpose, samples were adopted as rows $(n=96)$ and analytical responses as columns $(\mathrm{n}=21)$, totalling 2,016 data points. Prior to analysis, the data set was standardized to unit variance (auto-scaling) using Chemoface software (UFLA, Brazil). PCA analysis was also conducted using the geographical origin (Brazil and Europe), the type of juice (conventional, organic, and biodynamic) as samples, as well as uniting biodynamic and organic as a singles class.

Aiming at classifying the juice samples according to the geographical origin (Brazil or Europe) or by production management system (conventional, organic, biodynamic), k-nearest neighbours (KNN), soft independent modelling of class analogy (SIMCA), and partial least squares discriminant analysis (PLSDA) were applied using Pirouette v. 4.5 software (Infometrix, USA), to estimate classification models for: $i$ ) the geographical origin of grape juice; ii) production management system iii) type of juice using only two classes (conventional and biodynamic + organic juices); iv) conventional and organic juices produced in Brazil; and v) juices produced in Europe. In these models, juices belonging to a certain class are known and the main objective is to establish implicit or explicit classification models (Özdestan et al., 2013). Prior to the analyses, data were auto-scaled to unit variance. The performance of the fitted PLSDA models was validated using the leave-one-out approach (internal validation). This procedure involves the removal of one sample in a random way from the data set, and the model is built with the remaining samples, then the removed sample is included in the model and its class membership is predicted. This process is applied until all samples are removed once (Ruiz-Sambiás et al., 2013). The best PLSDA model was redeveloped and also externally validated using the Kennard-Stone algorithm by splitting the data set into training (75\%) and validation set (25\%) and the correct classification rate (\%) of samples was calculated using Chemoface 1.5 software (UFLA, Brazil).

\subsection{Results and Discussion}

\subsubsection{Phenolic composition and antioxidant activity}

The phenolic composition of organic, biodynamic and conventional grape juices produced in Brazil and Europe are described in Table 4.2. The contents of total phenolic compounds, flavonoids, monomeric anthocyanins, and antioxidant power are in agreement with works that studied grape juices (Ishimoto et al., 2006; Dani et al., 2007; Burin et al., 2010). A statistical comparison between organic and conventional 
Brazilian juices was performed and it is possible to observe that, with exception of chlorogenic acid $(\mathrm{p}=0.01)$ and myricetin contents $(\mathrm{p}=0.01)$, the contents of phenolic compounds and antioxidant activity measured by DPPH, CUPRAC, and ferrous-ion chelating activity were similar between juices, while there was a marginal difference $(\mathrm{p}=0.08)$ between organic and conventional juices of up to $15 \%$ for total flavonoid content and $46 \%$ for delphinidin-3-glucoside $(\mathrm{p}=0.10)$. Besides statistically non-significant $(\mathrm{p}=0.48)$, the content of transresveratrol of conventional juice was, in average, $28 \%$ higher as compared to organic juice. In contrast, more remarkable differences between organic, biodynamic and conventional grape juices coming from Europe were observed for total phenolic compounds $(\mathrm{p}=0.03)$, total proanthocyanidins $(\mathrm{p}=0.03),(-)$-epicatechin $(\mathrm{p}<0.01)$, $(+)$-catechin $(\mathrm{p}<0.01)$, gallic acid $(\mathrm{p}<0.01), p$-coumaric acid $(\mathrm{p}<0.01)$, quercetin $(\mathrm{p}<0.01)$, and myricetin $(\mathrm{p}<0.01)$. 


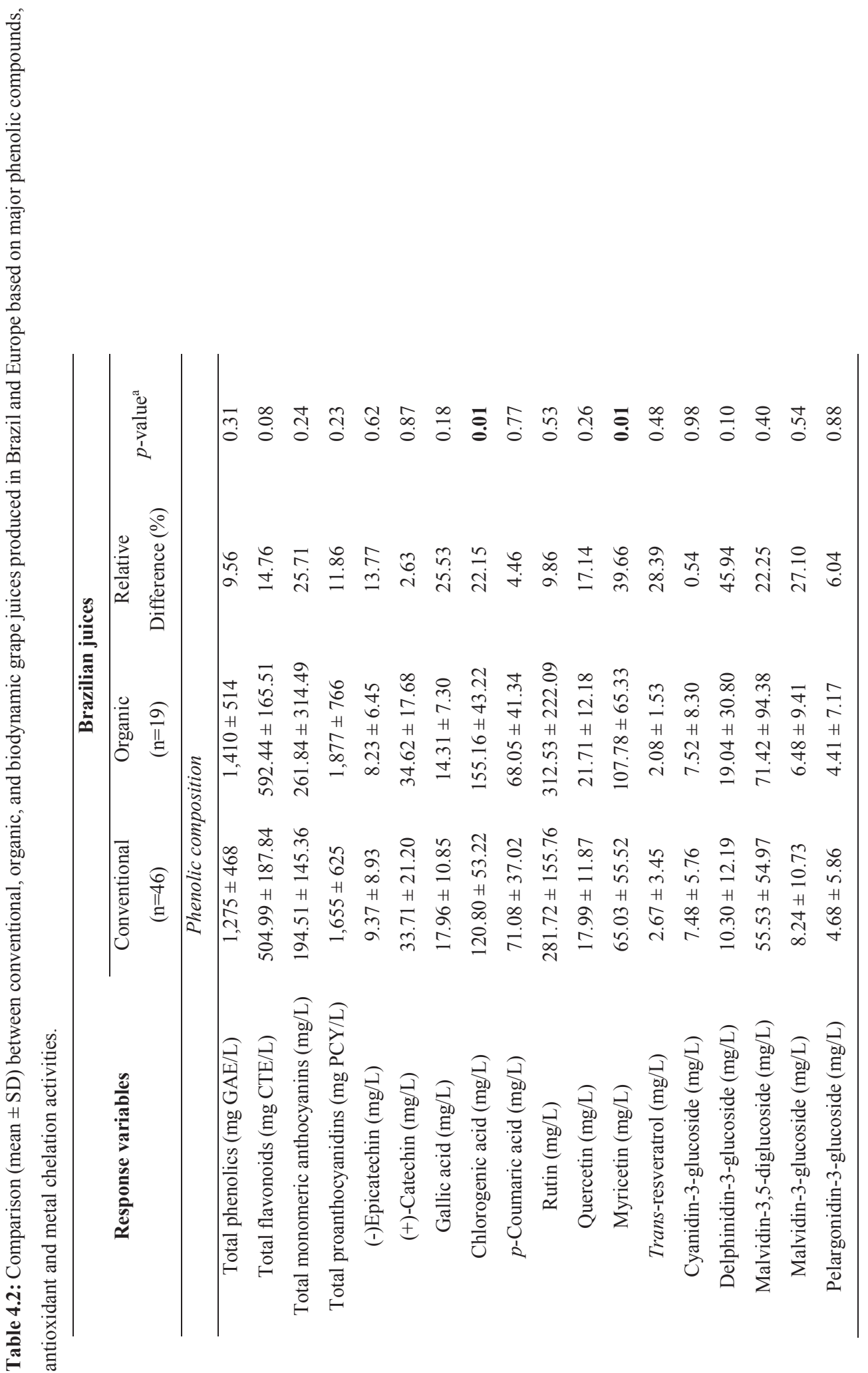




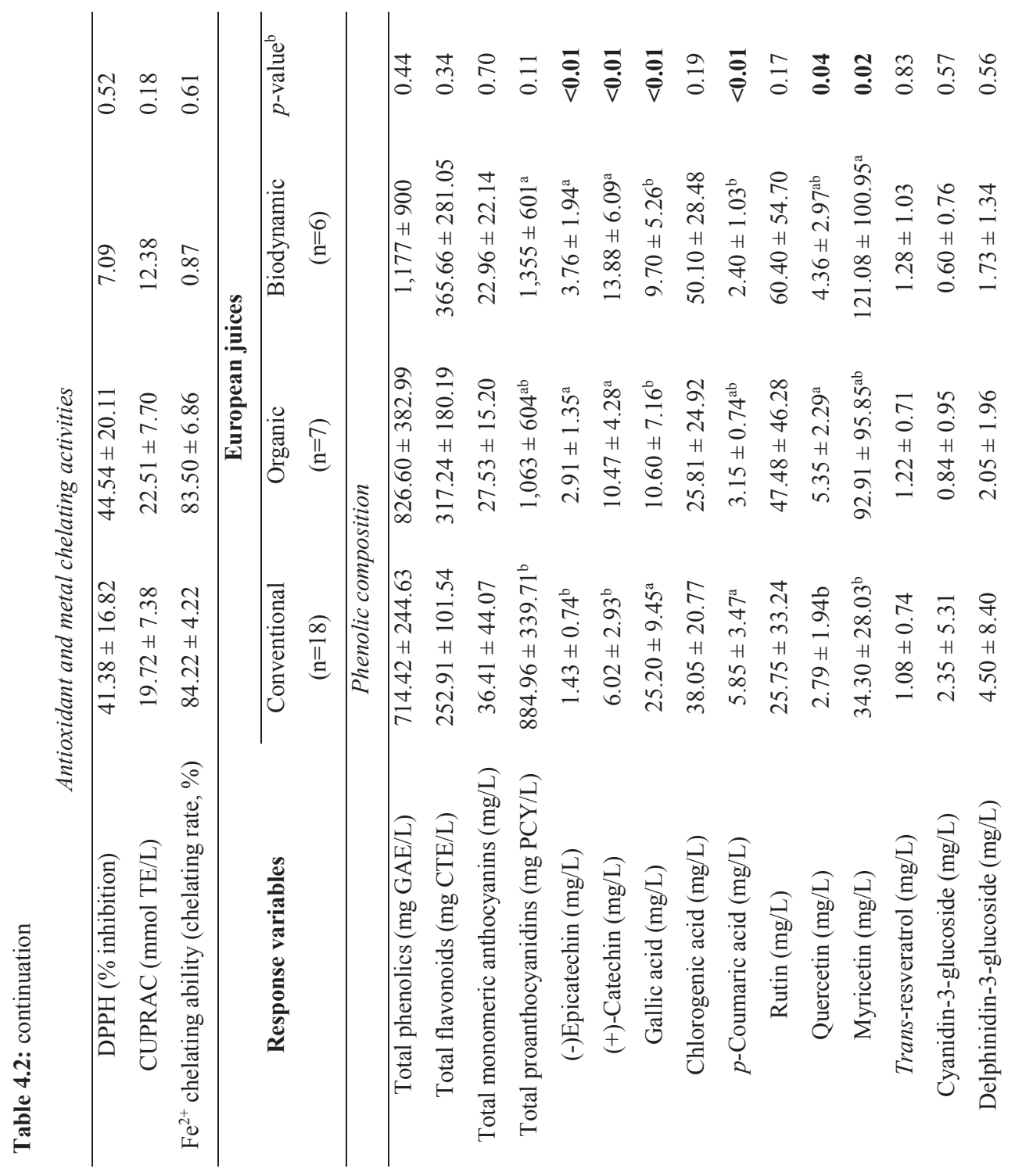




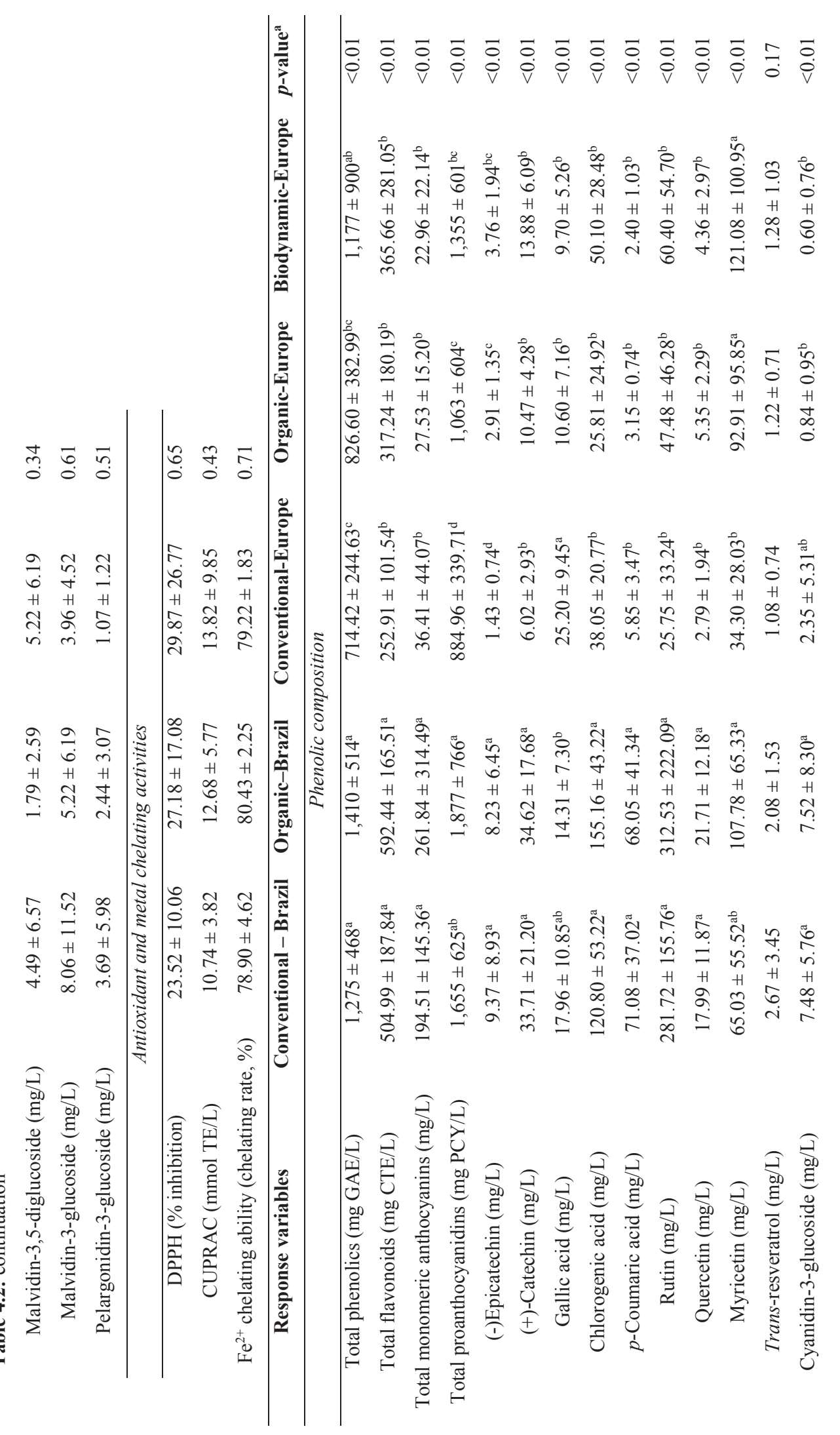




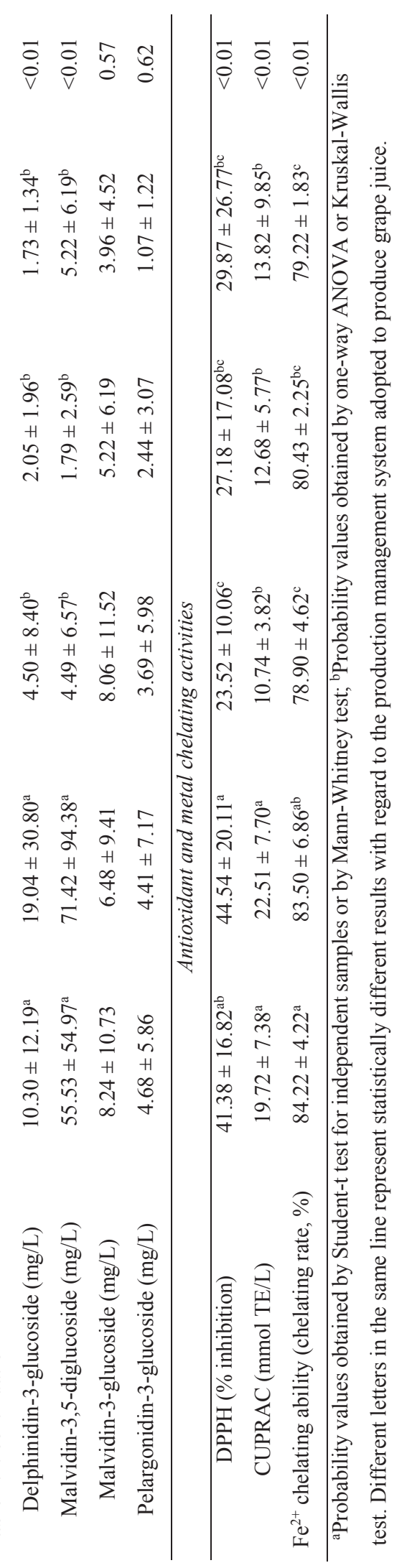


A multiple comparison among all five groups of grape juices (Brazil - organic and conventional; Europe - organic, biodynamic, and conventional) was performed and results are shown in Table 4.2. Interestingly, significant differences $(\mathrm{p}<0.01)$ were obtained for all chemical and antioxidant properties, with exception for pelargonidin-3-glucoside $(\mathrm{p}=0.62)$ and malvidin-3-glucoside $(\mathrm{p}=0.57)$. Besides statistically nonsignificant ( $\mathrm{p}=0.17$ ), the trans-resveratrol content of Brazilian grape juices was up to $200 \%$ higher than the concentration found in European juices. Overall, Brazilian juices, regardless of the production management system used to produce the grapes, presented considerably higher contents of total phenolic content, flavonoids, monomeric anthocyanins, total proanthocyanidins, flavonols (except for myricetin), flavanols, cyanidin-3-glucoside, delphinidin-3-glucoside, and malvidin-3,5-diglucoside. This trend was also observed for the antioxidant activity. Complementarily, biodynamic and organic juices produced in Europe presented similar contents of total phenolic content, proanthocyanidins, gallic acid, and the antioxidant activity (DPPH) in comparison with conventional Brazilian juices. Additionally, the combined effect of geographical origin and management cultivation system was only significant for gallic acid $(\mathrm{p}=0.030)$ and chlorogenic acid $(\mathrm{p}=0.045)$.

There is no scientific consensus regarding the correlation between chemical composition and antioxidant activity of various vegetables cultivated under conventional, organic, or biodynamic production management systems. For example, Dani et al. (2007) evaluated the chemical composition and antioxidant capacity of $V$. labrusca grape juices ( $\mathrm{n}=4$ organic and $\mathrm{n}=4$ conventional) produced in Brazil and verified that organic juices presented a higher concentration of total phenolic content, trans-resveratrol, total anthocyanins, and free-radical scavenging activity toward DPPH and superoxide dismutase-like activity as compared to conventional grape juices. Similrly, Vrček et al. (2011) analyzed the phenolic composition and antioxidant activity measured by the DPPH and ABTS methods of organic and conventional Croatian wines and verified that organic wines presented higher antioxidant capacity and higher contents of chlorogenic acid, ferulic acid, (+)-catechin, trans-resveratrol, hydroxybenzoic acids and flavonols. Conversely, Mulero et al. (2010) evaluated the polyphenolic composition and antioxidant activity of Monastrell ( $V$. vinifera) grape berry and wine (both organic and conventional) and verified no correlation between production management system, antioxidant level and phenolic composition.

A high repeatability (coefficient of variation $<8 \%$ ) was attained for all assays (data not shown), however, a high variation in commercial grape juices could be observed, as the standard deviation was relatively high for most responses. This can be explained once the sample set was compromised by artisanal and industrially-processed grape juices marketed in different locations, grape varieties, and production management systems. Additionally, it is important to note that Brazilian grape juices are basically made of Vitis labrusca and American hybrid grapes, such as Bordeaux, Concord, Niagara, and Isabel varieties, while European grape juices are usually made of Cabernet Sauvignon and Merlot ( $V$. vinifera), or blends with Concord ( $V$. labrusca) and Muscadine ( . rotundifolia) grapes. Therefore, if the technological process adopted by the producers, the differences within varieties, and the terroir used to cultivate the grapes are taken into consideration, differences in results were expected and seem reasonable (Lima et al., 2014; Natividade et al., 2013). 
In this work, three assays were used to estimate the in vitro antioxidant activity of grape juices: free radical-scavenging of DPPH, cupric reducing antioxidant activity, and ferrous-ion chelating activity. The first one is related to the electron transfer, specifically electron transfer from the antioxidant pool to the free radical that may initiate the peroxidation in cells (Dawidowicz \& Olszowy, 2012), whereas CUPRAC is associated to the ability of an extract to reduce substances by electron transfer, at a physiological $\mathrm{pH}$. In summary, phenolic compounds $(\mathrm{PhOH})$ decrease the lipid oxidation in cells by donating electrons $(\mathrm{H})$ to reactive species $\mathrm{ROO}^{*}+$ $\mathrm{PhOH} \rightarrow \mathrm{ROOH}+\mathrm{PhO}^{*}$, creating intermediate phenolic radicals $\left(\mathrm{PhO}^{*}\right)$ that are much more stable at physiological conditions. Ferrous-ion chelating ability is associated to binding transition metal ions in a way they become unable to generate reactive species, especially hydroxyl radicals, via Fenton reaction $\left(\mathrm{H}_{2} \mathrm{O}_{2}+\right.$ $\mathrm{Fe}^{2+} \rightarrow \mathrm{Fe}^{3+} \mathrm{OH}^{-}+\mathrm{OH}^{-}$) or by decomposing lipid peroxides into peroxyl and alkoxyl radicals that accelerate lipid peroxidation at different levels in many organs (Brewer, 2011). In our study, CUPRAC and DPPH data were highly correlated $(\mathrm{r}=0.898, \mathrm{p}<0.01)$, while ferrous-ion chelating ability was also significantly correlated to CUPRAC $(\mathrm{r}=0.513)$ and DPPH $(\mathrm{r}=0.453)$.

In this aspect, it is essential to understand how the antioxidant activity of a food matrix, in our case the grape juice, is linked to the chemical composition. For this purpose, correlation analysis was applied and results are summarized in Table 4.3. Some of the phenolic compounds that displayed a significant correlation $(\mathrm{p}<0.001)$ with DPPH and CUPRAC assays were: $p$-coumaric acid $(\mathrm{r}=0.577 ; \mathrm{r}=0.567)$, gallic acid $(\mathrm{r}=0.335$; $\mathrm{r}=0.375)$, chlorogenic acid $(\mathrm{r}=0.691 ; \mathrm{r}=0.766)$, rutin $(\mathrm{r}=0.855 ; \mathrm{r}=0.848)$, quercetin $(\mathrm{r}=0.694 ; \mathrm{r}=0.725)$, myricetin $(\mathrm{r}=0.352 ; \mathrm{r}=0.465)$, cyanidin-3-glucoside $(\mathrm{r}=0.612 ; \mathrm{r}=0.694)$, delphinidin-3-glucoside $(\mathrm{r}=0.640$; $\mathrm{r}=0.710)$, and malvidin-3,5-diglucoside $(\mathrm{r}=0.685 ; \mathrm{r}=0.679)$. (+)-Catechin and (-)-epicatechin also were correlated to DPPH $(r=0.466 ; \mathrm{r}=0.492)$ and CUPRAC $(\mathrm{r}=0.472 ; \mathrm{r}=0.540)$. The ferrous-ion chelating activity of grape juices correlated $(\mathrm{p}<0.05)$ significantly (besides intermediate-low $r$-values) with $p$-coumaric acid $(\mathrm{r}=0.493)$, chlorogenic acid ( $\mathrm{r}=0.483)$, cyanidin-3-glucoside $(\mathrm{r}=0.533)$, delphinidin-3-glucoside $(\mathrm{r}=0.378)$, malvidin-3,5-diglucoside $(\mathrm{r}=0.470)$, quercetin $(\mathrm{r}=0.486)$, rutin $(\mathrm{r}=0.532),(+)$-catechin $(\mathrm{r}=0.342)$, and $(-)$ epicatechin ( $\mathrm{r}=0.367)$. Trans-resveratrol correlated $(\mathrm{p}<0.01)$ with DPPH $(\mathrm{r}=0.499)$, CUPRAC $(\mathrm{r}=0.527)$, and less effectively with ferrous-ion chelating activity $(\mathrm{r}=0.251, \mathrm{p}=0.01)$. In a recent study conducted by Lima et al. (2014), authors analyzed the chemical composition and the antioxidant capacity (DPPH and ABTS) of $n=6$ Brazilian V. labrusca juices and verified a significant correlation with rutin, myricetin, gallic acid, $p$-coumaric acid, pelargonidin-3-glucoside, cyanidin-3-glucoside and delphinidin-3-glucoside, while no correlation ( $>0.05$ ) was found between in vitro antioxidant capacity and the content of trans-resveratrol, malvidin-3,5glucoside, and (-)-epicatechin. 
Table 4.3: Correlation matrix among antioxidant activity and phenolic composition of European and Brazilian grape juices.

\begin{tabular}{cccc}
\hline Response variables & DPPH & CUPRAC & $\begin{array}{c}\text { Ferrous-ion chelating } \\
\text { ability }\end{array}$ \\
\hline Total phenolic content & 0.913 & 0.943 & 0.468 \\
Total flavonoids & 0.882 & 0.955 & 0.531 \\
Total monomeric anthocyanins & 0.731 & 0.739 & 0.508 \\
Total proanthocyanidins & 0.843 & 0.904 & 0.556 \\
DPPH & 1.000 & 0.898 & 0.453 \\
CUPRAC & 0.898 & 1.000 & 0.513 \\
Ferrous-ion chelating ability & 0.453 & 0.513 & 1.000 \\
Trans-resveratrol & 0.499 & 0.527 & $0.251^{\mathrm{a}}$ \\
Gallic acid & 0.335 & 0.375 & $0.224^{\mathrm{c}}$ \\
Chlorogenic acid & 0.691 & 0.766 & 0.483 \\
p-Coumaric acid & 0.557 & 0.567 & 0.493 \\
(-)Epicatechin & 0.492 & 0.540 & 0.367 \\
(+)-Catechin & 0.466 & 0.472 & 0.342 \\
Rutin & 0.855 & 0.848 & 0.532 \\
Quercetin & 0.694 & 0.725 & 0.487 \\
Myricetin & 0.352 & 0.465 & $0.266^{\mathrm{a}}$ \\
Cyanidin-3-glucoside & 0.612 & 0.694 & 0.533 \\
Delphinidin-3-glucoside & 0.640 & 0.710 & 0.378 \\
Malvidin-3,5-diglucoside & 0.685 & 0.679 & 0.470 \\
Malvidin-3-glucoside & $0.229^{\mathrm{b}}$ & $0.236^{\mathrm{b}}$ & $0.242^{\mathrm{b}}$ \\
Pelargonidin-3-glucoside & $0.213^{\mathrm{c}}$ & $0.239^{\mathrm{b}}$ & $0.271^{\mathrm{a}}$ \\
\hline
\end{tabular}

All correlation coefficients are statistically significant at $\mathrm{p}<0.01$, with exception for: ${ }^{\mathrm{a}} \mathrm{p}=0.01,{ }^{\mathrm{b}} \mathrm{p}=0.02$, and ${ }^{\mathrm{c}} \mathrm{p}=0.03$.

Although data for the in vitro antioxidant activity and metal chelation capacity of Brazilian organic and conventional juices as well as European biodynamic juices suggest they are better options as compared to the other juice groups, generalization of what is the best type of juice should be pondered. As well outlined by Forman et al. (2014), quenching free radicals using in vitro methods does not necessarily translate into having antioxidant properties in vivo, once many factors such as the concentration and solubility of antioxidants, bioavailability, location of free radical (eletrophiles) production, and where the antioxidants are more prone to be in cells/tissues are major factors in limiting in vivo effectiveness. However, experimental research with grape-based products, such as juice, white, rose, and red wines as well as with other fruit juices has shown a positive and significant correlation between in vitro and in vivo protocols. For example, it has been shown that the higher the concentration of antioxidants in the matrix, the higher the protection against lipid peroxidation reactions in the blood and higher plasma antioxidant activity of rats fed with papaya juice (Mehdipour et al., 2006), and a negative correlation was observed between total phenolic content and lipid peroxidation products in kidneys, liver and lungs of rats treated with chronic wine consumption (Rodrigo et al., 2005). Likewise, a recent study conducted by Macedo et al. (2013) has shown that in vitro antioxidant activity of red wines (ORAC, DPPH) was positively correlated $(\mathrm{r}=0.49, \mathrm{p}=0.01)$ to the antioxidant capacity in plasma of rats treated 
with red wines containing increasing in vitro antioxidant capacity. Additionally, not only the lipid peroxidation level is decreased in plasma and brain and the plasma antioxidant activity is increased in diabetic-induced rats, but also the endogenous antioxidant defense is boosted by the ingestion of phenolic compounds from jaboticaba (Myrciaria jaboticaba), a grape-like Brazilian berry (Alejandro et al., 2013).

\subsubsection{Multivariate statistical analysis}

When many chemical markers and other quality traits from a large number of juices are assessed, the use of exploratory chemometrics tools, such as principal component analysis and clustering methods aids in the identification of similarities among samples and also facilitates the visualization of intrinsic characteristics of groups of juices simultaneously (Salvatore et al., 2013). Principal component analysis was applied to study the data structure and to look for trends in the experimental data (Figure 4.1). From Figure 4.1A, it is possible to observe that when all groups of juices are evaluated, no clear separation is observed, but higher levels of $(+)$-catechin, (-)-epicatechin, $p$-coumaric acid, myricetin, chlorogenic acid, and quercetin are observed for Brazilian juices. In Figure 4.1B, when the three production management systems are analyzed regardless of the producing region, no accurate inferences can be made for conventional and organic juices. Conversely, in Figure 4.1C it is possible to observe a more accurate and clear separation between Brazilian and European juices, regardless of the production management system. 


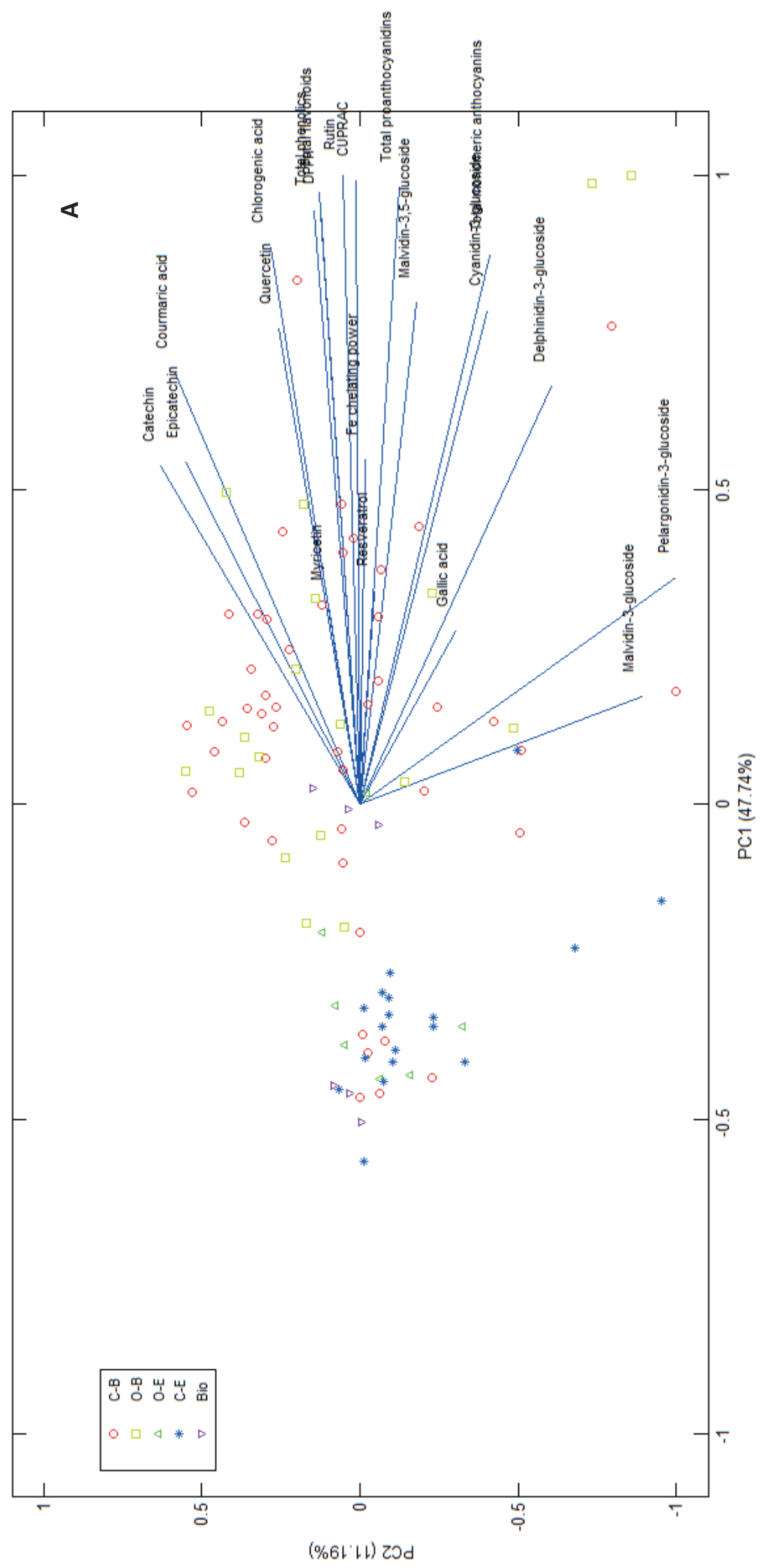




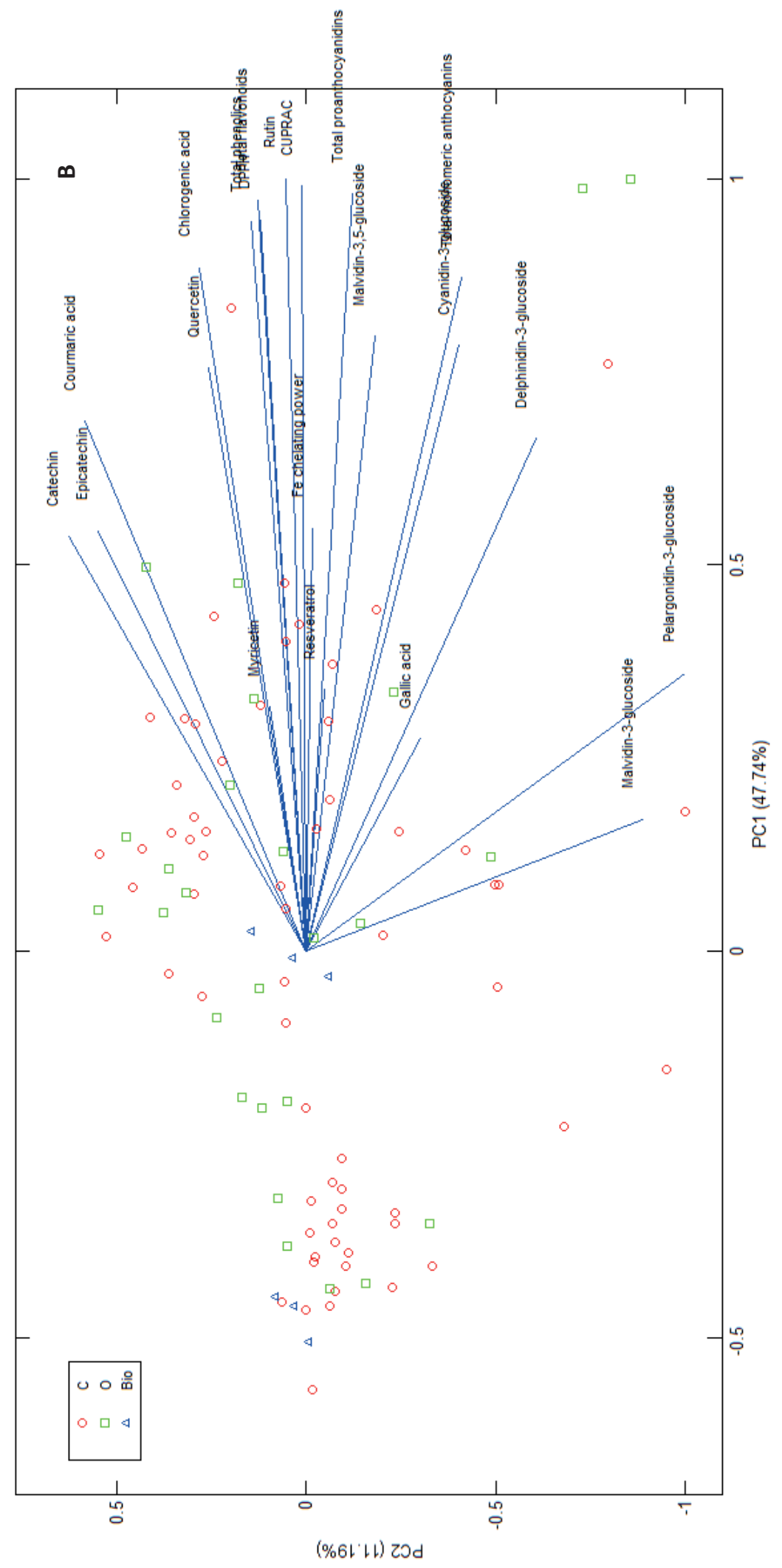

$\stackrel{\circ}{\circ}$ 


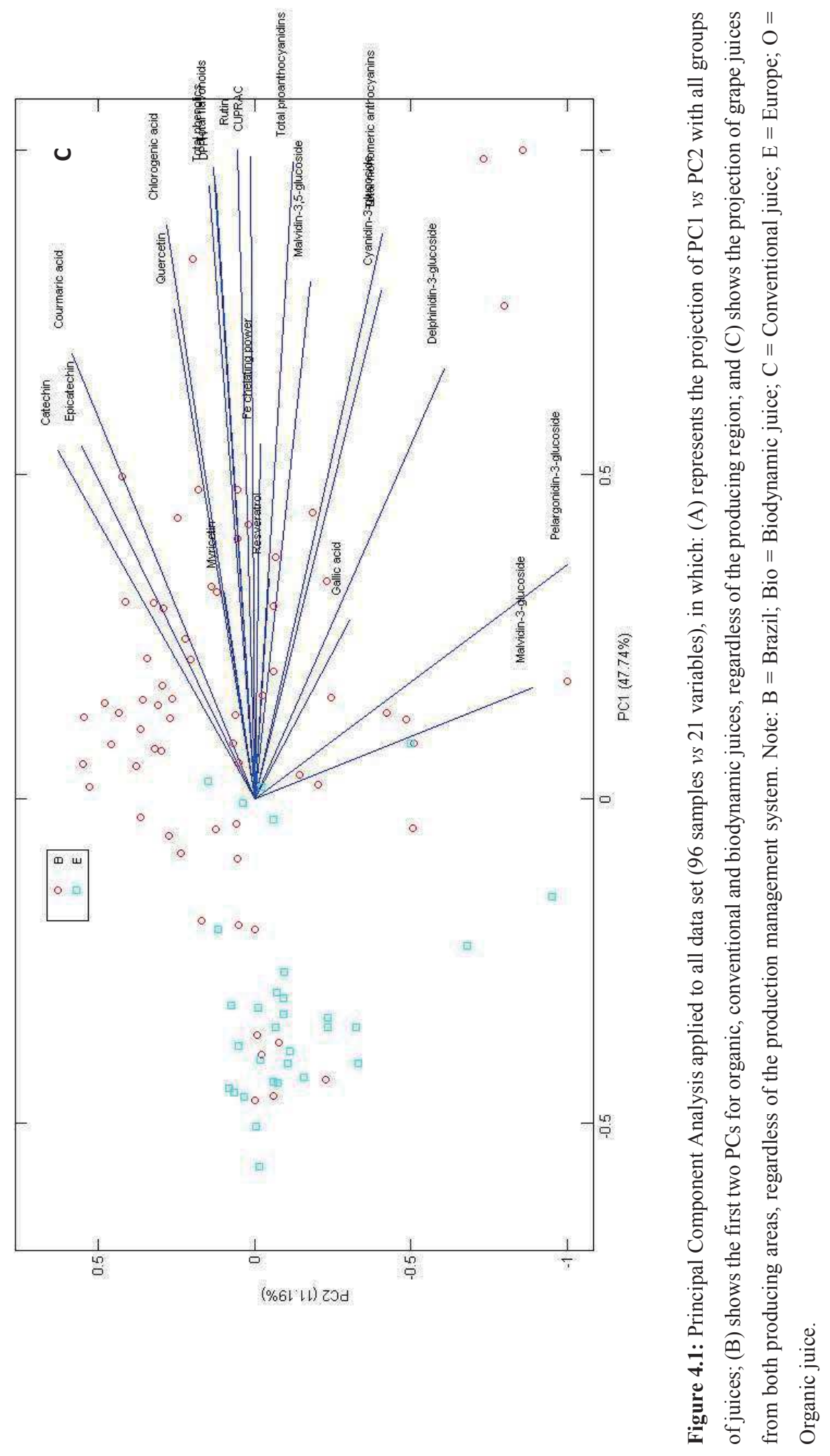


Besides being attractive, PCA cannot be considered a classification method, as it is an unsupervised multivariate statistical technique. For this reason, KNN, SIMCA, and PLSDA, which are supervised multivariate statistical methods, were used to further investigate the possible classification of juices based on different parameters and to assess which variables are responsible for such differentiation and results are presented in Table 4.4. With respect to the classification models using supervised statistical techniques, PLSDA differentiated $91 \%$ and $97 \%$ of the Brazilian and European grape juice samples ( $92 \%$ overall correct classification), in which the free-radical scavenging activity toward DPPH, total phenolic content, gallic acid and malvidin-3-glucoside were the variables responsible for the classification (higher discriminant power). Complementarily, this model was externally validated using the Kennard-Stone algorithm and a total of $88 \%$ of samples were correctly classified, demonstrating that PLSDA was efficient in classifying grape juices from Brazil and Europe based on chemical markers and antioxidant activity.

Table 4.4: Results for the classification of samples based on different parameters: producing region regardless of the production management system; classification of type of juices (biodynamic, organic, and conventional juice) regardless of the producing region; classification of all types of juices with their respective geographical origin and production management system; and classification performed by uniting biodynamic and organic juices as compared to conventional ones.

Correct classification

$\begin{array}{lll}\text { Chemometric techniques } & \text { Properties } & \text { Parameter of analysis }\end{array}$

\begin{tabular}{|c|c|c|c|}
\hline \multirow{2}{*}{ K-nearest neighbour (KNN) } & \multirow{2}{*}{$\mathrm{k}=2$} & Brazil $(n=65)$ & 97 \\
\hline & & Europe $(\mathrm{n}=31)$ & 84 \\
\hline \multirow{2}{*}{$\begin{array}{l}\text { Soft Independent Modelling of } \\
\text { Class Analogy (SIMCA) }\end{array}$} & \multirow{2}{*}{2 factors } & Brazil $(n=65)$ & 100 \\
\hline & & Europe $(\mathrm{n}=31)$ & 77 \\
\hline Partial Least Squares & 2 latent & Brazil $(n=65)$ & 91 \\
\hline \multirow[t]{2}{*}{ Discriminant Analysis (PLS-DA) } & variables & Europe $(\mathrm{n}=31)$ & 97 \\
\hline & \multirow{3}{*}{$\mathrm{k}=3$} & Conventional $(\mathrm{n}=64)$ & 91 \\
\hline \multirow[t]{2}{*}{ K-nearest neighbour (KNN) } & & Organic $(n=26)$ & 12 \\
\hline & & Biodynamic $(n=6)$ & 67 \\
\hline \multirow{3}{*}{$\begin{array}{l}\text { Soft Independent Modelling of } \\
\text { Class Analogy (SIMCA) }\end{array}$} & 3 factors & Conventional $(\mathrm{n}=64)$ & 69 \\
\hline & 4 factors & Organic $(n=26)$ & 92 \\
\hline & 1 factors & Biodynamic $(n=6)$ & 33 \\
\hline \multirow{3}{*}{$\begin{array}{c}\text { Partial Least Squares } \\
\text { Discriminant Analysis (PLS-DA) }\end{array}$} & \multirow{3}{*}{$\begin{array}{l}1 \text { latent } \\
\text { variable }\end{array}$} & Conventional $(\mathrm{n}=64)$ & 92 \\
\hline & & Organic $(n=26)$ & 32 \\
\hline & & Biodynamic $(n=6)$ & 0 \\
\hline
\end{tabular}


Table 4.4: continuation

K-nearest neighbour (KNN) $\quad \mathrm{k}=6$

Soft Independent Modelling of

Class Analogy (SIMCA)

Class Analogy (SIMCA)

Partial Least Squares

Discriminant Analysis (PLS-DA) variable
Organic - Brazil $(n=19) \quad 1$

Organic - Europe $(\mathrm{n}=7) \quad 0$

Conventional - Europe $(\mathrm{n}=18) \quad 89$

Biodynamic - Europe $(\mathrm{n}=6) \quad 50$

2 factors Conventional - Brazil $(n=46) \quad 74$

3 factors Organic - Brazil $(\mathrm{n}=19) \quad 89$

2 factors Organic - Europe $(\mathrm{n}=7) \quad 43$

3 factors Conventional - Europe $(\mathrm{n}=18) \quad 83$

1 factor Biodynamic - Europe $(\mathrm{n}=6) \quad 50$

Conventional - Brazil $(\mathrm{n}=46) \quad 70$

Organic - Brazil $(\mathrm{n}=19) \quad 26$

Organic - Europe $(\mathrm{n}=7) \quad 0$

Conventional - Europe $(\mathrm{n}=18) \quad 89$

Biodynamic - Europe $(\mathrm{n}=6) \quad 0$

Conventional $(\mathrm{n}=64)$

Organic/Biodynamic $(\mathrm{n}=32) \quad 84$

Conventional $(\mathrm{n}=64)$

Organic/Biodynamic $(\mathrm{n}=32) \quad 84$

Conventional $(\mathrm{n}=64)$

Discriminant Analysis (PLS-DA) variable $\quad$ Organic/Biodynamic $(n=32) \quad 31$

Intraregional models

\section{Brazilian samples}

\begin{tabular}{cccc}
\hline K-nearest neighbour (KNN) & $\mathrm{k}=2$ & Organic $(\mathrm{n}=19)$ & 37 \\
& & Conventional $(\mathrm{n}=46)$ & 80 \\
Soft Independent Modelling of & \multirow{2}{*}{ factors } & Organic $(\mathrm{n}=19)$ & 89 \\
Class Analogy (SIMCA) & & Conventional $(\mathrm{n}=46)$ & 78 \\
Partial Least Squares Discriminant & 1 latent & Organic $(\mathrm{n}=19)$ & 37 \\
Analysis (PLS-DA) & variable & Conventional $(\mathrm{n}=46)$ & 89 \\
\hline
\end{tabular}

\section{European samples}

K-nearest neighbour $(\mathrm{KNN}) \quad \mathrm{k}=3$

Soft Independent Modelling of

Class Analogy (SIMCA)
3 factors
94

Conventional $(\mathrm{n}=18)$

77

Organic/Biodynamic $(\mathrm{n}=13)$

Conventional $(\mathrm{n}=18)$ 
Table 4.4: continuation

$\begin{array}{cccc}\text { Partial Least Squares Discriminant } & 1 \text { latent } & \text { Organic/Biodynamic }(\mathrm{n}=13) & 54 \\ \text { Analysis (PLS-DA) } & \text { variable } & \text { Conventional }(\mathrm{n}=18) & 100\end{array}$

On the other hand, no supervised statistical method was efficient in differentiating organic and biodynamic juices, regardless of the place of origin. Once organic and biodynamic presented very similar properties (chemical compounds and bioactivity), they were then combined in one class (organic/biodynamic) and chemometrics models were redeveloped. KNN was able to differentiate juices with $84 \%$ (conventional) and 91\% (organic/biodynamic) correct classification, respectively, in which the content of trans-resveratrol, gallic acid, and pelargonidin-3-glucoside were the chemical markers that contributed more pronouncedly to the differentiation among classes. These data altogether demonstrate that organic and biodynamic purple grape juice present very similar chemical composition (phenolic compounds), antioxidant and metal chelating capacities.

When the place of origin and production management system were analyzed simultaneously, only conventional and organic juices from Brazil (74\% and $89 \%$ correct classification, respectively) and conventional European juices (83\% correct classification) were correctly differentiated using SIMCA, in which p-coumaric acid, malvidin-3-glucoside, and total monomeric anthocyanins were the chemical compounds that presented highest discriminant power. This result shows the importance of grape juice pigments (anthocyanins) in the differentiation of samples from different producing locations and farming systems. Similarly, Llobodanin et al. (2014) quantified the total phenolic content, total monomeric anthocyanins, antioxidant activity (DPPH, ORAC), and instrumental color of 666 red wines from Argentina, Brazil, Chile, and Uruguay and proposed a multivariate unsupervised classification based on PCA and cluster analysis and verified that wines with higher antioxidant activity presented higher total phenolic content, total monomeric anthocyanins, delphinidin-3-glucoside, malvidin-3-glucoside, and cyanidin-3-glucoside, among other compounds.

To obtain authentication models for individual producing region (either Brazil or European countries), SIMCA, KNN, and PLSDA models were constructed and results seem to be more accurate and classification results were more consistent (Table 4.4). Regarding the Brazilian juices, SIMCA was the best tool to separate organic from conventional samples, with $89 \%$ and $78 \%$ of correct classification, in which the content of transresveratrol, gallic acid, and pelargonidin-3-glucoside presented the highest discriminant power. For European juices, SIMCA classified $100 \%$ and $94 \%$ of organic/biodynamic and conventional juices classes and the contents of cyanidin-3-glucoside, malvidin-3-glucoside, and delphinidin-3-glucoside were the factors affecting the differentiation between classes.

As a conclusion, significant differences were obtained in chemical composition and antioxidant activity among biodynamic, conventional and organic grape juices from Brazil and Europe, except for transresveratrol, malvidin-3-glucoside, and pelargonidin-3-glucoside. Overall, Brazilian juices, regardless of the production management system used to produce the grapes, presented higher total phenolic content, flavonoids, anthocyanins, proanthocyanidins, flavonols (except for myricetin), flavanols, cyanidin-3- 
glucoside, delphinidin-3-glucoside, and malvidin-3,5-diglucoside. Chemometric tools (supervised statistical methods) were successfully used to classify purple grape juices based on chemical composition and antioxidant activity, specifically PLSDA by classifying Brazilian and European juices (interregional models), KNN in differentiating European conventional and organic/biodynamic samples, and SIMCA in differentiating juices cultivated under different production management systems from the same growing region (intraregional models).

\subsection{References}

Alezandro, M. R., Granato, D., Genovese, M. I. (2013). Jaboticaba (Myrciaria jaboticaba (Vell.) Berg), a Brazilian grape-like fruit, improves Plasma lipid profile in streptozotocin-mediated oxidative stress in diabetic rats. Food Research international, 54(1), 650-659.

Apak, R., Güclü, K., Özyürek, M., Celik, S. E. (2008). Mechanism of antioxidant capacity assays and the CUPRAC (cupric ion reducing antioxidant capacity) assay. Microchimica Acta, 160(4), 413-419.

Brand-Williams, W., Cuvelier, M. E., Berset, C. L. W. T. (1995). Use of a free radical method to evaluate antioxidant activity. LWT-Food Science and Technology, 28(1), 25-30.

Brewer, M. S. (2011). Natural antioxidants: sources, compounds, mechanisms of action, and potential applications. Comprehensive Reviews in Food Science and Food Safety, 10(4), 221-247.

Burin, V. M., Falcão, L. D., Gonzaga, L. V., Fett, R., Rosier, J. P., Bordignon-Luiz, M. T. (2010). Colour, phenolic content and antioxidant activity of grape juice. Food Science and Technology (Campinas), 30(4), 1027-1032.

Carter, P. (1971). Spectrophotometric determination of serum iron at the submicrogram level with a new reagent (ferrozine). Analytical Biochemistry, 40(2), 450-458.

Dani, C., Oliboni, L. S., Umezu, F. M., Pasquali, M. A., Salvador, M., Moreira, J. C. F., Henriques, J. A. P. (2009). Antioxidant and antigenotoxic activities of purple grape juice—organic and conventional—in adult rats. Journal of medicinal food, 12(5), 1111-1118.

Dawidowicz, A. L., Olszowy, M. (2012). Mechanism change in estimating of antioxidant activity of phenolic compounds. Talanta, 97, 312-317.

Dani, C., Oliboni, L. S., Vanderlinde, R., Bonatto, D., Salvador, M., Henriques, J. A. P. (2007). Phenolic content and antioxidant activities of white and purple juices manufactured with organically-or conventionally-produced grapes. Food and Chemical Toxicology, 45(12), 2574-2580.

Dani, C., Oliboni, L. S., Vanderlinde, R., Pra, D., Dias, J. F., Yoneama, M. L., Bonatto, D., Salvador, M., Henriques, J. A. (2009). Antioxidant activity and phenolic and mineral content of rose grape juice. Journal of Medicinal Food, 12(1), 188-192.

Forman, H. J., Davies, K. J., Ursini, F. (2014). How do nutritional antioxidants really work: nucleophilic tone and para-hormesis versus free radical scavenging in vivo. Free Radical Biology and Medicine, 66, 2435.

Ibravin. (2014). Instituto Brasileiro do Vinho. Estatísticas. Available at: http://www.ibravin.org.br/dadosestatisticos. Access on: 8 Feb. 2014. 
Ishimoto, E. Y., Ferrari, C. K., Bastos, D. H., Torres, E. A. (2006). In vitro antioxidant activity of Brazilian wines and grape juices. Journal of Wine Research, 17(2), 107-115.

Jung, K. J., Wallig, M. A., Singletary, K. W. (2006). Purple grape juice inhibits 7, 12-dimethylbenz [a] anthracene (DMBA)-induced rat mammary tumorigenesis and in vivo DMBA-DNA adduct formation. Cancer letters, 233(2), 279-288.

Lee, J., Durst, R. W., Wrolstad, R. E. (2005). Determination of total monomeric anthocyanin pigment content of fruit juices, beverages, natural colorants, and wines by the $\mathrm{pH}$ differential method: collaborative study. Journal of AOAC International, 88(5), 1269-1278.

Lima, M., Silani, I., Toaldo, I. M., Corrêa, L., Biasoto, A., Pereira, G., Bordignon-Luiz M. T., Ninow, J. L. (2014). Phenolic compounds, organic acids, and antioxidant activity of grape juices produced from new Brazilian varieties planted in the Northeast region of Brazil. Food Chemistry, 161, 94-103.

Llobodanin, L. G., Barroso, L. P., Castro, I. A. (2014). Prediction of the functionality of young South American red wines based on chemical parameters. Australian Journal of Grape and Wine Research, 20(1), 1524.

Macedo, L. F. L., Rogero, M. M., Guimaraes, J. P., Granato, D., Lobato, L. P., Castro, I. A. (2013). Effect of red wines with different in vitro antioxidant activity on oxidative stress of high-fat diet rats. Food Chemistry, 137(1), 122-129.

Mehdipour, S., Yasa, N., Dehghan, G., Khorasani, R., Mohammadirad, A., Rahimi, R., Abdollahi, M. (2006). Antioxidant potentials of Iranian Carica papaya juice in vitro and in vivo are comparable to $\alpha$ tocopherol. Phytotherapy Research, 20(7), 591-594.

Mulero, J., Pardo, F., Zafrilla, P. (2010). Antioxidant activity and phenolic composition of organic and conventional grapes and wines. Journal of Food Composition and Analysis, 23(6), 569-574.

Natividade, M. M. P., Corrêa, L. C., de Souza, S. V. C., Pereira, G. E., de Oliveira Lima, L. C. (2013). Simultaneous analysis of 25 phenolic compounds in grape juice for HPLC: Method validation and characterization of São Francisco Valley samples. Microchemical Journal, 110, 665-674.

Özdestan, Ö., van Ruth, S. M., Alewijn, M., Koot, A., Romano, A., Cappellin, L., Biasioli, F. (2013). Differentiation of specialty coffees by proton transfer reaction-mass spectrometry. Food Research International, 53(1), 433-439.

Park, Y. K., Park, E., Kim, J. S., Kang, M. H. (2003). Daily grape juice consumption reduces oxidative DNA damage and plasma free radical levels in healthy Koreans. Mutation Research/Fundamental and Molecular Mechanisms of Mutagenesis, 529(1), 77-86.

Porter, L. J. (1989). Tannins. In: Methods in plant biochemistry. Plant Phenolics, Harborne, J. B., Ed., Academic Press: New York, 389-419.

Rodrigo, R., Castillo, R., Carrasco, R., Huerta, P. Moreno, M. (2005). Diminution of tissue lipid peroxidation in rats is related to the in vitro antioxidant capacity of wine. Life Sciences, 76(8), 889-900.

Rodrigues, A. D., Scheffel, T. B., Scola, G., dos Santos, M. T., Fank, B., de Freitas, S. C. V., Salvador, M. (2012). Neuroprotective and anticonvulsant effects of organic and conventional purple grape juices on seizures in Wistar rats induced by pentylenetetrazole. Neurochemistry International, 60(8), 799-805. 
Ruiz-Sambiás, C., Arrebola-Pascual, C., Tres, A., van Ruth, S., Cuadros-Rodriguez, C. (2013). Authentication of geographical origin of palm oil by chromatographic fingerprinting of triacylglycerols and partial least squares-discriminant analysis. Talanta, 116, 788-793.

Salvatore, E., Cocchi, M., Marchetti, A., Marini, F., de Juan, A. (2013). Determination of phenolic compounds and authentication of PDO Lambrusco wines by HPLC-DAD and chemometric techniques. Analytica Chimica Acta, 761, 34-45.

Singleton, V. L., Rossi, J. A. (1965). Colorimetry of total phenolics with phosphomolybdic-phosphotungstic acid reagents. American journal of Enology and Viticulture, 16(3), 144-158.

Toaldo, I. M., Cruz, F. A., Alves, T. L., Gois, J. S., Borges, D. L. G., Cunha, H. P., Silva, E. L., \& BordignonLuiz, M. T. (2015). Bioactive potential of Vitis labrusca L. grape juices from the Southern Region of Brazil: Phenolic and elemental composition and effect on lipid peroxidation in healthy subjects. Food Chemistry, 173, 527-535.

Vinson, J. A., Teufel, K., Wu, N. (2001). Red wine, dealcoholized red wine, and especially grape juice, inhibit atherosclerosis in a hamster model. Atherosclerosis, 156(1), 67-72.

Vrček, I. V., Bojić, M., Žuntar, I., Mendaš, G., Medić-Šarić, M. (2011). Phenol content, antioxidant activity and metal composition of Croatian wines deriving from organically and conventionally grown grapes. Food Chemistry, 124(1), 354-361.

Zhishen, J., Mengcheng, T., Jianming, W. (1999). The determination of flavonoid contents in mulberry and their scavenging effects on superoxide radicals. Food Chemistry, 64(4), 555-559.

ZibaeeNezhad, M. J., Mohammadi, E., Babaie Beigi, M. A., Mirzamohammadi, F., Salehi, O. (2012). The effects of unripe grape juice on lipid profile improvement. Cholesterol, 2012. 


\section{OHapteR 5:}

\section{GEOGRAPHICAL PROVENANCING OF \\ PURPLE GRAPE JUICES FROM DIFFERENT \\ PRODUCTION MANAGEMENT SYSTEMS BY \\ PROTON TRANSFER REACTION MASS \\ SPECTROMETRY}

This chapter is published as: GRANATO, D.; KOOT, A.; van RUTH, S. M. Geographical provenancing of purple grape juices from different production management systems by proton transfer reaction mass spectrometry using supervised statistical techniques. Journal of the Science of Food and Agriculture, 95, 26682677, 2015. 


\begin{abstract}
Organic, biodynamic, and conventional purple grape juices (PGJ; $\mathrm{n}=79$ ) produced in Brazil and Europe were characterized by volatile organic compounds $(m / z$ 20-160) measured by proton transfer reaction mass spectrometry (PTR-MS) and classification models were built using supervised statistical techniques. K-nearest neighbours (KNN) and soft independent modelling of class analogy (SIMCA) models discriminated adequaly the Brazilian from European PGJ (overall accuracy of $87 \%$ and $81 \%$, respectively). Partial least squares discriminant analysis (PLSDA) classified 100\% European and 96\% Brazilian PGJ. Similarly, when samples were grouped as either conventional or organic/biodynamic, the PLSDA model classified $81 \%$ conventional and $83 \%$ organic/biodynamic juices. Intraregional PLSDA models (juices produced in the same region - either Europe or Brazil) were developed and were deemed accurate in discriminating Brazilian organic from conventional PGJ (81\% accuracy) as well as European conventional from organic/biodynamic PGJ (94\% accuracy). PGJ from Brazil and Europe as well as conventional and organic/biodynamic PGJ were distinguished with a high accuracy, but no statistical model was able to differentiate organic and biodynamic grape juices. These data support the hypothesis that no clear distinction between organic and biodynamic grape juices can be made with respect to VOCs.
\end{abstract}

Keywords: headspace analysis, food analysis, volatile profile, chemometrics, SIMCA, PLSDA.

\title{
5.1 Introduction
}

In 2011 and 2012, a consumption of about 38,950 and 36,601 million L of fruit juices, including 100\% juices and nectars, was registered worldwide, in which Europe, North America, Asia Pacific, Africa and the Middle East, and Latin America accounted for about 10.8, 9.8, 6.8, 3.6, 3.4 million liters, respectively. In 2012, the per capita consumption was about $21 \mathrm{~L}$ in the EU, $27 \mathrm{~L}$ in North America, $5 \mathrm{~L}$ in South America and only $2 \mathrm{~L}$ in Asia Pacific (AIJN, 2012). From the total of juices consumed in Europe, two-thirds of this amount is related to $100 \%$ fruit juices (labeled as pure juices). In South America, Brazil is the largest producer of orange juice and the second largest producer of grape juice and in 2010, the Brazilian per capita consumption of grape juices was $\sim 3$ L. Additionally, the marketing of grape juices in Brazil, in 2013, has increased up to 2,000\% compared to 2003 and exportation to European countries has risen considerably in the last 5 years (Ibravin, 2014). Therefore, the monitoring of sensory, physicochemical, and microbiological features of such beverages is necessary to ascertain of their quality and typicality.

The fingerprinting aiming at assessing quality of fruit juices may be performed by means of different analytical techniques, such as high-performance liquid chromatography (HPLC) of phenolic compounds, carotenoids, vitamins, quantification of minerals and trace elements via flame atomic absorption spectrometry (FAAS) or inductively coupled plasma mass spectrometry (ICP-MS), and gas chromatography (GC) of major volatile compounds. However, if the investment in time and reagents needed for these analyses are taken into consideration along with the time required to prepare the sample, the use of expensive chemicals, and employment of multiple-steps to conduct the analysis, analytical and financial restrictions are clearly evident. Aiming at overcoming these limitations, efforts in developing and validating non-destructive and highly sensitive methods are necessary. Herein, proton transfer reaction mass spectrometry (PTR-MS) has been 
highlighted as a suitable analytical technique for monitoring the quality of food/feed and also non-food products by measuring the volatile organic compounds (VOCs) present in the sample (Biasioli et al., 2003; Biasioli et al., 2011).

In food science and technology applications, headspace PTR-MS has been more extensively used to assess a product's authenticity, typicality, and overall quality by profiling the VOCs. Some of the various foods and beverages that have already been investigated, with promising and positive results are wines (Spitaler et al., 2007), butter (Macatelli et al., 2009), vegetable oils (Ruiz-Samblás et al., 2012), meat products (Pulgar et al., 2013), coffee (Özdestan et al., 2013), fruits (Biasioli et al., 2003; Granitto et al., 2007) and even fruit juices (Aprea et al., 2009; van Ruth, Frasnelli, \& Carbonell, 2011). The advantage of PTR-MS over GC-MS and GCFID is that it is a non-destructive and rapid technique that does not require sample preparation, thus saving time and avoiding adulteration prior to analysis. Moreover, PTR-MS is highly sensitive (detecting parts per trillion by volume) and, therefore, represents a suitable alternative to assess a product's authenticity, typicality, and geographical origin.

The evaluation of samples based on analytical parameters (i.e., chemical markers, volatile composition, antioxidant activity) aiming to assess their origin, presence of frauds and adulteration is remarkably facilitated by the use of multivariate statistical techniques, especially by combining analytical measurements data with supervised techniques, such as partial least squares discriminant analysis (PLSDA), k-nearest neighbours (KNN), and soft independent modeling of class analogy (SIMCA), as well as unsupervised pattern recognition techniques, such as principal component analysis (PCA) and cluster analysis. The main goal of these supervised statistical methods (is to classify/discriminate/differentiate samples based on analytical data and then try to predict the class of unknown samples based on the same parameters used to characterize them (Berrueta, Alonso-Salces, \& Heberger, 2007). Once when a large number of samples is usually analyzed on the basis of various markers/parameters, data structure is rather complex and thus requires the use of different statistical methods to propose classification rules and to attest the product authenticity and geographical provenance, for example.

When it comes fruit juices, there are several commercial types that consumers have to make his/decision: the juice may be pure (100\% juice), concentrate ( $\left.60{ }^{\circ} \mathrm{Brix}\right)$, or nectar (pure juice diluted from $25-99 \%)$ coming from conventional, organic, or biodynamic production management systems. These practices differ with respect to land and pesticide use, yield, and environmental impact. In one hand, conventional farming uses high-yield cultivars and intense use of chemical fertilizers and pesticides, which enhances negative biological and environmental consequences and thus impacting in the sustainability and, on the other hand, organically-grown cultivars are grown in small and medium-size farms once this system is more labor intensive (i.e. planning, pesticide scouting) and the yield is usually lower than the observed in conventional practice. Additionally, organic and biodynamic production management systems incorporate cultural, biological, and mechanical practices that foster cycling of resources, ecological balance, and protection of biodiversity once these cultures do not use chemical fertilizers, hormones and pesticides, genetically modified organisms, and farmers usually perform crop rotation and composting in addition to using green and animal manure and natural fertilizers. Obviously, once the yield of organic/biodynamic crops is usually lower as 
compared to conventional methods, the commercial value of the products is usually higher, and consumers pay a premium price and expect that the organic food they acquire not only be raised by organic methods but be protected from commingling with non-organic products. Thus, the evaluation of organic and biodynamic as compared to conventional food products is required

Because the quality of grape juice is of paramount importance in the actual scenario, especially in South America and some European countries, and a considerable amount of juice is marketed worldwide, monitoring of the geographical origin and the respective production management system used to cultivate grapes is demanded. Thus in the current work we evaluated, for the first time in the literature, the possibility to distinguish purple grape juices (organic, biodynamic, and conventional) from two geographical origins (Brazil and European countries) on the basis of volatile organic compounds measured by PTR-MS with the implementation of multivariate supervised statistical methods.

\subsection{Materials and Methods}

\subsubsection{Sampling}

Authentic commercial samples of purple grape juices $(\mathrm{n}=79)$ labeled $100 \%$ fruit juice (no addition of water and/or sucrose) produced in Brazil ( $\mathrm{n}=53$, in which 17 are certified organic and 36 are conventional juices) and Europe ( $\mathrm{n}=26$, in which 7 are certified organic, 5 are certified biodynamic, and 14 are conventional juices) were investigated. All biodynamic juices were organic certified by third parties. The Brazilian juices were acquired in following producing states: Santa Catarina, Paraná, Rio Grande do Sul, São Paulo, Minas Gerais, Sergipe, Ceará, and Paraíba, which correspond to more than $95 \%$ of the grape producers in Brazil. The grape juices produced in European countries were acquired in France, Italy, United Kingdom, the Netherlands, Germany, Austria, and Spain. Grape juices (at least 1 liter of each sample) were brought to the laboratory, and the floating particles were removed by centrifugation $(400 \mathrm{x} g, 10 \mathrm{~min})$ and samples were analyzed for VOCs.

\subsubsection{Proton transfer reaction mass spectrometry (PTR-MS)}

The VOCs of grape juices were analyzed via headspace PTR-MS. The basic principles of this analytical technique is: the sample gas (vapour) containing in the headspace enters into a drift tube, where it is mixed with $\mathrm{H}_{3} \mathrm{O}^{+}$ions formed in a hollow cathode ion source, thus ionizating most VOCs by proton transfer reactions $\left(\mathrm{H}_{3} \mathrm{O}^{+}+\mathrm{VOC} \rightarrow \mathrm{H}_{2} \mathrm{O}+\mathrm{VOC} \cdot \mathrm{H}^{+}\right)$. Volatile compounds that have proton affinities higher than water ( $>166.5 \mathrm{kcal} / \mathrm{mol}$ ), such as esters, aldehydes, alcohols, carbonyl compounds, and some volatile acids, are then ionized, mass analyzed in a quadrupole mass spectrometer and eventually detected as ion counts s $\mathrm{s}^{-1}$ (cps) by a secondary electron multiplier. The outcome is a mass resolved fingerprint of the total volatile profile of juice samples (Spitaler et al., 2007).

For headspace PTR-MS analysis, a commercial PTR-MS apparatus was used (Ionicon GmbH, Innsbruck, Austria). Briefly, $5 \mathrm{~mL}$ of grape juice was placed in a glass flask $(250 \mathrm{~mL})$ and temperature was equilibrated at $30{ }^{\circ} \mathrm{C}$ for $30 \mathrm{~min}$ in a water bath. The headspace was drawn from the sample flask at a rate of $52 \mathrm{~mL}$ headspace gas/min, and transferred into the high sensitivity PTR-MS for on-line analysis. The ionisation conditions in the reaction chamber were maintained at $600 \mathrm{~V}$ for drift voltage, reaction chamber and inlet 
temperature were set at $60^{\circ} \mathrm{C}$ via Teflon $(0.25 \mathrm{~mm})$ tubing, and 2.20-2.25 mbar for drift pressure. Experimental results were obtained for the mass-to-charge ratio $(\mathrm{m} / \mathrm{z})$ range 20-160 using a dwell time of $0.2 \mathrm{~s} / \mathrm{mass}$, resulting in a cycle time of about $30 \mathrm{~s}$.

The PTR-MS was operated at a standard $E / N$ (ratio of electric field strength across the reaction chamber, $E$, to buffer gas density, $N$, within the chamber $)$ of $115 \mathrm{Td}\left(1 \mathrm{Td}=10^{-17} \mathrm{~V} \cdot \mathrm{cm}^{2}\right)$ and each sample was analyzed for 5 complete mass scans (cycles), in triplicate, and an empty bottle served as blank. Masses were analysed in a quadrupole mass spectrometer and detected as ion counts per second (cps) by a secondary electron multiplier (SEM). Mass Ion intensities during the cycles 2, 3 and 4 were converted to ppbv (parts per billion in volume; volume mixing ratios) according to Hansel et al. (1995) and background adjustment was applied, and subsequently averaged. Ions with very small concentration (below the limit of quantification, LOQ) and those related to water ion $\mathrm{H}_{5} \mathrm{O}_{2}{ }^{+}\left(\mathrm{m} / z\right.$ 37) and $\mathrm{O}_{2}(\mathrm{~m} / \mathrm{z} 32)$ clusters were removed from the data set. Mean mass spectrum of the blanks (MMSB) belonging to individual samples was calculated and the LOQ for each day of analysis was calculated as LOQ $=$ MMSB $+10 *$ SD and only masses above the LOQ were considered for statistical analysis.

\subsubsection{Statistical data analysis}

Results are presented by means followed by standard deviation of three independent replicates. Three different strategies for data analysis were employed:

1) First strategy: to use the whole PTR-MS spectra $(m / z 20-160)$ to analyze differences in the following groups: (i) Brazilian vs European juices; ii) biodynamic vs organic vs conventional juices; iii) conventional vs organic/biodynamic juices;

2) Second strategy: to use specific ions for each of the groups cited above based on significant differences highlighted by univariate statistics between groups. For this purpose, significant differences in ions were determined by either Student-t test/Mann-Whitney-U test (two groups) or one-way ANOVA (three groups) after checking homoscedasticity and normality by the Brown-Forsythe's and Shapiro-Wilk's tests, respectively. Significant differences were highlighted when $\mathrm{p} \leq 5 \%$. These statistical analyses were performed using Statistica v.7 (Statsoft, USA).

For both data analysis strategies, the averages of triplicate PTR-MS measurements were subjected to principal component analysis to explore the data structure and to tentatively identify groups of similar samples using two-dimensional and three-dimensional projections (scatter plots of samples on the factor-plane). Additionally, partial least squares discriminant analysis (PLSDA), k-nearest neighbours (KNN), and soft independent modelling of class analogy (SIMCA) were carried using Pirouette 4.5 software (Infometrix, USA) and Chemoface v. 1.6 (UFLA, Brazil) in order to classify grape juice samples based on the PTR-MS spectra (Biancolillo et al., 2014).

3) Third strategy: to use the whole PTR-MS spectra $(\mathrm{m} / \mathrm{z} 20-160)$ to classify purple grape juice coming from the same geographical origin (either Brazil or Europe) based on the production management system $(\mathrm{ORG}+\mathrm{CONV}$ for Brazilian juices and ORG + BIO + CONV or ORG/BIO + CONV for European juices). For all chemometric methods, auto-scaling was the pre-processing technique applied to standardize 
the whole data set. The performance of the fitted models obtained by PLSDA was internally validated using the leave-one-out approach, which involves the removal of one sample in a random way from the data set, and the model is built with the remaining samples, then the removed sample is included in the model and its class membership is predicted. This process is applied until all samples are removed once. PLSDA models were also externally validated by predicting the identity of the purple grape juices in the test set. For this purpose, samples were split into training (calibration) set ( $80 \%$ of samples) and test (validation) set ( $20 \%$ of samples) using the Kennard-Stone algorithm. In addition, the overall accuracy of the models was calculated as the total percentage of correctly classified samples for both internal and external validation procedures (Stanimirova et al., 2010).

\subsection{Results and Discussion}

\subsubsection{Exploratory techniques}

Our main goal was to differentiate commercial grape juices (organic, biodynamic, and conventional) from two geographical origins (Brazil and Europe). For this purpose, volatile organic compounds were quantified by means of PTR-MS and the mean headspace PTR-MS mass spectra of the volatile compounds $(\mathrm{m} / \mathrm{z}$ 20-160) of purple grape juices are presented in Figure 5.1. It can be noted that Brazilian samples presented higher concentrations of ions at $\mathrm{m} / \mathrm{z} 29,33,43,47,59,61$, and 89 compared to European juices (Figure 5.1A) and, in general, conventional juices had higher mean levels for all ions compared to organic and biodynamic juices (Figures 5.1B and 5.1C). In order to be more specific, statistical comparisons between groups (European $v s$ Brazilian; organic vs conventional vs biodynamic; conventional $v s$ organic/biodynamic) were performed to highlight intrinsic differences. In fact, biodynamic juices presented the lowest mean values for almost all ions measured, while conventional juices presented the highest mean values for the ions. A total of 23 masses in the $m / z$ 20-160 range were statistically different $(\mathrm{p} \leq 0.05)$ among these three groups (Table 5.1 ).

Table 5.1: Volume mixing ratios in ppbv [means (SD)] for conventional, organic, and biodynamic purple grape juices obtained by PTR-MS for significant different masses among crop systems.

\begin{tabular}{ccccc}
\hline Ion $(\mathrm{m} / \mathrm{z})$ & Conventional $(\mathrm{n}=50)$ & Organic $(\mathrm{n}=24)$ & Biodynamic $(\mathrm{n}=5)$ & $p$-value \\
\hline 42 & $71.22(61.10)$ & $60.67(51.10)$ & $1.60(2.62)$ & 0.04 \\
53 & $0.45(0.32)$ & $0.30(0.23)$ & $0.21(0.13)$ & 0.04 \\
56 & $0.84(0.70)$ & $0.52(0.64)$ & $0.16(0.36)$ & 0.03 \\
67 & $0.65(0.58)$ & $0.35(0.44)$ & $0.24(0.37)$ & 0.03 \\
69 & $17.52(8.64)$ & $12.80(7.02)$ & $6.14(1.97)$ & $<0.01$ \\
70 & $2.96(1.95)$ & $2.15(2.05)$ & $0.45(0.19)$ & 0.01 \\
80 & $0.19(0.24)$ & $0.09(0.14)$ & $0.00(0.00)$ & 0.03 \\
84 & $2.03(1.24)$ & $1.68(1.40)$ & $0.61(0.22)$ & 0.05 \\
92 & $0.09(0.15)$ & $0.02(0.05)$ & $0.00(0.00)$ & 0.04 \\
95 & $5.29(4.38)$ & $2.51(3.26)$ & $0.00(0.00)$ & $<0.01$ \\
96 & $0.47(0.38)$ & $0.19(0.28)$ & $0.00(0.00)$ & $<0.01$ \\
97 & $34.61(34.70)$ & $11.46(8.54)$ & $5.08(3.73)$ & $<0.01$ \\
98 & $1.99(1.94)$ & $0.65(0.53)$ & $0.25(0.23)$ & $<0.01$
\end{tabular}


Table 5.1: continuation

\begin{tabular}{ccccc}
99 & $1.26(0.80)$ & $0.60(0.51)$ & $0.71(0.88)$ & $<0.01$ \\
101 & $1.16(1.05)$ & $0.62(0.79)$ & $0.47(0.9)$ & 0.05 \\
107 & $4.23(4.44)$ & $1.86(1.75)$ & $1.11(1.01)$ & 0.02 \\
113 & $4.18(6.84)$ & $0.55(0.40)$ & $0.00(0.00)$ & 0.02 \\
114 & $0.29(0.47)$ & $0.05(0.15)$ & $0.00(0.00)$ & 0.03 \\
119 & $0.30(0.30)$ & $0.17(0.17)$ & $0.00(0.00)$ & 0.02 \\
127 & $0.32(0.53)$ & $0.07(0.20)$ & $0.00(0.00)$ & 0.04 \\
135 & $0.49(0.40)$ & $0.31(0.33)$ & $0.09(0.00)$ & 0.03 \\
143 & $1.10(1.00)$ & $0.83(0.88)$ & $0.00(0.00)$ & 0.04 \\
153 & $0.70(0.62)$ & $0.49(0.59)$ & $0.00(0.00)$ & 0.03 \\
\hline
\end{tabular}

Note: aProbability values obtained by one-way ANOVA ( 3 groups) or by Student- $t$ test (2 groups).

However, when samples were grouped as either conventional or organic/biodynamic, a total of 62 ions were different between the two groups (Table 5.2). When the comparison was made between geographical origins, more complex results were obtained: a total of 66 ions were different between Brazilian and European juices (Table 5.3). As observed, a high variability in data was obtained and this reflects intrinsic differences in juice processing, type of container used to market the juices, grape variety, mixture of different grape varieties, and even the possibility of adulteration of juices with the addition of water, sucrose, and/or aroma compounds as well as addition of authentic grape juice with cheaper alternatives (apple and pear juices, for example) (Muntean. 2010; Obón et al., 2011).

Table 5.2: Volume mixing ratios in ppbv [means (SD)] for conventional and organic/biodynamic purple grape juices obtained by PTR-MS for significant different masses between groups (conventional or organic/biodynamic).

\begin{tabular}{cccc}
\hline Ions $(\mathrm{m} / \mathrm{z})$ & Conventional $(\mathrm{n}=50)$ & Organic/Biodynamic $(\mathrm{n}=29)$ & $p$-value \\
\hline 27 & $4.48(2.58)$ & $2.59(2.10)$ & $<0.01$ \\
29 & $506(303)$ & $266(216)$ & $<0.01$ \\
38 & $0.86(1.20)$ & $0.32(0.87)$ & 0.05 \\
42 & $98.11(50.46)$ & $50.48(51.59)$ & $<0.01$ \\
43 & $2340(2119)$ & $983.54(1,106)$ & $<0.01$ \\
44 & $55.53(51.52)$ & $23.78(26.49)$ & $<0.01$ \\
47 & $5,367(3,044)$ & $2,859(2,218)$ & $<0.01$ \\
48 & $137.37(83.72)$ & $70.80(56.62)$ & $<0.01$ \\
49 & $13.09(7.85)$ & $6.83(5.36)$ & $<0.01$ \\
56 & $0.73(0.49)$ & $0.46(0.61)$ & 0.05 \\
59 & $314(220)$ & $206(192)$ & 0.04 \\
60 & $11.12(7.64)$ & $7.22(6.60)$ & 0.03 \\
61 & $2,134(2,132)$ & $889(1152)$ & 0.01 \\
62 & $52.05(53.50)$ & $21.45(28.43)$ & 0.01 \\
65 & $106(65.74)$ & $53.93(44.17)$ & $<0.01$ \\
66 & $2.57(1.57)$ & $1.34(1.11)$ & $<0.01$ \\
67 & $0.87(0.52)$ & $0.33(0.42)$ & $<0.01$ \\
69 & $19.40(9.19)$ & $11.65(6.90)$ & $<0.01$
\end{tabular}


Table 5.2: continuation

\begin{tabular}{|c|c|c|c|}
\hline 70 & $3.80(1.62)$ & $1.86(1.97)$ & $<0.01$ \\
\hline 73 & $29.14(31.67)$ & $15.88(13.50)$ & 0.04 \\
\hline 74 & $1.28(1.44)$ & $0.66(0.69)$ & 0.04 \\
\hline 75 & $99.61(74.49)$ & $43.30(43.81)$ & $<0.01$ \\
\hline 76 & $3.57(2.62)$ & $1.49(1.58)$ & $<0.01$ \\
\hline 77 & $0.84(0.54)$ & $0.41(0.39)$ & $<0.01$ \\
\hline 79 & $9.47(7.81)$ & $4.13(4.52)$ & $<0.01$ \\
\hline 80 & $0.24(0.21)$ & $0.07(0.13)$ & $<0.01$ \\
\hline 81 & $4.98(3.31)$ & $2.83(2.27)$ & $<0.01$ \\
\hline 82 & $0.32(0.24)$ & $0.17(0.17)$ & 0.01 \\
\hline 84 & $2.52(1.10)$ & $1.50(1.34)$ & $<0.01$ \\
\hline 89 & $499(503)$ & $186(242)$ & $<0.01$ \\
\hline 90 & $22.87(22.76)$ & $8.58(11.11)$ & $<0.01$ \\
\hline 91 & $3.27(2.96)$ & $1.23(1.47)$ & $<0.01$ \\
\hline 92 & $0.11(0.16)$ & $0.01(0.05)$ & $<0.01$ \\
\hline 93 & $36.93(40.43)$ & $13.08(14.49)$ & $<0.01$ \\
\hline 94 & $1.82(1.87)$ & $0.63(0.71)$ & $<0.01$ \\
\hline 95 & $7.29(3.47)$ & $2.08(3.11)$ & $<0.01$ \\
\hline 96 & $0.65(0.32)$ & $0.16(0.27)$ & $<0.01$ \\
\hline 97 & $36.73(39.94)$ & $10.36(8.24)$ & $<0.01$ \\
\hline 98 & $2.13(2.22)$ & $0.58(0.51)$ & $<0.01$ \\
\hline 99 & $1.10(0.56)$ & $0.62(0.57)$ & $<0.01$ \\
\hline 101 & $1.45(1.04)$ & $0.59(0.77)$ & $<0.01$ \\
\hline 102 & $0.05(0.08)$ & $0.01(0.04)$ & 0.05 \\
\hline 105 & $4.26(6.32)$ & $1.01(1.35)$ & 0.01 \\
\hline 107 & $5.42(4.70)$ & $1.73(1.74)$ & $<0.01$ \\
\hline 113 & $5.80(7.47)$ & $0.46(1.46)$ & $<0.01$ \\
\hline 114 & $0.40(0.51)$ & $0.04(0.14)$ & $<0.01$ \\
\hline 115 & 11.07 (6.99) & $5.69(6.77)$ & $<0.01$ \\
\hline 116 & $0.79(0.50)$ & $0.40(0.48)$ & $<0.01$ \\
\hline 118 & $1.03(1.36)$ & $0.30(0.34)$ & 0.01 \\
\hline 119 & $0.41(0.28)$ & $0.14(0.21)$ & $<0.01$ \\
\hline 121 & $0.46(0.73)$ & $0.12(0.22)$ & 0.02 \\
\hline 124 & $0.11(0.25)$ & $0.00(0.00)$ & 0.02 \\
\hline 125 & $0.09(0.17)$ & $0.01(0.04)$ & 0.02 \\
\hline 127 & $0.17(0.27)$ & $0.06(0.19)$ & 0.06 \\
\hline 129 & $0.42(0.38)$ & $0.24(0.29)$ & 0.04 \\
\hline 135 & $0.62(0.38)$ & $0.27(0.32)$ & $<0.01$ \\
\hline 137 & $3.85(2.52)$ & $2.08(1.94)$ & $<0.01$ \\
\hline 138 & $0.41(0.29)$ & $0.21(0.21)$ & $<0.01$ \\
\hline 143 & $1.48(0.91)$ & $0.69(0.86)$ & $<0.01$ \\
\hline 144 & $0.09(0.11)$ & $0.04(0.08)$ & 0.04 \\
\hline 149 & $0.24(0.16)$ & $0.12(0.17)$ & 0.01 \\
\hline 153 & $0.86(0.63)$ & $0.41(0.57)$ & $<0.01$ \\
\hline
\end{tabular}

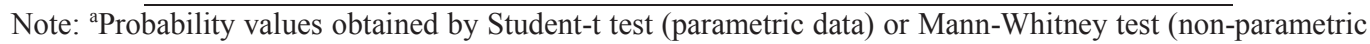
data). 
Table 5.3: Volume mixing ratios in ppbv [means (SD)] for Brazilian and European purple grape juices obtained by PTR-MS for significant different masses between geographical origins.

\begin{tabular}{|c|c|c|c|}
\hline Ions $(\mathrm{m} / \mathrm{z})$ & Brazil $(n=53)$ & Europe $(n=26)$ & $p$-value ${ }^{\mathrm{a}}$ \\
\hline 27 & $4.10(2.46)$ & $1.73(1.38)$ & $<0.01$ \\
\hline 28 & $0.16(0.26)$ & $0.00(0.00)$ & NA \\
\hline 29 & 449 (289) & $169(135)$ & $<0.01$ \\
\hline 33 & $4,130(2485)$ & $2,732(2,276)$ & 0.02 \\
\hline 34 & $49.50(32.24)$ & $32.42(29.43)$ & 0.03 \\
\hline 35 & $8.65(5.45)$ & $5.56(4.86)$ & 0.02 \\
\hline 38 & $0.73(1.16)$ & $0.06(0.32)$ & 0.01 \\
\hline 42 & $94.00(47.19)$ & $1.66(5.71)$ & $<0.01$ \\
\hline 43 & $2,054(1,911)$ & $547(1,709)$ & $<0.01$ \\
\hline 44 & $48.93(46.26)$ & $13.82(43.02)$ & $<0.01$ \\
\hline 45 & 476 (376) & $1,476(1,074)$ & $<0.01$ \\
\hline 46 & $11.21(8.88)$ & $34.45(25.42)$ & $<0.01$ \\
\hline 47 & $4,774(2,919)$ & $1,867(1,420)$ & $<0.01$ \\
\hline 48 & $121(79)$ & $45.08(36.06)$ & $<0.01$ \\
\hline 49 & $11.58(7.41)$ & $4.41(3.55)$ & $<0.01$ \\
\hline 51 & $48.06(30.02)$ & $29.41(25.69)$ & 0.01 \\
\hline 52 & $0.59(0.41)$ & $0.37(0.36)$ & 0.02 \\
\hline 55 & $13.00(4.72)$ & $21.93(17.82)$ & $<0.01$ \\
\hline 59 & $309(214)$ & $143(181)$ & $<0.01$ \\
\hline 60 & $10.90(7.38)$ & $5.00(10.15)$ & $<0.01$ \\
\hline 61 & $1,880(1,930)$ & $481(450)$ & $<0.01$ \\
\hline 62 & $45.81(48.30)$ & $11.95(46.82)$ & $<0.01$ \\
\hline 65 & $93.07(62.28)$ & $33.17(26.49)$ & $<0.01$ \\
\hline 66 & $2.29(1.50)$ & $0.82(0.64)$ & $<0.01$ \\
\hline 67 & $0.73(0.54)$ & $0.12(0.29)$ & $<0.01$ \\
\hline 69 & $17.86(8.78)$ & $10.29(4.96)$ & $<0.01$ \\
\hline 70 & $3.50(1.81)$ & $0.62(0.42)$ & $<0.01$ \\
\hline 75 & $86.66(69.03)$ & $27.91(74.01)$ & $<0.01$ \\
\hline 76 & $3.08(2.45)$ & $0.91(2.56)$ & $<0.01$ \\
\hline 79 & $8.45(7.09)$ & $2.19(6.77)$ & $<0.01$ \\
\hline 80 & $0.21(0.20)$ & $0.04(0.19)$ & $<0.01$ \\
\hline 81 & $4.50(3.04)$ & $2.48(4.86)$ & 0.03 \\
\hline 82 & $0.28(0.23)$ & $0.13(0.32)$ & 0.02 \\
\hline 84 & $2.43(1.16)$ & $0.62(0.42)$ & $<0.01$ \\
\hline 89 & $430(452)$ & $97.45(80.35)$ & $<0.01$ \\
\hline 90 & $19.70(20.48)$ & $4.38(15.74)$ & $<0.01$ \\
\hline 91 & $2.75(2.70)$ & $0.94(2.07)$ & $<0.01$ \\
\hline 92 & $0.08(0.14)$ & $0.02(0.06)$ & 0.03 \\
\hline 93 & $30.67(35.33)$ & $5.35(8.92)$ & $<0.01$ \\
\hline 94 & $1.52(1.64)$ & $0.18(0.44)$ & $<0.01$ \\
\hline 95 & $6.09(3.84)$ & $0.08(0.41)$ & $<0.01$ \\
\hline 96 & $0.53(0.36)$ & $0.01(0.04)$ & $<0.01$ \\
\hline 101 & $1.22(1.00)$ & $0.41(0.73)$ & $<0.01$ \\
\hline
\end{tabular}


Table 5.3: continuation

$\begin{array}{lccc}102 & 0.04(0.07) & 0.02(0.02) & 0.03 \\ 105 & 3.31(5.42) & 0.29(0.88) & 0.01 \\ 107 & 4.43(4.22) & 1.04(1.19) & <0.01 \\ 113 & 4.19(6.65) & 0.00(0.00) & \mathrm{NA} \\ 114 & 0.29(0.46) & 0.00(0.00) & \mathrm{NA} \\ 115 & 10.61(6.76) & 0.57(2.51) & <0.01 \\ 116 & 0.76(0.49) & 0.03(0.14) & <0.01 \\ 118 & 0.87(1.15) & 0.04(0.22) & <0.01 \\ 119 & 0.36(0.27) & 0.01(0.03) & <0.01 \\ 121 & 0.36(0.63) & 0.10(0.20) & 0.04 \\ 127 & 0.15(0.26) & 0.37(0.68) & 0.04 \\ 133 & 0.29(0.30) & 0.00(0.00) & \mathrm{NA} \\ 135 & 0.55(0.38) & 0.11(0.18) & <0.01 \\ 136 & 0.02(0.04) & 0.00(0.00) & 0.05 \\ 137 & 3.52(2.40) & 1.26(2.22) & <0.01 \\ 138 & 0.38(0.27) & 0.12(0.28) & <0.01 \\ 143 & 1.38(0.89) & 0.07(0.26) & <0.01 \\ 144 & 0.09(0.11) & 0.01(0.03) & <0.01 \\ 149 & 0.23(0.16) & 0.00(0.00) & \mathrm{NA} \\ 151 & 0.06(0.14) & 0.00(0.00) & \mathrm{NA} \\ 153 & 0.81(0.62) & 0.15(0.31) & <0.01 \\ 154 & 0.05(0.07) & 0.02(0.03) & 0.01 \\ 155 & 0.39(0.38) & 0.07(0.15) & <0.01\end{array}$

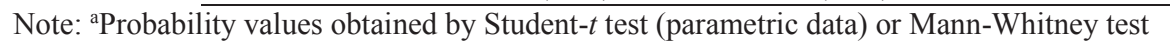
(non-parametric data). NA= not applicable 


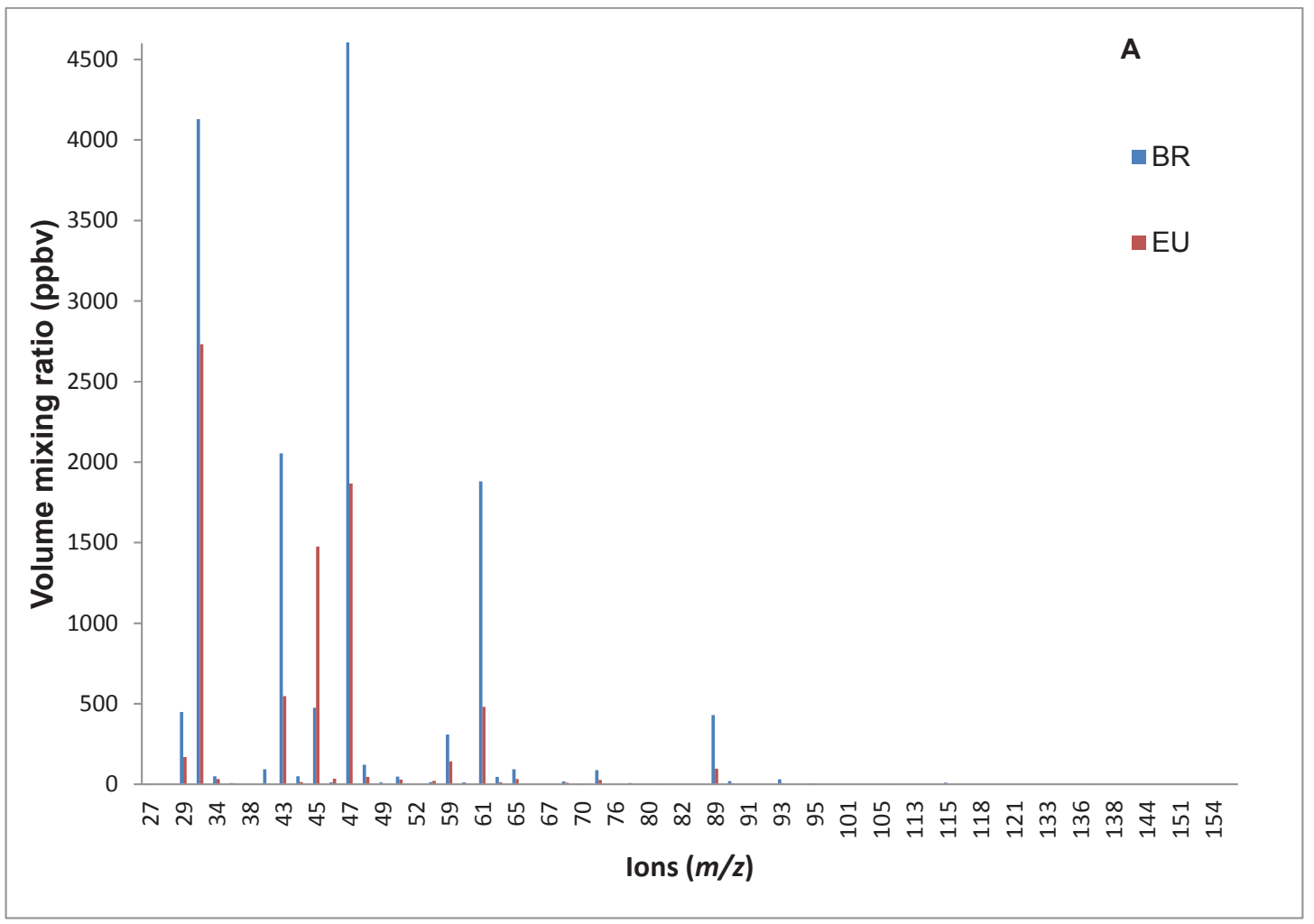



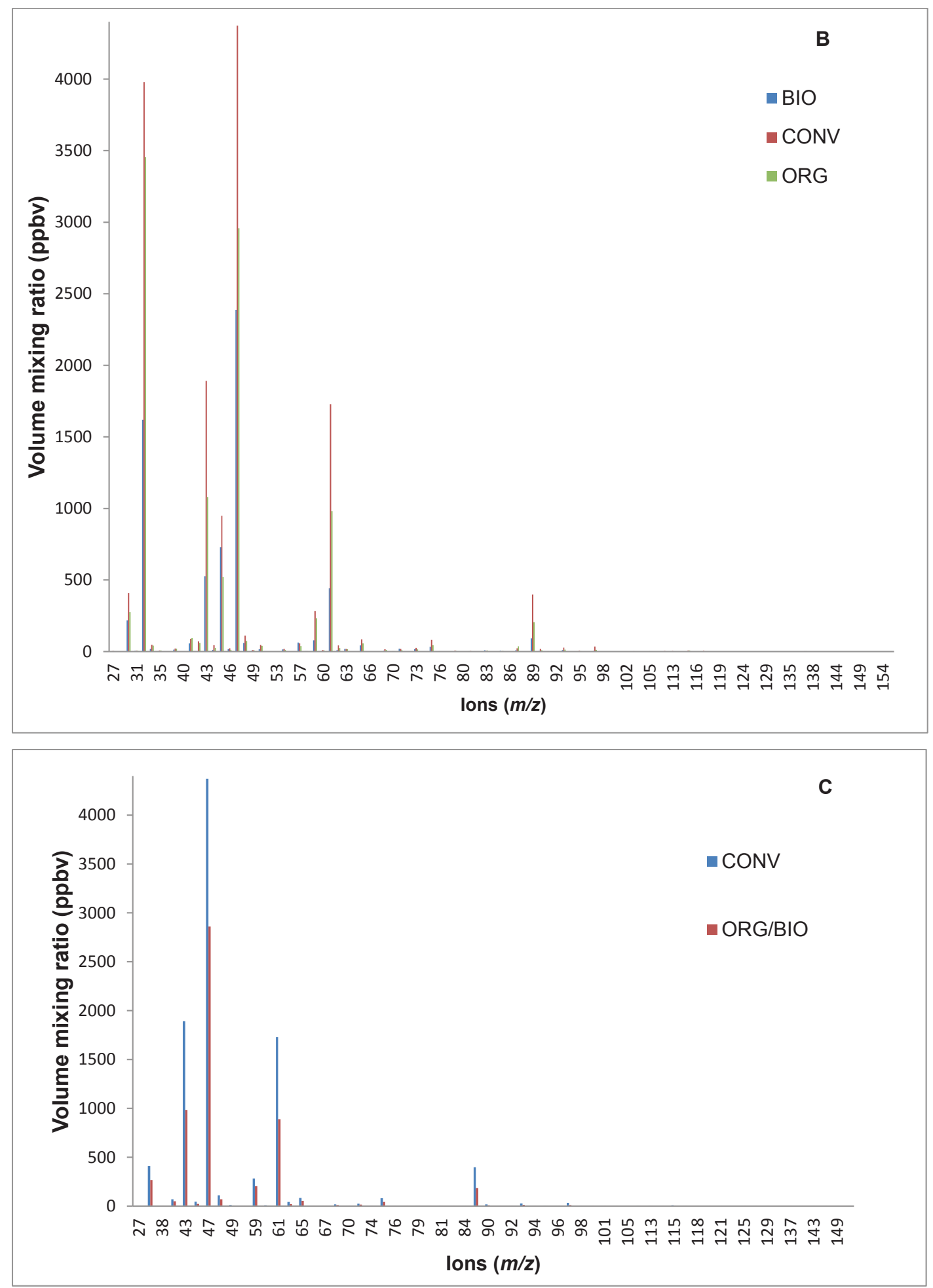
Figure 5.1: Comparison of the mean headspace PTR-MS mass spectra of the volatile compounds of Brazilian (BR) and European (EU) purple grape juices (A), juices came from organic (ORG), biodynamic (BIO) and conventional (CONV) crop systems (B) and juices classified as conventional and organic/biodynamic (C).

It is important to note that sample classification based on PTR-MS spectra often relies on unsupervised multivariate methods (typically PCA). Using either 2D or 3D PCA containing both scores and loadings (Figure 5.2), it was possible to verify a differences between European and Brazilian juices (Figure 5.2A), and the 3D projection was able to explain $97 \%$ of data variability. However, when biodynamic, organic, and conventional grape juices were analyzed, samples were mixed and no inferences could be drawn regarding an unsupervised classification of juices based on all ions (Figure 5.2B) and a total of up $77 \%$ of data variability was explained using two principal components. Likewise, when samples were divided either in conventional and organic/biodynamic juices, a more clear separation was observed, although no differentiation was observed overall (Figure 5.2C). It is worth to pinpoint that PCA cannot be considered a classification method and, therefore, should only be used to check for similarities (and therefore differences) among samples simultaneously. In order to overcome this characteristic, pattern recognition techniques were also employed in the current study. 


$$
\left.\diamond_{\mathrm{BR}}\right\rangle_{\mathrm{BR}}
$$

A

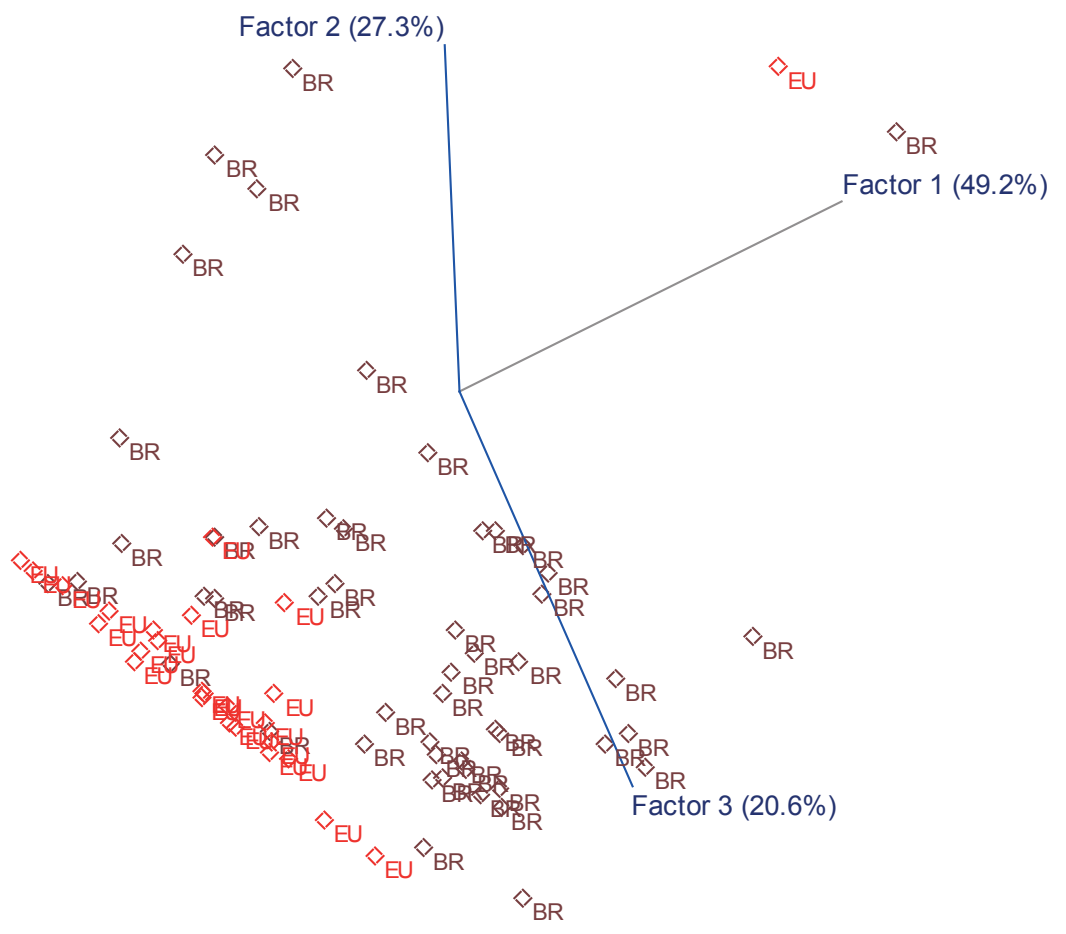


B
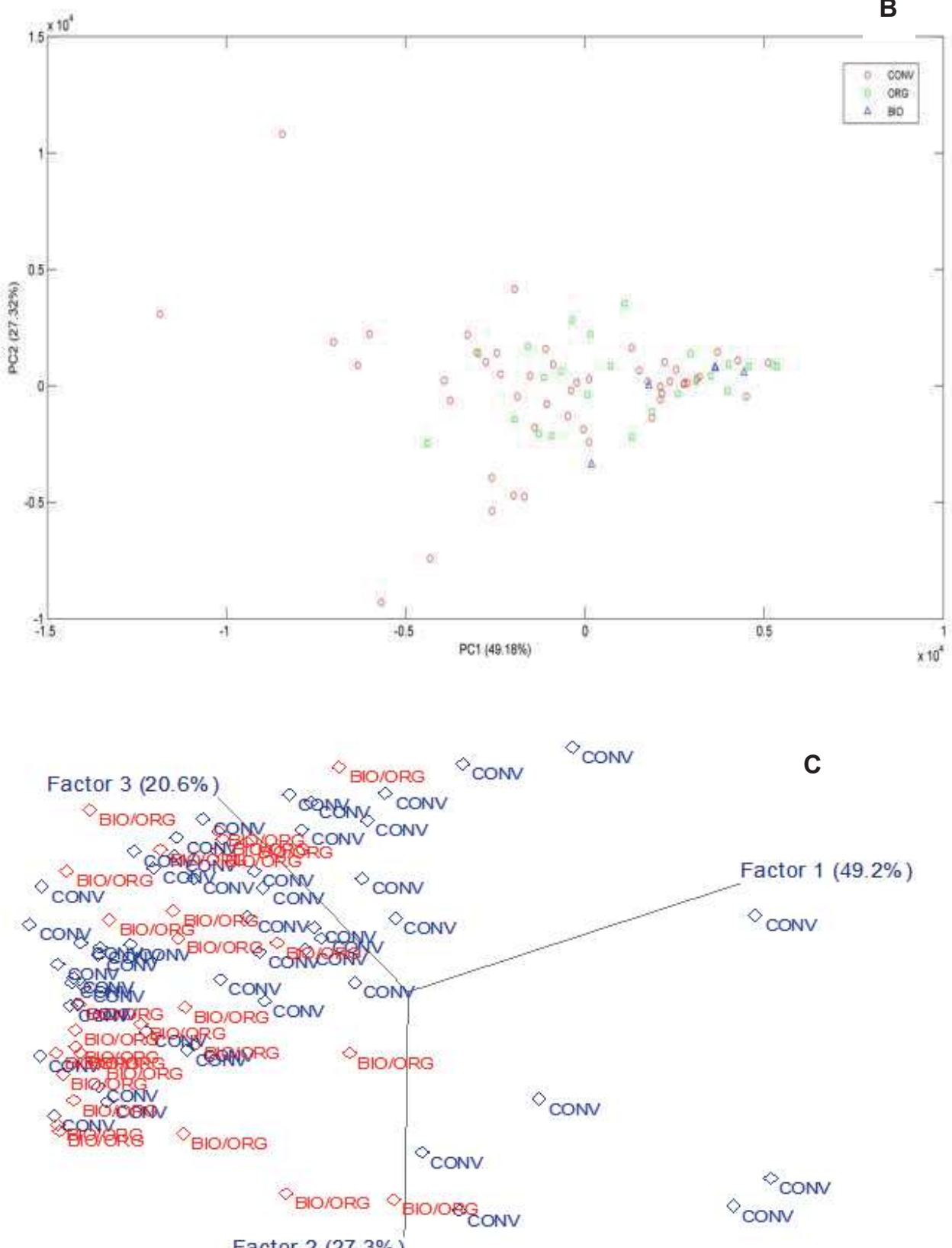

Factor $2(27.3 \%)$

Figure 5.2: Principal component analysis based on volatile organic compounds of grape juices measured by PTR-MS taking into account all mass-to-charge ratio $(\mathrm{m} / \mathrm{z})$ and the geographical origin $(\mathrm{A})$, the three production management systems (B), and on the basis of classifying juices as either conventional and organic/biodynamic $(\mathrm{C})$. 


\subsubsection{Class-modelling and classification models}

\subsubsection{Effect of crop system and geographical origin}

As compared to clustering methods and PCA, supervised multivariate methods, such as partial least squares discriminant analysis (PLSDA), k-nearest neighbours (KNN), and soft independent modelling of class analogy (SIMCA) have been shown to be more efficient because they do not consider the whole variability of the data set but only the variability related to the given task (Biasioli et al., 2003). In theory, SIMCA builds a confidence limit for each class, also known as interclass distance, using PCA and then project the unclassified samples into each principal components space aiming at assigning them to the class in which they fit best or even to no class (Wold, 1976). KNN is a supervised learning algorithm in which samples are classified based on the category of the majority of its k-nearest neighbours and has been already shown to adroitly classify different beverages on the basis of VOC (Gómez-Meire et al., 2014). PLSDA is a supervised statistical technique based on the reduction on the space of the independent variables, in which the factors are components having maximal correlation with the dependent variable (the class membership, i.e. producing country, crop system, etc), maximizing the separation among classes. The partial least squares model expresses a linear relationship between a response $y(n \times 1)$ and a set of $p$ explanatory variables $\mathrm{X}(n \times p)$ (Berrueta, Alonso-Salces, \& Heberger, 2007).

To try and classify the commercial grape juices based on VOCs profile, SIMCA, KNN, and PLSDA were applied using all ion masses higher than the LOQ within the range $m / z$ 20-160 and results are in Table 5.4. Using only two factors, SIMCA was able to discriminate $77 \%$ of Brazilian and $89 \%$ of European purple grape juices, with an overall accuracy of $81 \%$, in which $\mathrm{m} / \mathrm{z} 42,45,46,70$, and 119 were the most discriminating variables. Similarly, a satisfactory discrimination was obtained by KNN once $91 \%$ of Brazilian and $81 \%$ of European juices were adroitly classified using $\mathrm{k}=3$, and the model presented $87 \%$ accuracy. 


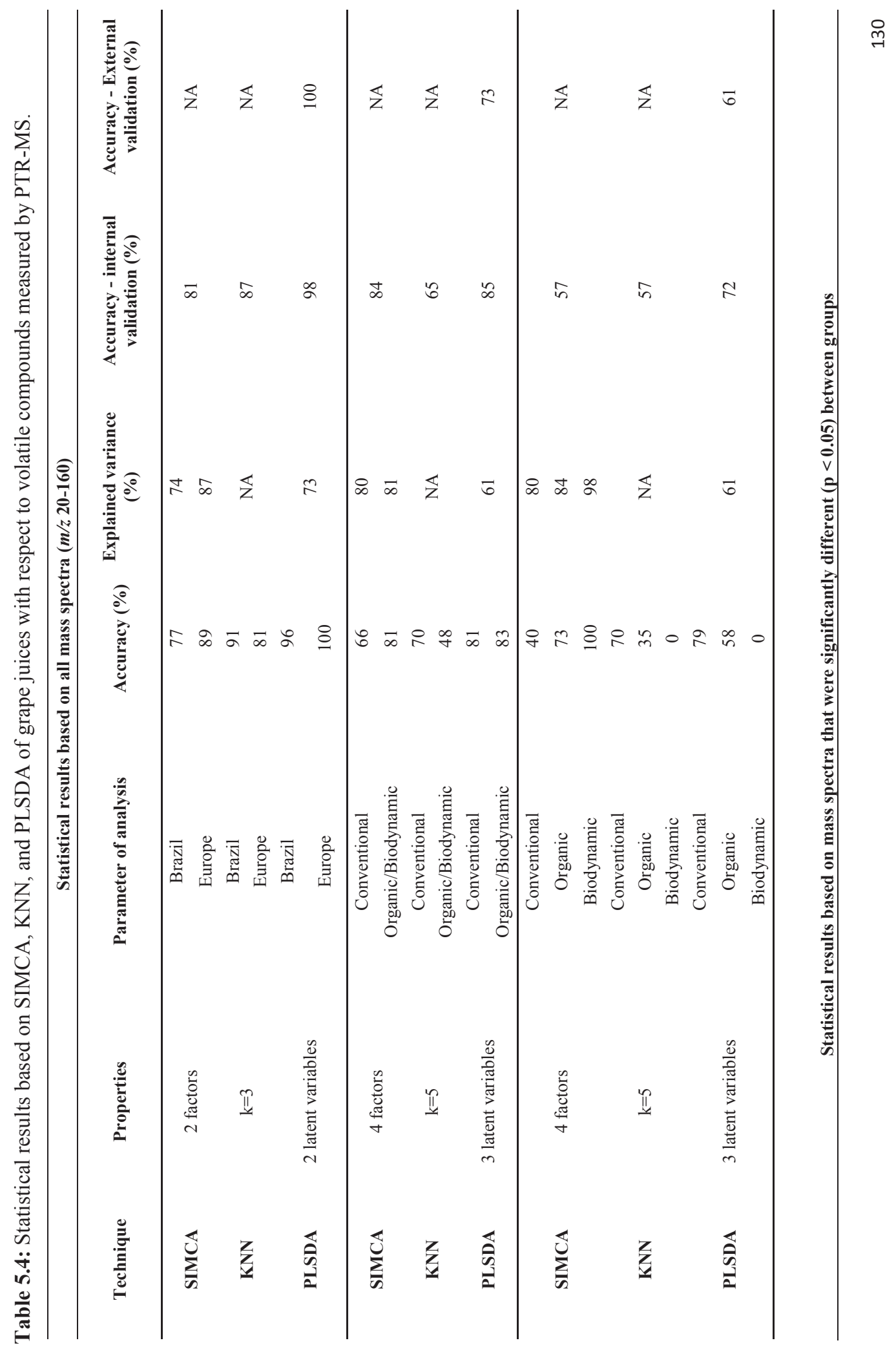




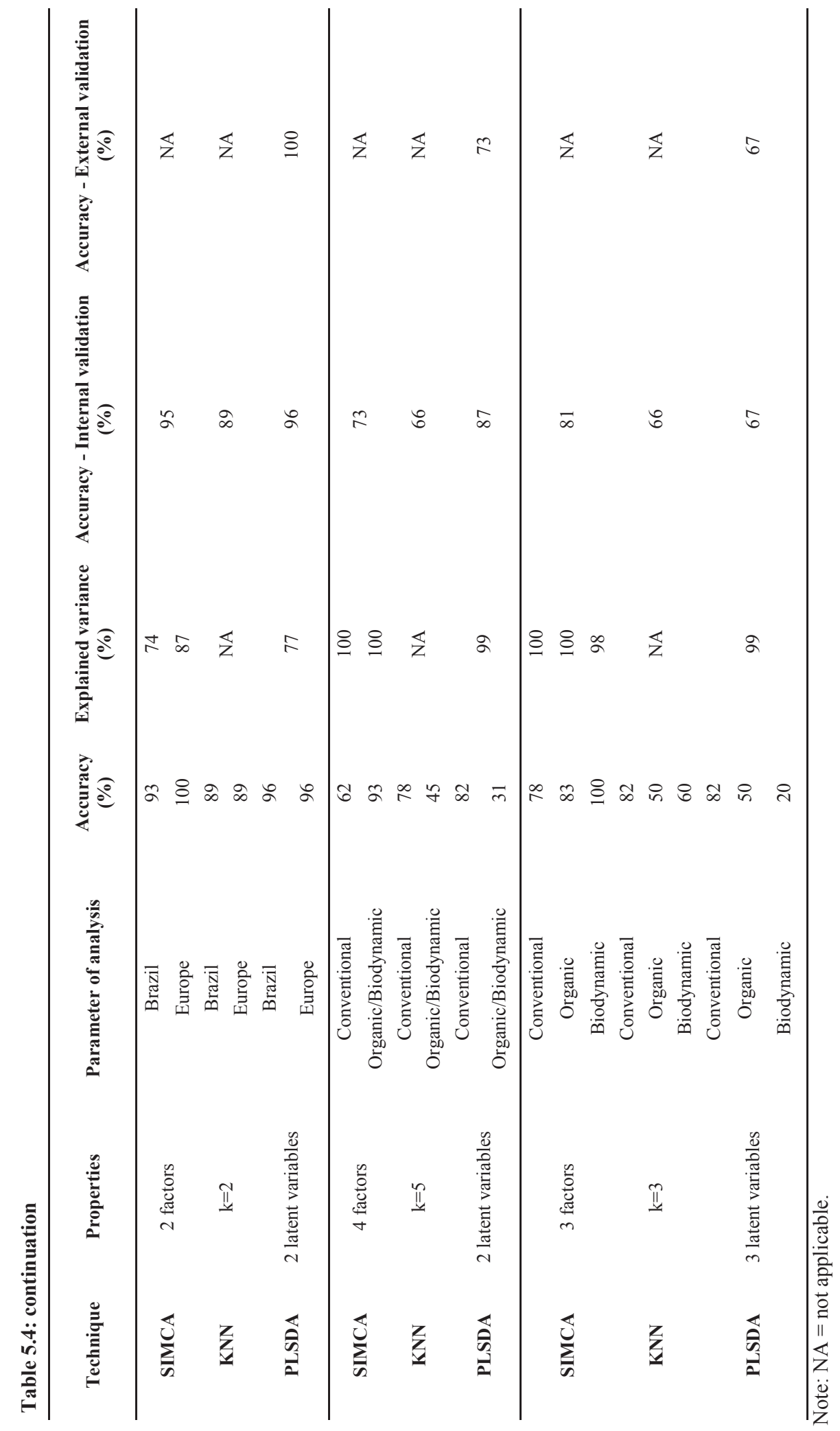


When PLSDA was applied and cross-validated using the leave-one-out approach, 100\% of European and $96 \%$ of Brazilian grape juices were correctly classified, and the model was highly efficient. The most important variables responsible for this classification were $m / z 42,47,43,59$, and 75. Obviously, the geographical origin (terroir) plays a role in the synthesis of VOC, but the use of different grape varieties may be the main responsible for such differentiation: while Brazilian grape juices are basically made of hybrid grapes (Vitis labrusca), such as Isabel, Concord, Bordeaux, and Niagara, varieties, European grape juices are usually made of Merlot and Cabernet Sauvignon grapes ( $V$. vinifera $)$ or blends with Concord $(V$. labrusca) and Muscadine ( $V$. rotundifolia) juices. Another important difference that may have contributed to this result is that European juices are, in most cases, made of concentrates $\left(\sim 60^{\circ} \mathrm{Brix}\right)$, which means that juices are subjected to more unit operation steps involving temperature and storage conditions, thus influencing their chemical profile, including the volatile composition. When conventional, organic, or biodynamic juices were used as classes, no statistical method was able to discriminate juices efficiently ( 57 to $72 \%$ accuracy). Using both KNN and SIMCA, not even one biodynamic juice was correctly classified using all mass spectra and a 3D scatter plot built using PCA corroborates this fact (Figure 5.2C). However, when juices were grouped as either conventional or organic/biodynamic, a more suitable classification was obtained, in which PLSDA was able to discriminate conventional ( $81 \%$ accuracy) and organic/biodynamic juices ( $83 \%$ accuracy), regardless of the geographical origin, with an overall accuracy of $85 \%$. In the same sense, SIMCA also presented a suitable accuracy (84\%) in differentiating both classes.

The chemical composition of foods is highly affected by the growth and physiopathological conditions of the plant, as well as by the environmental factors, also known as terroir. In this sense, the main difference between organic and conventional crop systems relies on the use of chemical fertilizers and/or pesticides in the latter crop system, changing the soil fertility and production yield, as well as the nutritional composition (including the secondary metabolites) of the plant (Balisteiro, Rombaldi, \& Genovese, 2012). In fact, the ineffectiveness of differentiating organic, biodynamic, and conventional foods based on different markers is already well-recognized in the literature worldwide. For example, Heimler et al. (2009) measured the phenolic content and antioxidant activity of conventional and biodynamic chicory (Chicorium intybus L.) and no difference was found in the antioxidant activity, total phenolic, and total flavonoid content.

Once no satisfactory results were obtained using all PTR-MS spectra when either the three crop systems or the 'conventional' and 'organic/biodynamic' classes were used, another classification was proposed taking into consideration only the ions with significant differences $(\mathrm{p} \leq 0.05)$ between groups (Tables 5.1, 5.2, and 5.3) and the correct classification rate between the two approaches was compared. Table 5.4 contains the results of the new classification and it is possible to observe that when the ions with differences between Brazilian and European juices were analyzed, higher accuracy was obtained for all chemometric techniques, which means that only masses with statistical differences $(\mathrm{p}<0.05)$ between producing regions should be used to differentiate purple grape juices. Similarly, when organic, biodynamic, and conventional juices were analyzed, higher classification accuracy was obtained for SIMCA and KNN; nonetheless, PLSDA was not benefited from this approach, once these statistical parameters remained almost unchanged. On the other hand, when the significant ions were used to discriminate conventional and organic/biodynamic samples, the 
classification accuracy was deemed decreased, which means that, besides nonsignificant from a statistical standpoint, the other ions that were not included in the analysis contribute to the overall classification of juices.

\subsubsection{Intraregional classification of grape juices}

As observed in the results, geographical discrepancies seem to be partly related to different grape varieties and production processes adopted in both producing regions. Therefore, the high variability due to varieties and producing processes adopted by producers from the same region might have masked intrinsic differences in VOC profile between ORG/BIO and conventional from the same region. In this sense, PLSDA was performed for each of the two geographical origins (Brazil and Europe) aiming at classifying grape juices from different crop systems. Table 5.5 shows that when juices from the same area were analyzed, higher accuracy rates were obtained: for Brazilian samples, PLSDA classified 82 and $92 \%$ of ORG and CONV juices with an overall accuracy of 89 and $81 \%$ in the internal and external validation, respectively. The variables that presented the highest discriminating power were $m / z 96>m / z 95>m / z 73>m / z ~ 83$. When European juices were analyzed, 92 and 100\% of ORG/BIO and CONV samples were adroitly classified, presenting accuracy rates of 96 and $94 \%$ in the internal and external validation procedures, respectively. Ion masses $\mathrm{m} / \mathrm{z} 69>\mathrm{m} / \mathrm{z}$ $97>m / z 98>m / z 45$ were the most important variables in providing the observed classification.

Table 5.5: Partial least squares discriminant analysis data for different grape juices coming from Europe and Brazil.

\begin{tabular}{|c|c|c|c|c|c|c|}
\hline $\begin{array}{c}\text { Geographical } \\
\text { origin }\end{array}$ & $\begin{array}{c}\text { Production } \\
\text { management system }\end{array}$ & $\begin{array}{c}\text { Latent } \\
\text { variables }\end{array}$ & Accuracy (\%) & $\begin{array}{c}\text { Explained } \\
\text { variance (\%) }\end{array}$ & $\begin{array}{c}\text { Accuracy - } \\
\text { internal } \\
\text { validation } \\
(\%)\end{array}$ & $\begin{array}{c}\text { Accuracy - } \\
\text { External } \\
\text { validation (\%) }\end{array}$ \\
\hline Brazil & $\begin{array}{c}\text { Organic } \\
\text { Conventional }\end{array}$ & 3 & $\begin{array}{l}82 \\
92\end{array}$ & 82 & 89 & 81 \\
\hline Europe & $\begin{array}{c}\text { Organic } \\
\text { Conventional } \\
\text { Biodynamic }\end{array}$ & 3 & $\begin{array}{l}57 \\
86 \\
40\end{array}$ & 78 & 69 & 80 \\
\hline Europe & $\begin{array}{c}\text { Organic/Biodynamic } \\
\text { Conventional }\end{array}$ & 2 & $\begin{array}{c}92 \\
100\end{array}$ & 83 & 96 & 94 \\
\hline
\end{tabular}

Obviously, the ideal situation would be to obtain a statistical model to discriminate organic, biodynamic and conventional juices that would be valid to all grape juices produced worldwide; however, our study showed that intraregional PLSDA models (juices produced in the same region - either Europe or Brazil) presented much better accuracy in discriminating organic from conventional grape juices (Brazil) and organic/biodynamic from conventional juices (Europe) as compared to the models generated using both geographical origins simultaneously. 


\subsection{References}

Aprea, E., Biasioli, F., Carlin, S., Endrizzi, I., Gasperi, F. (2009). Investigation of volatile compounds in two raspberry cultivars by two headspace techniques: solid-phase microextraction/gas chromatographymass spectrometry (SPME/GC- MS) and Proton-Transfer Reaction- Mass Spectrometry (PTRMS). Journal of Agricultural and Food Chemistry, 57(10), 4011-4018.

Balisteiro, D. M., Rombaldi, C. V., Genovese, M. I. (2013). Protein, isoflavones, trypsin inhibitory and in vitro antioxidant capacities: Comparison among conventionally and organically grown soybeans. Food Research International, 51(1), 8-14.

Berrueta, L. A., Alonso-Salces, R. M., Héberger, K. (2007). Supervised pattern recognition in food analysis. Journal of Chromatography A, 1158(1), 196-214.

Biancolillo, A., Bucci, R., Magrì, A. L., Magrì, A. D., Marini, F. (2014). Data-fusion for multiplatform characterization of an Italian craft beer aimed at its authentication. Analytica Chimica Acta, 820, 23-31.

Biasioli, F., Gasperi, F., Aprea, E., Mott, D., Boscaini, E., Mayr, D., Märk, T. D. (2003). Coupling proton transfer reaction-mass spectrometry with linear discriminant analysis: a case study. Journal of Agricultural and Food Chemistry, 51(25), 7227-7233.

Biasioli, F., Gasperi, F., Yeretzian, C., Märk, T. D. (2011). PTR-MS monitoring of VOCs and BVOCs in food science and technology. TrAC Trends in Analytical Chemistry, 30(7), 968-977.

European Fruit Juice Association (AIJN). Liquid Fruit - Market report (2013). Available at: http://www.kups.org.pl/files/?id_plik=1530. Access on: 29 April 2014.

Gómez-Meire, S., Campos, C., Falqué, E., Díaz, F., Fdez-Riverola, F. (2014). Assuring the authenticity of northwest Spain white wine varieties using machine-learning techniques. Food Research International, 60, 230-240.

Granitto, P. M., Biasioli, F., Aprea, E., Mott, D., Furlanello, C., Märk, T. D., Gasperi, F. (2007). Rapid and non-destructive identification of strawberry cultivars by direct PTR-MS headspace analysis and data mining techniques. Sensors and Actuators B: Chemical, 121(2), 379-385.

Hansel, A., Jordan, A., Holzinger, R., Prazeller, P., Vogel, W., Lindinger, W. (1995). Proton transfer reaction mass spectrometry: on-line trace gas analysis at the ppb level. International Journal of Mass Spectrometry and Ion Processes, 149, 609-619.

Heimler, D., Isolani, L., Vignolini, P., Romani, A. (2009). Polyphenol content and antiradical activity of Cichorium intybus L. from biodynamic and conventional farming. Food Chemistry, 114(3), 765-770.

Ibravin. Instituto Brasileiro do Vinho. Estatísticas. URL http://www.ibravin.org.br/dados-estatisticos. Access on: 8 Feb. 2014.

Maçatelli, M., Akkermans, W., Koot, A., Buchgraber, M., Paterson, A., van Ruth, S. (2009). Verification of the geographical origin of European butters using PTR-MS. Journal of Food Composition and Analysis, 22(2), 169-175.

Muntean, E. (2010). Simultaneous carbohydrate chromatography and unsuppressed ion chromatography in detecting fruit juices adulteration.Chromatographia, 71(1), 69-74. 
Obón, J. M., Díaz-Garcí, M. C., Castellar, M. R. Red fruit juice quality and authenticity control by HPLC. Journal of Food Composition and Analysis, 24(6), 760-771.

Özdestan, Ö., van Ruth, S. M., Alewijn, M., Koot, A., Romano, A., Cappellin, L., Biasioli, F. (2013). Differentiation of specialty coffees by proton transfer reaction-mass spectrometry. Food Research International, 53(1), 433-439.

Pulgar, J. S., Soukoulis, C., Carrapiso, A. I., Cappellin, L., Aprea, E., Romano, A., Gasperi, F., Biasioli, F. (2013). Effect of the pig rearing system on the final volatile profile of Iberian dry-cured ham as detected by PTR-ToF-MS. Meat Science, 93(3), 420-428.

Ruiz-Samblás, C., Tres, A., Koot, A., van Ruth, S. M., González-Casado, A., Cuadros-Rodríguez, L. (2012). Proton transfer reaction-mass spectrometry volatile organic compound fingerprinting for monovarietal extra virgin olive oil identification. Food Chemistry, 134(1), 589-596.

Spitaler, R., Araghipour, N., Mikoviny, T., Wisthaler, A., Dalla Via, J., Märk, T. D. (2007). PTR-MS in enology: Advances in analytics and data analysis. International Journal of Mass Spectrometry, 266(1), $1-7$.

Stanimirova, I., Üstün, B., Cajka, T., Riddelova, K., Hajslova, J., Buydens, L. M. C., Walczak, B. (2010). Tracing the geographical origin of honeys based on volatile compounds profiles assessment using pattern recognition techniques. Food Chemistry, 118(1), 171-176.

van Ruth, S. M., Frasnelli, J., Carbonell, L. (2008). Volatile flavour retention in food technology and during consumption: juice and custard examples. Food Chemistry, 106(4), 1385-1392.

Wold, S. (1976). Pattern recognition by means of disjoint principal components models. Pattern Recognition, 8(3), 127-139. 


\section{OHAPTER 6:}

\section{GENERAL DISCUSSION}




\subsection{Introduction}

In the current study, our main aim was to investigate the reflectance of origin (botanical, production management system, and geographical origin) on the unique compositional traits of purple grape juices (volatile organic compounds, instrumental taste profile, phenolic compounds and in vitro antioxidant activity). In this sense, some quality traits of purple grape juices were subsequently applied to authenticate the origins of the juices. Unraveling the mechanisms by which the botanical origin (grape genus/species), the production management system and geographical origin affect the traits of juices helps to underpin typicality and quality, which in turn can be used to discriminate and authenticate particular juices.

In this view, this chapter discusses the interconnections between the Research Questions (Chapter 1) and the main findings of the study (Chapters 2-5). Chapter 6 is sub-divided according to the observed impact of the botanical origin, the production management system, and the geographical origin of the grapes on the juices. Additionally, the directions for further exploration of the strategy to authenticate the origin of grape juices by means of analytical and statistical methods are also highlighted together with the main conclusions, research limitations and issues for further research.

\subsection{Overall discussion of the findings}

\subsubsection{Impact of the various origin aspects on the features of juices}

\subsubsection{Botanical origin}

The search for markers to authenticate the botanical origin of a wide variety of foods is still a common and required practice from commercial and scientific standpoints (Mikulic-Petkovsek et al., 2015; Silva et al., 2016). In the current study, the effect of botanical origin of juices on their quality traits was studied in Chapter

2.

In Chapter 2, we aimed at mapping the quality of various juices from different botanical origins (apple, elderberry, cranberry, orange, red beet, blueberry, pomegranate, and some mixed juices) from instrumental taste, phenolic compounds and antioxidant capacity perspectives. Elderberry and red beet juices presented a high intensity of sourness and saltiness, while orange and pomegranate juices seemed to be the most bitter and astringent juices. Elderberry and pomegranate juices presented the highest total phenolic content and antioxidant activity measured by three different assays (FRAP, CUPRAC, DPPH) and also presented the highest intensity of instrumental astringency, corroborating the data obtained by Duymus, Goger, and Baser (2014) who analyzed Sambucus nigra (elderberry) cultivated in Turkey. Orange, apple and cranberry juices had the lowest levels of total phenolics and flavonoids, DPPH and CUPRAC. Furthermore, juices were grouped according to their total phenolic content, their individual phenolic composition, and antioxidant activity. In the current work, correlation analysis showed that total phenolic content, specifically gallic acid, p-coumaric acid, anthocyanins, flavanols and flavonols, are the main contributors to the antioxidant activity. Our results are in agreement with those reported by Díaz-García et al. (2013) who analyzed the individual phenolic composition and the total phenolic content of blueberry, orange, purple grape, cranberry, and apple 
juices and concluded that blueberry $(384.50 \mathrm{mg} \mathrm{GAE} / 100 \mathrm{~mL})$ had the highest content of phenolic compounds, followed by cranberry (192.537 mg GAE/100 mL), apple (114.21 mg GAE/100 mL), and orange (84.06 mg GAE/100 mL). Our results are also in-line with those reported by Wang, Cao, and Prior (1996) who analyzed different fruits and concluded that grape juice had the highest antioxidant activity, followed by grapefruit, tomato, orange, and apple juices.

Although grape juices were not included in the experimental design of Chapter 2, these juices were comprehensively studied in the following chapters using the same experimental conditions applied in Chapter 2 , and results may be compared accordingly. Overall, compositional differences are well known between juices coming from distinct botanical origins and even within species from the same genus, i.e. between varieties of grapes, especially when the individual characterization of phenolic compounds is considered (Silva et al., 2016). As a conclusion from this section, we noted that the botanical origin of juices is considerably affecting the instrumental taste profile, phenolic compound composition, and antioxidant activity of juices.

\subsubsection{Production management system}

In the current thesis, the effects of the production management system on juice quality traits were studied in Chapters 3, 4 and 5.

In Chapter 5, purple grape juices from three production management systems in Brazil and Europe were analyzed for their volatile organic compounds. In general, conventional (CONV) juices had higher mean levels for all ions compared to organic (ORG) and biodynamic (BIO) juices. More specifically, in fact, biodynamic juices presented the lowest mean values for almost all ions measured, while conventional juices presented the highest mean values for the ions. When organic and biodynamic samples were grouped in only one class, they showed consistent differences (lower ion intensities) compared to the conventional samples for 53 ions. In addition, intraregional differences between the production systems were observed (juices produced in the same region - either Europe or Brazil). The ions $\mathrm{m} / \mathrm{z} 96>\mathrm{m} / \mathrm{z} 95>\mathrm{m} / \mathrm{z} 73>\mathrm{m} / \mathrm{z} 83$ were the main variables that presented the highest discriminating power of Brazilian organic and conventional purple grape juices, in which organic samples presented the lowest values. CONV and ORG/BIO European juices were differentiated with $\mathrm{m} / \mathrm{z} 69>\mathrm{m} / \mathrm{z} 97>\mathrm{m} / \mathrm{z} 98>\mathrm{m} / \mathrm{z} 45$ being the most important variables, where CONV juices presented higher mean values as compared to ORG/BIO. Our data corroborates the findings obtained by Parpinello, Rombolá, Simoni and Versari (2015) who analyzed the volatile composition (gas chromatographymass spectrometry) of ORG and BIO red wines and a very similar profile/content was observed between classes. Differences in the profile and ion intensities are probably related to the various biosynthesis pathways regulators (enzyme protein content and the expression of corresponding structural genes) in response to biotic interactions (pathogens and herbivores) and multiple environmental and technological factors used to produce the grapes and the juice, respectively, such as light intensity, atmospheric $\mathrm{CO}_{2}$ concentration, soil type and chemical composition, temperature, relative humidity, and nutrient status (Muhlemann et al., 2012; Dudareva, Klempien, Muhlemann, \& Kaplan, 2013). It is also hypothesized that the level and type of nitrogen and phosphorus may also be responsible for the content of VOCs in grape juice. 
In Chapter 3, the European ORG, BIO, and CONV purple grape juices were analyzed for their instrumental taste profile, some chemical markers (total phenolic content and total $o$-diphenols content), and antioxidant activity. No significant difference ( $>>0.05$ ) between ORG, BIO, and CONV juices was observed for instrumental richness, umami, saltiness, sourness, astringency, bitterness, total phenolic content, total soluble solids, $\mathrm{pH}$, ortho-diphenols, copper chelating activity, and ferric reducing antioxidant activity. As a comparative, organic and biodynamic juices were grouped in the same class, ORG/BIO, and results showed that only copper chelating activity was statistically different $(\mathrm{p}=0.02)$ between groups $(\mathrm{ORG} / \mathrm{BIO}=44 \%$ inhibition; $\mathrm{CONV}=36 \%$ inhibition), probably because of a slightly higher total phenolic content $(\mathrm{ORG} / \mathrm{BIO}=998 \mathrm{mg} / \mathrm{L} ; \mathrm{CONV}=714 \mathrm{mg} / \mathrm{L} ; \mathrm{p}=0.12)$ and $o$-diphenols content $(\mathrm{ORG} / \mathrm{BIO}=430 \mathrm{mg} / \mathrm{L}$; $\mathrm{CONV}=297 \mathrm{mg} / \mathrm{L} ; \mathrm{p}=0.06$ ). These data are in agreement with other vegetables and plant-based products, in which no significant differences were observed between cultivation systems (ORG x BIO; ORG x CONV) when the phenolic composition and antioxidant capacity were analyzed (Reeve et al., 2005; Luthria et al., 2012; Tassoni, Tango, \& Ferri, 2013).

In Chapter 4, ORG, CONV, and BIO grape juices produced in Brazil and in Europe were analyzed for major classes and individual (HPLC) phenolic compounds and in vitro antioxidant activity aiming to elucidate special characteristics related to the production management system as well as the geographical origin. For the Brazilian samples, the contents of chlorogenic acid (5-o-caffeoylquinic acid) and myricetin were statistically higher in ORG juices, while the in vitro antioxidant activity measured by three assays (DPPH, CUPRAC, and iron chelating ability) were not different between production management systems for both geographical origins. For the European juices, some differences were observed: BIO and ORG juices presented higher contents of (-)-epicatechin, quercetin, (+)-catechin, and myricetin compared to the CONV juices. Similarly, Parpinello, Rombolá, Simoni, and Versari (2015) analyzed the chemical composition of ORG and BIO Sangiovese red wines and verified that significant differences were observed only for cianidin-3glucoside, protocatechuic acid, quercetin, and trans-resveratrol. In a study conducted by Machado et al. (2011), ORG juices (Isabel, Bordeaux, and Concord - Vitis labrusca) presented three times more trans-resveratrol and about 50\% less rutin compared to the CONV Bordeaux juices, while the level of condensed tannins was higher $(\mathrm{p}<0.05)$ in ORG juices.

Summarizing the results from this section, it is concluded that the production management system (ORG/BIO versus CONV) is influencing the VOC profiles, some phenolic compounds and copper chelating activity. It is not affecting the instrumental taste profile nor the in vitro antioxidant activity results. ORG and BIO purple grape juices can be differentiated by their VOC profiles but not by the other characteristics studied.

\subsubsection{Geographical origin}

The effects of geographical origin of grape juices, the so-called terroir effect, were studied in Chapter 4 and Chapter 5. Grape juices from two continents were compared and the results are presented in Chapter 4 and 5. Purple grape juices from Brazil and European countries from three production management systems were analyzed for their volatile organic compositions (Chapter 5). Overall, Brazilian grape juices presented higher ion intensities as compared to European grape juices. The most important variables responsible for the 
geographical differentiation were $m / z$ 42, 47, 43, 59, and 75. Obviously, the geographical origin (terroir) plays a role in the synthesis of VOC (Perestrelo, Barros, Rocha, and Câmara, 2014). However, many factors are impacting on this results, including the fact that in Europe, most juices are likely to come from Vitis vinifera or blends with $V$. labrusca/V. rotundifolia varieties, while Brazilian juices are majorly made of Vitis labrusca and/or hybrid grapes. In the current study, no information on the grape varieties was available but this could be an underlying aspect in the differentiation between the juices from the two continents. Furthermore, there may be consistent differences in processing between Brazilian and European companies. However, for authentication purposes it is valuable to know that these geographical differences exist, no matter where they originate from.

Grape juices produced in Brazil and in Europe were also analyzed for their phenolic composition and in vitro antioxidant activity and different multivariate statistical techniques were employed to determine the special features associated with the geographical origin of the grapes (Chapter 4). Brazilian juices, regardless of the production management system adopted, presented higher total phenolic content and flavonoids, total anthocyanins (including cyanidin-3-glucoside, delphinidin-3-glucoside, and malvidin-3,5-diglucoside), proanthocyanidins, flavonols, and flavanols. The free-radical scavenging activity toward 2,2-diphenyl-1picrylhydrazyl, total phenolic content, gallic acid, and malvidin-3-glucoside were the variables responsible for the differentiation of geographical origin of grape juices. When all groups of grape juice samples were compared taking into consideration the cultivation system and producing region, Brazilian samples had higher values of all phenolic compounds and antioxidant activity, except for trans-resveratrol, malvidin-3-glucoside and pelargonidin-3-glucoside in comparison to the European juices. The content of myricetin of European BIO juices was found to be 1.9 and 1.1 times higher than the content found for Brazilian CONV and ORG grape juices, respectively.

We verified that the geographical origin of grape juice affects the chemical composition and antioxidant activity of the juices. These observations are in agreement with those reported by Costa, Silva, Cosme, and Jordão (2015) who analyzed some physicochemical parameters and the phenolic composition of French red grape varieties ( $V$. vinifera) cultivated at two different Portuguese terroirs. Guo, Yue, Yuan, and Wang (2013) characterized the chemical profile (phenolic compounds) of $n=51$ apple juices coming from five varietals and six Chinese regions by high-performance liquid chromatography coupled to photodiode array detection (HPLC-PDA) and mass spectrometry. Authors were able to classify the samples from different varietals and geographical origins with $98 \%$ and $91 \%$ accuracy, respectively. Overall, some factors that contribute to discrepancies within production regions are agronomical practices, climate conditions (including the drought and light/UV intensity), type and frequency of fertilization, type of pesticide (in the case of CONV products), soil conditions and its chemistry, fruit maturity and juice yield, among others (Xu et al., 2011; Teixeira, Eiras-Dias, Castellarin, \& Gerós, 2013; Carbonell-Bejerano et al., 2014).

From this section is concluded that the geographical origin of grape juice affects its VOCs profile, instrumental taste parameters, phenolic composition, and in vitro antioxidant activity. These differences may be due to innumerous reasons, such as intrinsic factors (grape variety used in the manufacture of the juice, physiopathological conditions and degree of maturity of grapes at the harvest time) and extrinsic factors 
(terroir effect - geomorphology, soil type and its chemical/biological conditions, and climate conditions, especially temperature, sunlight exposure, humidity, and irrigation), as well as consistent processing differences between origins.

\subsection{Implications of identified special traits of juices for authentication}

As the volatile composition, instrumental taste profile, chemical composition related to the phenolic composition, and antioxidant activity of different purple grape juices were characterized, multivariate statistical techniques (chemometrics) were used to develop classification models. The results are summarized in Table 6.1.

Table 6.1: Overview of marker groups successful in authentication of the botanical origin, production management system, and geographical origin of grape juices in the current thesis.

\begin{tabular}{ccccc}
\hline Factor & $\begin{array}{c}\text { Volatile organic } \\
\text { compounds }\end{array}$ & $\begin{array}{c}\text { Instrumental } \\
\text { taste profile }\end{array}$ & $\begin{array}{c}\text { Phenolic } \\
\text { compounds }\end{array}$ & $\begin{array}{c}\text { Antioxidant } \\
\text { activity }\end{array}$ \\
\hline $\begin{array}{c}\text { Botanical origin } \\
\text { Production }\end{array}$ & NA & + & + & + \\
management system & + & $+/-$ & $+/-$ & $+/-$ \\
Geographical origin & + & $+/-*$ & + & + \\
\hline
\end{tabular}

Note: $\mathrm{NA}=$ not applicable; *only for grape juices produced in different European countries.

\subsubsection{Botanical origin}

When the botanical origin was assessed, juices from different species (apple, pomegranate, elderberry, orange, blueberry, cranberry, red beet) were analyzed for instrumental taste profiles, phenolic composition, and in vitro antioxidant activity (FRAP, CUPRAC, and DPPH). Hierarchical cluster analysis was used to group the juice samples according to their content of total phenolic content and antioxidant activity (CUPRAC and FRAP), and three clusters were suggested and we verified that pomegranate and elderberry juices presented the highest total phenolic content (including gallic acid), and antioxidant activity. For authentication of juices based on the botanical origin, our experimental results show that:

Simple determinations of major phenolic compounds and in vitro antioxidant activity using UV/VIS spectrophotometry provide suitable information for characterization of juices from different botanical origins.

\subsubsection{Production management system}

When the production management systems were evaluated, interesting results were obtained. The VOC profile was used as a quality attribute to differentiate juices from different production management systems. When conventional, organic, or biodynamic juices were used as classes, no statistical method was able to discriminate juices efficiently. However, when juices were grouped as either conventional or ORG/BIO, the PLSDA model classified $81 \%$ conventional and $83 \%$ ORG/BIO juices. For Brazilian samples, PLSDA classified 82 and $92 \%$ of ORG and CONV juices and $\mathrm{m} / \mathrm{z} 96>\mathrm{m} / \mathrm{z} 95>\mathrm{m} / \mathrm{z} 73>\mathrm{m} / \mathrm{z} 83$ presented the highest 
discriminating power. When European juices were analyzed, 92 and 100\% of ORG/BIO and CONV samples were adroitly classified, in which ion masses $m / z 69>m / z 97>m / z 98>m / z 45$ were the most important variables in providing the observed classification. Organic and biodynamic juices were grouped (ORG/BIO) and 12 out of $13 \mathrm{ORG} / \mathrm{BIO}$ samples and 17 out of $18 \mathrm{CONV}$ juices were correctly classified. Therefore, the combination of ORG and BIO grape juices in one class seems to be a suitable strategy to classify the juices. In the PLSDA analysis, a total of $86 \%$ accuracy was obtained and the most discriminating variables were copper chelating activity, $\mathrm{pH}$, and instrumental sourness.

Using the chemical composition (phenolics) and antioxidant activity as markers, no supervised statistical method was efficient in differentiating organic and biodynamic juices, regardless of the place of origin. In order to obtain authentication models, SIMCA, KNN, and PLSDA models were constructed. Regarding the Brazilian juices, SIMCA was the best tool to separate ORG from CONV juices, with $89 \%$ and $78 \%$ of correct classification, in which the content of trans-resveratrol, gallic acid, and pelargonidin-3glucoside presented the highest discriminant power. For European juices, SIMCA classified 100\% and 94\% of ORG/BIO and CONV juices classes and the contents of cyanidin-3-glucoside, malvidin-3-glucoside, and delphinidin-3-glucoside were the factors affecting the differentiation between classes.

For authentication of grape juices based on the production management system, our experimental results imply that:

$>$ For PTR-MS data, $m / z<100$ were sufficient to discriminate not only Brazilian ORG from CONV grape juices but also ORG/BIO from CONV European grape juices by PLSDA;

> The measurement of instrumental bitterness, saltiness, and astringency is sufficient to differentiate BIO, ORG, and CONV purple grape juices produced in Europe using SIMCA models. Alternatively, authentication of production management system of European grapes can also be assessed by the anthocyanin profile (cyanidin-3-glucoside, malvidin-3-glucoside, and delphinidin-3-glucoside). Similarly, for Brazilian grape juices, the levels of trans-resveratrol, gallic acid, and pelargonidin-3-glucoside were the best predictors of production management systems.

\subsubsection{Geographical origin}

When the geographical origin of grapes was used as a factor of analysis and the VOC profile as predictor, PLSDA classified 100\% European and 96\% Brazilian juices, in which the most important variables responsible for this differentiation were $m / z 42,47,43,59$, and 75 . When the ions with differences between Brazilian and European juices were analyzed, the number of juices correctly classified was increased: SIMCA was able to differentiate $93 \%$ and $100 \%$ of Brazilian and European purple grape juices, while PLSDA was able to classify $96 \%$ of Brazilian and European purple grape juices. All these data indicate that only masses with statistical differences obtained by analysis of variances between producing areas should be used to classify purple grape juices based on their geographical origin. Classification models were also tested using the phenolic compounds and antioxidant properties of juices and results showed that a total of $91 \%$ of Brazilian and $97 \%$ of European juices were adroitly classified using PLSDA when the producing region was considered, in which the free-radical scavenging activity toward DPPH, total phenolic content, gallic acid and malvidin- 
3-glucoside were the variables responsible for the classification. Our results are in accordance with other reports on fruits. For example, Muilwijk, Heenan, Koot, and van Ruth (2015) studied the effects of terroir, production management system, and variety of tomatoes cultivated in Italy on the VOC fingerprints, and verified that both production region and production management system impacted considerably on the VOC profile, but compared to these two factors, minor differences were observed between the two varieties of tomatoes studied.

For authentication of grape juices based on their geographical origin (Brazil versus Europe), our experimental results showed that:

Rapid and simple authentication of the geographical origin of grape juices can be performed by quantifying the total content of gallic acid and malvidin-3-glucoside and measuring the antioxidant activity by the DPPH assay in combination with PLSDA modeling. Alternatively, the geographical origin can also be authenticated using the VOC profile $(m / z<100)$ using PTR-MS and PLSDA;

Alternatively, the authentication of geographical origin of grape juice can be carried out using the VOC profile of juices, more specifically using the ions that have statistical differences $(p<0.05)$ between regions.

\subsection{Final conclusions}

As final considerations, from the standpoint of chemistry and in vitro antioxidative properties, experimental research conducted so far has strongly evidenced that the difference between grape juices of various origins is the result of multifactorial and interlinked effects that should not be interpreted separately. This implies that the geographical origin, seasonality, the number of samples analyzed in each class, together with the proper statistical methods used to compare the botanical origin, production management systems, and producing region, and the analytical method used to assess the markers of interest (i.e., sensitivity, specificity, limits of detection and quantification) should also be taken into consideration prior to draw any conclusions about differences in the origins of grape juices.

Accordingly, from this $\mathrm{PhD}$ thesis we conclude that:

- The botanical origin of juices affected considerably their unique compositional traits, namely instrumental taste profile, physicochemical properties, phenolic composition, and in vitro antioxidant activity of juices from different botanical sources.

- The effects of production management system on the quality attributes (instrumental taste profile, phenolic composition, and antioxidant activity) of purple grape juice were discrete and almost undistinguishable using bivariate statistical methods, especially between organic and biodynamic grape juices. When organic and biodynamic juices were grouped in one single class, a significant differentiation from conventional juices could be made;

- The geographical origin of grape juices affected considerably their VOC profiles, the instrumental taste profile (of European grape juices), the phenolic composition, and antioxidant activity.

\subsection{Research limitations and recommendations for future research}


The empirical studies in this thesis have a number of limitations, which are discussed in Chapters 2, 3, 4 and 5. In addition, based on the findings in the chapters, this section provides some advice regarding how future research could improve knowledge about the quality traits and classification of purple grape juices from different origins. Figure 6.1 summarizes the points to consider in future researches aimint to classify grape juices according to multiple factors. Increasing the size of sample sets would help to improve the differentiation and to include more natural variance. As well known, production and processing factors, storage conditions, among other extrinsic factors impact on the final composition of purple grape juices. Therefore, increasing the sample set will help to build a more extensive database. Alternatively, future works should also focus on other quality markers, such as carotenoids and other trace elements (minerals) as the basis for differentiating the multiple origins of purple grape juices. Similarly, from the agronomical standpoint, the VOC profile, instrumental taste profile, chemical composition, physicochemical properties, and antioxidant activity of purple grape juices should also be analyzed in response to other factors, such as soil type and composition, climate conditions, and type and frequency of fertilization.

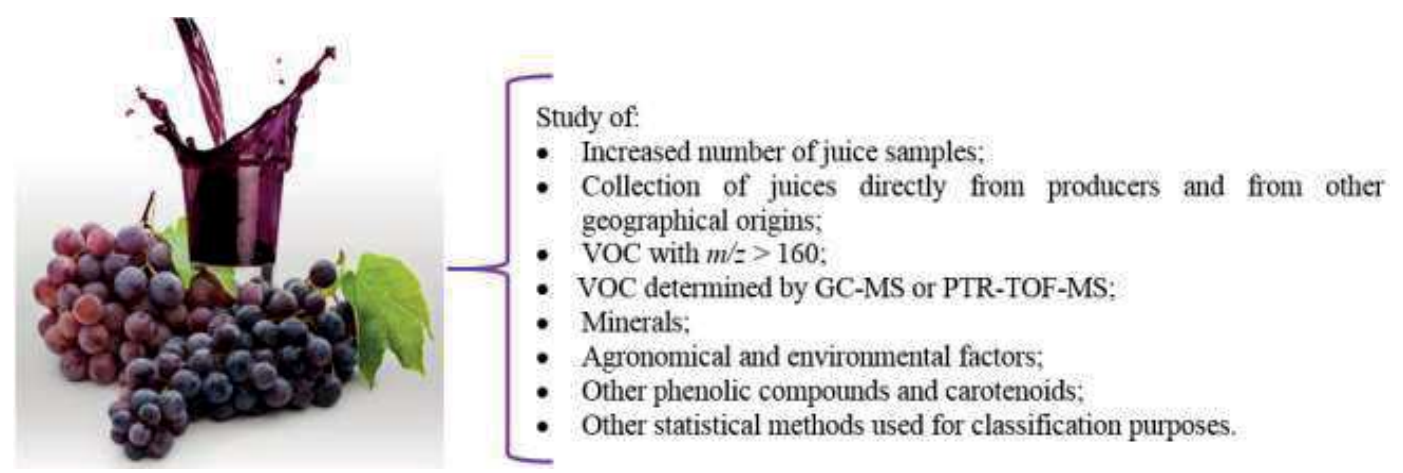

Figure 6.1: Points to consider in future research aiming to classify grape juices according to multiple factors.

It is also advisable to explore additional data treatments for use of authentication methods in practice, especially multivariate statistical analyses, such as artificial neural networks (Matera et al., 2014), polynomial partial least-squares regression (Riahi, Pourbasheer, Ganjali, \& Norouzi, 2009), machine-learning algorithms (Barbosa et al., 2015), orthogonal partial least-squares discriminant analysis (Zhou et al., 2015), among others. The use of these statistical methods may enhance the classification of grape juices based on multiple juice quality parameters (i.e., chemical markers and antioxidant activity) and may lead to the development and validation of other authentication models for purple grape juices considering their botanical origin, production management system, and geographical origin.

The authentication of purple grape juices from different origins, especially juices from distinct production management systems, is of pivotal importance for both consumers and industry. While the authentication of organic/biodynamic juices brings more confidence for consumers that pay a premium price for those products, the juice industry may be an allied of governmental bodies to combat frauds/adulterations in the manufacture chain. Notwithstanding the limitations, the present thesis filled in a number of gaps in 
existing knowledge regarding the special compositional traits of purple grape juices from different origins. By providing a more detailed view on the VOC composition, instrumental taste profile, physicochemical properties, phenolics and antioxidant activity of these juices, this thesis hopefully stimulates further research in the field of authentication of food products.

\subsection{References}

Barbosa, R. M., Batista, B. L., Barião, C. V., Varrique, R. M., Coelho, V. A., Campiglia, A. D., Barbosa Jr, F. (2015). A simple and practical control of the authenticity of organic sugarcane samples based on the use of machine-learning algorithms and trace elements determination by inductively coupled plasma mass spectrometry. Food Chemistry, 184, 154-159.

Burin, V. M., Ferreira-Lima, N. E., Panceri, C. P., Bordignon-Luiz, M. T. (2014). Bioactive compounds and antioxidant activity of Vitis vinifera and Vitis labrusca grapes: Evaluation of different extraction methods. Microchemical Journal, 114, 155-163.

Cappellin, L., Loreto, F., Aprea, E., Romano, A., del Pulgar, J. S., Gasperi, F., Biasioli, F. (2013). PTR-MS in Italy: a multipurpose sensor with applications in environmental, agri-food and health science. Sensors, 13, 11923-11955.

Carbonell-Bejerano, P., Diago, M. P., Martínez-Abaigar, J., Martínez-Zapater, J. M., Tardáguila, J., NúñezOlivera, E. (2014). Solar ultraviolet radiation is necessary to enhance grapevine fruit ripening transcriptional and phenolic responses. BMC Plant Biology, 14, 183-200.

Díaz-García, M. C., Obón, J. M., Castellar, M. R., Collado, J., Alacid, M. (2013). Quantification by UHPLC of total individual polyphenols in fruit juices. Food Chemistry, 138(2-3), 938-949.

Dudareva, N., Klempien, A., Muhlemann, J. K., Kaplan, I. (2013). Biosynthesis, function and metabolic engineering of plant volatile organic compounds. New Phytologist, 198(1), 16-32.

Duymus, H. G., Goger, F., Baser, H. C. (2014). In vitro antioxidant properties and anthocyanin compositions of elderberry extracts. Food Chemistry, 155, 112-119.

Guo, J., Yue, T., Yuan, Y., Wang, Y. (2013). Chemometric Classification of apple juices according to variety and geographical origin based on polyphenolic profiles. Journal of Agricultural and Food Chemistry, 61(28), 6949-6963.

Lago-Vanzela, E. S., Da Silva, R., Gomes, E., García-Romero, E., Hermosín-Gutiérrez, I. (2011). Phenolic composition of the edible parts (flesh and skin) of Bordô grape (Vitis labrusca) using HPLC-DAD-ESIMS/MS. Journal of Agricultural and Food Chemistry, 59(24), 13136-13146.

Lima, M. S., Dutra, M. C. P., Toaldo, I. M., Corrêa, L. C., Pereira, G. E., Oliveira, D., Bordignon-Luiz. M. T., Ninow, J. L. (2015). Phenolic compounds, organic acids and antioxidant activity of grape juices produced in industrial scale by different processes of maceration. Food Chemistry, 188, 384-392.

Luthria, D, Singh, A. P., Wilson, T., Vorsa, N., Banuelos, G. S., Vinyard, B. T. (2010). Influence of conventional and organic agricultural practices on the phenolic content in eggplant pulp: plant-to-plant variation. Food Chemistry, 121(5), 406-411. 
Machado, M. M., Montagner, G. F. F. S., Athayde, A. B. M. L., Rocha, M. I. U. M., Lera, L. P. B., Belló, C., Cruz, I. B. M. (2011). Determination of polyphenol contents and antioxidant capacity of no-alcoholic red grape products (Vitis labrusca) from conventional and organic crops. Química Nova, 34(5), 798803.

Matera, J. A., Cruz, A. G., Raices, R. S. L., Silva, M. C., Nogueira, L. C., Quintério, S. L., Cavalcanti, R. N., Freiras, M. Q., Conte Júnior, C. A. (2014). Discrimination of Brazilian artisanal and inspected pork sausages: Application of unsupervised, linear and non-linear supervised chemometric methods. Food Research International, 64, 380-386.

Mikulic-Petkovsek, M., Ivancic, A., Todorovic, B., Veberic, R., Stampar, F. (2015). Fruit phenolic composition of different elderberry species and hybrids. Journal of Food Science, 80(10), C2180C2190.

Muhlemann, J. K, Maeda, H., Chang, C. Y., San Miguel, P., Baxter, I., Cooper B., Perera, M. A., Nikolau, B. J., Vitek, O., Morgan, J. A., Dudareva, N. (2012). Developmental changes in the metabolic network of snapdragon flowers. PLoS ONE, 7, e40381.

Muilwijk, M., Heenan, S., Koot, A., van Ruth, S. M. (2015). Impact of production location, production system, and variety on the volatile organic compounds fingerprints and sensory characteristics of tomatoes. Journal of Chemistry, 2015, 1-7.

Parpinello, G. P., Rombolá, A. D., Simoni, M., Versari, A. (2015). Chemical and sensory characterisation of Sangiovese red wines: Comparison between biodynamic and organic management. Food Chemistry, $167,145-152$.

Perestrelo, R., Barros, A. S., Rocha, S. M., Câmara, J. S. (2014). Establishment of the varietal profile of Vitis vinifera L. grape varieties from different geographical regions based on HS-SPME/GC-qMS combined with chemometric tools. Microchemical Journal, 116, 107-117.

Reeve, J. R., Carpenter-Boggs, L., Reganold, J. P., York, A. L., McGourthy, G., McCloskey, L. P. (2005). Soil and winegrape quality in biodynamically and organically managed vineyards. American Journal of Enology and Viticulture, 56, 367-376.

Riahi, S., Pourbasheer, E., Ganjali, M. R., Norouzi, P. (2009). Investigation of different linear and nonlinear chemometric methods for modeling of retention index of essential oil components: Concerns to support vector machine. Journal of Hazard Materials, 166(2-3), 853-859.

Silva, J. K., Cazarin, C. B. B., Correa, L. C., Batista, A. G., Furlan, C. P. B., Biasoto, A. C. T., Pereira, G. E., Camargo, A. C., Maróstica Junior, M. R. (2016). Bioactive compounds of juices from two Brazilian grape cultivars. Journal of the Science of Food and Agriculture, 96(6), 1990-1996.

Slegers, A., Angers, P., Ouellet, E., Truchon, T., Pedneault, K. (2015). Volatile compounds from grape skin, juice and wine from five interspecific hybrid grape cultivars grown in Québec (Canada) for wine production. Molecules, 20, 10980-11016.

Sun, X., Li, L., Ma, T., Liu, X., Huang, W., Zhan, J. (2015). Profiles of phenolic acids and flavan-3-ols for select Chinese red wines: a comparison and differentiation according to geographic origin and grape variety. Journal of Food Science, 80(10), C2170-C2179. 
Tassoni, A., Tango, N., Ferri, M. (2013). Comparison of biogenic amine and polyphenol profiles of grape berries and wines obtained following conventional, organic and biodynamic agricultural and oenological practices. Food Chemistry, 139, 405-413.

Teixeira, A., Eiras-Dias, J., Castellarin, S. D., Gerós, H. (2013). Berry phenolics of grapevine under challenging environments. International Journal of Molecular Sciences, 14(9), 18711-18739.

Wang, H., Cao, G., Prior, R. L. (1996). Total antioxidant capacity of fruits. Journal of Agricultural and Food Chemistry, 44, 701-705.

Xu, C., Zhang, Y., Zhu, L., Huang, Y., Lu, J. (2011). Influence of growing season on phenolic compounds and antioxidant properties of grape berries from vines grown in subtropical climate. Journal of Agricultural and Food Chemistry, 59(4), 1078-1086.

Zhou, X., Yang, Z., Haughey, S. A., Galvin-King, P., Han, L., Elliott, C. T. (2015). Classification the geographical origin of corn distillers dried grains with solubles by near infrared reflectance spectroscopy combined with chemometrics: A feasibility study. Food Chemistry, 189, 13-18. 


\begin{abstract}
Grape juices represent one of the most consumed fruit juices because of its sensory properties, availability, reasonable price, and more recently because of their functional properties demonstrated by a vast number of in vitro, in vivo, clinical, and epidemiological studies. Although grape juices have been the target of a high number of studies, it is still not fully known how geographical origin and production management system, affect the chemical profile, quality traits related to flavor, and in vitro antioxidant of grape juices. Therefore, the main objective of this study is to elucidate the reflectance of origin (botanical, geographical, production system) in the unique compositional traits of juices from different botanical origins, with emphasis on purple grape juices. Subsequently, chemometric methods were used to try to authenticate the origin of grape juice based on the grape juice's quality traits. Results showed that it was possible to note that the instrumental taste profile, chemical composition related to phenolic compounds, and antioxidant activity of juices from distinct botanical origins differ considerably. More specifically, pomegranate and elderberry juices presented the highest phenolic content and antioxidant activity, implying that the botanical origin of juices affected remarkably their unique instrumental taste profile and physicochemical parameters, phenolic composition, and in vitro antioxidant activity. The production managements systems, (organic/biodynamic, ORG/BIO, versus conventional, CONV) is influencing the volatile organic composition (VOC) profiles, some phenolic compounds and copper chelating activity. It is not affecting the instrumental taste profile nor the in vitro antioxidant activity results. ORG and BIO purple grape juices can be differentiated by their VOC profiles but not by the other characteristics studied. More specifically, CONV juices had higher mean levels for all ions compared to ORG and BIO juices. More specifically, in fact, BIO juices presented the lowest mean values for almost all ions measured. When European grape juices were studied, no significant difference ( $>>0.05$ ) between ORG, BIO, and CONV juices was observed for instrumental richness, umami, saltiness, sourness, astringency, bitterness, total phenolic content, total soluble solids, $\mathrm{pH}$, ortho-diphenols, copper chelating activity, and ferric reducing antioxidant activity. For the Brazilian samples, the contents of chlorogenic acid and myricetin were statistically higher in ORG juices, while the in vitro antioxidant activity measured by three assays (DPPH, CUPRAC, and iron chelating ability) were not different between production management systems. For the European juices, some differences were observed: BIO and ORG juices presented higher contents of (-)-epicatechin, quercetin, (+)-catechin, and myricetin compared to the CONV juices. The VOC profile, instrumental taste parameters, phenolic composition, and in vitro antioxidant activity is highly affected between regions, in which Brazilian juices presented higher ion intensities as compared to the European juices. Brazilian juices, regardless of the production management system adopted, presented higher total phenolic content and flavonoids, total anthocyanins, proanthocyanidins, flavonols, and flavanols, except for transresveratrol, malvidin-3-glucoside and pelargonidin-3-glucoside. From this work, we can conclude that the geographical and botanical origins affect significantly the VOC profiles, instrumental taste profile, the phenolic composition, and antioxidant activity of grape juices.
\end{abstract}




\section{ACKNOWLEDGEMENTS}

This thesis is the result of much work and collaboration with some brilliant people around me during 2013-2016. The biggest help came from Prof. Dr. Saskia van Ruth to whom I would like express my deepest gratitude for accepting the task to help me improve my scientific skills under your supervision. I truly thank you for all suggestions, comments, criticism, guidance, dedication and enthusiasm throughout this period. I also thank Prof. Dr. Vincenzo Fogliano for helping me out with the thesis and for his suggestions of improvements. In addition, I acknowledge all the help provided by Prof. Dr. Edoardo Capuano for teaching me some chemometric tools and for 'opening my eyes' for Food Authentiticy.

I also want to deeply thank Eric Cuijpers and Alex Koot for all dedication and time spent with me during my lab days, especially for helping me to operate new equipments, and Erwin Brower for helping me in the collection of the European juice samples and for helping me out with all administrative issues during my stay at RIKILT-WUR.

A word of gratitude goes to my friends Ioannis Brotzakis, Pierre-Marie Boutanquoi, Isabelle Silvis, Valentina Acierno, and Marcell Kustos for sharing the great moments I had in Wageningen, especially in the lab dealing with the PTR-MS and with the electronic tongue. Guys, you are really nice and fun to be with!! Loved to have met you.

To my beloved family that helped to re-charge my batteries and continue with my $\mathrm{PhD}$ : Marcos Granato, Gustavo Granato, Matheus Gonçalves and Cleverson Neiverth. Dedico todos os meus esforços e conquistas para minha amada mãe, Maria Aparecida Granato, não apenas pelo incentivo, mas por todo trabalho árduo e contínuo para que eu pudesse me dedicar completamente aos estudos (graduação e pós-graduação) e à pesquisa. Sem dúvida, sem sua dedicação, eu não teria chego a esse nível de graduação. Muitíssimo obrigado por ser a mãe querida, dedicada, amável e compreensiva. 


\section{CURRICULUM VITAE}

Daniel Granato was born in Curitiba, Paraná State, Brazil, on $29^{\text {th }}$ February 1984 . He finished his secondary education at Dom Bosco School in 2001, after which he started his Bachelor degree in Food Engineering at the State University of Ponta Grossa, Brazil, being graduated in 2007. After graduation, he started studying the development of Functional Foods and obtained the degree of Master in Science in 2009. In 2009, Daniel started his Doctoral studies in Experimental Nutrition - Food Sciences at the University of São Paulo, Brazil, and obtained his PhD in 2011. Thereafter, Daniel worked for 2 years as a Scientific Researcher at Adolf Lutz Institute, Brazil, and started his second $\mathrm{PhD}$ at Wageningen University in 2014. The results of this research are described in this thesis. Meanwhile, Daniel finished his Post-Doctoral in Food Science and Technology at the State University of Ponta Grossa in July 2015 and he has worked as an Adjunct Professor in the Department of Food Engineering in the same University since then. His main research interests cover various topics in Functional Foods and Food Chemistry, including method validation, phenolic compounds, functional properties in vitro and in vivo. 


\section{LIST OF PUBLICATIONS}

\section{Peer-reviewed articles}

- Zielinski, A. A. F., Haminiuk, C. W. I., Schnitzler, E., van Ruth, S., Granato, D. (2014). Chemical composition, sensory properties, provenance, and bioactivity of fruit juices as assessed by chemometrics: a critical review and guideline. Comprehensive Reviews in Food Science and Food Safety, 13, 300-316.

- Granato, D., Karnopp, A. R., van Ruth, S. M. (2015). Characterization and comparison of phenolic composition, antioxidant capacity and instrumental taste profile of juices from different botanical origins. Journal of the Science of Food and Agriculture, 95, 1997-2006.

- Granato, D., Margraf, T., Brotzakis, I., Capuano, E., \& van Ruth, S. M. (2015). Characterization of conventional, biodynamic, and organic purple grape juices by chemical markers, antioxidant capacity, and instrumental taste profile. Journal of Food Science, 80, C55-C65.

- Granato, D., Koot, A., Schnitzler, E., \& van Ruth, S. M. (2015). Authentication of geographical origin and farming system of grape juices by phenolic compounds and antioxidant activity using chemometrics. Journal of Food Science, 80, C584-C593.

- Granato, D., Koot, A., van Ruth, S. M. (2015). Geographical provenancing of purple grape juices from different farming systems by proton transfer reaction mass spectrometry using supervised statistical techniques. Journal of the Science of Food and Agriculture, 95(13), 2668-2677.

- Granato, D., Carrapeiro, M. M., Fogliano, V., \& van Ruth, S. M. (2016). Effects of geographical origin, varietal and farming system on the chemical profile and functional properties of purple grape juices: a review. Trends in Food Science and Technology, 52, 31-48.

\section{Presentations in Congresses}

- Granato, D., Brotzakis, I., van Ruth, S. Antioxidant and metal chelating activities, taste profile and phenolic compounds of organic, biodynamic and conventional grape juices. In: $8^{\text {th }}$ World Congress on Polyphenols Application, 2014, Lisboa, Portugal. 2014. v. 1. p. 42.

- Granato, D., Brotzakis, I., Capuano, E., van Ruth, S. Classification of European grape juices based on analytical measurements. In: XXIV Congresso Brasileiro de Ciência e Tecnologia de Alimentos, 2014, Aracajú, Brazil. 2014. v. 1.p. 2. 